\title{
Direito, governança, novas tecnologias e desenvolvimento econômico sustentável, globalização e transformações na ordem social e econômica
}

Aires José Rover, José Renato Gaziero Cella, Marcos Leite, Maria de Fátima Ribeiro, Pilar Lasala

(coords.) 



\section{COMITÉ CIENTÍFICO}

\section{SERIE LEFIS}

\section{Coordinación}

Prof. Fernando Galindo Ayuda. Universidad de Zaragoza

Profa. María Pilar Lasala Calleja. Universidad de Zaragoza

Consejo asesor

Prof. Javier García Marco. Universidad de Zaragoza

Prof. Alejando González-Varas Ibáñez. Universidad de Zaragoza

Prof. Philip Leith. Universidad Queen's de Belfast

Prof. Emérito Abdul Paliwala. Universidad de Warwick

Prof. Aires Rover. Universidad Federal de Santa Catarina

Prof. Erich Schweighofer. Universidad de Viena

Prof. Ahti Saarenpää. Universidad de Rovaniemi 
DIREITO, GOVERNANÇA, NOVAS TECNOLOGIAS E DESENVOLVIMENTO ECONÔMICO SUSTENTÁVEL, GLOBALIZAÇÃO E TRANSFORMAÇÕES NA ORDEM SOCIAL E ECONÔMICA 

DIREITO, GOVERNANÇA, NOVAS TECNOLOGIAS

E DESENVOLVIMENTO ECONÔMICO SUSTENTÁVEL, GLOBALIZAÇÃO E TRANSFORMAÇÕES

NA ORDEM SOCIAL E ECONÔMICA

\author{
Aires José Rover, José Renato Gaziero Cella, \\ Marcos Leite, Maria de Fátima Ribeiro, \\ Pilar Lasala \\ (coords.)
}


DIREITO, governança, novas tecnologias e desenvolvimento econômico sustentável, globalização e transformações na ordem social e econômica [Recurso electrónico] / Aires José Rover... [et al.] (coords.). - Zaragoza : Prensas de la Universidad de Zaragoza, 2019 327 p; 22 cm.- (LEFIS series; 18)

ISBN 978-84-17633-52-3

1. Informática-Derecho-Brasil. 2. Internet en la administración pública ROVER, Aires José

34(81):004

004.738.5:35

Cualquier forma de reproducción, distribución, comunicación pública o transformación de esta obra solo puede ser realizada con la autorización de sus titulares, salvo excepción prevista por la ley. Diríjase a CEDRO (Centro Español de Derechos Reprográficos, www.cedro.org) si necesita fotocopiar o escanear algún fragmento de esta obra.

(C) LEFIS

(C) CONPEDI, Conselho Nacional de Pesquisa e Pós-Graduação em Direito Brasil.

(C) De la presente edición, Prensas de la Universidad de Zaragoza (Vicerrectorado de Cultura y Proyección Social)

$1 .^{a}$ edición, 2019

El Centro Universitário de João Pessoa - PB - UNIPÊ ha subvencionado parcialmente la edición de este libro.

Prensas de la Universidad de Zaragoza. Edificio de Ciencias Geológicas, c/ Pedro Cerbuna, 12. 50009 Zaragoza, España. Tel.: 976761 330. Fax: 976761063

puz@unizar.es http://puz.unizar.es

https://www.conpedi.org.br/

Esta editorial es miembro de la UNE, lo que garantiza la difusión y comercialización de sus publicaciones a nivel nacional e internacional. 


\section{SUMÁRIO}

\section{DIREITO, GOVERNANÇA E NOVAS TECNOLOGIAS}

APRESENTAÇÃO.

Pilar Lasala, José Renato Gaziero Cella, Aires José Rover.

A INTERNET COMO ATOR EMERGENTE ANTE AO DIREITO AMBIENTAL INTERNACIONAL: A IMPORTÂNCIA DA INFORMAÇÃO E EDUCAÇÃO À PROTEÇÃO DO MEIO AMBIENTE.

Mateus Catalani Pirani.

APLICABILIDAD, LÓGICA Y INTELIGENCIA ARTIFICIAL EN EL DERECHO .32

José Renato Gaziero Cella, Vinícius Borges Fortes.

RELAÇÕES LÍQUIDAS E DIREITO AO ESQUECIMENTO: NOVOS DESAFIOS DE PROTEÇÃO NAS RELAÇÕES DE TRABALHO.

Denise Pires Fincato, Cíntia Ione Santiago Guimarães.

UM QUADRO EXPLICATIVO PARA IMPLANTAÇÃO DO PROCESSO JUDICIAL ELETRÔNICO: ESTUDO DE CASO COMARCA DE CHAPECÓ 2014-2016. .68

Rodrigo da Costa Vasconcellos, Aires José Rover.

\section{DESENVOLVIMENTO ECONÔMICO SUSTENTÁVEL, GLOBALIZAÇÃO E TRANSFORMAÇÕES NA ORDEM SOCIAL E ECONÔMICA}

APRESENTAÇÃO

Maria De Fátima Ribeiro, Marcos Leite Garcia.

A CONEXÃO INERENTE ENTRE OS DIREITOS HUMANOS E A AGENDA 2030 NO CONTEXTO DOS ESPAÇOS TRANSNACIONAIS FRENTE OS NEGÓCIOS INTERNACIONAIS

Rafael Burlani Neves, Marcos Leite Garcia.

A PERDA DA INFLUÊNCIA ESTATAL NAS RELAÇÕES DE CONSUMO E A INVOLUÇÃO DA PROTEÇÃO ADMINISTRATIVA DAÍ

DECORRENTE.

Dennis Verbicaro Soares, Gabriela Ohana Rocha Freire.

A RESISTÊNCIA À REFORMA TRABALHISTA BRASILEIRA DE 2017: Desobediência Civil de Magistrados ou Controle de Constitucionalidade Difuso?....

Cristiane Heredia Sousa, Adalberto Simão Filho.

ANÁLISE DE IMPACTO REGULATÓRIO (AIR) E SUAS ETAPAS. 158

Gabriel Fliege de Lucena Stuckert.

APLICATIVOS DE ECONOMIA COLABORATIVA: O CASO DO UBER E AIRBND NO

BRASIL 176

Handerson Gleber de Lima Cavalcanti, Arnaldo Sobrinho de Morais Neto. 
FUNDAMENTO EXISTENCIAL E CONTRATUAL DA PROTEÇÃO CONTRA O SUPERENDIVIDAMENTO NA SOCIEDADE DA INFORMAÇÃO

Maíra Matsue Shimizu de Sousa, Roberto Senise Lisboa.

HERMETISMO NO PROCESSO DE RECALL DE MEDICAMENTOS NO BRASIL: AFRONTA AO DIREITO À INFORMAÇÃO E CONSEQUENTE AMEAÇA À SAÚDE E SEGURANÇA DO CONSUMIDOR.

Juliana Barbalho Brasileiro, Carolina Valença Ferraz.

O DIREITO AO DESENVOLVIMENTO SUSTENTÁVEL DA ZONA COSTEIRA. .232 Lair da Silva Loureiro Filho.

O FENÔMENO DA ECONOMIA DE COMPARTILHAMENTO: NOVOS PARADIGMAS SOCIAIS, ECONÔMICOS E TECNOLÓGICOS.

Kerolinne Barboza da Silva, Fernando Antônio de Vasconcelos.

O PAPEL DA EMPRESA NO DESENVOLVIMENTO SUSTENTÁVEL: DA FUNÇÃO SOCIAL DA EMPRESA AOS VALORES SOCIAIS PARA O MERCADO E A SOCIEDADE

Emília Paranhos Santos Marcelino, Hertha Urquiza Baracho.

O PAPEL REGULATÓRIO DA TRIBUTAÇÃO EXTRAFISCAL AMBIENTAL E SEU IMPACTO PARA A FUNÇÃO SOCIAL DA EMPRESA

Regina Célia de Carvalho Martins, Maria de Fatima Ribeiro.

TRIBUTAÇÃO E DESIGUALDADES REGIONAIS: NECESSIDADE DE INTERLOCUÇÃO ENTRE ECONOMIA E DIREITO PARA A CONCRETIZAÇÃO DO DESENVOLVIMENTO SUSTENTÁVEL 311

Maria Marconiete Fernandes Pereira, Flavia de Paiva Medeiros de Oliveira. 


\section{DIREITO, GOVERNANÇA E NOVAS TECNOLOGIAS ${ }^{1}$}

\section{APRESENTAÇÃO}

Os encontros internacionais do Conselho Nacional de Pesquisa e Pós-graduação em Direito (Conpedi) têm se consolidado como referência na disseminação de pesquisas que tratam dos novos fenômenos que envolvem o direito, com especial destaque ao Grupo de Trabalho - GT "Direito, Governança e Novas Tecnologias", que tem se consolidado ao longo dos anos.

Nessa edição as apresentações foram subdivididas em dois grandes tópicos, com dois artigos de caráter mais geral e três artigos mais específicos.

Os dois artigos que envolvem temas mais gerais são intitulados “¿Por qué informática jurídica hoy (2018)?” e “Aplicabilidad, lógica y inteligéncia artificial en el derecho"; e os três artigos específicos têm como título "Relações líquidas e direito ao esquecimento: novos desafios de proteção nas relações de trabalho", "Um quadro explicativo para implantação do processo judicial eletrônico: estudo de caso comarca de chapecó: 2014-2016" e "A internet como ator emergente ante ao direito ambiental internacional: a importância da informação e educação à proteção do meio ambiente".

O grupo de artigos que se segue tem um tema que sempre está presente de alguma forma: os dados pessoais e a sua proteção. A hiperexposição pessoal nas redes sociais, os dados pessoais sensíveis e o direito ao esquecimento na internet, inclusive advindo das relações de trabalho, foram tópicos debatidos.

Enfim, os coordenadores do GT convidam a todos a lerem o teor integral dos artigos, agradecendo a participação dos autores pesquisadores dessa edição.

Coordenadores do GT:

Prof. Dra. Pilar Lasala - UNIZAR

Prof. Dr. José Renato Gaziero Cella - IMED

Prof. Dr. Aires José Rover - UFSC

\footnotetext{
${ }^{1}$ Nota Técnica: Os artigos que não constam neste livro foram selecionados para publicação na Plataforma Index Law Journals, - http://indexlaw.org/index.php/conpedireview/index.
} 


\title{
A INTERNET COMO ATOR EMERGENTE ANTE AO DIREITO AMBIENTAL INTERNACIONAL: A IMPORTÂNCIA DA INFORMAÇÃO E EDUCAÇÃO À PROTEÇÃO DO MEIO AMBIENTE
}

\author{
Mateus Catalani Pirani \\ Universidade Católica de Santos
}

\section{Resumo}

O princípio da participação popular permite à sociedade civil participar das tomadas de decisões e efetivação das políticas públicas de defesa ao meio ambiente. Entretanto, a sociedade somente poderá participar adequadamente deste processo ao obter informações ambientais adequadas. A Internet insere-se nesse contexto como agente promissor dentro da mídia, exercendo condição de ator emergente nas relações internacionais com influência para a proteção ambiental. Nesta vertente analisa-se a necessidade da informação para participação popular na proteção do meio ambiente, ponderando acerca do incremento da participação popular através do acesso à Internet e educação ambiental.

Palavras-chave: Direito Ambiental Internacional, mídia, Internet, informação, educação ambiental.

\section{Abstract/Resumen/Résumé}

The principle of popular participation allows civil society to engage in decision-making and implementation of public policies in order to protect the environment. However, society can only properly participate in this process by obtaining adequate environmental information. Internet inserts itself in this context as a promising agent within the media, exercising the status of an emerging player in international relations with relevant impact over environmental protection. In that way, analyses the importance of information for popular participation in environment preservation, pondering over the Internet spread around the globe.

Keywords/Palabras-claves/Mots-clés: International Environmental Law, Media, Internet, Information, Environmental Education. 


\section{Introdução}

A questão ambiental deve estar inserida em temas e notícias das mais diversas áreas, e não apenas durante a cobertura de desastres ambientais. Nesse sentido, A mídia pode inserirse de forma cívica, educando o receptor da mensagem para a questão ambiental ao tratar do tema.

Tendo em vista o princípio da participação popular, que permite o envolvimento direto da sociedade civil nas questões ambientais, a mídia exerce papel de importância em fornecer as informações adequadas para possibilitar tal participação.

Por esta razão, objetiva-se abordar, portanto, a relação entre Direito, Meio Ambiente e meios de comunicação de massa, dando-se enfoque à Internet, pois esta vai além de um meio de comunicação, mas funciona como um serviço de valor agregado de alcance mundial.

Busca estudar a conscientização ambiental com base nas informações transmitidas pelos veículos de comunicação, vez que grande parte da população baseia seus conhecimentos sobre o tema nas informações advindas da mídia; analisar a potencialidade da informação na educação ambiental, tendo aquela o poder de transformar indivíduos em cidadãos ambientais, procurando assim perpetuar a educação ambiental para as presentes e futuras gerações.

\section{Direito Ambiental Internacional}

Após o início do século XXI, a raça humana vêm enfrentando questões globais diversas, trazendo desafios para solucionar os conflitos gerados pelos clássicos sujeitos de Direito Internacional. Entre tais questões, estão aquelas envolvidas com a qualidade do meio ambiente. Essas mostram-se complexas (como, por exemplo, a poluição de mares e oceanos além de fronteiras nacionais, aquecimento da atmosfera, entre outros), que não comportam soluções já implementadas, costumeiramente surtindo efeito a um único território nacional.

Com a necessidade de uma nova abordagem emerge então o Direito Ambiental Internacional (DAI), permitindo novos regimes jurídicos e a utilização de instrumentos com o auxílio de novos atores no cenário internacional, através da implementação da governança global.

O Direito Ambiental Internacional surge assim como elemento fundamental, e seu campo compreende tanto a chamada hard law, que consiste basicamente em tratados - acordos com força legal firmados entre Estados, e ratificados pelos respectivos governos, quanto pela soft law, formada por guias de conduta não obrigatórios adotados em processos internacionais (GONÇALVES; COSTA, 2015, p. 104). 
O Direito Ambiental Internacional procura tratar as questões globais com instrumentos jurídicos (convenções e tratados internacionais); e não jurídicos (resultados de painéis e pesquisas da comunidade científica), através de mecanismos de solução multidisciplinares, como engenharia, os meios de informação providos pela tecnologia, entre outros.

\begin{abstract}
Esse ramo do direito internacional impõe aos seus estudiosos a busca e a aceitação de novos modos de perceber as relações entre os Estados e os demais atores da vida internacional e da sua regulação pelo direito, ou por outros conjuntos normativos, não necessariamente jurídicos. Maior flexibilidade e criatividade são exigidas, na produção, no estudo e na aplicação das normas internacionais (REI; NASSER, 2007, p. 02).
\end{abstract}

Com a aplicação de princípios voltados à proteção ambiental(como precaução e prevenção, desenvolvimento sustentável, responsabilidade comum porém diferenciada, cooperação, entre outros), tendo a colaboração da sociedade internacional, o Direito Ambiental Internacional enfatiza a preservação da qualidade do meio ambiente aliado ao desenvolvimento sustentável, por meio da governança global.

\title{
2.1. Governança Global
}

A expressão governança tornou-se comum nas áreas das Ciências Humanas e Ciências Sociais Aplicadas, como imprescindível para os processos de desenvolvimento econômico e social, vez que abrange as áreas política, tecnológica, cultural, entre outras, pois é o “conjunto de processos inter-relacionados que operam através de todos os campos primários do poder social' (HELD; MCGREW, 2001, p. 18).

Abrange-se, outrossim, a solução de conflitos entre Estados e atores não estatais, estabelecendo formas e mecanismos de gestão compartilhada do poder de maneira transparente, onde Estados, organizações internacionais, empresas multinacionais e organizações da sociedade civil possam ter papel relevante (GONÇALVES, 2014, p. 83).

O crescimento na interdependência dos povos gerou diversos conflitos não mais aprisionados às fronteiras Estatais. "Novas relações internacionais e o advento de tecnologias da comunicação consolidam a interdependência global" (POLISTCHUK; TRINTA, 2003, p. 41). Dessa maneira, a "governança é meio, ferramenta, instrumento para solução de problemas" (GONCALVES; COSTA, 2015, p. 109), No passo que, "sua falta passa a ser identificada como responsável pela ausência de avanços no processo de desenvolvimento apesar das significativas transferências de recursos como ajuda para tais países” (GONÇALVES; COSTA, 2015, p. 93). 
Surgiu então o conceito de "Governança Global", através da Comissão sobre Governança Global, criada pela Organização das Nações Unidas (ONU), em 1992 (com relatório oficial de 1994), como sendo:

[...] a totalidade das diversas maneiras pelas quais os indivíduos e instituições, públicas e privadas, administram seus problemas comuns. É um processo contínuo pela qual é possível acomodar interesses conflitantes e realizar ações cooperativas. Governança diz respeito não só a instituições e regimes formais autorizados a impor obediência, mas a acordos informais que atendam aos interesses das pessoas e instituições (COMISSÃO SOBRE GOVERNANÇA GLOBAL, 1996, p.2) ${ }^{1}$.

Em suma, "governança é um fenômeno mais amplo do que governo; abrange as instituições governamentais, mas implica também em mecanismos informais, de caráter nãogovernamental” (ROSENAU, 2000, p. 15-16).

\subsection{Globalização}

O fenômeno da globalização vem provocando alterações significativas no mundo contemporâneo, trazendo muitas vezes consequências incertas e indeterminadas para a sociedade, além de modificar a relação entre os Estados Nacionais.

Com o advento desse fenômeno, há um aumento dos litígios internacionais decorrente do aumento das próprias relações internacionais, influenciadas pela diminuição das barreiras físicas, possibilitada pelos meio de comunicação e pela inovação tecnológica. A fim de estimar maior dimensão contemporânea da globalização em macro, relevante a explanação de microconceitos pertinentes ao tema.

A globalização tem sido diversamente concebida como ação à distância [...]; como compressão espaço-temporal [...]; como interdependência acelerada [...]; como um mundo em processo de encolhimento (erosão das fronteiras e das barreiras geográficas à atividade socioeconômica); e, entre outros conceitos, como a integração global, reordenação das relações de poder inter-regionais, consciência da situação global e intensificação da interligação inter-regional [g.n.] (HELD; MCGREW, 2001, p. 1113).

A característica de Ação à Distância compreende a capacidade que os acontecimentos locais de um país, sejam políticos, econômicos ou culturais, tem de gerar consequências nas relações internas de outros Estados distantes. Já a questão da Compressão Espaço-Temporal

\footnotetext{
${ }^{1}$ Marco também dessa comissão foi a introdução no processo de solução de problemas comuns novos mecanismos e atores na busca pela construção de um consenso, através do resultado final de um processo de discussão e interação entre todos os envolvidos naquela problemática (ao invés da coerção e da imposição).
} 
possibilita uma aproximação global, fazendo com que o tempo não passe de uma mera questão física, não atuando mais como agente limitador das atividades humanas (HELD; MCGREW, 2001, p. 13).

A difusão e evolução dos meios de comunicação de massa, em especial a Internet, possibilitam um contato instantâneo e eletrônico, ultrapassando assim barreiras físicas antes limitadoras do fenômeno da Globalização. A Interdependência Acelerada faz com que as ações tomadas por um Estado passem a repercutir diretamente na organização política e econômica de outros (HELD; MCGREW, 2001, p. 15).

Diante da derrubada de barreiras físicas, fazendo com que as atividades e interesses coletivos tomem escala internacional, o Estado se vê diante de um desafio direto para o princípio territorial da organização social e política moderna, em que não podendo negligenciar as questões ambientais.

Tratando-se a Internet da rede mundial de computadores, é, portanto assunto de escala internacional e positivada de acordo com os interesses econômicos privados, onde poderiam existir pactos de Direito Internacional Público, a fim de promover e difundir a educação ambiental por meio de uma Internet universal e neutra. O resultado do processo de globalização não é determinado, uma vez que uma nova arquitetura mundial está em desenvolvimento.

O resultado desse movimento, intensificado nas últimas décadas, é a redução do poder dos Estados e o aumento do protagonismo de outro atores, como indivíduos, empresas e sociedade civil organizada. Não se trata do fim da soberania estatal, como apregoado por alguns, mas a emergência de um novo paradigma de soberania, fundado em dois conceitos básicos: a capacidade de representação dos interesses aos governados e a legitimidade conferida a suas ações (GONÇALVES, 2014, p. 88).

Neste contexto, surgem atores não estatais de influência internacional, uma vez que a globalização permite a ampliação de relações e atividades sociais, intensificando os fluxos globais.

\subsection{Governança Ambiental Global: novos atores}

Tendo aumentado a interdependência no cenário internacional, surgem novas organizações estruturadas de grande relevância, que passam a compor o processo de governança. "Se o processo de globalização tem um impacto sobre o desenvolvimento do Direito Internacional, a prática e as opiniões dos atores não-estatais não podem mais ser excluídos da avaliação do Direito" (NOORTMANN, 2001, p. 74). 
Tendo em vista os avanços tecnológicos que viabilizaram a maior integração nas relações internacionais, o fenômeno da globalização e da governança, surge no cenário internacional a chamada sociedade global. Dentro dessa, há a ascensão da "sociedade civil transnacional ${ }^{2 "}$ - os chamados atores não estatais.

É evidente que a governança não se resume a ação ou papel de atores não governamentais: ela envolve os Estados, as organizações internacionais, atores não estatais. Mas estes têm papel relevante no processo de governança, vista como forma e processo de resolver problemas comuns (GONÇALVES, 2014, p. 67).

Atuando nesse sentido, as Organizações Não Governamentais (ONGs) veem um crescimento exponencial e a extensão de suas atividades nos mais variados campos. Protagonistas da atuação no cenário interno e no internacional, as ONGs tem papel indiscutível no que diz respeito ao meio ambiente, tendo atuação ativa em debates para tomadas de decisões em âmbito global, influenciando a elaboração de tratados para proteção ambiental (GONÇALVES; COSTA, 2015, p. 71/72).

Tal influência das ONGs se faz por meio de propagandas e manifestações principalmente veiculadas pela mídia, utilizando-se dos meios de comunicação e a Internet para alcançar seus objetivos, gerando assim conscientização em da população com acesso à informação, tendo habilidade de "articular-se com grande competência em todas as formas de imprensa (rádio, TV, jornal impresso, revista), bem como utiliza a Internet, construindo redes de divulgação e integração internacionais" (GONÇALVES; COSTA, 2015, p. 72).

Portanto, as demais entidades permanecem com a condição de atores, tendo em vista que, tradicionalmente, somente os Estados podem ser considerados sujeitos de personalidade jurídica internacional, todavia, os atores não estatais não podem ser excluídos desta sistemática, uma vez que são parte essencial dos processos de governança, desempenhando protagonismo junto as relações internacionais.

\subsection{Governança e informação: Internet como um ator emergente}

Além dos novos atores já citados, existem outros que também exercem influência no cenário internacional. Estes exercem forte papel na opinião pública mundial, valendo-se das novas tecnologias da comunicação, bem como influencia os rumos da política externa.

\footnotetext{
2 “[...] grupos, indivíduos e instituições que são independentes dos Estados e das fronteiras estatais, mas que estão, ao mesmo tempo, preocupados com os assuntos públicos” (MATIAS, 2005, p. 446).
} 
A influência da opinião pública nas questões internacionais deve ser percebida sob um duplo aspecto: primeiramente, como um vetor apreendido, com maior ou menor sensibilidade, pelos outros atores internacionais, os quais tendem a incorporar as demandas da opinião pública fazendo-a participar da definição do conteúdo da ação internacional dos atores tradicionais. [...] A segunda forma de manifestação da opinião pública é recente e decorre da ação da denominada sociedade civil organizada, sobretudo pelas redes de telecomunicações (SEITENFUS, 2004, p. 161/162).

Trata-se da mídia e dos veículos de comunicação de massa, que fazem cada vez mais parte dos processos de implementação e promoção de políticas internacionais, gerando entendimento dos interesses, cooperação e articulação, inclusive no âmbito da proteção ambiental, neste cenário, tem-se a Internet como protagonista desta atuação.

Logo, as relações formadas em razão de produtos da globalização são intensificadas com as reduções das barreiras de espaço e tempo, possibilitadas pela comunicação social, gerando senso de responsabilidade frente à indivisibilidade do mundo e sua imperativa proteção.

Através deste tipo de informação, a população mede a gravidade da situação ocorrida, podendo ainda propagar o testemunho ocular recebido, e difundir a ideia na Rede, efetivando e potencializando esforços para a preservação em comunidade. Pode-se dar como exemplo os diversos avanços ocorridos durante a ECO-92, que se deram por conta da conscientização publica, alavancada pelos meios de comunicação da época.

A moderna tecnologia de informação também está impulsionando as nações-Estados em direção à cooperação com outras, para que o trabalho mundial possa ser feito. À medida que as notícias dos problemas mundiais, reais ou percebidos, se espalhavam [...] Os acontecimentos numa região podem ter imensas consequências em outra. [...] A difusão da informação está sendo promovida por um número imenso de novos dispositivos que surgem quase diariamente (WRISTON, 1994. p. 160).

Portanto, nota-se que atos favoráveis ao meio ambiente no aspecto formal ou informal, como no caso da propagação da informação para a opinião pública podem contribuir para a edificação de uma percepção positiva em relação ao meio ambiente.

\section{Sociedade e os veículos de comunicação de massa}

É certo que a comunicação deu início aos avanços da civilização humana, vez que a partir da difusão da comunicação de massa, iniciaram-se as mudanças críticas na evolução. 
Assim, a história humana pode ser contada a partir do desenvolvimento da comunicação ${ }^{3}$, cujo alcance "foi assegurado de maneira definitiva pela invenção dos meios eletrônicos que aproveitam diversos tipos de ondas para transmitir signos: o telegrafo, o telefone, o rádio, a televisão e, finalmente, o satélite" (BODERNAVE, 2013, p. 30).

A comunicação passa a exercer influência no âmbito individual e coletivo. Com o ingresso na era dos computadores, há de se destacar também como veículo de massa a Internet, isto é, possibilita-se a circulação de mensagens independente de territórios geográficos, de tempo, das diferenças culturais e de interesses. Qualquer pessoa que tenha acesso à Internet pode processar e difundir conteúdos online (PERUZZO, 2005, p. 268), permitindo organização e expressão da opinião pública em uma escala maior, inclusive em questões de caráter ambiental.

\subsection{Sociedade Digital}

Em virtude dos mencionados avanços tecnológicos, grande parte da atual sociedade está diretamente conectada à Internet. Os internautas correspondem a $47 \%$ da população mundial, estimada em 7,6 bilhões ${ }^{4}$. A quantidade de usuários de Internet mais do que dobrou em apenas oito anos. (TRACTO, 2017, online).

Ter acesso à esta ferramenta não trata mais de luxo, mas de garantir a evolução da sociedade em questões econômicas, culturais e sociais. Afetam não só as bases estruturais da sociedade, como influenciam, também, às alterações comportamentais. A Internet imergiu o mundo ${ }^{5}$ em uma realidade virtual, e o seu contínuo desenvolvimento implica alterações na sociedade como um todo.

Hoje pertence ao senso comum, do homem médio, afirmar que o mundo está globalizado. Contudo, o mundo só atingiu tal proporção de globalização por estar conectado à Rede Mundial de Computadores, a Internet.

Neste sentido, Paesani, fundamentada em autores como Castells, Siqueira Junior e Miguel Reale, compreende que a contemporaneidade vivencia um processo de integração que

\footnotetext{
${ }^{3}$ A operação típica da sociedade é a comunicação, entendida como ato de transmitir, receber e compreender a informação. A própria evolução sociocultural é exemplo da contínua transformação e ampliação das possibilidades de comunicação (CAMPILONGO, 2000, p. 162).

${ }^{4}$ Disponibilidade: a proximidade da infraestrutura necessária para acesso. Atualmente, $78 \%$ da população mundial está coberta por redes mobile, o que significa que 1,6 bilhão de pessoas vivem em regiões sem sinal de celular. (TRACTO, 2017, online).

${ }^{5}$ Facilidade: a capacidade de acesso, incluindo habilidades, consciência e aceitação cultural. No mundo todo, um bilhão de pessoas são desprovidas de habilidades elementares de alfabetização. Nos países em desenvolvimento, dois terços das pessoas que não tem conexão não entendem o que é a Internet (TRACTO, 2017, online).
} 
vai além do fenômeno da globalização. Enquanto este decorre da evolução tecnológica e transforma o papel do Estado Nacional, aquele é caracterizado pela aproximação cultural, comercial e institucional dos Estados (PAESANI, 2014, p.14).

Surgem, então, na contemporaneidade, conceitos como "Sociedade de Informação", "cidadania digital" e "Direito Digital", empregados na tentativa de descrever os aspectos provocados pelas novas tecnologias de comunicação na humanidade, e a seguir explanados.

\subsection{Sociedade da Informação}

O termo "Sociedade da Informação", compreende uma sociedade que se constitui e se desenvolve sobre tecnologias de informação e comunicação que englobam a aquisição, o armazenamento, o processamento e a distribuição da informação por meios eletrônicos, utilizados pela população em circunstâncias sociais, econômicas e também políticas - o compartilhamento de informações por meio de um espaço virtual para amplitude do exercício da cidadania e da democracia (PAESANI, 2014, p.15).

Tubella afirma que as novas formas de interação social permitidas pela Internet obrigam a reconsideração de conceitos como comunidade e identidade. Defende, também, que o principal impacto da Internet na sociedade é a expansão cultural para além de barreiras geográficas, possibilitando a comunicação "from many to many" - sendo essa a mais relevante diferença entre a rede e os preexistentes meios de comunicação $(2005$, p.56).

É possível sustentar o posicionamento de que fator substancial para o desenvolvimento de uma identidade coletiva é a comunicação (TUBELLA, 2005, p.57). A Internet potencializa tal comunicação, facilitando a obtenção dos mais diversos conteúdos por quem a acessa, acelera o recebimento e a emissão de dados e garante, ao menos em tese, que seus usuários tenham acesso a um fluxo de informações independente de controles prévios como os que se verificam nos veículos de comunicação tradicionais.

O contato dos veículos de massa com o público alvo, através da comunicação transmitida, gera a opinião pública. Dessa forma, tais veículos tornam-se protagonistas, ao difundir o conteúdo, como também portadores da opinião pública, na condição de intérpretes.

[...] Esses movimentos podem ser revelados por um confronto sistemático do conteúdo das mensagens difundidas pelos meios de comunicação (imprensa, rádio e televisão) como também por sondagens de opinião, comparativas ou simultâneas (MERLE, 1981, p. 313). 


\subsection{Internet e Direitos Humanos}

A Internet tem provocado mudanças no cotidiano e no direito, principalmente em relação aos Direitos Humanos. Em 1948, a ONU adotou a Declaração Universal dos Direitos Humanos, reconhecendo os direitos de todo ser humano ${ }^{6}$. Dentre eles, as liberdades de opinião e expressão, diretamente ligados ao usuário da Internet (DUDH, online).

Ao decorrer do tempo, foram firmadas dimensões de direitos humanos, tidos como decorrentes da dignidade humana tratando, em suas primeiras dimensões dos direitos civis e políticos, bem como os direitos econômicos e sociais, difusos e coletivos.

No entanto, cabe em destaque os Direitos Humanos de quarta dimensão, que dizem respeito à informação. Paulo Bonavides, ao lecionar sobre o tema, afirma serem aqueles inerentes à democracia, à informação e o direito ao pluralismo (2006, p.571). Sobre um óptica diferenciada, Celso Ribeiro Bastos e André Ramos Tavares, apontam ser, também, o fenômeno da globalização e os avanços tecnológicos são responsáveis pela ascensão dessa nova categoria de direitos humanos (2000, p.389).

De acordo com Nunes, pode-se falar em direitos de quinta dimensão; são provenientes da última década no século XX, e que ainda não foram totalmente reconhecidos pacificamente pela doutrina (2010, online). São reconhecidos o direito a honra, o direito de imagem, ressaltando o princípio da dignidade humana. Tais direitos podem ser definidos como virtuais, uma vez que são defendidos em relação à Internet e ao seu uso por parte dos usuários (2010, online). Desta forma, o acesso à Internet passou a ser um direito de todo cidadão, conforme prevê o $\operatorname{artigo} 4^{\text {o }}$, I da Lei ${ }^{\circ} 12.965 / 14^{7}$.

Após a grande massificação da Internet, esta passa a ser utilizada mecanismo de influência nas decisões políticas ao redor do mundo. Diante desse cenário se torna o acesso a ela também um direito que deve ser proporcionado pelo Estado em respeito inclusive aos direitos humanos, dado o envolvimento da Internet com o tema.

Os veículos de comunicação devem assumir a responsabilidade pelo compromisso em informar e fomentar os Direitos Humanos, sendo imprescindível, ainda, que a mídia auxilie na conscientização de tais direitos. No atual cenário global, percebe-se que a informação tem papel fundamental para o reconhecimento, inclusão social e conscientização, além do fomento ao

\footnotetext{
${ }^{6}$ Sem distinção de etnia, cor, gênero, língua, religião, ideologia política ou de qualquer outro tipo de origem (art. $\left.2^{\circ}-\mathrm{DUDH}\right)$

${ }^{7}$ Artigo $4^{\circ}$ - A disciplina do uso da internet no Brasil tem por objetivo a promoção: I - do direito de acesso à internet a todos.
} 
respeito.

O progresso tecnológico transformou a informação em um bem jurídico capaz não só de satisfazer a necessidade de saber, como também de influir decisivamente no seu uso. Proteger a capacidade de reflexão é o que se propõe o direito de informação (CARVALHO, 2003, p. 209/210).

Neste sentido, a mídia pode ser a chave facilitadora para o fomento de um discurso de promoção dos Direitos Humanos. O acesso à informação de qualidade passa a ser condição necessária para o exercício da participação social. É necessário que as pessoas tenham acesso à informação para que possam ter voz ativa em debates e influenciar nos acontecimentos, numa sociedade que não há participação sem que haja informação.

A informação constitui a base para qualquer tomada de decisão, seja no âmbito dos governos, seja na iniciativa privada, seja nas movimentações sociais. É do conhecimento e da análise dos fatos que se podem propor medidas atinentes à busca de caminhos adequados às necessidades. Isso se aplica, também, ao meio ambiente (GRANZIERA, 2011, p. 67).

No mesmo sentido, o acesso à informação trata-se da capacidade de investir, descobrir, recuperar e decodificar o histórico de mensagens recebidas pelos veículos de massa, transmitindo novas mensagens a partir da primeira recebida. Isso implica deixar a condição de receptor passivo para adquirir um posicionamento de transmissão ativa, mobilizando a opinião pública e dando a ela "importante papel no equacionamento da política ambiental” (MILARÉ, 1993, p. 197).

Para que isso ocorra, é necessário mecanismos que visem implementar os princípios da Agenda 21 e da Agenda 2030 referentes a tornar a educação ${ }^{8}$ e a informação "pressupostos para que a participação popular para que a defesa do meio ambiente seja efetivada" (AYALA, 2005, p. 330).

Em derradeiro, pertinente se faz trazer à baila as menções de Edith Brown Weiss, acerca da necessidade de consciência para promoção da equidade intergeracional. Esta teoria parte da concepção de que as atuais gerações que habitam o planeta terra, não estão em nível hierárquico superior aos habitantes ainda não nascidos, cabendo, portanto, o dever de uso racional e sustentável dos recursos ambientais, de maneira a garantir a sua existência às futuras gerações (1992, online).

\footnotetext{
8 "Evitar o agravamento da situação ambiental que o planeta enfrenta é conscientizar a sociedade, sobre a necessidade de conviver de forma harmoniosa com o ambiente (social e ecológico)" (ZENONE, 2006, p. 159).
} 
Eis que a proposta desenvolvida pela teoria é inovadora, porquanto, pretende preservar espécies animais e vegetais, bem como a qualidade do ar, água e recursos terrestres para que as próximas gerações possam conhecê-las e gozá-las, tais como estão disponíveis em nossos dias atuais, estando reconhecidas como sujeitos de direitos, e para que isso tudo se concretize é necessário que a informação alcance as bases sociais (KISS, 2005, p. 54/55).

\section{Do direito à informação ambiental de qualidade}

De modo geral, o direito à informação está definido desde 1948, com a Declaração Universal dos Direitos Humanos, da Assembleia Geral das Nações Unidas, no artigo 19: “Toda pessoa tem direito à liberdade de opinião e expressão; este direito inclui a liberdade de, sem interferência, ter opiniões e de procurar, receber e transmitir informações e ideias por quaisquer meios, independentemente de fronteiras" (DUDH, online).

Quanto a informação ambiental dois princípios da Declaração de Estocolmo (de 1972) relacionam-se diretamente a este termo: Princípios $19^{9}$ e $20^{10}$, bem como o faz o Princípio $10^{11}$, da Declaração do Rio de Janeiro (de 1992). No âmbito específico da União Europeia, o artigo $2^{\circ}$, da Diretiva n ${ }^{\circ} 313$, de 1990, da Comissão das Comunidades Europeias (CEE), dispõe sobre a liberdade de acesso à informação ambiental, definindo o termo "informação relativa ao ambiente".

Qualquer informação disponível sob forma escrita, visual, oral ou de base de dados relativa ao estado das águas, do ar, do solo, da fauna, da flora, dos terrenos e dos espaços naturais, às atividades (incluindo as que provocam perturbações, tais como os ruídos) ou medidas que os afetem ou possam afetar negativamente e às atividades ou medidas destinadas a protegê-los, incluindo medidas administrativas e programas de gestão ambiental.

Ademais, a informação ambiental deve ser "veraz, contínua, tempestiva e completa", bem como conter as características da "tecnicidade, compreensibilidade e rapidez"

\footnotetext{
${ }^{9}$ Princípio 19 - É indispensável um esforço para a educação em questões ambientais [...] para fundamentar as bases de uma opinião pública [...] É igualmente essencial que os meios de comunicação de massas evitem contribuir para a deterioração do meio ambiente humano e, ao contrário, difundam informação de caráter educativo sobre a necessidade de protegê-lo [...].

${ }^{10}$ Princípio 20 - Devem-se fomentar em todos os países, especialmente nos países em desenvolvimento, a pesquisa e o desenvolvimento científicos referentes aos problemas ambientais [...] intercâmbio de informação científica atualizada e de experiência sobre a transferência deve ser objeto de apoio e de assistência, a fim de facilitar a solução dos problemas ambientais.

${ }^{11}$ Princípio 10 - O melhor modo de tratar as questões ambientais é com a participação de todos os cidadãos [...] toda pessoa deverá ter acesso adequado à informação sobre o ambiente de que dispõem as autoridades públicas, incluí da a informação sobre os materiais e as atividades que oferecem perigo a suas comunidades, assim como a oportunidade de participar dos processos de adoção de decisões. [...].
} 
(MACHADO, 2006, p. 91), devendo também ser rápida, tendo em vista a irreversibilidade da demora nos danos ambientais. Diante de risco significativo para a vida humana e para o meio ambiente a informação deve ser prestada imediatamente (MACHADO, 2006, p. 92).

Por fim, vale salientar que, em muitos casos, a informação ambiental deve ser disponibilizada de forma sistemática de maneira que se torne contínua, inibindo a conscientização da população por meio da periodicidade.

O receptor da informação não tem necessidade de comprovar seu interesse com ela, tendo em vista que é coletivo, pertence a todos. Assim, a informação deve ser encaminhada à autoridade ambiental responsável, para que seja suficiente para a tomada de decisões eficientes para a proteção jurídica do meio ambiente, de modo que se torna base e fundamento para tais deliberações.

\subsection{Princípio da informação ambiental}

Além da Declaração de Estocolmo, a Agenda 21, produto da Conferência das Nações Unidas sobre Meio Ambiente e Desenvolvimento, analisa que os recebedores de informações também se tornam provedores dela, e dispõe, em seu Capítulo 40, a meta da melhoria na disponibilidade das informações para melhor tomada de decisões.

Posteriormente, em agosto de 2015, foram elaborados os "Objetivos do Desenvolvimento Sustentável”, trazidos pela Agenda 2030 (também da ONU), que se propõe a fornecer programas, com vistas ao desenvolvimento sustentável. Entre tais Objetivos encontram-se "assegurar a educação inclusiva e equitativa e de qualidade, e promover oportunidades de aprendizagem ao longo da vida para todos" (Objetivo $\left.\mathrm{n}^{\circ} .04\right)$.

Tal objetivo se esmiúça de maneira a englobar áreas mais específicas a serem trabalhadas para o alcance das metas estipuladas. Dessa maneira os itens 4.7 e $4.7 b^{12}$ fazem expressa menção à necessidade da educação para a promoção do desenvolvimento sustentável, expressando a importância da tecnologia e da comunicação nesse papel.

Assim, tendo sido positivada a necessidade da informação e educação ambiental em âmbito global, se vê também necessária a cooperação internacional entre os Estados soberanos,

\footnotetext{
124.7 Até 2030, garantir que todos os alunos adquiram conhecimentos e habilidades necessárias para promover o desenvolvimento sustentável [...]. 4.b Até 2020, substancialmente ampliar globalmente o número de bolsas de estudo para os países em desenvolvimento, [...], incluindo programas de formação profissional, de tecnologia da informação e da comunicação, técnicos, de engenharia e programas científicos em países desenvolvidos e outros países em desenvolvimento.
} 
a fim de que os objetivos estipulados tornem-se metas cumpridas.

É fundamental para a construção de um modelo de sustentabilidade que haja uma gestão integrada (por meio de cooperação internacional), visando a produção e divulgação de informações de qualidade que propiciem a educação ambiental dos cidadãos acerca da defesa e proteção do meio ambiente.

Atualmente, a participação dos cidadãos é resguardada entre normas garantidoras dos direitos humanos, vez que "a participação garante o funcionamento democrático das sociedades e introduz maior transparência na gestão dos assuntos públicos” (LANCHOTTI, 2014, p. 223).

Atuando como princípio fundamental da democracia, a participação deve ser instrumentalizada com condições para a sua realização. No Brasil, o caput, do artigo 225, da Constituição Federal, exerce esse papel, impondo tanto ao Poder Público, quanto à coletividade o dever de defender e preservar o meio ambiente.

A participação social na preservação do meio ambiente é imprescindível, vez que efetivam as normas constitucionais de proteção ambiental com a conscientização e atuação da população. "Essas formas de participação popular, ao serem exercidas, valorizam a sociedade e fazem nascer a esperança de um mundo melhor" (PORTA, 2006, p. 30).

O direito à informação ambiental tornou-se ferramenta ao cumprimento da proteção ambiental, por meio da formação da educação ambiental. O povo com educação ambiental necessita da informação ambiental para saber o que, por que, como, quando e onde fazer ou deixar de fazer, e o povo com informação ambiental, mas sem educação ambiental, não dará importância às informações ou não saberá utilizá-las (WESCHENFELDER, 2012, p. 185) educação (aliada a informação) é o elemento de construção de equilíbrio e qualidade ambiental.

A partir da educação ambiental que as pessoas conscientizadas da importância do meio ambiente mostram-se mais eficientes e eficazes em protegê-lo, bem como propagam a consciência a respeito das questões ambientais (FREITAS, 2008, s/p). Também é necessário que a Educação Ambiental integre valores multidisciplinares, a fim de que haja a implementação de um processo de aprendizado socioambiental.

Neste contexto, a Declaração Universal de Direitos Humanos, da Assembleia Geral da ONU, de 1948, em seu preâmbulo destaca a importância da educação para a concretização de todos os outros direitos por ela proclamados ${ }^{13}$

\footnotetext{
${ }^{13}$ Com o objetivo de que cada indivíduo e cada órgão da sociedade, tendo sempre em mente esta Declaração, se esforce, através do ensino e da educação, por promover o respeito a esses direitos e liberdades, e, pela adoção de medidas progressivas de caráter nacional e internacional, por assegurar o seu reconhecimento e a sua observância universal e efetiva, tanto entre os povos dos próprios Estados-Membros, quanto entre os povos dos territórios sob sua jurisdição.
} 
Durante a Conferência de Estocolmo de 1972 foi desenvolvido o Programa Ambiental das Nações Unidas (PNUMA) e o Plano de Ação Mundial para a Educação Ambiental, servindo de base para que, em 1975, na cidade de Belgrado, seja lançado pela Unesco e pelo PNUMA o Programa Internacional de Educação Ambiental, que estabelece os princípios orientadores da educação ambiental em nível global.

Este Encontro resulta na Carta de Belgrado, que tem como meta "melhorar todas as relações ecológicas, incluindo a relação da humanidade com a natureza e das pessoas entre si”, além de determinar que a educação ambiental deva ser contínua, multidisciplinar, voltada aos interesses nacionais e crítica em relação ao modelo de desenvolvimento em curso.

Devido a sua importância, a educação ambiental pode ser entendida como a base para a criação de responsabilidades em prol do meio ambiente, através da formação de uma opinião pública qualificada.

\section{A influência da Internet como novo ator para o Direito Ambiental Internacional}

Os conteúdos veiculados pelos meios de comunicação, em especial a Internet (serviço de valor agregado), produzem a chamada homogeneização, que corresponde a "certa 'massificação' da opinião pública mundial, em consenso generalizado" (POLITSCHUK; TRINTA, 2003, p. 45).

Essa forma de comunicação impacta de forma generalizada a vida social e cultural, tendo em vista que pode ser utilizada para a construção de paradigmas, dando destaque a fenômenos em detrimento de outros. Logo, os veículos de comunicação se tornam formadores da opinião pública, vez que são por princípio socializantes e populares.

Atuando além da condição de veículo de comunicação, a Internet, vê a possibilidade de disseminar de modo ainda mais rápido e generalizado uma mensagem, popularizando este conteúdo e dando a ele repercussão e tornando-o onipresente aos atores sociais relevantes, desempenhado importante papel de existência e multiplicação do psicossocial coletivo. A formação de tal consciente coletivo pode ser utilizado pelos meios de comunicação a fim de que sejam disseminadas mensagens com cunho em prol do meio ambiente.

Logo, a comunicação possibilita aos receptores a sensação de pertencimento ao espaço público, evidenciando a necessidade a defesa e proteção do meio ambiente. Tal sensação de pertencimento possibilitada, pela informação veiculada, potencializa a participação popular nas questões ambientais. 


\subsection{A Internet como educadora ambiental da sociedade}

A Internet tem este papel de ensinar através da informação, tendo potencial de educação e promoção da cidadania, construindo assim uma sociedade sustentável. Dessa maneira, é crucial o papel da mídia no abastecimento da informação necessária aos cidadãos para a compreensão do mundo que os cerca e melhor adaptação de suas condutas para convívio em sociedade e proteger o meio ambiente.

Daí a importância dos meios de comunicação social na educação ambiental e na informação ambiental e com essas para o exercício da democracia participativa ambiental para concretizar a força normativa do direito de todas as pessoas ao meio ambiente ecologicamente equilibrado e, assim, construir uma cultura de equilíbrio ambiental no Brasil (WESCHENFELDER, 2012, p. 224).

Neste sentido existe o Objetivo Estratégico de médio prazo n ${ }^{\circ} .9$ (a ser implementado entre os anos de 2014 a 2021), da UNESCO: "Promover liberdade de expressão, desenvolvimento das mídias e acesso universal a informação e ao conhecimento" (UNESCO, 2013, p. 39), visando a construção da paz pela ação conjunta da comunicação e informação, através da promoção da liberdade de expressão, tornando-se facilitador dos Direitos Humanos.

A mídia sempre teve, portanto, papel intimamente relacionado ao processo de informação e educação ambiental, uma vez que traduz os dados científicos, econômicos e tecnológicos para a grande "massa". Além disso, a Internet é capaz de mobilizar público em prol do meio ambiente, edificando mecanismos e conceitos com o objetivo primordial de vida com qualidade e dignidade, sempre com enfoque no desenvolvimento sustentável

Cumpre aos meios de comunicação uma função de colaboração, que é exercida tendose por conteúdo a publicidade das informações e práticas educativas sobre o meio ambiente, que também é exercida pela incorporação da dimensão ambiental em sua programação. Pode-se considerar essa obrigação, também, como integrante das condições que permitem a realização do direito à informação ambiental (LEITE; AYALA, 2004, p. 173).

A concessão de espaços midiáticos e a realização de programas que promovam a educação e a cidadania ambiental refletem-se no esclarecimento dos cidadãos sobre a necessidade de proteção ambiental para as presentes e futuras gerações.

A comunicação dá forma aos padrões de vida em sociedade, assim ensinando o ser humano a se encaixar naquela determinada sociedade ou grupo cultural. "O impacto dos meios sobre as ideias, as emoções, o comportamento econômico e político das pessoas, cresceu tanto que se 
converteu em fator fundamental de poder e domínio em todos os campos da atividade humana" (BORDENAVE, 2013, p. 33).

Com a informação provida pelos veículos de comunicação, há maior relação entre as pessoas, ao compartilhar as informações recebidas, de maneira que de seres isolados passam a ser considerados interdependentes, se influenciando de maneira mútua.

Nesse aspecto há necessidade de se ampliar o usual conceito de informação ambiental para informação socioambiental, para agregar o conjunto de informações produzidas e disseminadas por órgãos do Poder Público [...] (BARROS, 2007, p. 466).

Informações acerca do meio ambiente relevantes podem ser utilizadas pela sociedade a fim de efetivar práticas positivas sustentáveis. Nesse sentido, a Carta da Terra (criada na Rio/92 e adotada posteriormente pela Unesco, em 2000), afirma que é necessário a criação de uma relação saudável entre a sociedade e o meio ambiente, integrando, "na educação formal e na aprendizagem ao longo da vida, os conhecimentos, valores e habilidades necessárias para um modo de vida sustentável" (Princípio 14).

A noção de desenvolvimento sustentável permeia a produção intelectual e a agenda política do mundo contemporâneo, sendo certo que seu conceito abrange várias áreas, combinando um ponto de equilíbrio entre o crescimento econômico, a igualdade social e a proteção do meio ambiente. Para a Comissão Mundial sobre Meio Ambiente e Desenvolvimento:

Desenvolvimento Sustentável é definido como aquele que atende às necessidades (que são determinadas social e culturalmente) das gerações atuais sem comprometer a capacidade das futuras gerações. (COMISSÃ̃ MUNDIAL SOBRE MEIO AMBIENTE E DESENVOLVIMENTO, 1991, p. 10).

O conceito de desenvolvimento sustentável é alcançado, portanto, quando se aufere (por parte tanto Poder Público, quanto pelos particulares) o equilíbrio entre o desenvolvimento econômico e social, bem como o respeito aos valores ambientais sustentáveis. Através desse conceito, é criada uma nova cultura a respeito do meio ambiente, através de um conjunto de conhecimentos voltados a proteção ambiental, difundidos pelos meios de comunicação de massa e pela Internet.

As pessoas têm tendência para incluir ou excluir dos seus próprios conhecimentos aquilo que os mass media incluem ou excluem do seu próprio conteúdo. Além disso, o público tende a atribuir àquilo que esse conteúdo inclui uma importância que reflete de perto a ênfase atribuída pelos mass media aos acontecimentos, aos problemas, às pessoas (SHAW, 1979, p. 96). 
Isso porque, o pressuposto lógico para o direito ao ambiente ecologicamente equilibrado das futuras gerações é o conhecimento (feito por meio de informação para educação) por parte das presentes gerações.

\section{Conclusão}

O acesso à informação ambiental, combustível para o desenvolvimento sustentável, tem como o maior divulgador a mídia. São os veículos de comunicação de massa, que chegam as mais diversas residências globais, e, podem contribuir para a mudança de significados da relação entre sociedade e meio ambiente por meio da concessão de diversos tipos de mensagens persuasivas, dando sentido para ações ambientalmente positivas. Dessa forma, a mídia tem um poder simbólico no que se refere a produção de conteúdo que pode provocar reações, influenciando nos resultados dos eventos das atividades sociais.

A Internet tem capacidade de formar e/ou moldar a opinião pública e inclinar a "massa" para um determinado ponto de vista desejado, interferindo na configuração do debate público, que podem fazer com que o agente receptor da mensagem deixe de assumir uma postura passiva com relação às informações obtidas, passando à atividade, para uma contribuição ativa.

A mídia exerce, assim, papel importante na vida política e pública nacional e internacional por meio da persuasão de ideias, culturas e valores, tornando-se um ator emergente neste cenário. A informação pelos veículos de comunicação, por meio da Internet, é essencial para a conscientização pública a respeito da defesa e proteção do meio ambiente, bem como da promoção do desenvolvimento sustentável.

\section{Referências bibliográficas}

AYALA, Patryck de Araújo. Transparência e participação pública no procedimento administrativo ambiental: problemas e perspectivas no direito brasileiro. In Anais $9^{\circ}$

Congresso Internacional de Direito Ambiental: Paisagem, natureza e direito. São Paulo: Instituto O Direito por um Planeta Verde, 2005.

BARROS, Lucivaldo Vasconcelos. A defesa do direito à informação socioambiental em juízo ou fora dele. In Anais do $\mathbf{1 1}^{\circ}$ Congresso Internacional de Direito Ambiental. v. 1. 
São Paulo: Imprensa Oficial do Estado de São Paulo, 2007.

BASTOS, Celso Ribeiro; TAVARES, André Ramos. Tendências do direito público no limiar de um novo milênio. 1. ed. São Paulo: Saraiva, 2000.

BONAVIDES, Paulo. Curso de direito constitucional. 18. ed. São Paulo: Malheiros, 2006.

BORDENAVE, Juan E. Diaz. O que é comunicação. São Paulo: Brasiliense, 2013.

CAMPILONGO, Celso Fernandes. O direito na sociedade complexa. São Paulo: Max Limonad, 2000.

CARVALHO, Luiz Gustavo Grandnetti Castanho de. Liberdade de informação e o direito difuso à informação verdadeira. 2.ed. Rio de Janeiro: Renovar, 2003.

COMISSÃO SOBRE GOVERNANÇA GLOBAL. Nossa comunidade global - Relatório da Comissão sobre Governança Global. Rio de Janeiro: Editora FGV, 1996.

COMISSÃO MUNDIAL SOBRE MEIO AMBIENTE E DESENVOLVIMENTO. Nosso futuro comum. 2.ed. Rio de Janeiro: Editora Getúlio Vargas, 1991.

DIREITOS HUMANOS. Declaração Universal dos Direitos do Homem - art. $2^{\mathbf{o}}$.

Disponível em: http://www.direitoshumanos.usp.br/index.php/Declaração-Universal-dosDireitos-Humanos/declaracao-universal-dos-direitos-humanos.html Acesso em 3 de maio de 2018.

FREITAS, Vladimir Passos de. Apresentação. In GALLI, Alessandra. Educação ambiental como instrumento para o desenvolvimento sustentável. Curitiba: Juruá, 2008.

GONÇALVES, Alcindo; COSTA, José Augusto Fontoura. Governança Ambiental Global: possibilidades e limites. In GRANZIERA, Maria Luiza Machado; REI, Fernando Cardozo Fernandes (coord.). Direito Ambiental Internacional: Avanços e retrocessos. São Paulo: Atlas, 2015. 
GONÇALVES, Alcindo. Governança Global e o Direito Internacional Público. In JUBILUT, Liliana Lyra (org). Direito Internacional Atual. São Paulo: Elsevier, 2014.

GRANZIERA, Maria Luiza Machado. Direito Ambiental. 2. ed. São Paulo: Atlas, 2011.

HELD, David; McGREW, Anthony. Prós e Contras da Globalização. Rio de Janeiro: Zahar, 2001.

KISS. Alexandre. Justiça ambiental e religiões cristãs. In: PRADO, Ines Virginia;

AKEMI, Sandra \& SILVA, Solange Teles da. Desafios do direito ambiental do século XXI: estudos em homenagem a Paulo Affonso Leme Machado. São Paulo: Malheiros, 2005.

LANCHOTTI, Andressa de Oliveira. Evaluación de impacto ambiental y desarrollo sostenible. Belo Horizonte: Arraes Editores, 2014.

LEITE, José Rubens Morato; AYALA, Patryck de Araújo. Direito Ambiental na Sociedade de Risco. 2ed. Rio de Janeiro: Forense Universitária, 2004.

MACHADO, Paulo Affonso Leme. Direito à informação e Meio Ambiente. São Paulo: Malheiros, 2006.

MATIAS, Eduardo Felipe P. A Humanidade e suas fronteiras: do estado soberano à sociedade global. São Paulo: Paz e Terra, 2005.

MERLE, Marcel. Sociologia das relações internacionais. Tradução de Ivone Jean. Brasília: Universidade de Brasília, 1981.

MILARÉ, Édis. Direito do Ambiente. São Paulo: Revista dos Tribunais, 2000.

NOORTMANN, Math. Non-state actors in International Law. In ARTS, Bas; 
NOORTMANN, Math; REINALDA, Bob (Ed.). Non-state actors in international relations. Burlington: Ashgate, 2001.

NUNES, Dymaima Kyzzy. As gerações de direitos humanos e o estado democrático de direito. In: Âmbito Jurídico, Rio Grande, XIII, n. 77, jun 2010. Disponível em: $<$ http://www.ambito juridico.com.br/site/index.php?n_link=revista_artigos_leitura\&artigo_id=7897>. Acesso em 7 de maio 2018

PAESANI, Liliana Minardi. Direito e Internet: liberdade de informação, privacidade e responsabilidade civil. 7. ed. São Paulo: Atlas, 2014, p. 14.

PERUZZO, Cicília M. Krohling. Internet e democracia comunicacional: entre os entraves, utopias e o direito à comunicação. In MELO, José Marques; SATHLER, Luciano (orgs). Direitos à comunicação na sociedade da informação. São Bernardo do Capo: UMESP, 2005.

POLISTCHUCK, Ilana; TRINTA, Aluizio Ramos. Teorias da comunicação: o pensamento e a prática do jornalismo. Rio de Janeiro: Campus, 2003.

PORTA, Marcos de Lima. Escritos: Temas de direito público. Rio de Janeiro: Litteris Ed., 2006.

REI, Fernando Cardozo Fernandes; NASSER, Salem Hikmat. Direito Internacional do meio ambiente: Ensaios em homenagem ao prof. Guido Fernando Silva Soares. In Interfacehs. vol. 1, no.3 - Resenha 1. São Paulo: Centro Universitário SENAC, 2007. Disponível em: $<$ http://www.revistas.sp.senac.br/index.php/ITF/article/viewFile/455/410>. Acesso em $11 \mathrm{de}$ novembro de 2016.

ROSENAU, James N. Governança, Ordem e Transformação na Politica Mundial. In ROSENAU, James N; CZEMPIEL, Ernst-Otto. Governança sem governo: ordem e transformação na política mundial. Brasília: Ed. UnB/ São Paulo: Imprensa Oficial do Estado de São Paulo, 2000.

SEITENFUS, Ricardo Antônio Silva. Relações internacionais. Barueri,SP: Manole, 2004. 
SHAW, E. Agenda setting and mass conimunication theory. In Gazette - International Journal for Mass Communication Studies. Vol. XXV, nº. 02, pp. 96/105. Holanda: University of Amsterdam, 1979.

TRACTO. Portal online. Quantas pessoas têm acesso à Internet no mundo? Disponível em: https://www.tracto.com.br/quantas-pessoas-tem-acesso-a-internet-no-mundo/ Acesso em 15 de março de 2018.

TUBELLA, Imma. Television and Internet in the construction of identity. Apud CASTELLS, Manuel; CARDOSO, Gustavo, eds. The network society: from knowledge to policy. Washington, DC: Johns Hopkins Center for Transatlantic Reactions, 2005.

UNESCO - United Nations Educational, Scientific and Cultural Organization. Draft Medium-Term Strategy: 37 C/4 2014-2021. Paris: UNESCO, 2013.

WEISS, Edith Brown. Intergenerational equity: a legal framework for global environmental change. Tokyo: United Nations University Press, 1992. Disponível em: $<$ http://www.unu.edu/unupress/unupbooks/uu25ee/uu25ee0y.htm\#12.\%20intergeneratio nal $\% 20$ equity: $\% 20 \mathrm{a} \% 20$ legal $\% 20$ framework $\% 20$ for $\% 20$ global $\% 20$ environmental $\% 20$ c hange>. Acesso em 30 de abril de 2018.

WRISTON, Walter B. O crepúsculo da soberania. São Paulo: Makron Books, 1994.

ZENONE, Luiz Cláudio. Marketing social. São Paulo: Thomson Learning, 2006. 


\title{
APLICABILIDAD, LÓGICA Y INTELIGENCIA ARTIFICIAL EN EL DERECHO
}

\author{
José Renato Gaziero Cella \\ Facultad Meridional - PPGD/IMED \\ Vinícius Borges Fortes \\ Facultad Meridional - PPGD/IMED
}

\section{Resumen}

Eugenio Bulygin, en uno de sus primeros trabajos publicados, fechado en 1965 (Der Begriff der Wirkamkeit), hace consideraciones sobre el concepto de eficacia, en el que desarrolla una crítica a la teoría de Alf Ross y, con el propósito de aclarar esa crítica, reflexiona sobre la concepción de Hans Kelsen acerca la eficacia del Derecho. A partir de aquel momento tuvo lugar un verdadero debate entre Bulygin y Ross, sin embargo no se tuvo noticia, hasta el año 2002, casi 20 años después del fallecimiento de Kelsen (1881-1973), de alguna respuesta de éste a Bulygin en relación a aquel artículo suyo de 1967, hasta que el Instituto Hans Kelsen de Viena encuentra un manuscrito, probablemente redactado entre 1967 y 1970, en el que Kelsen polemiza con Bulygin acerca del tema de la validez y eficacia del Derecho, de manera que sólo recientemente Bulygin pudo presentar su réplica en el debate en cuestión. El artículo, por intermedio del método hipotético deductivo, trata de ese debate entre Bulygin y Kelsen, en el que se tocan temas como la justificación de la decisión judicial y la deducibilidad lógica de las normas jurídicas; la idea de aptitud judicial; la aplicabilidad; la distinción entre sistema y orden jurídicos. De todos modos, tenemos a partir de ese debate una importante clave para el perfeccionamiento de la teoría pura del Derecho, de sus relaciones lógicas, de sus premisas básicas intangibles como siendo el positivismo jurídico, el escepticismo ético, la separación entre ser y deber y la neutralidad científica, y que el concepto de aplicabilidad de Bulygin permite, también, que se verifique las relaciones lógicas de los sistemas jurídicos y, aun delante de contradicciones, sistemas no clásicos de lógica, a ejemplo de las lógicas paraconsistentes, pueden ser aplicados para aplicaciones de la Inteligencia Artificial en el Derecho.

Palabras-clave: Controversia Bulygin-Kelsen sobre la validez y eficacia, El positivismo jurídico, Escepticismo ético, Deducibilidad Lógica de Normas Legales, Inteligencia Artificial. 


\section{Abstract/Resumen/Résumé}

Eugenio Bulygin, in one of his first published work, dated 1965 (Der Begriff der Wirkamkeit), considers the concept of effectiveness, in which it develops a critique of the theory of Alf Ross and, in order to clarify this criticism, reflects on the design of Hans Kelsen on the effectiveness of Law. From that moment it gave a true debate between Bulygin and Ross, but it was not news, by the year 2002, nearly 20 years after the death of Kelsen (1881-1973), any response to this Bulygin respect of that article 1967 until the Hans Kelsen Institute of Vienna located a manuscript, probably written between 1967 and 1970, in which Kelsen polemic with Bulygin on the subject of the validity and effectiveness of the Law, so that only recently Bulygin could present its rejoinder the debate in question. The article, through the hypothetical deductive method, addresses this debate between Bulygin and Kelsen, where it comes to issues such as the justification of the judgment and logic deductibility of legal rules; the idea of judicial competence; applicability; the distinction between legal system and order. Anyway, we have from this debate an important key to the refinement of the pure theory of Law, their logical relations, their intangible basic premises as legal positivism, ethical skepticism, the separation between being and duty and neutrality scientific and that Bulygin's concept of applicability allows, also, that the logical relations of legal systems be verified and, even in the face of contradictions, non-classical systems of logic, as in the case of paraconsistent logics, can be applied for applications of Artificial Intelligence in Law.

Keywords/Palabras-claves/Mots-clés: Controversy Bulygin-Kelsen on Validity and Effectiveness, Legal positivism, Ethical skepticism, Deductibility Logic of Legal Standards, Artificial Intelligence.

\section{Introducción}

Eugenio Bulygin, en uno de sus primeros trabajos publicados, fechado en 1965 (Der Begriff der Wirkamkeit), hace consideraciones sobre el concepto de eficacia, en el que desarrolla una crítica a la teoría de Alf Ross y, con el propósito de aclarar esa crítica, reflexiona sobre la concepción de Hans Kelsen acerca la eficacia del Derecho.

A partir de aquel momento tuvo lugar un verdadero debate entre Bulygin y Ross, sin embargo no se tuvo noticia, hasta el año 2002, casi 20 años después del fallecimiento de Kelsen (1881-1973), de alguna respuesta de éste a Bulygin en relación a aquel artículo suyo de 1967, hasta que el Instituto Hans Kelsen de Viena encuentra un manuscrito, probablemente redactado 
entre 1967 y 1970, en el que Kelsen polemiza con Bulygin acerca del tema de la validez y eficacia del Derecho, de manera que sólo recientemente Bulygin pudo presentar su réplica en el debate en cuestión.

El artículo trata, por intermedio del método hipotético deductivo, de esto debate entre Bulygin y Kelsen, en el que se tocan temas como la justificación de la decisión judicial y la deducibilidad lógica de las normas jurídicas; la idea de aptitud judicial; la aplicabilidad; la distinción entre sistema y orden jurídicos y la aplicación de la Inteligencia Artificial en el Derecho.

De todos modos, tenemos a partir de ese debate una importante clave para el perfeccionamiento de la teoría pura del Derecho, de sus relaciones lógicas, de sus premisas básicas intangibles como siendo el positivismo jurídico, el escepticismo ético, la separación entre ser y deber y la neutralidad científica.

\section{Premisas Intangibles en el Pensamiento de Eugenio Bulygin}

No hay verdades morales.

Esa es una de las principales hipótesis que Bulygin mantiene para el refinamiento de los postulados de la Teoría Pura del Derecho.

Si hubiese verdades morales para determinar la conducta humana, las normas de derecho positivo serían superfluas:

En el caso de que se pudiese tener conocimiento del orden absolutamente justo, cuya existencia es postulada por la doctrina del derecho natural, el derecho positivo sería superfluo, o mejor, desprovisto de sentido. Confrontada con la existencia de un orden justo de la sociedad, inteligible en términos de naturaleza, razón o voluntad divina, la actividad de los legisladores equivaldría a una tonta tentativa de crear iluminación artificial en pleno sol (KELSEN, H. 1998, p. 18-19).

La separación entre el Derecho y la Moral resultante de la relatividad de esta última es un trazo característico del positivismo jurídico refinado en el siglo XX. Gustav Radbruch, que llegó a ser uno de los más férreos defensores del positivismo jurídico durante la década del 30, daba clara preferencia al Derecho en caso de conflicto con la Justicia, “...pues es más importante la existencia del orden jurídico que su justicia, ya que la justicia es la segunda gran misión del Derecho, siendo la primera, la seguridad jurídica, la paz” (RADBRUCH, 1930, p. 34).

¿La razón puede llevar al conocimiento de la verdad? La respuesta escéptica, que niega tal posibilidad a la razón, aunque esté presente desde la Antigüedad clásica, se acentúa 
sobremanera a partir del siglo XX.

Según Aristóteles, la filosofía nace de la perturbación ante los acontecimientos del mundo (ARISTÓTELES, 2002, A 2, 982 a 29 - b 22, p. 11), de aquello que es imprevisible, del devenir. En un primer momento el hombre crea el mito para que éste explique el caos existente, buscando un sentido de orden. Sin embargo, los mitos sobreviven de creencias que fácilmente pueden ser destruidas y no poseen la radicalidad que la filosofía, desde el comienzo, se propuso buscar, o sea, "la idea de un saber que sea irrefutable; y que sea irrefutable no porque la sociedad y los individuos tengan fe en él o vivan sin dudar de él, sino porque él mismo es capaz de rebatir a todos sus adversarios. La idea de un saber que no puede ser negado ni por hombres ni por dioses, ni por cambio de los tiempos o de las costumbres. Un saber absoluto, definitivo, no controvertido, necesario, indubitable.” (SEVERINO, 1986, p. 29).

Por medio de la episteme, previendo y anticipando el devenir de la vida, el hombre se libera del terror, haciendo previsible lo que antes era imprevisible. La episteme surge como el gran remedio contra el terror de la vida.

Es justamente contra la idea de la filosofía como episteme que, desde la antigüedad, pasando por la Edad Media y por la modernidad, que se rebelarán los pensadores contemporáneos, entre los cuales el nihilismo de Nietzsche parece ser el más radical.

El nihilismo es justamente el rechazo de respuesta a los porqués metafísicos, pues percibe que no hay un fin a ser alcanzado.

En efecto, las tentativas dogmáticas de fundar conocimientos quedaron estremecidas. Los dogmáticos comenzaron a ser acusados de absolutistas, fundamentacionistas, objetivistas. En contrapartida los escépticos y su relativismo ganan un nuevo aliento y pasan a rescatar toda su tradición milenaria.

El pensamiento de Kelsen, por ejemplo, en consonancia con el relativismo de los escépticos, extrae la idea de que la ciencia debe ser neutra, lo que lleva a la búsqueda de una pureza metodológica que se basa en la ausencia de juicios de valor.

Sin embargo, según aduce Bulygin (KELSEN, BULYGIN, WALTER, 2005, p. 99), Kelsen es perfectamente consciente de los peligros que amenazan su teoría, visto que "una teoría positivista del Derecho se encuentra ante la tarea de buscar entre dos extremos, ambos insostenibles, la vía media correcta. Un extremo es la tesis de que entre la validez, como lo debido, y la eficacia, como un hecho real, no existe relación alguna; de que la validez del Derecho es enteramente independiente de su eficacia. El otro extremo es la tesis de que la validez del Derecho es idéntica a su eficacia” (KELSEN, 1960, p. 215). 
A fin de alejarse de los dos extremos que reputa insostenibles - el derecho natural, para el cual la validez del Derecho no tiene ninguna relación con a su eficacia; y el realismo jurídico, para el cual la validez del Derecho coincide con su eficacia - Kelsen propone la tesis de la separación, que afirma que no hay relación conceptual entre el Derecho y la Moral; y la tesis de la normatividad, que afirma la separación entre el Derecho y los hechos, puesto que el Derecho consiste en normas irreductibles a hechos.

No pocos autores trataron de señalar el fracaso de Kelsen en la búsqueda del camino medio que anhelaba. Mário G. Losano, por ejemplo, discurre que la norma básica no es una norma en sentido kelseniano, hecho ese que, según este autor, estaría directamente ligado a los límites de la teoría pura del Derecho:

\begin{abstract}
Hans Kelsen afirma que la teoría pura del Derecho tiene por objeto la normatividad y no el valor; y con ese argumento rebate las críticas que le fueron dirigidas por las teorías iusnaturalistas. Sin embargo, se recorremos de vuelta toda la estructura jerárquica de las normas que delegan validez unas a otras, llegaremos a la norma fundamental, o sea, a aquella en que se basa la construcción kelseniana: ella es la fuente primera de la validez de todo el ordenamiento jurídico. El mismo Kelsen, sin embargo, debe admitir que esa no es una norma jurídica en el sentido definido por la teoría pura del Derecho. Para ésta, de hecho, son jurídicas apenas las normas estatuidas por el legislador; la norma fundamental, al contrario, "debe ser presupuesta, por cuanto no puede ser puesta por una autoridad, cuya competencia debería reposar sobre una norma aun más elevada". El juego de palabras no resuelve el problema de fondo: Si la norma fundamental no es una norma jurídica positiva, es algo que el jurista acepta basándose en su evaluación de justicia o de oportunidad, o sea, con base en una elección que, para Kelsen, es no-científica en tanto que irracional (o mejor, subjetiva). Si, sin embargo, la norma fundamental es un expediente gnoseológico para encerrar en sistema unitario los varios niveles normativos, estamos delante de un elemento teórico (perteneciente al mundo de la naturaleza, del "ser") que condiciona la existencia de una norma (perteneciente al mundo del Derecho, del "deber-ser"); pasaje que Hans Kelsen considera inconciliable con el presupuesto de pureza metodológica. Mientras tanto, respondiendo a sus adversarios, ...Kelsen apuntará sin hesitar hacia las columnas de Hércules de toda la teoría jurídica, la frontera extrema del Derecho, más allá de la cual se abre un mundo diferente: "El problema del derecho natural es el eterno problema de aquello que está por tras del derecho positivo. Y quien procura una respuesta encontrará - temo - no la verdad absoluta de una metafísica ni la justicia absoluta de un derecho natural. Quien levanta ese velo sin cerrar los ojos se ve fijado por la mirada desorbitada de la Gorgona del poder" (LOSANO, 1996, p. XIX-XX).
\end{abstract}

En esa misma línea crítica está el pensamiento de Celano (1999), según el cual tanto la tesis de la separación como la tesis de la normatividad resultan insostenibles en el interior de la teoría pura.

Bulygin, por su vez, reconoce que no hay dudas de que muchas de las formulaciones kelsenianas son, de hecho, incompatibles con su positivismo normativista, razón por la cual su propuesta es la de reconstruir la teoría pura del Derecho, con la asunción de su defensa, inclusive contra Kelsen en los puntos en que sus afirmaciones resulten incompatibles con las 
tesis siguientes, que son postuladas como intangibles:

a) Positivismo jurídico. Todo derecho es derecho positivo, esto es, consiste en normas creadas y aniquiladas mediante actos humanos.

b) Escepticismo ético. No hay normas verdaderas; las normas en general y las normas morales en particular no son ni verdaderas ni falsas. Esto ocurre porque no hay hechos normativos que hagan verdaderas a las normas. En particular, no hay hechos morales que correspondan a las normas morales, y por lo tanto no es posible un conocimiento objetivo de la moral. En cambio, como la existencia de las normas jurídicas positivas depende de actos humanos, es posible un conocimiento objetivo del Derecho. No las normas jurídicas, pero sí las proposiciones que afirman la existencia de tal o cual norma jurídica son objetivamente verdaderas o falsas. Esto hace posible una ciencia del Derecho.

c) Separación entre ser y deber. De lo que es no se sigue que deba ser, y del hecho de que algo deba ser no se sigue que lo sea.

d) Ciencia jurídica avalorativa. La ciencia jurídica consiste en la descripción del Derecho positivo y no en su valoración. La valoración de los órdenes jurídicos positivos como justos o injustos es asunto de la política, no de la ciencia (KELSEN, BULYGIN, WALTER, 2005, p. 101-102).

Teniendo como intangibles las premisas encima, Bulygin tratará de refinar la teoría pura del Derecho en lo que se refiere al problema de la validez y de la eficacia, lo que le permitirá salvar esa teoría de las críticas formuladas por Losano, Celano y, especialmente, de las trampas que el mismo Kelsen armó para sí.

\section{Propuestas de Eugenio Bulygin para la Reconstrucción de la Teoría Pura del Derecho}

Las conclusiones más importantes a que Bulygin llegó en su refinamiento de la teoría pura del Derecho (cf. KELSEN, BULYGIN, WALTER, 2005, p. 117-118) son las de que el término validez es ambiguo en Kelsen. Cabe distinguir por lo menos dos conceptos muy diferentes que figuran con este rótulo: pertenencia y obligatoriedad.

Pertenencia es un concepto descriptivo. El enunciado la norma $\mathrm{N}$ pertenece al sistema S expresa una proposición verdadera o falsa.

Obligatoriedad es un concepto normativo. El enunciado la norma $\mathrm{N}$ tiene fuerza obligatoria expresa una norma, que no es ni verdadera ni falsa.

Si pertenencia es interpretada como existencia de una norma, entonces es necesario distinguir entre sistema y orden. Un sistema normativo es un conjunto de normas referidas a un momento temporal. Un orden normativo es un conjunto (secuencia temporal) de sistemas normativos. Esto obliga a distinguir entre la pertenencia de una norma a un sistema y la pertenencia de un sistema a un orden. 
Dada la ambigüedad del término validez, el problema de la relación entre validez y eficacia ha de tratarse en forma separada; entre pertenencia y eficacia no hay ninguna conexión.

Para la definición de pertenencia, la hipótesis de la norma básica resulta completamente innecesaria. Sólo para la validez como fuerza obligatoria necesita Kelsen la norma básica.

El concepto de fuerza obligatoria es interpretado por muchos autores (Ross, Raz, Nino, Losano, Celano) como deber moral de obedecer el Derecho, lo que resulta incompatible con el positivismo de Kelsen.

Pero la obligatoriedad puede ser interpretada como una obligación jurídica, para lo cual Bulygin propone el término aplicabilidad. Una norma es aplicable cuando una norma jurídica positiva (llamada norma de aplicación) establece el deber (o la facultad) del juez de aplicarla a un determinado caso.

Aplicabilidad no debe confundirse con pertenencia. Los jueces pueden estar obligados o autorizados a aplicar normas que no pertenecen a su sistema y ni siquiera a su orden jurídico.

El análisis de la estructura formal de ambos conceptos muestra que aplicabilidad es muy distinta de la obligatoriedad, tal como la entiende Kelsen. Su definición de obligatoriedad relativa presupone la obligatoriedad absoluta, lo que lo lleva a la suposición de la norma básica. La hipótesis de tal norma básica resulta innecesaria para la aplicabilidad.

\section{Relaciones Lógicas y Derecho}

¿El juez crea Derecho?

Los teóricos del Derecho, al responder esa pregunta, tradicionalmente presentan dos opiniones extremas y conflictivas, una de ellas acentúa el papel de las normas y limita la decisión judicial a una operación mecánica, la que Bulygin denomina de teoría del silogismo judicial (KELSEN, BULYGIN, WALTER, 2005, p. 35); y la otra teoría casi niega toda la importancia de las normas y enfatiza la función creadora del juez.

Según Bulygin ya había notado en 1965 (cf. KELSEN, BULYGIN, WALTER, 2005, p. 36), ambas concepciones comparten un error común, el de no distinguir problemas lógicos y psicológicos:

Una decisión jurídica está fundada normativamente, si puede ser derivada de manera lógica de determinadas normas (junto con las proposiciones descriptivas de los hechos). La fundamentación o justificación normativa es, por lo tanto, una cuestión de lógica. La relación lógica entre las normas y la decisión es la de implicación lógica; las normas implican la decisión o (lo que es lo mismo) la decisión es deducible mediante leyes lógicas. La vinculación del juez a "la ley y al Derecho" [...] consiste 
justamente en que el juez debe justificar sus decisiones mediante normas jurídicas. En casi todos los órdenes jurídicos modernos los jueces están obligados a fundar sus sentencias, esto es, a justificarlas expresamente.

Sin embargo, esta relación lógica entre las normas que justifican la decisión y esta última es confundida, a menudo, con la motivación causal del juez. Cuáles son los motivos que determinan la decisión del juez es una cuestión psicológica que no incide en absoluto en la fundamentación de la sentencia.

Si se tiene presente esta diferencia entre problemas lógicos y psicológicos, resulta claro que las dos teorías esbozadas más arriba sólo son aparentemente antagónicas, pues se mueven en planos distintos (KELSEN, BULYGIN, WALTER, 2005, p. $37-$ 38).

Así, por un lado, "del hecho de que la sentencia sea deducible de las normas no se sigue en absoluto que la actividad del juez sea mecánica" (KELSEN, BULYGIN, WALTER, 2005 , p. 38), y, por otro lado, la crítica realista está equivocada al pretender disociar la lógica deductiva de la aplicación del Derecho. El error consiste en el hecho de que el realismo no logró distinguir lo que viene a ser explicar y justificar una decisión y, también, que hay una diferencia entre justificación interna y justificación externa. La distinción entre explicar y justificar es traída por Manuel Atienza (1993, p. 125):

Para aclarar el primer par de conceptos [explicar y justificar], se puede utilizar una distinción que procede de la filosofía de la ciencia, entre el contexto de descubrimiento y el contexto de justificación de las teorías científicas. Así, por un lado la actividad consistente en descubrir o enunciar una teoría y que, según la opinión generalizada, no es susceptible de un análisis de tipo lógico; lo único que cabe aquí es mostrar cómo se genera y se desarrolla el conocimiento científico, lo que constituye una tarea que compete al sociólogo y al historiador de la ciencia. Pero, por otro lado, está el procedimiento consistente en justificar o validar la teoría, esto es, en confrontarla con los hechos a fin de mostrar su validez; esta última tarea requiere un análisis de tipo lógico (aunque no sólo lógico) y está regida por las reglas del método científico (que, por lo tanto, no son de aplicación en el contexto de descubrimiento).

Vale decir que esa distinción puede ser utilizada en el campo de la aplicación del Derecho, de ahí porque es posible concluir que una cosa es el procedimiento mediante el cual se establece una determinada premisa o conclusión, lo que es bien diferente del procedimiento que consiste en justificar la referida premisa o conclusión.

Se debe destacar que, en general, los órganos jurisdiccionales no tienen que explicar los motivos por los cuales decidieron de esta o de aquella forma, debiendo apenas justificar sus decisiones. ${ }^{1}$

Por lo tanto, teniendo en vista la distinción es fácil verificar el equívoco en que incurren las teorías realistas que reducen validez a la eficacia, de manera que para ellas el

\footnotetext{
${ }^{1}$ Decir que el juez tomó su decisión debido a fuertes creencias religiosas o por razones políticas e ideológicas significa enunciar una razón explicativa, mientras que decir que el juez se basó en determinada interpretación de un dispositivo legal significa enunciar una razón justificativa.
} 
proceso de toma de decisión de los órganos jurisdiccionales no se efectúa según un modelo lógico. $^{2}$

El segundo aspecto que las teorías realistas no tuvieron en cuenta fue el hecho de no haber percibido, según es mencionado encima, que hay una diferencia entre justificación interna y justificación externa.

La justificación interna es el camino que va de la premisa normativa (premisa mayor), en la cual debe ser subsumida la premisa fática (premisa menor), hasta ser deducida una conclusión válida. ${ }^{3}$

Ninguna decisión jurídica puede prescindir de ese tipo de justificación.

Pues bien, la justificación interna sólo es suficiente cuando ni la norma, ni la comprobación de los hechos suscitan dudas razonables.

Ocurre que en innumerables casos el estabelecimiento de la premisa normativa y/o de la premisa fática implica una cuestión problemática, haciéndose necesario el uso de argumentos adicionales en favor de las premisas que se pretenden utilizar, argumentos esos que probablemente no serán puramente deductivos. Ese tipo de argumentación es lo que se denomina justificación externa.

En esa línea de razonamiento, Bulygin demuestra que las conclusiones a que llegan las dos posiciones opuestas - teoría del silogismo judicial y realismo jurídico - no son incompatibles entre sí, aunque a menudo sean consideradas como tesis opuestas e, inclusive contradictorias:

Es un prejuicio muy difundido y arraigado entre los juristas que relaciona la relación lógica de fundamentación con la doctrina de la actividad mecánica del juez. Tanto los partidarios como los adversarios de la teoría del silogismo cometen a menudo el mismo error, al argumentar del siguiente modo: "la sentencia es deducible de las normas, por lo tanto, el juez es un autómata" o "el juez no es un autómata, por lo tanto, la sentencia no es deducible de las normas". (KELSEN, BULYGIN, WALTER, 2005, p. 38, nota 31)

En efecto, "el conocimiento de los factores que motivan al juez es de mucha importancia para el abogado práctico que pretende influir en el juez y predecir la sentencia; el conocimiento de las normas es indispensable para el juez o para el jurista que trata de justificar o de criticar la sentencia”(KELSEN, BULYGIN, WALTER, 2005, p. 39).

\footnotetext{
2“El error consiste, precisamente, en haber confundido el contexto de descubrimiento y el contexto de justificación. Es muy posible que, de hecho, las decisiones se tomen precisamente como ellos [los realistas] sugieren, esto es, que el proceso mental del juez va de la conclusión a las premisas y no al revés, e inclusive cabe pensar que la decisión (al menos en algunos casos) es, sobre todo, fruto de juicios previos; pero eso no anula la necesidad de justificar la decisión, ni tampoco convierte esa tarea en algo imposible" (ATIENZA, 1993, p. 126).

${ }^{3}$ Quien acepta las premisas debe aceptar también las conclusiones, o, dicho de otro modo, para quien acepta las premisas las conclusiones de ellas resultantes están justificadas.
} 


\section{Aplicabilidad, Lógica y Inteligencia Artificial}

Hay casos en que la elección de las premisas que serán objeto de deducción puede conducir a resultados distintos, hecho que no se coaduna con la lógica clásica e impone la utilización de alguna otra lógica subyacente, puesto que hay una lógica subyacente por tras de cualquier razonamiento, aun aplicada de forma intuitiva.

Bulygin, al tratar el concepto normativo de validez, presenta la idea de aplicabilidad de tal modo que "se eviten tanto la superposición entre fuerza obligatoria y los deberes jurídicos, como la connotación moral. La validez normativa puede ser concebida como un deber jurídico y no moral (...). Una norma es aplicable cuando un juez debe aplicarla a un determinado caso"(KELSEN, BULYGIN, WALTER, 2005, p. 110).

Supóngase un caso en que el deber jurídico de aplicación apunte hacia soluciones contradictorias entre sí. Imagínese que presidiarios bajo custodia de alguna autoridad estatal decidan realizar una huelga de hambre con el propósito de presionar al gobierno a satisfacer alguna reivindicación; presúmase también que dichos presos hayan manifestado la intención de llevar la huelga hasta las últimas consecuencias, o sea, estén dispuestos aun a morir si sus pretensiones no son satisfechas.

Considérese que son aplicables, en el sentido de Bulygin, tanto el derecho a la libre manifestación del pensamiento como la garantía del derecho a la vida, de manera que se tenga un dilema con al menos tres deberes jurídicos, afectos al juez, incompatibles entre sí: a) la administración está obligada y autorizada a alimentar a los presos a la fuerza, aunque ellos se encuentren en estado de plena conciencia y manifiesten, en consecuencia, su negativa al respecto; b) la administración solamente está autorizada a tomar ese tipo de medida cuando el preso haya perdido la conciencia; y c) la administración no está autorizada a tomar tales medidas, ni siquiera en ese último caso.

La lógica clásica no tolera contradicciones, de manera que sistemas no clásicos han sido desarrollados para intentar tratar casos como el del ejemplo.

En efecto, uno de los desarrollos recientes en el campo de la lógica deóntica es la formulación de sistemas no clásicos de lógica deóntica paraconsistente con operadores deónticos bidimensionales, o sea, operadores morales y jurídicos distintos.

Para la formulación de tales sistemas contribuyeron varias motivaciones, como la elaboración de una lógica que incluye nociones normativas y valorativas y el análisis de conexiones puramente lógicas entre conjuntos de enunciados morales, jurídicos y axiológicos, 
sin prejuzgar relaciones de otra naturaleza que puedan existir entre esos conjuntos (cf. VERNENGO, 1989).

Entre los diversos sistemas, será indicado apenas el cálculo $\underline{L}_{1}$ para representar formalmente tales decisiones ${ }^{4}$.

\section{EL SISTEMA $\underline{L}_{1}$}

$\underline{L}_{1}$ es construido sobre el cálculo $\mathrm{C}_{1}$ de Da $\operatorname{Costa}^{5}$ (es una extensión conservativa de $\mathrm{C}_{1}$ ) como cálculo proposicional standard más Om (obligatorio moralmente) y Oj (obligatorio jurídicamente) como operadores primitivos, $\mathrm{Fj}$ (prohibido jurídicamente), Fm (prohibido moralmente), $\mathrm{Pj}$ (permitido jurídicamente), Pm (permitido moralmente) como operadores derivados y tiene los siguientes postulados específicos: ${ }^{6}$

- Postulados deónticos:

$\mathrm{Om}(\mathrm{A} \rightarrow \mathrm{B}) \rightarrow(\mathrm{OmA} \rightarrow \mathrm{OmB})$

$\mathrm{OmA} \rightarrow \neg \mathrm{Om} \neg \mathrm{A}$

$\mathrm{OmA} \rightarrow(\mathrm{OmA})^{\circ}$

\section{$\mathrm{A} / \mathrm{OmA}$}

- Postulados legales

$\mathrm{Oj}(\mathrm{A} \rightarrow \mathrm{B}) \rightarrow(\mathrm{OjA} \rightarrow \mathrm{OjB})$

$\mathrm{OjA} \rightarrow \neg \mathrm{Oj} \neg \mathrm{A}$

$\mathrm{OjA} \rightarrow(\mathrm{OjA})^{\circ}$

$\mathrm{A} / \mathrm{OjA}$

- Postulados mixtos

$\mathrm{OjA} \rightarrow \mathrm{OmA}$

$\mathrm{OmA} \rightarrow \mathrm{PjA}$

${ }^{4} \mathrm{El}$ sistema $\underline{L}_{1}$ aquí presentado es el sistema desarrollado por Nicola GRANA (1990, p. 74-77). En esa obra pueden ser encontrados mayores detalles sobre los diversos sistemas de lógica deóntica paraconsistente y desarrollos recientes, así como el cálculo $\mathrm{C}_{1}$ de DA COSTA, que le sirven como sistema de base.

${ }^{5}$ Presentado al final, en el Apéndice.

${ }^{6} \mathrm{~A}^{\circ}$ abrevia $\neg\left(\mathrm{A}^{\wedge} \neg \mathrm{A}\right)$, en que $\neg$ es llamada negación débil e $\sim$ es llamada negación fuerte, equivalente a la negación de la lógica proposicional clásica. Cf. Apéndice. 
Teorema 1

En $\underline{L}_{1}$ es posible derivar:

Donde: $F m A=\operatorname{def} O m \neg A$

$\mathrm{Fj} \mathrm{A}=\mathrm{defO} \mathrm{j} \neg \mathrm{A}$

$\sim \mathrm{FmA}=\mathrm{defO} \sim \mathrm{A}$

$\sim \mathrm{Fj} \mathrm{A}=\operatorname{defOj} \sim \mathrm{A}$

$\mid-\mathrm{PmA} \rightarrow \mathrm{PjA}$

$\mid-\mathrm{FmA} \rightarrow \neg \mathrm{OjA}$

$\mid-\mathrm{FjA} \rightarrow \mathrm{FmA}$

$\mid-\mathrm{OjA} \rightarrow \mathrm{PmA}$

$\mid-\mathrm{Om}(\mathrm{OjA} \rightarrow \mathrm{OmA})$

$\mid-\mathrm{Oj}(\mathrm{OjA} \rightarrow \mathrm{OmA})$

Teorema 2

Son teoremas de $\underline{L}_{1}$

$\mathrm{T} 1 \quad \mathrm{OmA} \rightarrow \mathrm{Om}(\mathrm{AvB})$

$\mathrm{T} 2 \quad \mathrm{OjA} \rightarrow \mathrm{Oj}(\mathrm{AvB})$

T3 $\quad \mathrm{FmA}^{\wedge} \mathrm{A}^{\circ} \rightarrow \neg \mathrm{OmA}$

T4 $\quad \mathrm{FjA}^{\wedge} \mathrm{A}^{\circ} \rightarrow \neg \mathrm{OjA}$

T5 $\quad \mathrm{OmB} \rightarrow \mathrm{Om}(\mathrm{AvB})$

T6 $\quad \mathrm{OjB} \rightarrow \mathrm{Oj}(\mathrm{AvB})$

T7 $\quad \mathrm{A}^{\circ} \rightarrow \neg\left(\mathrm{OmA}^{\wedge} \mathrm{FmA}\right)$

$\mathrm{T} 8 \quad \mathrm{~A}^{\circ} \rightarrow \neg\left(\mathrm{OjA}^{\wedge} \mathrm{FjA}\right)$

T9 $\mathrm{Om} \sim \mathrm{A} \rightarrow \sim \mathrm{OmA}$

$\mathrm{T} 10 \quad \mathrm{Oj} \sim \mathrm{A} \rightarrow \sim \mathrm{OjA}$

$\mathrm{T} 11 \quad \mathrm{Om}\left(\mathrm{A}^{\wedge} \mathrm{B}\right) \leftrightarrow \mathrm{OmA}^{\wedge} \mathrm{OmB}$

T12 $\mathrm{Oj}\left(\mathrm{A}^{\wedge} \mathrm{B}\right) \leftrightarrow \mathrm{Oj}^{\wedge} \mathrm{Oj}^{\mathrm{B}}$

$\mathrm{T} 13 \quad \mathrm{OmA}^{\wedge} \mathrm{Om} \sim \mathrm{A} \rightarrow \mathrm{OmB}$ 
$\mathrm{T} 14 \quad \mathrm{OjA}^{\wedge} \mathrm{Oj} \sim \mathrm{A} \rightarrow \mathrm{OjB}$

$\mathrm{T} 15 \sim\left(\mathrm{OmA}^{\wedge} \sim \mathrm{OmA}\right)$

$\mathrm{T} 16 \sim\left(\mathrm{Oj}^{\wedge} \sim \mathrm{OjA}\right)$

$\mathrm{T} 17 \quad \mathrm{OmA}^{\wedge} \mathrm{Om}(\mathrm{A} \rightarrow \mathrm{B}) \rightarrow \mathrm{OmB}$

T18 $\quad \mathrm{OjA}^{\wedge} \mathrm{Oj}(\mathrm{A} \rightarrow \mathrm{B}) \rightarrow \mathrm{OjB}$

Teorema 3

En $\underline{L}_{1}$ no son válidos los siguientes esquemas:

1- $\mathrm{Om} \neg\left(\mathrm{A}^{\wedge} \neg \mathrm{A}\right)$

2- $\mathrm{Oj} \neg\left(\mathrm{A}^{\wedge} \neg \mathrm{A}\right)$

3- $\mathrm{Om}\left(\mathrm{A}^{\wedge} \neg \mathrm{A}\right) \rightarrow \mathrm{OmB}$

4- $\mathrm{Oj}\left(\mathrm{A}^{\wedge} \neg \mathrm{A}\right) \rightarrow \mathrm{OjB}$

5- $\mathrm{OmA}^{\wedge} \mathrm{Om} \neg \mathrm{A} \rightarrow \mathrm{OmB}$

6- $\mathrm{OjA}^{\wedge} \mathrm{Oj} \neg \mathrm{A} \rightarrow \mathrm{OjB}$

7- $\mathrm{FmA}^{\wedge} \mathrm{Fm} \neg \mathrm{A} \rightarrow \mathrm{OmB}$

8- $\mathrm{FjA}^{\wedge} \mathrm{Fj} \neg \mathrm{A} \rightarrow \mathrm{OjB}$

9- $\mathrm{FmA} \rightarrow \neg \mathrm{OmA}$

$10-\mathrm{FjA} \rightarrow \neg \mathrm{OjA}$

$11-\neg\left(\mathrm{FmA}^{\wedge} \mathrm{PmA}\right)$

12- $\neg\left(\mathrm{FjA}^{\wedge} \mathrm{PjA}\right)$

13- Om $\left(\neg \mathrm{A}^{\wedge} \neg \neg \mathrm{A}\right) \rightarrow \mathrm{OmB}$

14- Oj $\left(\neg \mathrm{A}^{\wedge} \neg \neg \mathrm{A}\right) \rightarrow \mathrm{OjB}$

15- $\mathrm{FmA}^{\wedge} \mathrm{Fm} \neg \mathrm{A} \rightarrow \mathrm{FmB}$

16- $\mathrm{Fj}^{\wedge} \mathrm{Fj} \neg \mathrm{A} \rightarrow \mathrm{FjB}$

En la justificación de la primera posición (la administración estaría autorizada a alimentar a los presos a la fuerza, aun contra su voluntad), se podrían invocar contenidos de derecho natural, como el derecho a la vida, tanto en términos ontológicos como en términos jurídico-positivos, como superiores a cualquier otro derecho de la persona humana. Básicamente es ese el significado claro del postulado mixto de $\underline{L}_{1}$, indicado encima, 
$\mathrm{OmA} \rightarrow \mathrm{PjA}$. Ese postulado hace de todo deber moral un permiso jurídico, dando base a las corrientes iusnaturalistas que consideran que las normas morales (en el caso presente, el derecho a la vida) implican la no validez de normas jurídicas con ella incompatibles. En ese caso, el derecho natural es considerado superior a los órdenes positivos, revocando la moral autónoma del individuo. Así, no cabría al huelguista disponer del derecho a la vida, ni aun él estaría inmune a la acción pública de la administración. ${ }^{7}$

Son de destacar las dos principales características del sistema $\underline{L}_{1}$ : a) el sistema no excluye situaciones moral o jurídicamente contradictorias (también denominados dilemas deónticos ${ }^{8}$ ) y; b) para ese sistema, de una contradicción no es posible derivar cualquier proposición, como acontece con la lógica clásica, en que la contradicción vuelve trivial el sistema.

Las dos características están expresadas por el Teorema 3. Las fórmulas 1, 2, 9, 10, 11 y 12 demuestran la primera característica, y las fórmulas restantes demuestran la segunda característica. En general, el principio clásico de la no contradicción $\neg\left(\mathrm{A}^{\wedge} \neg \mathrm{A}\right)$ no es una fórmula válida en el sistema.

Así es posible afirmar que la lógica subyacente a la apreciación judicial del caso de los huelguistas de hambre es un sistema como $\underline{L}_{1}$. En ese sistema, las soluciones $n^{\circ} 1,2$ y 3 , contradictorias entre sí, pueden ser representadas intuitivamente dentro del mismo sistema lógico, sin que eso cause el colapso del sistema, principalmente la posición intermedia $\mathrm{n}^{\mathrm{o}} 2$. En sistemas de lógica deóntica standard, las fórmulas del Teorema 3 de $\underline{L}_{1}$ son válidas, lo que no permite la representación y la admisión de situaciones y decisiones contrarias entre sí.

En ese sistema, al admitir cualquiera de las tres soluciones posibles, se debería necesariamente excluir las otras dos del referido sistema, lo que no ocurre en el caso de la adopción de sistemas de lógica deóntica paraconsistente, que admiten contradicciones sin que se pierda el valor lógico de las inferencias (la condición de no-trivialidad).

Sistemas de lógica deóntica standard originan, también, las conocidas paradojas del Buen Samaritano, de la obligación derivada y de Ross, entre otros, y excluyen situaciones y decisiones contradictorias, como, por ejemplo, una acción que es obligatoria y no es al mismo tiempo $\left(\mathrm{OA}^{\wedge} \mathrm{O} \neg \mathrm{A}\right)$.

Así, $\underline{L}_{1}$ puede expresar indirectamente, en su conjunto de fórmulas válidas, los esquemas de razonamientos utilizados por juristas y diversos órganos jurisdiccionales, en que

\footnotetext{
${ }^{7}$ Una interpretación distinta de ese mismo postulado, así como otros sistemas de lógica deóntica paraconsistente con operadores morales y jurídicos, puede ser encontrada en PUGA, DA COSTA, VERNENGO, 1990, p. 22. ${ }^{8}$ Para mayores detalles sobre dilemas deónticos, cf. PUGA, 1985.
} 
la idea de aplicabilidad, en el sentido definido por Bulygin, puede ser tratada en términos lógicos. Además de eso, las contradicciones no deben ser necesariamente excluidas de la racionalidad jurídica, pues contradicciones e inconsistencias no son contrarias a la razón.

Lógicas paraconsistentes, por ejemplo, se muestran aptas para servir como lógica subyacente de las decisiones judiciales, ya que "en un contexto dado, la Lógica subyacente es única" (DA COSTA, 1994, p. 19). Las lógicas paraconsistentes poseen un dominio más amplio que el de la lógica clásica, puesto que asumen que las contradicciones pueden hacer parte de contextos racionales.

A partir de eso sistema, o mediante la construcción de algún otro sistema similar, se puede aplicar la lógica en sistemas computacionales y verificar si los resultados resultantes pueden ser útiles al intérprete del derecho en los casos en que se ve ante un mismo dilema como el del ejemplo, todo ello en el marco del proceso judicial electrónico con la utilización de la Inteligencia Artificial.

\section{Consideraciones Finales}

Bulygin asume como sus hipótesis intangibles: a) el positivismo jurídico, o sea, que todo Derecho es derecho positivo, esto es, consiste en normas creadas y aniquiladas mediante actos humanos; b) el escepticismo ético, o sea, no hay normas verdaderas; las normas en general y las normas morales en particular no son ni verdaderas ni falsas. Esto ocurre porque no hay hechos normativos que hagan verdaderas las normas. En particular, no hay hechos morales que correspondan a las normas morales, y por lo tanto no es posible un conocimiento objetivo de la moral. En cambio, como la existencia de las normas jurídicas positivas depende de actos humanos, es posible un conocimiento objetivo del Derecho. No las normas jurídicas, pero sí las proposiciones que afirman la existencia de tal o cual norma jurídica son objetivamente verdaderas o falsas. Esto hace posible una ciencia del Derecho; c) la separación entre ser y deber, o sea, de lo que es no se sigue que deba ser, y del hecho de que algo deba ser no se sigue que lo sea; y d) una ciencia jurídica avalorativa, o sea, la ciencia jurídica consiste en la descripción del derecho positivo y no en su valoración. La valoración de los órdenes jurídicos positivos como justos o injustos es asunto de la política, no de la ciencia.

A partir de esas premisas, Bulygin reconstruye la teoría pura del Derecho y, en el que se refiere al problema de la validez, hace ver que este término es ambiguo en Kelsen. Según Bulygin, cabe distinguir por lo menos dos conceptos muy diferentes que figuran con este rótulo: pertenencia y obligatoriedad. Pertenencia es un concepto descriptivo. El enunciado la norma $\mathrm{N}$ 
pertenece al sistema $\mathrm{S}$ expresa una proposición verdadera o falsa. Obligatoriedad es un concepto normativo. El enunciado la norma $\mathrm{N}$ tiene fuerza obligatoria expresa una norma, que no es ni verdadera ni falsa.

Si pertenencia es interpretada como existencia de una norma, entonces es necesario distinguir entre sistema y orden. Un sistema normativo es un conjunto de normas referidas a un momento temporal. Un orden normativo es un conjunto (secuencia temporal) de sistemas normativos. Esto obliga a distinguir entre la pertenencia de una norma a un sistema y la pertenencia de un sistema a un orden.

Dada la ambigüedad del término validez, el problema de la relación entre validez y eficacia ha de tratarse en forma separada; entre pertenencia y eficacia no hay ninguna conexión.

Para la definición de pertenencia, la hipótesis de la norma básica resulta completamente innecesaria. Sólo para la validez como fuerza obligatoria necesita Kelsen la norma básica.

El concepto de fuerza obligatoria es interpretado por muchos autores (Ross, Raz, Nino, Losano, Celano) como deber moral de obedecer al Derecho, lo que resulta incompatible con el positivismo de Kelsen.

Pero la obligatoriedad puede ser interpretada como una obligación jurídica, para lo cual Bulygin propone el término aplicabilidad. Una norma es aplicable cuando una norma jurídica positiva (llamada norma de aplicación) establece el deber (o la facultad) del juez de aplicarla a un determinado caso.

Aplicabilidad no debe confundirse con pertenencia. Los jueces pueden estar obligados o autorizados a aplicar normas que no pertenecen a su sistema y ni siquiera a su orden jurídico.

El análisis de la estructura formal de ambos conceptos muestra que aplicabilidad es muy distinta de la obligatoriedad, tal como la entiende Kelsen. Su definición de obligatoriedad relativa presupone la obligatoriedad absoluta, lo que lo lleva a la suposición de la norma básica. La hipótesis de tal norma básica resulta innecesaria para la aplicabilidad.

Por fin, fue visto que el concepto de aplicabilidad de Bulygin permite, también, que se verifique las relaciones lógicas de los sistemas jurídicos $\mathrm{y}$, aun delante de contradicciones, sistemas no clásicos de lógica, a ejemplo de las lógicas paraconsistentes, pueden ser aplicados para aplicaciones de la Inteligencia Artificial en el Derecho.

\section{Referencias bibliográficas}

ARISTÓTELES. Metafísica. Traducción de Marcelo Perine, São Paulo: Loyola, 2002. 
ATIENZA, M. Traslajusticia: una introducción al derecho y al razonamiento jurídico. Barcelona: Ariel, 1993.

CELANO, B. La teoria del diritto di hanskelsen: una introduzione critica. Bologna: Il Mulino, 1999.

DA COSTA, N.C.A. Ensaio sobre os fundamentos da lógica. 2. ed., São Paulo: Hucitec, 1994. . Sistemas formais inconsistentes. Curitiba: UFPR, 1993.

GRANA, N.Lógica deóntica paraconsistente. Napoli: Liguori, 1990.

KELSEN, H.Reine rechtslehre. 2.ed., Wien: Franz Deuticke, 1960.

.Teoria geral do direito e do estado. 3. ed. Tradução de Luís Carlos Borges, São Paulo: Martins Fontes, 1998.

KELSEN, H., BULYGIN, E., WALTER, R. Validez y eficacia del derecho. Buenos Aires: Astrea, 2005.

LOSANO, M.G. Prefácio à edição italiana da obra o problema da justiça. In: KELSEN, H. O problema da justiça. 2. ed. Traducción de João Baptista Machado, São Paulo: Martins Fontes, 1996, p. VII-XXXIII.

PUGA, L.Z. Uma lógica do querer: preliminares sobre um tema de mally. Tesis de Doctorado en Matemática. São Paulo: Pontifícia Universidade Católica de São Paulo, 1985.

PUGA, L.Z., DA COSTA, N.C.A., VERNENGO, R.J. Derecho, moral y preferencias valorativas.In:Theoria, Segunda Época, ano V, n. 12-13, nov.1990.

RADBRUCH, G. Introducción a la ciencia del derecho. Traducción de Luis Recasens Siches, Madrid: Revista de Derecho Privado, 1930. 
ROVER, A.J. Informática no direito: inteligência artificial: introdução aos sistemas especialistas legais. Curitiba: Juruá, 2001.

SEVERINO, E. A filosofia antiga. v. 1. Traducción de José Eduardo Rodil, Lisboa: Edições $70,1986$.

VERNENGO, R.J. Sobre algumas relações lógicas entre sistemas normativos jurídicos e morais. In: Revista Brasileira de Filosofia, XXXVIII, n. 155, São Paulo: 1989.

\section{Apéndice}

Será presentada, de manera abreviada, la parte sintáctica del cálculo $C_{1}$. En verdad los cálculos que sirven de base para los sistemas paraconsistentes constituyen una jerarquía de cálculos $\mathrm{Cn}, 1 \leq \mathrm{n} \leq \omega$, siendo cada uno más débil que los precedentes, desarrollados originalmente por Newton Carneiro Affonso da Costa. Los cálculos deben satisfacer las siguientes condiciones: a) contener el máximo posible de esquemas y reglas de deducción del cálculo clásico; b) el principio de la no contradicción $\neg\left(\mathrm{A}^{\wedge} \neg \mathrm{A}\right)$ no debe ser válido y; c) de dos fórmulas contradictorias $\mathrm{A}^{\wedge} \neg \mathrm{A}$ no debe ser posible, en general, deducir una fórmula arbitraria.

$\mathrm{C}_{1}$ posee los siguientes postulados, en que $\mathrm{A}^{\circ}$ es la abreviación de $\neg\left(\mathrm{A}^{\wedge} \neg \mathrm{A}\right)$ :

$1-\mathrm{A} \rightarrow(\mathrm{B} \rightarrow \mathrm{A})$

$2-(\mathrm{A} \rightarrow \mathrm{B}) \rightarrow((\mathrm{A} \rightarrow(\mathrm{B} \rightarrow \mathrm{C})) \rightarrow(\mathrm{A} \rightarrow \mathrm{C})$

3- $\mathrm{A}, \mathrm{A} \rightarrow \mathrm{B} / \mathrm{B}$

4- $\left(\mathrm{A}^{\wedge} \mathrm{B}\right) \rightarrow \mathrm{A}$

5- $\left(\mathrm{A}^{\wedge} \mathrm{B}\right) \rightarrow \mathrm{B}$

6- $\left(\mathrm{A} \rightarrow\left(\mathrm{B} \rightarrow\left(\mathrm{A}^{\wedge} \mathrm{B}\right)\right)\right.$

$7-\mathrm{A} \rightarrow(\mathrm{AvB})$

$8-\mathrm{B} \rightarrow(\mathrm{AvB})$

9- $(\mathrm{A} \rightarrow \mathrm{C}) \rightarrow((\mathrm{B} \rightarrow \mathrm{C}) \rightarrow(\mathrm{AvB} \rightarrow \mathrm{C}))$

10- Av $\neg \mathrm{A}$

$11-\neg \neg \mathrm{A} \rightarrow \mathrm{A}$

$12-\mathrm{B}^{\circ} \rightarrow((\mathrm{A} \rightarrow \mathrm{B}) \rightarrow((\mathrm{A} \rightarrow \neg \mathrm{B}) \rightarrow \neg \mathrm{A}))$

$13-\mathrm{A}^{\circ \wedge} \mathrm{B}^{\circ} \rightarrow(\mathrm{A} \rightarrow \mathrm{B})^{\circ}$

$14-\mathrm{A}^{\circ \wedge} \mathrm{B}^{\circ} \rightarrow\left(\mathrm{A}^{\wedge} \mathrm{B}\right)^{\circ}$ 
$15-\mathrm{A}^{\circ \wedge} \mathrm{B}^{\circ} \rightarrow(\mathrm{AvB})^{\circ}$

\section{Teorema 1}

En $\mathrm{C}_{1}$ todas las reglas de deducción del cálculo proposicional clásico del Teorema 2 del libro de Kleene Introduction to Metamathematics son verdaderas, con excepción de la regla de reducción al absurdo, que en $\mathrm{C}_{1}$ se enuncia:

Si $\Gamma, \mathrm{A}\left|-\mathrm{B}^{\circ}, \Gamma, \mathrm{A}\right|-\mathrm{B}$ y $\Gamma, \mathrm{A} \mid \longrightarrow \mathrm{B}$, entonces $\Gamma \mid \longrightarrow \mathrm{A}$.

Teorema 2. Entre otros, los siguientes esquemas no son válidos en $\mathrm{C}_{1}$.

$\neg \mathrm{A} \rightarrow(\mathrm{A} \rightarrow \mathrm{B})$,

$\mathrm{A} \rightarrow(\neg \mathrm{A} \rightarrow \mathrm{B})$,

$\left(\mathrm{A}^{\wedge} \neg \mathrm{A}\right) \rightarrow \mathrm{B}$,

$(\mathrm{A} \rightarrow \mathrm{B}) \rightarrow((\mathrm{A} \rightarrow \neg \mathrm{B}) \rightarrow \neg \mathrm{A})$,

$(\mathrm{A} \leftrightarrow \neg \mathrm{A}) \rightarrow \mathrm{B}$,

$\neg\left(\mathrm{A}^{\wedge} \neg \mathrm{A}\right)$,

$(\mathrm{A} \rightarrow \mathrm{B}) \rightarrow(\neg \mathrm{AvB})$,

$(\mathrm{A} \rightarrow \mathrm{B}) \rightarrow(\neg \mathrm{B} \rightarrow \neg \mathrm{A})$,

$\neg \mathrm{A} \rightarrow(\mathrm{A} \rightarrow \neg \mathrm{B})$,

$\mathrm{A} \rightarrow(\neg \mathrm{A} \rightarrow \neg \mathrm{B})$,

$\left(\mathrm{A}^{\wedge} \neg \mathrm{A}\right) \rightarrow \neg \mathrm{B}$,

$\mathrm{A} \rightarrow \neg \neg \mathrm{A}$,

$(\mathrm{A} \leftrightarrow \neg \mathrm{A}) \rightarrow \neg \mathrm{B}$,

$\left((\mathrm{AvB})^{\wedge} \neg \mathrm{A}\right) \rightarrow \mathrm{B}$,

$\mathrm{A} \leftrightarrow \neg \neg \mathrm{A}$.

Demostración: Se emplean las matrices siguientes, en que los valores distinguidos son 1 y 2:

$\mathrm{A}^{\wedge} \mathrm{B}$ :

\begin{tabular}{l|llll}
$\mathrm{A}$ & $\mathrm{B}$ & 1 & 2 & 3 \\
\hline 1 & & 1 & 1 & 3
\end{tabular}




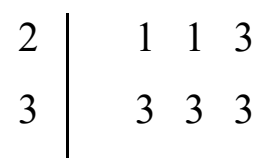

AvB:

\begin{tabular}{l|llll}
$\mathrm{A}$ & $\mathrm{B}$ & 1 & 2 & 3 \\
\hline 1 & & 1 & 1 & 1 \\
2 & & 1 & 1 & 1 \\
3 & & 1 & 1 & 3
\end{tabular}

$\mathrm{A} \rightarrow \mathrm{B}:$

\begin{tabular}{l|llll}
$\mathrm{A}$ & $\mathrm{B}$ & 1 & 2 & 3 \\
\hline 1 & & 1 & 1 & 3 \\
2 & & 1 & 1 & 3 \\
3 & & 1 & 1 & 1
\end{tabular}

$\neg \mathrm{A}:$

\begin{tabular}{l|l}
$\mathrm{A}$ & $\neg \mathrm{A}$ \\
\hline 1 & 3 \\
2 & 1 \\
3 & 1
\end{tabular}

En $\mathrm{C}_{1}$ la clase de las proposiciones es descompuesta en proposiciones de dos tipos: en la clase de las bien comportadas, toda fórmula válida en el cálculo clásico también es válida en $\mathrm{C}_{1}$; si A es mal comportada, es posible tener $\mathrm{A}^{\wedge} \neg \mathrm{A}$. También son distinguidas dos clases de negaciones: La negación fuerte, que posee las mismas propiedades de la negación clásica; y la negación débil, que admite contradicciones. A Depender del contexto, se puede emplear una u otra negación.

Así, los cálculos paraconsistentes no fueron elaborados para eliminar la lógica clásica, pero para ampliar sus dominios e incluirla como un caso particular.

Se remite al lector interesado en mayores detalles técnicos sobre $\mathrm{C}_{1}$ a la consulta de DA COSTA, 1993. 


\title{
RELAÇÕES LÍQUIDAS E DIREITO AO ESQUECIMENTO: NOVOS DESAFIOS DE PROTEÇÃO NAS RELAÇÕES DE TRABALHO
}

\author{
Denise Pires Fincato \\ Pontifícia Universidade Católica do Rio Grande do Sul \\ Cíntia Ione Santiago Guimarães \\ Pontifícia Universidade Católica do Rio Grande do Sul
}

\section{Resumo}

O estudo transita pelo cenário da Sociedade do Conhecimento e das tecnologias que lhe são próprias (informação e comunicação) para abordar as novas necessidades de proteção do ser humano trabalhador, especialmente decorrentes da exposição de sua intimidade e privacidade no meio digital, quer por conta própria, quer por ato de terceiros (entre eles o próprio Estado). Utilizando-se de método hipotético-dedutivo, procedimentos histórico-comparativos, estruturais e funcionalistas, além de interpretação sistemática, a pesquisa evolui para concluir que, dada a cultura do povo brasileiro, faz-se necessária a elaboração de legislação adequada a proteger o trabalhador, garantindo-lhe a eficácia do chamado "direito ao esquecimento", não desprezando, obviamente, a utilidade de políticas públicas que permitam a construção e o amadurecimento de cultura autoprotetiva, derivada do aprendizado de um protocolo para a convivência social digital.

Palavras-chave: Sociedade do Conhecimento, Relações Líquidas, Direito ao Esquecimento, Relações de Trabalho.

\section{Abstract/Resumen/Résumé}

The study goes through the Knowledge Society scenario and its own technologies (information and communication) to address the new needs of protecting the working human being, especially arising from the exposure of their privacy and privacy in the digital environment, either on their own, or by act of third parties (among them the State itself). Using a hypothetical-deductive method, historical-comparative, structural and functionalist procedures, in addition to a systematic interpretation, the research evolves to conclude that, given the culture 
of the Brazilian people, it is necessary to elaborate adequate legislation to protect the worker, guaranteeing the effectiveness of the so-called "right to oblivion", not neglecting, obviously, the utility of public policies that allow the construction and maturation of a self-protective culture, derived from the learning of a protocol for digital social coexistence.

Keywords/Palabras-claves/Mots-clés: Knowledge Society, Liquid Relations, Right to Forgetfulness, Work relationships.

\section{Introdução}

A proteção ao trabalhador tem assumido inúmeras formas em tempos de uso intensivo das tecnologias da informação e comunicação. A tecnologia serve tanto como ferramenta de labor, ambiente de trabalho ou instrumento de controle. Como instrumento de controle, porém, não necessariamente limita-se ao monitoramento do empregado durante a execução de suas funções laborais, servindo também ao seu controle no âmbito das relações sociais que mantiver, mesmo que não laborais.

Debater novos temas na seara do Direito do Trabalho é de essencial importância, uma vez que a evolução tecnológica, por vezes, desafia princípios legais destinados à proteção da dignidade do trabalhador. Nas relações empregatícias, as ferramentas de informação e comunicação, além de dinamizarem as operações, se mal utilizadas, possibilitam a violação de direitos essenciais.

A bem de evoluir de forma lógica e produtiva, este estudo primeiramente enfrenta os impactos advindos do inserção das tecnologias de automação e conexão no meio laboral, analisando, por exemplo, possibilidades de o empregado ser substituído por máquinas ou de necessitar de maior qualificação para operá-las.

Avançando, retrata a necessidade de acatamento dos princípios protetivos nas relações de trabalho subordinado, na tentativa de equalizar a relação estabelecida entre empregado e empregador. Nesta mesma subdivisão, o artigo tratará da premência de regulamentação de um direito que ainda não está posto no ordenamento brasileiro, o "Direito ao Esquecimento", sendo sua aplicação às relações de trabalho, o objetivo geral deste artigo.

As reflexões seguintes expõem a problemática que se institui a partir dos conflitos de direito estabelecidos no ordenamento brasileiro ao se deparar com a necessidade de tutelar princípios. Nesta senda, é necessário enfrentar o conflito entre o sigilo, a imagem e a privacidade do trabalhador versus o direito de acesso à informação de todos - inclusive e 
especialmente do empregador - e a ideia de que se faz necessária a implementação do Direito ao Esquecimento.

O último bloco detalha as possíveis ocorrências, positivas ou negativas, decorrentes da localização de diversas informações acerca de um determinado indivíduo, disponível nas redes sociais digitais. A utilização dos dados encontrados poderá ser benéfica, ou não, dependendo de seu conteúdo e da finalidade de acesso a tais informações.

Refletir sobre soluções ponderáveis para equacionar os conflitos oriundos da utilização de sistemas digitais já é rotina entre juristas, pesquisadores, magistrados e legisladores. Porém, ainda são muitas as situações problemáticas não previstas em lei, pois a evolução tecnológica ocorre de forma mais célere que a reação legislativa.

O estudo se desenvolveu a partir do método de abordagem hipotético-dedutivo, com métodos de procedimento histórico, estruturalista e funcionalista. A interpretação ocorreu a partir de operações sistemáticas e a pesquisa foi eminentemente bibliográfico-documental.

\section{Sociedade do Conhecimento: Tecnologias nas Relações de Trabalho}

É preciso compreender a flexibilidade e mobilidade relacional que ocorreu nas últimas décadas e que ganhou força também no meio laboral. São efeitos de uma era tecnológica que invadem a seara tanto do empregado quanto do empregador, reinventando as dinâmicas laborais e transformando as divisões sociais do trabalho. Em uma breve digressão histórica é possível perceber algumas transformações ao longo dos anos que culminaram numa organização baseada na informação e no conhecimento. Nesse sentido, conforme Fincato:

A tecnologia atrela-se ao trabalho para facilitar e otimizar o fazer humano. Assim ocorreu com as ferramentas de agricultura (enxadas, pás), com os teares, com o computador. A ideia de sua utilização sempre foi o de facilitar o trabalho e, com isto, economizar tempo e esforço humano.

[...]

$\mathrm{Na}$ Sociedade do Conhecimento, entretanto, verificam-se reflexos distintos dos outrora projetados. O uso das tecnologias permitiu ao homem trabalhar mais e mais rápido. Permitiu-lhe, ainda, trabalhar mesmo que fora de seu local de trabalho. A quebra do tempo-espaço de trabalho trouxe conflitos essenciais, que desafiam as estruturas do Direito do Trabalho, enquanto normatização protetiva em sua natureza. $[\ldots]$

Sem dúvidas, é via tecnologia que os grandes saltos e rupturas do desenvolvimento se processam. Basta que se mencionem as grandes invenções (escrita, eletricidade, telefone) e se observe o que lhes sobreveio no campo do trabalho. Também já atestada historicamente, no âmbito do trabalho, que a evolução tecnológica traz consigo a necessidade e o implemento de novos processos produtivos e a necessidade de mais especialização e/ou capacitação de parte dos trabalhadores (FINCATO, 2014, p. 9 e ss). 
Em razão disto, foram implementados novos processos produtivos, especialmente de automação ${ }^{1}$ que culminaram em uma contemporânea divisão do trabalho com exigência progressivamente especializada em pequenas tarefas. Para Huws (2009), isso acarretou em "novos grupos localizados entre o proletariado paradigmático e a burguesia: o capataz, o artesão qualificado ou o gerente de compras, por exemplo" (HUWS, 2009, p. 38). Evidenciou-se, portanto, a divisão social do trabalho com categorias bem definidas e delimitadas de acordo com suas funções. Esse modelo repercutiu ao longo dos anos, sobretudo pela lógica da divisão hierárquica do trabalho, inclusive nas etapas contemporâneas do desenvolvimento social.

Especialmente a partir das três décadas finais do século XIX iniciou-se uma etapa denominada sociedade pós-industrial na qual o setor terciário (comércio e serviços) expandiuse, passando gradativamente a incorporar parcelas maiores de trabalhadores em relação ao setor secundário (indústrias). Em ambos os setores a utilização das tecnologias em voga tornaram-se crescentes, provocando constantes alterações nas formas de gerir e de executar o trabalho, particularmente com o emprego das tecnologias de informação e comunicação $(T I C \text { 's })^{2}$.

A introdução de novas tecnologias na rotina de trabalho humano é um fenômeno que vem sendo debatido com maior intensidade nos últimos tempos. Pode-se reconhecer, inclusive, que as tecnologias da informação e comunicação estão completamente inseridas na rotina da maioria dos trabalhadores, sendo ferramenta essencial para algumas categorias.

Pode-se considerar a tecnologia como mecanismo apto à extensão da capacidade física e mental do homem e, por estar presente em inúmeras formas de organização, essa compreensão também pode ser estendida para os objetivos laborais. A evolução das redes de informática ampliou a capacidade de trabalhar e de redistribuir o tempo necessário à realização de diversas atividades. Na sociedade do conhecimento, embora corriqueiros, há significativos exemplos de

\footnotetext{
${ }^{1}$ Foi em meados do século XIX que o termo automação foi introduzido no mundo laboral. A nomenclatura originou-se a partir da invenção do Automat, criado pelo norte-americano Chistopher Spencer, cuja programação permitia a feitura de parafusos e engrenagens. Logo após, com a criação dos robôs, a automação ganharia mais força, impactando o cenário do trabalho por substituir a mão de obra humana (GIDDENS, 2005. p. 310).

2 "Tecnologia pode ser definida, genericamente, como atividade socialmente organizada, baseada em planos e de caráter essencialmente prático. Tecnologia compreende, portanto, conjuntos de conhecimentos e informações utilizados na produção de bens e serviços, provenientes de fontes diversas, como descobertas científicas e invenções, obtidas por meio de distintos métodos, a partir de objetivos definidos e com finalidades práticas. Todo objeto técnico tem uma história, uma trajetória, faz parte de uma cultura. A tecnologia está articulada com a inovação, que é indissociavelmente técnica e social. A inovação é o modo de evolução do objeto técnico e, como tal, está presente em qualquer campo, desde a alta tecnologia até processos tecnológicos simples. Na produção das condições materiais de vida em qualquer sociedade, encontram-se presentes a criação, a apropriação e a manipulação de técnicas que carregam em si elementos culturais, políticos, religiosos e econômicos, constituintes da própria existência social. Na sociedade capitalista, tecnologia caracteriza-se por ser um tipo específico de conhecimento, com propriedades que o tornam apto a, uma vez aplicado ao capital, imprimir determinado ritmo a sua valorização. Como toda produção humana, a tecnologia deve ser pensada no contexto das relações sociais e dentro de seu desenvolvimento histórico". (BAUMGARTEN, 2006, p. 288).
} 
inovações tecnológicas que, juntamente com os modelos de gestão, contribuem para a transformação das práticas laborais. Pode-se citar o uso do telefone, do computador e da internet como definidores de novas formas de trabalhar e de organizar o trabalho.

Ainda é possível considerar o telefone como um dos principais canais de comunicação com o mercado (empresas e consumidor), por ser o meio mais popular e acessível, pois desde o seu invento foi considerado como um serviço essencial. Registre-se que sua utilização não exige do usuário sequer alfabetização. “Através dele se realizam grandes negócios, se conhecem as opiniões das empresas sobre as empresas, produtos e serviços, enfim, pode-se afirmar que ele ainda é o 'filé' das comunicações à distância" (DANTAS, 1989). O computador é o meio (máquina) em que se processa e armazena a informação, bem como no qual se deflagra a condução dos dados. Como aparato que retém o tratamento da informação, torna-se indispensável em atividades que envolvam a análise e transformação de dados, assim como sua comunicação. Via de regra, utiliza-se a Internet para conduzir e propagar as informações armazenadas no computador (ou na nuvem, sua variação em tempos de Sociedade Digital). Trata-se de um meio de comunicação conhecido pela velocidade e amplitude com que conduz e compartilha informações em rede, permitindo, pela elevada conexão entre as pessoas, a horizontalização e a pulverização de dados.

Neste sentido, Huws (2009, p. 38) descreve a implementação das tecnologias de informação e comunicação (TIC's) como uma onda de mudanças tecnológicas que beneficiou tanto a produção quanto o consumo de bens. Considerou, inclusive, um modelo de "divisão digital" como forma de ruptura de paradigmas no atual contexto laboral. Ou seja, para o autor

\begin{abstract}
A utilização intensiva das novas tecnologias da informação e da comunicação (TIC's) nas grandes empresas decorre da suma relevância que a inovação passou a ter no quadro de intensa competitividade engendrado pela quebra dos monopólios estatais e com o advento das políticas neoliberais que assolaram todo o mundo capitalista nos anos 1990. Com efeito, a convergência tecnológica entre a informática e as redes de telecomunicações, a telemática, foi altamente otimizada com a privatização deste setor, que passou assim a ser concebido e efetivado como um bem de capital dos mais cruciais do capitalismo contemporâneo (WOLFF, 2009, p. 90).
\end{abstract}

Assim, as ferramentas tecnológicas tornaram-se imprescindíveis para as empresas de produção de bens imateriais e de prestação de serviços, sobretudo, pela capacidade de processamento e armazenamento de dados, velocidade de comunicação com acesso em rede mundial e redução de custos que oportunizaram (BARBOZA e BENAKOUCHE, 1987, p. 52).

A inovação advinda das ferramentas de processamento e armazenamento de dados revolucionou o cenário produtivo, eis que permitiu elevar a informação ao status de matéria 
prima. O uso da informação como produto reconfigurou as mercadorias exploradas no capitalismo, traçando uma divisão interna do trabalho calcada na manipulação de dados. Wolff (2009, p. 90) fez alusão a esta nova fase como "processo de mercadorização da informação", em que objetivos e finalidades mercantis são agregados ao seu manejo.

Atualmente, não há como considerar a organização do trabalho de forma apartada do avanço tecnológico, da necessidade de informação e do desenvolvimento de técnicas capazes de agregar as inovações. As empresas necessitam desses recursos para manterem-se ativas e competitivas no mercado. Não há como resistir ao desenvolvimento do setor produtivo. Percebe-se que

\begin{abstract}
A tecnologia da informação está presente no que define as fronteiras de negócios, nas estruturas corporativas e na determinação da vantagem competitiva e, sendo o que direciona o valor e a criação de riqueza, torna-se a chave do sucesso para um número crescente de indústrias. Sendo assim, a Internet passa a ser uma das principais representantes da inovação gerada pela evolução da tecnologia da informação. Sua ascensão tem um impacto profundo sobre as empresas, já que tem uma infra-estrutura digital de baixo custo. Isso permite a comunicação, não só entre empresas, mas também entre consumidores, unindo todos em uma cadeia [ou teia?] de valor integrado (SANTILLE, 2002, p. 14).
\end{abstract}

Com isso, contempla-se a Internet (e as nuvens - Big Data) como um dos principais instrumentos utilizados pelas empresas para tratar, armazenar e transportar dados, informações e conhecimento, alterando o cenário e o ritmo da relação empregatícia, tornando clara a noção de que as relações laborais encontram-se em pleno "movimento", ou seja, já não se constituem mais fenômenos estáticos, passíveis de estudo via métodos tradicionais. Ao revés, são relações dinâmicas, que reclamam métodos holísticos para sua investigação e compreensão.

\title{
3. Relações de Trabalho: movimento e liquidez
}

De todo o exposto, pode-se dizer que as relações de trabalho na Sociedade do Conhecimento $^{3}$, estão em constante movimento, ou seja, reiteradamente ocorrem sistemáticas mudanças nas práticas do cenário laboral. Alguns arriscam dizê-las “líquidas”, apropriando-se

\footnotetext{
3 “A noção de "sociedade do conhecimento" (knowledge society) surgiu no final da década de 90. É empregada, particularmente, nos meios acadêmicos como alternativa que alguns preferem à "sociedade da informação [...]" $\mathrm{A}$ Sociedade da Informação é a pedra angular das sociedades do conhecimento. O conceito de "sociedade da informação", a meu ver, está relacionado à idéia da "inovação tecnológica", enquanto o conceito de "sociedades do conhecimento" inclui uma dimensão de transformação social, cultural, econômica, política e institucional, assim como uma perspectiva mais pluralista e de desenvolvimento. O conceito de "sociedades do conhecimento" é preferível ao da "sociedade da informação" já que expressa melhor a complexidade e o dinamismo das mudanças que estão ocorrendo. (...) o conhecimento em questão não só é importante para o crescimento econômico, mas também para fortalecer e desenvolver todos os setores da sociedade” (BURCH, p. 3)
} 
da terminologia baumaniana (BAUMAN, 2003). A tecnologia consagra novas maneiras de se trabalhar, sendo possível tecerem-se algumas vantagens ou desvantagens dependendo do ponto de vista e de quem observa tais fenômenos. São efeitos de uma era tecnológica e digital, com atores imersos numa vertiginosa espiral de mudanças sem fim.

O estopim de muitas dessas mudanças pode decorrer da utilização das novas mídias digitais, as mesmas que modernizaram e modernizam os postos de emprego, conectando patrões e empregados. Porém, garantir que tecnologias modernas são fatores de empregabilidade ou desemprego é um tanto quanto arriscado por tratar-se de uma relação (tecnologia e desemprego) extremamente complexa e dinâmica. É importante refletir acerca do determinismo tecnológico, pois é a própria sociedade quem impulsiona um desenvolvimento digital, sofrendo os impactos do mesmo.

Os impactos diretos são aparentes e dizem respeito aos postos de labor subtraídos do mercado (eis que ocupados por máquinas) ou que geram a necessidade de recapacitação do empregado que já não reúne habilidades para operar o novo equipamento, por desconhecimento da nova tecnologia.

De outra banda, os impactos indiretos no mundo laboral, são menos visíveis e dizem respeito às mudanças (radicais) implementadas pela tecnologia na forma de trabalhar e no próprio ramo produtivo, ou seja, quando se passa a facilitar transações em uma determinada área, como a das telecomunicações em que, por exemplo, criam-se novos produtos, logo, gerando-se possíveis novos postos e oportunidades de emprego/trabalho.

Por isso, alerta-se para o fato de que assim "como toda produção humana, a tecnologia deve ser pensada no contexto das relações sociais e dentro de seu desenvolvimento histórico" (BAUMGARTEN, 2006, p. 392). A cada período, de acordo com o momento histórico, os avanços tecnológicos permitiram a criação de novidades em termos de produção de bens e de serviços, originando também novos postos de trabalho (quiçá não emprego, mas este é outro debate). A geração de lucros culmina em mais investimentos logo, presumivelmente, também em mais empregos. Portanto, afirmar rasamente que a tecnologia desemprega não se revela apropriado, pois o quadro seria ainda mais desfavorável sem sua utilização e desenvolvimento.

Atribuir ao desenvolvimento tecnológico, portanto, todos os problemas que permeiam as relações laborais é precipitado, pois as características que interagem nesse vínculo ultrapassam o mero avanço digital. Tal presunção precipitada é localizável no próprio arcabouço constitucional (art. $7^{\circ}$, inc. XXVII - proteção em face da automação, nos termos da lei) e, talvez por seu equívoco originário, nunca tenha sido desenvolvido por lei ulterior. 
Existe um nexo de poder que sempre fez parte da relação entre patrão e empregado, esse se perpetua no tempo e é uma característica originária e inafastável. A relação de trabalho, conforme norte principiológico (RODRIGUEZ, 2004), deve oferecer proteção àquele que está em situação de hipossuficiência. É nesse momento que o Estado intervém para garantir o equilíbrio e a continuidade saudável da relação, tentando estabelecer a equalização entre os atores sociais nela envolvidos (igualdade material).

Essa proteção, alcançada pelo Estado, é entregue na forma de Leis que visam garantir ao hipossuficiente o alcance de um protagonismo na relação laboral, que normalmente transcorre de forma desigual, eis que de sua essência.

Para os fins deste estudo, aponta-se que merece destaque, na atualidade, o acesso pela entidade patronal às informações e dados dos trabalhadores, postados por estes ou por terceiros na rede mundial de computadores, e seu uso para fins de contratação, alterações ou extinção do vínculo empregatício.

Daí, uma das intervenções estatais esperadas contemporaneamente, atenderia à necessidade de regulamentar o chamado "Direito ao Esquecimento".

\section{Liquidez no cenário laboral: a proteção da privacidade do trabalhador}

O espaço virtual apresenta uma variada gama de possibilidades de interatividade, além de armazenar um grande número de informações que reclamam regulamentações, ainda inexistentes em nosso ordenamento. Uma das necessidades atuais é o denominado "direito ao esquecimento" que, em suma, viria garantir ao cidadão (no caso desta pesquisa, o trabalhador) que uma informação sua, considerada irrelevante aos demais, não seja perpetuada, espargida ilimitadamente e/ou perpetuamente mantida na Internet, notoriamente se hábil a atingir danosamente sua intimidade e privacidade.

Atualmente, há princípios ${ }^{4}$ que norteiam estas necessidades (HAINZENREDER,

\footnotetext{
${ }^{4}$ De acordo com Hainzenreder (2011, pp. 55), “(...), a vida privada compreenderia a esfera maior, onde se localizam os fatos que o indivíduo não deseja que se tornem públicos, ou seja, aqueles acontecimentos que não estariam ao alcance da coletividade em geral, englobando todas as notícias e situações que a pessoa deseja excluir do conhecimento de terceiros, a exemplo da imagem física e de comportamentos que só devem ser conhecidos por aqueles que integram regularmente com a pessoa. Dentro desse círculo, estaria a esfera íntima ou confidencial onde se encontram os fatos do conhecimento das pessoas que gozam da confiança do indivíduo. São as circunstâncias da sua vida que somente são compartilhadas com familiares, amigos e colaboradores. No centro está a esfera do secreto, objeto especial de proteção, em que se guardam os segredos revelados a poucas pessoas ou a ninguém, compreendendo assuntos extremamente reservados, como a vida sexual, por exemplo. Tal distinção possui um importante caráter prático, uma vez que quanto menor a esfera, maior o nível de proteção. Logo, o simples fato que envolve as situações de segredo já é o suficiente para caracterizar a violação da privacidade, enquanto que para se considerar violada a esfera da intimidade deve haver tanto o conhecimento como a divulgação da notícia para terceiros".
} 
2011, p. 55), no entanto, tais condicionantes ainda não são suficientes para solucionar litígios nesta seara. São princípios protetores da dignidade da pessoa humana e que, no foco deste estudo, garantem ao trabalhador a manutenção do sigilo sobre sua vida privada, notoriamente ante seu empregador. Em ampliação, pode-se citar a existência de alguns documentos internacionais e protetivos acerca do tema:

[...] Convenção Americana de Direitos Humanos (pacto de San José da Costa Rica), aprovada pela Organização dos Estados Americanos, assinada em 1969, que entrou em vigor em 1978. O Brasil está dentre os países que aderiram ao pacto (em 28.5.1992) e o ratificaram (em 25.9.1992). Com a ratificação ocorre o reconhecimento da jurisdição obrigatória da Corte Interamericana de Direitos Humanos.

$[\ldots]$

$\mathrm{Na}$ Convenção Americana de Direitos Humanos, anteriormente mencionada, o $\S 1^{\circ}$ declara expressamente que 'toda pessoa tem direito ao respeito de sua honra e ao reconhecimento de sua dignidade'.

$[\ldots]$

Em 1993 foi assinada a 'Carta de Viena', como resultado da 'Conferência Mundial de Direitos Humanos', com sua declaração e programa de ação. Estes textos contemplam a promoção e proteção dos direitos humanos prioritariamente em relação à comunidade internacional, reconhecendo que os direitos humanos têm origem na dignidade humana.

No âmbito da Comunidade Européia a 'Declaração dos Direitos e Liberdades Fundamentais', de 1989, prevê em seu art. 1': 'A dignidade humana é inviolável'. Posteriormente, em 2000, a 'Carta dos Direitos Fundamentais da União Européia' estabelece em seu art. $1^{\text {o: }}$ 'a dignidade humana é inviolável. Ela deve ser respeitada e protegida (GOSDAL, 2007, p. 60-1).

Cabe referir ainda, conforme Ruaro (2011, p. 190), que a Corte Europeia de Direitos Humanos, em um caso julgado em 16 de dezembro de 1992, ampliou o alcance do conceito sobre vida privada, passando a incluir o ambiente de trabalho como parte integrante da intimidade e privacidade pessoais, o que permitiria debater acerca do acesso e uso de conteúdos gerados, obtidos ou destinados ao âmbito de uma relação empregatícia.

Em ritmo expansionista, o artigo $8^{\circ}$ da Convenção Europeia de Direitos Humanos ${ }^{5}$, ao ser ampliado, passou a abranger a denominada "vida privada social" que, certamente, inclui a laboral.

A Constituição Federal de 1988 assegura, em seu artigo 5º inciso $\mathrm{X}^{6}$, a inviolabilidade

\footnotetext{
${ }^{5}$ ARTIGO $8^{\circ}$ Direito ao respeito pela vida privada e familiar 1. Qualquer pessoa tem direito ao respeito da sua vida privada e familiar, do seu domicílio e da sua correspondência. 2. Não pode haver ingerência da autoridade pública no exercício deste direito senão quando esta ingerência estiver prevista na lei e constituir uma providência que, numa sociedade democrática, seja necessária para a segurança nacional, para a segurança pública, para o bem - estar económico do país, a defesa da ordem e a prevenção das infracções penais, a protecção da saúde ou da moral, ou a protecção dos direitos e das liberdades de terceiros. Disponível em: https://www.echr.coe.int/Documents/Convention_POR.pdf, acessado em 04 maio 2018

${ }^{6}$ Constituição Federal/1988, art. 50: "Todos são iguais perante a lei, sem distinção de qualquer natureza, garantindo-se aos brasileiros e aos estrangeiros residentes no País a inviolabilidade do direito à vida, à liberdade, à igualdade, à segurança e à propriedade, nos termos seguintes: [...] X - são invioláveis a intimidade, a vida privada, a honra e a imagem das pessoas, assegurando o direito a indenização pelo dano material ou moral decorrente de
} 
dos indivíduos em âmbito particular, ou seja, abarca tanto a esfera familiar quanto a esfera de relações sociais, inclusive a de ordem profissional. De acordo com Hainzenreder (2011, pp. 56), "são direitos da personalidade inerentes ao indivíduo, que jamais desaparecem no tempo e que não se separam do seu titular. Por essa razão, são direitos existentes em qualquer relação jurídica. Portanto, à relação de emprego também são aplicáveis".

O objetivo é tratar da necessidade atual de regulamentação das disposições do empregado sobre situações de sua vida privada que eventualmente tenham sido registradas e/ou noticiadas por meio eletrônico (Internet) e, após armazenadas no meio virtual, não tenham sido apagadas, tornando-se públicas, de livre e amplo acesso.

A regulamentação, advoga-se, deverá observar a proteção aos fatos da vida privada do cidadão, que não fazem parte do interesse público (sequer de seu empregador) e que, especialmente quando mal utilizados e/ou interpretados, podem macular a imagem e dignidade da pessoa (especialmente como trabalhador). Em suma, deve-se ofertar ao cidadão a possibilidade de fazer desaparecer informações (mesmo que em meio/suporte digital) existentes a seu respeito, quando assim o desejar. As informações podem ser integrantes das redes sociais (twitter, orkut, facebook, outros), dos sistemas de busca (google, youtube, outros) e, sobretudo, de sistemas que deveriam garantir sigilo como os "e-jus" trabalhistas".

Registra-se que a Espanha já deu o primeiro passo neste sentido. Por meio da Lei Orgânica 15/1999 de 13 de dezembro, o Estado garantiu aos seus cidadãos o direito fundamental à proteção de dados de caráter pessoal. Esta Lei, em seu artigo 4.5, determina que:

Los datos de carácter personal serán cancelados cuando hayan dejado de ser necesarios o pertinentes para la finalidad para la cual hubieran sido recabados o registrados. No serán conservados en forma que permita la identificación del interesado durante un período superior al necesario para los fines en base a los cuales hubieran sido recabados o registrados. Reglamentariamente se determinará el procedimiento por el que, por excepción, atendidos los valores históricos, estadísticos o científicos de acuerdo con la legislación específica, se decida el mantenimiento integro de determinados datos".

Nos casos em que o cidadão considerar que teve sua reputação ou dignidade atingidas, sentindo-se ofendido em razão de ter seus fatos privados divulgados em rede, na Espanha, lhe é garantido solicitar seu cancelamento evitando a continuidade de sua propagação em âmbito

\footnotetext{
sua violação".

${ }^{7}$ www.advivo.com.br/blog/luisnassif/o-direito-ao-esquecimento-na-internet (acesso em 30/04/2018). O termo ejus significa o armazenamento eletrônico de informações judiciais. Eventualmente, por descuido, podem também estar disponíveis na Internet e livre ao acesso de todos.

${ }^{8} \mathrm{http}: / /$ noticias.juridicas.com/base_datos/Admin/lo15-1999.t2.html\#a4 (acesso em 30/04/2018).
} 
mundial e sua eternização no meio virtual. Neste país, o cidadão possui ainda o direito de ser informado quando seus dados forem divulgados, note-se:

El derecho de información previo al tratamiento de los datos de carácter personal es uno de los derechos básicos y principales contenidos en la Ley Orgánica 15/1999 de Protección de Datos de Carácter Personal; por tanto, si se van a registrar y tratar datos de carácter personal, será necesario informar a los interesados, a través del medio que se utilice para la recogida, del contenido del artículo 5,1 y 2 que regula el derecho de información de los afectados previo a la recogida de los datos. Con carácter general, cuando se recaban datos personales debe informarse a los interesados de lo expuesto anteriormente. ${ }^{9}$

Ou seja, pelo regramento espanhol, os interessados serão previamente informados e ficarão cientes do "local virtual" onde seus dados estarão armazenados, bem como receberão a previsão da quantidade de tempo que as informações permanecerão disponíveis em rede.

É inquestionável a segurança que estas regulamentações oferecem aos cidadãos, pois garantir o direito ao esquecimento implica em investir os indivíduos de prerrogativas sobre toda e qualquer informação da qual sejam titulares. Além disso, legitima o poder pessoal para decidir o que deve permanecer na rede mundial de computadores, ou não, evitando que a informação privada permaneça ad eternum na memória virtual coletiva, o que nem sempre é favorável.

\section{Direito ao Esquecimento: proteção à dignidade dos trabalhadores}

Para o foco deste estudo, o grande desafio enfrentado pelos trabalhadores decorre da divulgação de suas subjetividades (por ato próprio ou de terceiros) via Internet e a possibilidade de tais inserções (ou sua má interpretação) gerarem prejuízos especialmente à sua inserção profissional. Este desafio vem aumentado nas últimas décadas, pois os sistemas informacionais conectados em rede mundial facilitam o acesso a informações de qualquer tipo, inclusive pessoais. $\mathrm{O}$ respeito à privacidade e à intimidade ${ }^{10}$ do trabalhador é limite imposto também às relações de trabalho subordinado.

Entende-se ser tarefa do legislador proteger o cidadão, através de normas adequadas e suficientes, acerca de situações que poderão causar-lhe vexame, humilhação ou desprezo, afetando-lhe diretamente nos direitos de personalidade e desafiando os limites impostos pelo princípio da dignidade da pessoa humana, que está baseada na ideia de "personalidade moral"

\footnotetext{
${ }^{9}$ http://noticias.juridicas.com/base_datos/Admin/lo15-1999.t2.html\#a4 (acesso em 30/04/2018).

${ }^{10} \mathrm{O}$ direito à privacidade resguarda a moral pessoal tanto no âmbito familiar quanto no âmbito social e profissional e o direito à intimidade resguarda a personalidade e ambos são oriundos da proteção já garantida pelo princípio da dignidade da pessoa humana.
} 
do sujeito, alcançando a este uma garantia fundamental com respaldo na Constituição Federal do Brasil.

Assim e tendo em vista a cultura brasileira - que se pauta nas previsões minuciosas de documentos legislativos -, urge que legislação pontual seja acrescida ao arcabouço juslaboral brasileiro, prevendo a proteção que ora se aponta como necessária, de forma concreta e exauriente.

A positivação do chamado Direito ao Esquecimento ofereceria uma segurança ainda maior ao trabalhador eis que, como lembra Ruaro (2011, pp. 191), "sob a ótica do empregado deve-se ter em mente a sua hipossuficiência, à relação de subordinação empregatícia, à satisfação de seu superior, e às regras a que é submetido, muitas vezes sem a possibilidade de proteção e defesa suficiente de sua intimidade".

Um dos casos apontados, veiculado em artigo publicado no periódico espanhol El País de 08/01/2011, relata o fato de um cidadão que teve notícia a seu respeito veiculada trinta anos antes, em jornal que circulava em sua região, contendo resultado condenatório a si inculcado por naquela época ter urinado em logradouro público. O jornal, ao digitalizar seus exemplares antigos, disponibilizou o acesso a tais exemplares por meio da ferramenta de busca "Google". Sendo este cidadão atualmente um honrado professor, pode-se afirmar que o resgate a lume do fato pretérito afetou sua dignidade, eis que fora exposto algo que lhe era íntimo e que, com a sanção da multa a si imposta (há trinta anos, repise-se), já havia respondido pelo seu erro na forma e época próprias.

O interesse reside em não permitir que uma informação - íntima, pessoal e passível de sepultamento pelo esquecimento público, no cenário físico - se torne perpétua e pública no meio (mundo) digital, em razão da capacidade ilimitada de armazenamento e divulgação do ciberespaço, permitindo reacender situações de vida que o próprio indivíduo já poderia ter esquecido e que não gostaria que viessem à tona.

Adaptando o debate à moldura ora proposta, podem existir na rede mundial de computadores informações de que um trabalhador teria demandado na Justiça do Trabalho contra uma determinada empresa em que laborara em tempos passados. Ao candidatar-se à nova vaga de emprego, mesmo sendo extremamente qualificado, pode não ser selecionado em razão dessa informação. Embora os processos judiciais sejam públicos, há tempos já se retirou nos sítios de internet dos Tribunais Trabalhistas brasileiros a ferramenta de consulta "por nome da parte" evitando, com isto, que o próprio sítio web estatal se transformasse em "lista negra", consultada por empregadores, desejosos de não ter entre seus colaboradores pessoas que já houvessem demandado na Justiça do Trabalho. 
Parte-se da ideia de que, nestas relações, tal informação faz parte do rol privativo e íntimo de dados do cidadão que, atualmente no Brasil, não possui um direito regulamentado/positivado que the permita escolher entre divulgar ou não determinados episódios de sua vida, ademais exigindo que fatos relacionados ao seu nome sejam preservados em sigilo ou excluídos dos meios digitais. Tem-se a certeza que, atualmente, apenas a não postagem garantiria eficácia e efetividade ao direito ao "esquecimento".

Regulamentar e proteger os dados do cidadão tornou-se necessário, pois, atualmente, o acesso à Internet permite pesquisar acerca da vida (inclusive íntima) de qualquer pessoa.

Os empregadores naturalmente recorrem a sistemas de busca da internet e sites de relacionamento antes de contratar um empregado. Algumas empresas, sem pudores, solicitam ao candidato sua senha nos sites de relacionamento, quando da entrevista de seleção ao emprego (caso tal sítio seja protegido ou restrito). A tomada de decisão sobre a contratação (ou não), passará, então, por critérios que não perquirem apenas da habilidade e formação do candidato, podendo pautar-se em suas opções pessoais (partidárias, religiosas, de orientação sexual, entre outras).

Se o dever de proteção ao hipossuficiente é imposto primeiramente ao legislador, informando sua atividade típica legislativa, a proteção ao cidadão, para ser efetiva, não estanca na atuação estatal de mera criação de diplomas legais. Fiscalização constante das questões digitais e atuação admoestatória e inibitória concretas também devem ser inseridas na cultura das autoridades administrativas e judiciárias.

De outro lado e a contribuir, singelas companhas de esclarecimento ou até mesmo políticas públicas de formação para a vivência digital revelam-se impostergáveis pois, sem dúvidas, num cenário complexo como o digital, ainda mais complicado pela ineficiência protetiva estatal, incumbe ao próprio cidadão, na medida do possível, a autoproteção de sua privacidade e intimidade, o que começa pela consciência das consequências de seu compartilhamento e exibição na rede mundial de computadores.

\section{Conclusão}

As necessidades de tutela também evoluem, surgindo do progresso tecnológico e do aumento da complexidade do viver humano. A existência humana no espaço virtual têm diferentes contornos e dimensões, necessitando de diversos parâmetros e interpretações, de preferência normativas. Neste particular, embora cientes de que uma norma surge apenas após a constatação e valoração de um fato social, pensa-se que os tempos requerem maior velocidade 
legislativa ou, como alternativa, o início de uma caminhada para as chamadas "normas abertas", principiológicas, porosas e flexíveis.

Na era digital, manter o Direito do Trabalho estático ou engessado, alheio às tecnologias da informação e comunicação, traduz-se em risco a ser suportado especialmente pelos trabalhadores, normalmente não preparados para viver na sociedade em rede, embora lançados à mesma pelos apelos próprios da sociedade líquida (individualismo, autopromoção, etc.). Traça-se assim um novo desafio aos operadores do Direito: o de tutelar o trabalhador empregado em sua dimensão digital, estabelecendo construções teóricas e padronizações minimamente objetivas para as decisões dos conflitos em concreto. $\mathrm{O}$ confronto entre $\mathrm{o}$ princípio da dignidade da pessoa humana e o direito à informação, faz perceber interesses em oposição, em razão disso, advoga-se a necessidade de uma uniformização geral acerca do tema, provavelmente advinda de legislação suficiente e pertinente, mas não somente.

Como pré-dito, políticas públicas e educação para a vida no meio digital são ainda mais importantes que o regramento legal de condutas, cujos valores de influência cambiarão a cada ano, semestre ou mês.

Entretanto, vislumbra-se que, quer a cultura para a vida digital, quer a legislação protetiva, não se implementarão de imediato, sequer a médio prazo. Por isto, entende-se que a argumentação e poder comunicativo dos atores sociais e dos operadores jurídicos serão determinantes para bem conduzir as relações laborais de seres (empregadores e empregados) com dupla dimensão existencial: física e virtual.

\section{Referências Bibliográficas}

BARBOZA, Cícero; BENAKOUCHE, Rabah. Informática Social: a ameaça à privacidade, o desemprego. Petrópolis/ RJ: Vozes, 1987.

BAUMAN, Zygmunt. Modernidade Líquida. Tradução: Plínio Dentzien. Rio de Janeiro: Zahar, 2003.

BAUMGARTEN, Maíra. Tecnologia. In: CATTANI, Antônio David e HOLZMANN, Lorena. Dicionário de Trabalho e Tecnologia. Porto Alegre: UFRGS Editora, 2006.

BURCH, Sally. Sociedade da Informação / Sociedade do Conhecimento. Disponível em: http://dcc.ufrj.br/ jonathan/compsoc/Sally\%20Burch.pdf acessado em 04 maio 2018. 
CASTELLS, Manuel. La era de la información: la sociedad red. 2 ed. vol. 1. Madrid: Alianza Editorial, 2001.

DANTAS, Edmundo Brandão. Telemarketing - A Chamada para o Futuro. Rio de Janeiro: LTC, 1989.

FINCATO, Denise. Trabalho e tecnologia: reflexões. In: FINCATO, Denise; MATTE, Maurício e GUIMARÃES, Cintia (organizadores). Direito e tecnologia: reflexões sociojurídicas. Porto Alegre: Livraria do Advogado, 2014.

GIDDENS, Anthony. Sociologia. 4. ed. Porto Alegre: Artmed, 2005.

GOSDAL, Thereza Cristina. Dignidade do Trabalhador: um Conceito Construído sob o Paradigma do Trabalho Decente e da Honra. São Paulo: LTr, 2007.

HAINZENREDER Jr., Eugênio. Direito à privacidade X Poder diretivo do empregador: o uso do e-mail no trabalho. In: Anais IV Congresso Ibero-Americano de Teletrabalho e Teleatividades. Porto Alegre: Magister, 2011.

HUWS, Ursula. A Construção de um Cibertariado? O Trabalho Virtual num Mundo Real. In: ANTUNES, Ricardo e BRAGA, Ruy (org.). Infoproletários: degradação real do trabalho virtual. São Paulo: Boitempo, 2009.

MASI, Domenico de. O futuro do trabalho: fadiga e ócio na sociedade pós-industrial. Rio de Janeiro: José Olympio, 1999

RODRIGUEZ, Americo Plá. Princípios de Direito do Trabalho. 3 ed. São Paulo: LTr, 2004

RUARO, Regina Linden. A proteção de dados pessoais no teletrabalho. In: Anais IV Congresso Ibero-Americano de Teletrabalho e Teleatividades. Porto Alegre: Magister, 2011.

SANTILLE, Alexandre. Destruição Criadora da Internet na Lealdade às Marcas. In: 
TREVISAN, Leonardo e CASTRO, Maria da Conceição de Araújo (org.). Transformações no Trabalho. São Paulo: Olho D’Água, 2002.

WOLFF, Simone. O "Trabalho Informacional” e a Reificação da Informação sob os Novos Paradigmas Organizacionais. In: ANTUNES, Ricardo e BRAGA, Ruy (org.).

Infoproletários: degradação real do trabalho virtual. São Paulo: Boitempo, 2009. 


\title{
UM QUADRO EXPLICATIVO PARA IMPLANTAÇÃO DO PROCESSO \\ JUDICIAL ELETRÔNICO: ESTUDO DE CASO COMARCA DE CHAPECÓ 2014- $2016^{1}$
}

\author{
Rodrigo da Costa Vasconcellos \\ Universidade do Oeste de Santa Catarina - UNOESC \\ Aires José Rover \\ Universidade Federal de Santa Catarina - UFSC
}

\section{Resumo}

Este estudo avaliou a implantação do Processo Judicial Eletrônico na Comarca de Chapecó, O objetivo geral foi verificar se desta implantação era possível identificar critérios gerais de gestão e legalidade que permitissem construir um quadro explicativo para implantação do processo judicial eletrônico. A implantação do processo eletrônico em Santa Catarina está exigindo uma reestruturação que vem sendo executada gradativamente em todas as comarcas. O problema de pesquisa decorre desse movimento complexo de transformação que precisa assegurar o efetivo cumprimento das normas legais e de gestão do Judiciário. A abordagem metodológica será indutiva com o procedimento de estudo de caso.

Palavras-Chave: Processo judicial eletrônico, Implantação de sistemas, Sistema de automação do judiciário.

\begin{abstract}
Resumen/Résumé
This study evaluated the implementation of the Processo Judicial eletrônico (PJe) [Judicial electronic Process] in the Judiciary District of Chapecó. The general purpose was to verify if with this implementation was possible to identify broad criteria of management and legality that allowed to construct an explanatory scheme for the implementation of the PJe. The methodological approach will be predominantly inductive with the case study procedure. The
\end{abstract}

\footnotetext{
${ }^{1}$ Devido às regras de submissão várias explicações importantes do estudo de caso foram retiradas para manter-se no tamanho de artigo exigido.
} 
research is justified especially because it seeks to construct an explanatory scheme for the implementation of the electronic judicial process.

Keywords/Palabras-claves/Mots-clés: Electronic judicial process, Implantation of systems, System of automation of the judiciary.

\section{Introdução}

O contexto desta pesquisa ${ }^{2}$ envolve o tema do governo eletrônico que aparece como uma forma de infraestrutura única de comunicação compartilhada por diferentes órgãos públicos a partir da qual a tecnologia da informação e da comunicação é usada de forma intensiva para melhorar a gestão pública e o atendimento ao cidadão. Com essa organização, assume o objetivo de colocar o governo ao alcance de todos, ampliando as transparências das suas ações e incrementando a participação cidadã. Em síntese, o Governo Eletrônico é uma forma puramente instrumental de administração das funções do Estado (Poder Executivo, Poder Legislativo e Poder Judiciário) e de realização dos fins estabelecidos ao Estado Democrático de Direito que utiliza as novas tecnologias da informação e comunicação como instrumento de interação com os cidadãos e de prestação dos serviços públicos. Neste contexto ocorrem as mudanças no poder judiciário, em especial, a implantação do processo eletrônico. Este, por sua vez, é o resultado da informatização de um conjunto mínimo e significativo de ações e, por consequência, de documentos organizados e ordenados em uma sequência definida de fluxos de trabalho - representando fases processuais, atendendo a requisitos de autenticidade, temporalidade e integridade, com a eliminação do uso do papel (ROVER, 2009).

A implantação do processo eletrônico nas comarcas do Poder Judiciário brasileiro foi deflagrada há pouco mais de uma década; no entanto os avanços tecnológicos permitiram que somente agora o sistema pudesse ser inteiramente eletrônico. A eficiência na tramitação dos processos foi garantida também com a virtualização deles. O dever de prestar uma jurisdição com agilidade e eficiência pelo Poder Judiciário brasileiro está previsto no inciso LXXVIII do artigo $5^{\circ}$ da Constituição Federal. Desse modo, decorre a lei $n^{\circ} 11.419 / 96$, que dispõe sobre a informatização do processo judicial, permitindo o uso do meio eletrônico na tramitação dos processos judiciais, na comunicação de atos e na transmissão de peças processuais. Assim, a

\footnotetext{
${ }^{2}$ Este artigo decorre de parte de pesquisa realizada para a tese doutoral de Rodrigo Vasconcelos sob a orientação de Aires José Rover, na Universidade Federal de Santa Catarina.
} 
implantação do processo eletrônico tem por finalidade cumprir as exigências constitucionais, mas, do mesmo modo, permitir que o Poder Judiciário ofereça um serviço de maior celeridade da justiça à população brasileira.

Neste contexto, este estudo visa contribuir para o conhecimento acerca da melhor gestão do acesso à justiça em todos os graus de jurisdição a partir da análise de caso na região de Chapecó. Para tanto, parte-se da pergunta: A implantação do Processo Judicial Eletrônico na região de Chapecó atende ao princípio de eficiência de acordo com as diretrizes do CNJ? A hipótese a ser comprovada é que sim e para tanto o objetivo geral é verificar se a implantação do Processo Judicial Eletrônico na região de Chapecó permite identificar critérios gerais de gestão e legalidade a partir dos quais seja possível construir um quadro explicativo para implantação do processo judicial eletrônico. Como objetivos específicos, buscou-se apontar as especificidades conceituais, jurídicas e funcionais para a implantação do processo eletrônico; levantar dados de uma implantação do processo eletrônico em Chapecó e a partir de sua análise levantar parâmetros para um quadro para implantação do processo judicial eletrônico em geral.

Nesta pesquisa, escolheu-se como método principal o indutivo, com o procedimento de estudo de caso e utilizando uma abordagem quantitativa dos dados coletados. Para tanto, foi construído como instrumento de pesquisa um questionário composto por 28 perguntas específicas sobre questões referentes à implantação do e-SAJ, que puderam ser respondidos em uma escala do tipo Likert de 1 a 5 pontos, indo do totalmente de acordo ao totalmente em desacordo. Assim, para que fosse possível construir o questionário foi feita uma estruturação das dimensões a partir das variáveis obtidas a partir de conversas preliminares com servidores e magistrados no foro da Comarca de Chapecó. O universo pesquisado foi composto por 182 pessoas, entre servidores e magistrados, sendo que destes, 34 pessoas responderam ao questionário teste, sendo 7 magistrados e 27 servidores lotados no Foro da Comarca de Chapecó. A aplicação do questionário ocorreu no período de 27 de junho a 14 de julho de 2016 , através de um formulário online.

\section{Perguntas que geraram as variáveis do caso}

Para organização do quadro e definirmos seus conceitos foram feitas entrevistas não estruturadas visando ouvir os participantes de tal maneira que foram identificadas dimensões gerais, indicadores e variáveis extraídas dos resultados dessas entrevistas e em consonância com a doutrina e legislação que fundamentam a implantação dos sistemas de automação 
judiciária. Foi um processo cíclico de idas e voltas, definição de termos e seu aprimoramento bem como sua classificação dentro de um quadro. Observe-se que o processo de construção de uma classificação nada mais é do que delinear os componentes vinculados ao objetivo estabelecido no sentido de simplificar as informações tornando-as mais compreensíveis e quantificáveis. Assim, no âmbito deste trabalho, o quadro foi organizado em uma estrutura em três níveis, partindo das dimensões gerais, abaixo das quais estão os indicadores, compostos, por sua vez, por variáveis. Foram definidas cinco dimensões para um total de onze indicadores e vinte e oito variáveis. Para chegar nessa síntese, foram realizadas as questões abaixo, validadas através das entrevistas não estruturadas:

1) A implantação permitiu ao usuário conhecer o sistema para a execução adequada de suas tarefas?

2) Levou em conta as habilidades prévias dos usuários no uso dos meios informatizados?

3) Levou em conta a realidade e estrutura do foro?

4) Você estava interessado no avanço da implantação?

5) Você se sentiu estimulado para se capacitar?

6) A falta de formação jurídica compromete a capacitação?

7) Você chegou a pensar em se aposentar ou mudar de local de trabalho?

8) Você se sentiu capaz em se adaptar à nova realidade?

9) Os consultores tinham conhecimento técnico adequado do processo?

10) Os consultores conheciam a organização do foro?

11) Você acha que o usuário externo é melhor atendido com as mudanças ocorridas?

12) A OAB participou da implantação do SAJ em todas as etapas?

13) Durante a implantação foram trabalhadas muitas versões?

14) O sistema apresenta erros?

15) O sistema já está devidamente ajustado?

16) Conhece/utilizou outros sistemas de gestão de processo judicial eletrônico?

17) Todos os procedimentos respeitam o devido processo legal?

18) Você confia na funcionalidade do sistema?

19) O sistema apresenta a funcionalidade necessária para o seu perfil?

20) O sistema deveria realizar mais tarefas de forma automática?

21) O sistema executa adequadamente as tarefas automáticas?

22) A mudança para o novo sistema produziu maior celeridade processual?

23) A mudança permite uma qualificação da prestação jurisdicional?

24) A velocidade de banda da internet é adequada para o funcionamento do Sistema? 
25) Há órgãos que resistem ao processo de mudança?

26) O processo exigiu melhora dos equipamentos?

27) O uso da certificação parece adequado para garantir a segurança do sistema?

28) Todos os usuários têm condições de obter certificação para acessar o sistema?

Dessas perguntas consolidou-se as seguintes variáveis: execução das tarefas, habilidades prévias dos usuários, realidade e estrutura do foro, interesse do técnico, estímulo para qualificação, formação jurídica dos técnicos, aposentadoria, capacidade para mudar, conhecimento técnico, conhecimento da realidade local, atendimento, presença da $\mathrm{OAB}$, versões, erros, ajustamento, diversidade, parcialidade/imparcialidade, confiança, personalização, automatização de tarefas, velocidade de tramitação dos processos, eficiência, banda, integração com outros órgãos externos, melhora dos equipamentos, autenticação e usuários.

Adiante segue a discussão e consolidação de cada conceito para cada dimensão.

\section{Dimensões e indicadores}

A partir das questões e variáveis acima, procurou-se organiza-las em classes (dimensões) e subclasses (indicadores), de acordo com suas relações significativas. O processo de construção de um indicador ou de um sistema de indicadores começa com a identificação do que se pretende avaliar, medir ou analisar. A partir daí, busca-se delinear as dimensões, os componentes ou as ações operacionais vinculadas ao objetivo estabelecido. Para o acompanhamento dessas ações, buscam-se dados e estatísticas que, reorganizados sob a forma de taxas, proporções, índices ou mesmo em valores absolutos, transformam-se em indicadores (JANNUZZI, 2005). É importante ressaltar que os indicadores têm como objetivo simplificar as informações sobre fenômenos complexos e tornar a comunicação sobre eles mais compreensível e quantificável. No âmbito deste trabalho, os indicadores apontarão para o conjunto de variáveis capazes de permitir a avaliação da implantação dos sistemas de automação, em consonância com a legislação que ordena os processos de implantação. Novamente, este foi um processo de acertos e erros, consolidados após a validação através das entrevistas preliminares.

Tais dimensões e indicadores ficaram organizados da seguinte forma: na dimensão pessoas, temos os indicadores capacitação, adaptação/adaptabilidade, consultoria externa e usuários externos; na dimensão sistema, temos os indicadores usabilidade, legalidade, 
funcionalidade e celeridade; na dimensão comunicação, a variável tramitação; na dimensão infraestrutura, a variável equipamentos e na dimensão segurança, a variável certificação.

\section{Discussão dos dados da dimensão pessoas}

A dimensão pessoas organiza em torno de si seis indicadores relativos a um elemento considerado estrutural em toda e qualquer organização, o pessoal. Qualquer manual de administração discute sua relevância. Esses indicadores são: capacitação, adaptação/adaptabilidade, consultoria externa, usuários externos.

\section{Indicador capacitação}

O indicador capacitação procura identificar por qual maneira os usuários do SAJ foram capacitados para os exercícios de suas atividades com o novo instrumento. Tal indicador trás as seguintes variáveis: execução das tarefas, habilidades prévias dos usuários, realidade e estrutura do foro, interesse do técnico, estímulo para qualificação e formação jurídica dos técnicos. Para tanto, verifica-se a seguir, como cada uma das variáveis são satisfeitas.

A variável execução de tarefas permite verificar se o usuário consegue realizar todas as tarefas possíveis para o seu perfil no sistema implantado (foi utilizada em razão de terem surgido dúvidas entre os usuários internos quanto à forma correta de cumprir alguns procedimentos processuais. Muito embora a capacitação tenha permitido a todos os usuários do SAJ o conhecimento dos fluxos do processo, há um volume de passos que precisam ser conhecidos no dia a dia e com a utilização do instrumento virtual, para que ocorra a efetiva apropriação do seu funcionamento. Somente a capacitação não possibilita o domínio do seu funcionamento, bem como o efetivo conhecer de todas as suas potencialidades. Dos respondentes, apenas 14,71 \% entendem que a implantação do sistema de Automação da Justiça permitiu aos usuários o conhecimento sobre a execução de suas tarefas.

A variável habilidades prévias dos usuários identificou que a implantação de novas TIC's importa na exigência de habilidades específicas dos seus usuários. Ainda que se queira levar em conta um ator, há uma necessária distribuição do emprego dessa tecnologia sobre um relevante grupo de usuários que têm habilidades específicas, interesses misturados e expectativas diferentes e que atuam em campos diferentes. Desse modo, as habilidades prévias são minimamente consideradas, pois novas habilidades precisam ser desenvolvidas. Há um sem número de atividades novas a serem desempenhadas através do novo instrumento que antes não havia a necessidade de se conhecer. As configurações atuais das múltiplas funções dos agentes 
seguem múltiplas lógicas e com diferentes prioridades. No processo de mudança, nem todas as rotinas e habilidades específicas para a estrutura institucional pré-existente pode ser de forma harmônica e livre de problemas, transpostas para uma nova realidade institucional. Desse modo, percebe-se que as organizações precisam desenvolver novas habilidades em seus usuários para tornar possível o uso dos novos dispositivos técnicos, o que exigirá a utilização de novos programas de formação pessoal. Percebe-se que, pelo baixo número de respondentes (apenas 3 usuários, o que corresponde a 8,82\% dos respondentes) concordando com o reconhecimento destas habilidades, verifica-se uma alta necessidade dessas novas habilidades serem desenvolvidas nos usuários.

A variável realidade e estrutura do foro demonstrou que o cenário da implantação do novo sistema, o Foro da Comarca de Chapecó, apresenta um conjunto de elementos próprios da cultura local e dos hábitos e costumes dos usuários. Desse modo, para fazer a implantação do novo sistema, os treinadores devem considerar as características organizacionais do Foro de Chapecó, as características dos usuários, o dia a dia dos técnicos, entre outras peculiaridades do local e das pessoas que passariam a utilizar o novo sistema. São reconhecidos como fatores viabilizadores da gestão do conhecimento os fatores contextuais que afetam a probabilidade de a aprendizagem ocorrer: a cultura da organização orientada à aprendizagem, que consiste nas crenças partilhadas, ideologias e normas locais que influenciam na organização quando da tomada de ação; estrutura organizacional, que permite inovação e novas ideias, conforme Fischmann e Almeida (2009, p. 25). Os treinadores que atuaram na implantação do sistema em Chapecó foram os mesmos que atuaram na implantação do Plano de Unificação, Modernização e Alinhamento (PUMA) no maior tribunal de justiça do país, o Tribunal de Justiça do Estado de São Paulo. Informalmente, alguns respondentes expressaram essa não observância da realidade local pelos treinadores, o que 51,43 \%, a expressiva maioria, não considerou relevante.

A variável interesse do técnico nos informou que a implantação do SAJ despertou interesse pela inovação e/ou mudança de rotinas de trabalho em 73,53\% dos entrevistados. A inovação trazida pela implantação do SAJ criou a expectativa de aprimoramento da atividade jurisdicional, com a melhora dos fluxos processuais, redução da carga de trabalho e melhoria do ambiente das salas dos cartórios pela redução do volume de processos entre tantos outros fatores que podem ser de estímulo aos servidores.

A variável estímulo para qualificação demonstrou que a utilização de novas tecnologias pode significar uma grande barreira para aqueles profissionais ainda não 
familiarizados com os meios tecnológicos. Conhecer amplamente as novas ferramentas é essencial para o bom exercício das funções de cada perfil de usuário. Desse modo, é de grande importância que todos os usuários recebam um treinamento para que tenham uma visão geral do SAJ, treinamentos em instalação e configuração do ambiente tecnológico, treinamento nos fluxos, tanto dos procedimentos cíveis como criminais, treinamento na tecnologia adotada no SAJ, capacitação em desenvolvimento de competências técnicas e multiplicadores nos próprios tribunais. Essas qualificações permitirão que o usuário seja estimulado a fazer parte da instituição com sentimento de pertencimento. Durante a coleta de informações para a elaboração da pesquisa, soube-se, dentre os servidores mais antigos, que alguns se sentiram estimulados a se aposentar, eis que entenderam ser uma mudança de paradigma muito brusca e, temerosos da nova realidade, preferiram não continuar nas suas atribuições. Tal informação não se confirmou pelas respostas dos entrevistados. De todos os respondentes apenas 1 manifestou ter pensado em sua aposentadoria, e ainda não era dos mais antigos no serviço público.

Através da variável formação jurídica dos técnicos, constatou-se que formação jurídica dos usuários não é requisito para a capacitação, bem como para a utilização do sistema de automação. Na Comarca de Chapecó, têm-se servidores com formação nas mais diversas áreas diferentes do direito. No entanto, há uma política interna implementada pelo TJSC visando a estimular a qualificação dos usuários através de bolsas de estudos para a sua formação jurídica. A Diretoria de Recursos Humanos é responsável pelo gerenciamento e supervisão do quadro de pessoal do Poder Judiciário, tanto da Justiça de Primeiro Grau quanto da Secretaria do Tribunal de Justiça, envolvendo servidores efetivos e comissionados, inativos, juízes de paz, estagiários, voluntários e terceirizados. Esse trabalho envolve o controle do ingresso na carreira, com o acompanhamento dos processos de nomeação dos servidores, de contratação de estagiários e terceirizados, e de adesão dos voluntários. O Tribunal de Justiça mantém o Programa de Bolsa de Estudos, destinado a Magistrados e Servidores, para cursos de graduação, pós-graduação e para o curso da Escola Superior da Magistratura. Por intermédio do programa, o Poder Judiciário custeia $70 \%$ do valor da mensalidade e 100\% do Curso de Direito. Há um estímulo, portanto, para que os servidores tenham formação jurídica visando a aprimorar a prestação do serviço público pelo poder judiciário, pois a utilização de sistemas de automação passa a exigir mais dos servidores quanto ao conhecimento da técnica jurídica. Percebe-se a necessidade de informação qualificada pelo número de respondentes que manifestaram concordar, ainda que em parte, com a necessidade de formação jurídica para a compreensão da linguagem, totalizando $42,18 \%$. 


\section{Indicador adaptação/adaptabilidade}

Para Conceição (2011), existe a necessidade da sociedade e principalmente dos operadores jurídicos se permitirem conviver e trabalhar com esse novo sistema e principalmente recepcionar bem o novo, pois só dessa forma ocorrerá a ampliação de direitos de forma mais célere e democrática no Brasil e no judiciário brasileiro. Alvares (2011) ressalta que o Processo Eletrônico representa o resultado de uma mistura cultural e social, que se vê entrelaçada com a rapidez na prestação de determinados serviços, visando a dar maior rapidez aos procedimentos e possibilitar a ampliação do acesso ao judiciário bem como à justiça. Para Caldas e Louzada, (2013), os operadores deixaram, após essa melhoria tecnológica, de se prender a tarefas burocratizadas, passando a desenvolver sua função de forma útil e prática com mais rapidez, fazendo com que ocorresse uma melhoria do aproveitamento do trabalho e, consequentemente, refletindo na qualidade deste e, consequentemente, adaptando-se às novas rotinas laborativas. Nesse sentido, para o nosso enquadramento, definiu-se para o indicador adaptabilidade as variáveis aposentadoria e capacidade para mudar.

Durante a coleta de informações referentes à variável aposentadoria para a elaboração da pesquisa, soube-se, dentre os servidores mais antigos, que alguns se sentiram estimulados a se aposentar, eis que entenderam ser uma mudança de paradigma muito brusca e, temerosos da nova realidade, preferiram não continuar nas suas atribuições. Tal informação não se confirmou pelas respostas dos entrevistados. De todos os respondentes, apenas 1 manifestou ter pensado em sua aposentadoria, e ainda não era dos mais antigos no serviço público. Assim, a implantação do SAJ na rotina de trabalho dos servidores e magistrados não pode ser interpretada como um estímulo a deixar o judiciário ou mudar para um setor onde não haveria a necessidade de utilizá-lo.

Sobre a variável capacidade de mudar, soube-se que alguns servidores alegaram ter um tipo de formação bastante tradicionalista e formalista, o que, de certo modo, dificulta um pouco a adaptação a novas tecnologias e inovações. Esse formalismo talvez obstaculize um pouco a modernização que as novas tecnologias trazem. De qualquer modo, a própria cultura social atual já leva os mais jovens a essa adaptação, de modo que ela fica sempre mais difícil de ser implementada, quanto mais velho e mais formalista for a pessoa. Lembramos que toda e qualquer mudança exige esforço e um certo sacrifício. Ilustrativamente, ocorreu no passado, na mudança da velha máquina de escrever, quando se passou a utilizar os computadores pessoais. Muitas pessoas sofreram bastante até se adaptarem à nova tecnologia, comentaram bastante sobre a dificuldade de adaptação e sobre a exigência de um novo aprendizado, visto que, para 
os usuários que não dominavam a informática e não tinham conhecimento do uso de terminais de computador, sua profissão estaria, a priori, comprometida, o que poderia representar, pelo menos num período provisório, uma limitação ao exercício da profissão. A implantação do SAJ na Comarca de Chapecó permitiu aos usuários conhecer sua capacidade de adaptação. Dos respondentes, $79,41 \%$ reconheceram tal capacidade.

\section{Indicador consultoria externa}

Para a implantação e treinamento dos servidores teve papel relevante a pessoa do formador, neste caso uma consultoria externa, pois foi a pessoa responsável por atuar como referencial de conhecimento sobre o Sistema na unidade judiciária aonde estivesse alocado. Sua tarefa foi de significativa responsabilidade, pois também assumiu o dever de responder as dúvidas e apoiar os usuários de sua unidade judiciária. (SANTA CATARINA, 2015). O treinamento dos servidores foi realizado em duas etapas. Uma etapa utilizando técnicas de educação à distância, através de uma plataforma Moodle, pelo link http://eadsaj.tjsc.jus.br/moodle/vitrine/index.php, e outra etapa presencialmente. O curso em $\mathrm{EaD}$ foi um treinamento completo sobre o Sistema, contendo informações selecionadas por perfil de atuação. Sendo assim, existem cursos direcionados para os oficiais de justiça, cursos para cartório, gabinete, distribuição, entre outros. Também estão disponíveis apostilas sobre os procedimentos e fluxos do processo digital utilizado no Tribunal de Justiça de Santa Catarina. Os fluxos são divididos por matérias, portanto existe o fluxo Cível, Criminal, Juizado Especial, entre outros. Os cursos foram ministrados por instrutores da empresa Softplan que, eventualmente, foram acompanhados por servidores do Tribunal de Justiça do Estado de Santa Catarina. O indicador consultoria externa foi descrito através das variáveis conhecimento técnico e conhecimento da realidade local.

A variável conhecimento técnico permitiu saber que os consultores que atuaram na implantação do SAJ conheciam tecnicamente o processo de implantação do SAJ de forma bastante apurada. Dos respondentes ao questionário, $41,18 \%$ reconheceram a capacidade dos técnicos.

A variável conhecimento da realidade local permitiu saber que, embora fosse ampla e importante a experiência dos instrutores da Softplan na capacitação de outros Tribunais e do treinamento dado pelos instrutores internos deste Tribunal à Softplan, houve a percepção que muitas rotinas e procedimentos se diferenciavam dos utilizados no Tribunal de Justiça de Santa Catarina, causando divergência na instrução dos usuários. Certos da necessidade de adotar alguma providência visando a reduzir as distâncias entre os treinadores e os servidores do 
judiciário, houve a deliberação pelo Comitê Gestor da Execução Contratual para a disponibilização de servidores do TJSC para realizar o acompanhamento da implantação e do acompanhamento assistido da produção, objetivando o nivelamento do conhecimento por parte dos instrutores da Softplan. Houve também a realização de workshops entre integrantes das equipes de implantação do TJSC e da Softplan. Com isso houve melhora considerável no repasse do conhecimento referente aos procedimentos. No entanto foi identificado que ainda há necessidade do suporte aos servidores das comarcas nas fases de capacitação e de acompanhamento da produção. No questionário, 29,41 dos respondentes entendem que os técnicos conheciam a realidade local.

\section{Indicador usuário externo}

A utilização desses sistemas de automação de processos judiciais poderá ser feita por todas aquelas pessoas listadas nos incisos VIII e IX da Resolução 185 do CNJ. Os usuários internos são magistrados e servidores do Poder Judiciário bem como outros que se deve reconhecer acesso às funcionalidades internas do sistema de processamento em meio eletrônico, tais como estagiários e prestadores de serviço; como usuários externos, temos todos os demais usuários, incluídos partes, advogados, membros do Ministério Público, defensores públicos, peritos e leiloeiros. O indicador usuários externos, foi descrito pelas variáveis atendimento e presença da $\mathrm{OAB}$.

Durante a pesquisa sobre a variável atendimento, verificou-se que através do processo eletrônico, a intervenção e presença do serventuário da justiça são apenas para manter o impulso processual. A inserção de dados está a cargo do procurador da parte litigante. Observou-se, ainda, que o Poder Judiciário passará a necessitar de menor quantidade de servidores para atendimento ao público. Ao passo que a demanda por atendimento é menor, a tendência é que tais servidores passem a trabalhar em outras atividades mais relacionadas à resolução/julgamento da lide. Assim, a aplicação dos recursos tecnológicos previstos pela Lei 11.419 proporciona melhorias e modifica a forma como é realizado o atendimento ao público. $\mathrm{Na}$ medida em que os servidores estiverem menos envolvidos aos processos físicos, tem-se mais liberdade para o exercício de outras tarefas no âmbito dos cartórios. Percebe-se, então que o uso intensivo da Internet reduz significativamente o fluxo de pessoas nas unidades judiciais. Passa a ter necessidade de presença física apenas para as audiências. Porém, mesmo nesse caso, já existe autorização legislativa para a realização de tele audiência, prevista inicialmente para o atendimento aos detentos, que não mais serão deslocados de suas unidades prisionais. A diminuição da necessidade de espaços físicos destinados ao armazenamento de processos, a 
instalação de equipamentos de autoatendimento e a diminuição prevista no fluxo de pessoas no protocolo de atos são indicativos de que haverá a necessidade de reorganizar o layout das instalações físicas dos fóruns e tribunais, como também as rotinas de atendimento ao público. Mesmo não possuindo natureza impositiva, a Lei criou as condições necessárias para a alteração do rito processual, permitindo o uso pleno dos recursos tecnológicos atualmente disponíveis, estabelecendo uma oportunidade inigualável ao Poder Judiciário brasileiro para melhorar o atendimento ao público e o seu desempenho. Dos respondentes, 64,72\% entendem que implantação do SAJ permitiu que os usuários externos fossem mais bem atendidos pelo Poder Judiciário em Chapecó.

Acerca da variável presença da OAB, constatou-se que para a implantação do SAJ a presença ou não da $\mathrm{OAB}$ não era um fator preponderante. Embora advogados, estagiários, entre outros figurem como usuários externos ao SJ, a implantação do novo sistema de automação deveria ser conhecido também pela $\mathrm{OAB}$, mas num cenário diferente. Em todas as subseções do estado de Santa Catarina a OAB promoveu capacitações próprias para que os advogados pudessem conhecer o funcionamento do sistema. Houve, de certo modo, algum desencontro entre o TJSC e a OAB quanto à forma de organização da implantação do sistema, pois, em alguns documentos, a $\mathrm{OAB}$ manifestou sua contrariedade quanto à metodologia adotada. ${ }^{3} \mathrm{~A}$ OAB, Ministério Público, Advocacia Pública, Fazenda Nacional, que sempre estiveram ao lado das mudanças tecnológicas que possam beneficiar aos seus membros, clamam por um diálogo mais assíduo e transparente quanto às mudanças que vêm sendo implantadas pelo Poder Judiciário.

\section{Discussão dos dados da dimensão sistema}

Para a compreensão dessa dimensão, temos o conceito de sistema de automação, que foi introduzido pela lei 11.419/06 e estabeleceu em seu artigo 14 o uso de programas com código aberto e acessíveis por meio da rede mundial de computadores, um sistema de tramitação, armazenamento e manipulação de processos em meio digital, que implementa todo o procedimento judicial em meio eletrônico. O sistema do processo judicial eletrônico, por óbvio, deve obedecer a uma série de requisitos legais, principalmente ao estabelecido no Código de Processo Civil e outras leis esparsas. Essas informações, que outrora eram encaminhadas ao Poder Judiciário em papel, podem, com o avanço tecnológico, chegar através de formulários e ${ }^{3}$ Documento disponível no endereço eletrônico: $<$ http://www.tjsc.jus.br/documents/39812/42122/Of\%C3\%
ADcio+121-+GP-+OAB/9a2c9666-3879-4c71-9fc9-78b41e7c2c06> 
arquivos digitais. Para organizar essa temática enquadrando os principais conceitos a dimensão sistema organiza em torno de si quatro indicadores que são: Usabilidade, Legalidade, Funcionalidade e Celeridade.

\section{Indicador usabilidade}

Os estudos de usabilidade estão tanto no contexto da Ciência da Computação - onde também são conhecidos como estudos de engenharia de software - quanto no contexto da Ciência da Informação - referindo-se ao estudo de necessidades e uso da informação e avaliação de sistemas (ELLIS; ALLEN; WILSON, 1999). Pela definição constante da Norma ISO 9241, usabilidade "é a extensão em que um produto pode ser usado por usuários específicos para alcançar objetivos específicos com eficácia, eficiência e satisfação num contexto específico de uso". De uma maneira geral, os estudos de usabilidade em Ciência da Informação se propõem a ser um instrumento para viabilizar o desenvolvimento e/ou adequação de sistemas de informação a partir de uma perspectiva centrada no usuário, em suas necessidades, tarefas a serem executadas, condições de interação com o sistema, entre outros fatores. Como afirmam Barboza et al. (2000), quando um produto é avaliado na sua usabilidade, a ênfase é dada à sua otimização. As autoras, com base na norma ISO 9241, afirmam que existem três maneiras de medir diretamente a usabilidade de um produto: 1) pela análise de suas características requeridas num contexto específico de uso; 2) pela análise do processo de interação; 3) pela análise da eficácia e eficiência que resulta do uso de um produto. Dessa forma, as autoras propõem uma figura com a estrutura da usabilidade, ressaltando que é preciso identificar objetivos e decompor a usabilidade em atributos passíveis de serem mensurados, assim como o contexto de uso (BARBOZA et al., 2000). O indicador usabilidade foi descrito pelas variáveis versões, erros e ajustamento.

Na pesquisa sobre a variável versões constatou-se que o número de versões utilizadas trouxe uma expectativa de constante aprimoramento da implantação do SAJ, pois os avanços da implantação e do funcionamento do sistema eram representados pela expressão "virada de chave", o que representava a utilização de novas versões do sistema de automação. Ao todo foram 8 versões utilizadas, o que não significou a inexistência de problemas ou erros de funcionamento do sistema. Alguns relatos conseguem ilustrar tais problemas presentes no funcionamento: as rotinas de migração de dados, responsáveis por transferir as informações do sistema PG3 para o sistema PG5, estavam lentas e necessitavam constantemente de ajustes, pois apenas parte das informações dos processos estava sendo migrada, impedindo a utilização adequada de alguns processos e obrigando a suspensão das atividades para utilização do 
sistema. Algumas providências foram adotadas, como a solicitação para as devidas correções nas rotinas visando à migração integral dos processos; readequação da equipe da Softplan, inclusive com substituição da gerência do projeto; realocação de analistas com maior nível de experiência e qualificação; alteração das rotinas de migração para agilizar o processo de migração dos dados. O resultado obtido foi a melhora significativa nos problemas decorrentes da migração dos processos. Há expectativa para migração deste ciclo sem necessidade de suspensão das atividades dos servidores. As informações obtidas a partir da pesquisa realizada é que o sistema de automação apresentou inconsistência, exigindo a utilização de novas versões para que fossem corrigidos os erros presentes nas versões anteriores e causando insegurança nos usuários em virtude de sua instabilidade. Essa instabilidade é reconhecida por 76,47 \% dos respondentes, pois concordam que o sistema ainda apresenta erros de operação e 88,24 \% dos respondentes acreditam que o sistema ainda não está devidamente ajustado.

Para a variável erros o conjunto das respostas prestadas pelos participantes da pesquisa nos informa que a versão atual do SAJ apresenta erros de operação ou funcionamento inadequado, causando demoras ou não concluindo as tarefas. Ao todo, 76,47 \% dos respondentes concordam que o sistema ainda apresenta erros de operação.

A variável ajustamento significa, sinteticamente, facilidade de uso, que decorre da própria usabilidade. Assim, a usabilidade pode ser definida como o estudo ou a aplicação de técnicas que proporcionem a facilidade de uso de um dado objeto, no caso, um sítio. A facilidade de uso busca assegurar que qualquer pessoa consiga usar o sítio e que este funcione da forma esperada pela pessoa. Em resumo, a variável ajustamento abarca a: facilidade de uso; facilidade de aprendizado; facilidade de memorização de tarefas; produtividade na execução de tarefas; prevenção, visando à redução de erros; satisfação do indivíduo. Os números obtidos em resposta à pergunta da pesquisa nos informam que 88,24\% dos respondentes acreditam que o sistema ainda não está devidamente ajustado.

A variável diversidade foi utilizada visando, a saber, se o usuário conhecia ou utilizou outros sistemas como o E-jus, Esaj, Projudi, E-proc, PJE, SUAP, CRETA, entre outros. O uso das novas tecnologias em sistemas de automação de processos é novidade para $73,53 \%$ dos respondentes. A implementação desses sistemas propõe uma quebra de paradigma, uma mudança muito significativa nos modelos de trabalho e forma de operação, não somente para os servidores, advogados, procuradores, mas também para os magistrados. Inúmeras consequências podem surgir a partir da implementação de um sistema dessa natureza, tanto no que tange aos aspectos tecnológicos (inaptidão dos usuários, indisponibilidade do sistema, 
falhas de desenvolvimento), problemas de ordem legal (regulamentação de alguns procedimentos) e até mesmo à resistência ao novo modelo e a mudança, o conservadorismo, que pode ser manifestado por todos os tipos de usuários.

\section{Indicador legalidade}

Por este indicador entende-se a "obrigação de realizar suas atribuições com rapidez, perfeição e rendimento, além, por certo, de observar outras regras, a exemplo do princípio da legalidade" (GASPARINI, 2006, p. 21-2). Dentre essas interações, o processo judicial eletrônico se torna instrumento obrigatório para o acesso à justiça no âmbito dos Tribunais de Justiça, especialmente, no Tribunal de Justiça do Estado de Santa Catarina. A adoção desse instrumento compõe a reestruturação do Poder Judiciário em sua totalidade. Essa reestruturação vem sendo executada gradativamente em todas as comarcas do Estado de Santa Catarina. Assim, é de suma importância que a implantação dos sistemas de automação ocorra dentro da legalidade e assegure efetivo cumprimento das normas processuais e de gestão do Judiciário catarinense (ADORNO JÚNIOR; SOARES; ARRUDA; CALDAS; LOUZADA, 2013). A legalidade representa o dever e a obrigação de realizar suas atribuições com rapidez, perfeição e rendimento, além, por certo, de observar outras regras, que estabeleçam o pleno cumprimento do ordenamento jurídico (GASPARINI, 2006). O indicador legalidade foi descrito pela variável parcialidade/imparcialidade.

Durante a pesquisa sobre a variável parcialidade/imparcialidade verificou-se que o aspecto legalidade aqui abordado é um dos mais relevantes, senão o mais relevante neste estudo. Conhecer o efetivo cumprimento da legalidade na reestruturação de uma Comarca é de significativa importância. O aspecto legalidade traduz a ideia que a Administração Pública somente tem possibilidade de atuar quando exista lei que determine atuação vinculada, ou autorize - atuação discricionária, devendo obedecer estritamente ao estipulado na lei, ou sendo discricionária a atuação, observar os termos, condições e limites autorizados na lei. Especificamente, a legislação que previu a utilização do meio eletrônico para o processo judicial, Lei 11.419/2006, que já foi amplamente abordada neste trabalho. O referido diploma legal prevê uma série de quesitos para a implementação do processo judicial de forma virtual. A lei prevê que é necessário garantir a confiabilidade do sistema através da autenticidade das peças constantes dos autos, isto é, previsão de assinatura eletrônica e também cadastros dos agentes envolvidos nos órgãos judiciários. É importante mencionar, nesse contexto, que a legislação nacional trata das questões genéricas que os aspectos particulares ficam a cargo dos Tribunais criarem os seus regulamentos, pois o $\mathrm{CNJ}$ atribuiu autonomia para que todos os 
tribunais criem os seus próprios instrumentos digitais de gestão processual. De caráter mais específico, outras normas regulamentam a utilização de sistemas de automação de processos eletrônicos no âmbito do Poder Judiciário. Pela opinião dos respondentes, o equivalente a 79,41 $\%$ entende que os procedimentos adotados no SAJ respeitam o devido processo legal.

\section{Indicador funcionalidade}

O indicador abrange a capacidade do sistema se manter funcional, operacional, seja em que plataforma for. No caso do CNJ este lançou o sistema PJe, funcionando em plataforma de código aberto, tanto para o software quanto para o banco de dados, onde se destaca o desenvolvimento compartilhado entre os diferentes tribunais, com a recomendação que o sistema busque identificar a ocorrência de prevenção, litispendência e coisa julgada. Silva (2012) destaca que a lei andou muito bem ao sugerir que os sistemas adotem tais funcionalidades, na medida em que são de simples implementação e evitam problemas comuns na rotina forense com a ocorrência de demandas repetitivas. O indicador funcionalidade foi descrito pelas variáveis confiança, personalização e automatização de tarefas.

Acerca da variável confiança, constatou-se que a forma como se deu a reestruturação do Poder Judiciário apresentou elementos de verticalização e unilateralidade, presentes em estruturas burocratizadas. Desse modo, é comum que o funcionário se acostume com um certo procedimento e não seja estimulado a contribuir com sua melhoria, buscando manter a estrutura padronizada e predefinida. As propostas de melhorias poderiam ocasionar insegurança ao funcionário, o qual é especialista e já possui total conhecimento da tarefa no modo como ela é executada. O sistema em utilização para a gestão do processo eletrônico é confiável para o exercício das tarefas do seu perfil. Do questionário $44,12 \%$ dos respondentes confiam nas funcionalidades do sistema, e $47,06 \%$ dos respondentes foram indiferentes ao quesito confiança.

Durante a pesquisa sobre a variável personalização, confirmou-se que as rotinas e os procedimentos padronizados são regulados por normas técnicas atinentes à conduta do ocupante de certo cargo, cujas atividades são executadas de acordo com as rotinas e procedimentos. $\mathrm{O}$ melhor desempenho e a máxima produtividade são buscados através de um conjunto de regras que moldam as tarefas executadas pelo funcionário de acordo com as necessidades da organização. Os padrões estabelecidos para certas atividades tendem a facilitar o acompanhamento do desempenho dos funcionários. Com o emprego das novas tecnologias, essas mesmas regras disporão sobre as atividades previstas para cada perfil de usuário dos sistemas de automação. Desse modo, é inevitável que os sistemas apresentem todas as 
funcionalidades para cada perfil de usuário. Aqui, 38,24\% dos respondentes afirmam que as tarefas previstas para o seu perfil de usuário podem ser realizadas com facilidade.

$\mathrm{Na}$ variável automatização de tarefas (decorrente de duas perguntas: o sistema deveria realizar mais tarefas de forma automática e de forma adequada?) dado o avanço tecnológico dos sistemas informatizados, é razoável que tais sistemas auxiliem as inúmeras atividades dos usuários, dando suporte de modo automático dentro do princípio da máxima automação ou máximo apoio à decisão. Algumas tarefas já são realizadas de forma automatizadas e auxiliam de maneira muito importante na redução de tempo na tramitação dos feitos. Dentre várias atividades que demandam bastante tempo no processo, temos a citação por AR. Essa atividade já se realiza de forma automatizada e reduz o tempo morto no processo. $\mathrm{O}$ “iter" antigo que ocorre na tramitação dos processos físicos, demora aproximadamente de 30 a 60 dias somente as fases em que os correios devem realizar. Considerando que somente os correios têm demorado de 30 a 60 dias para retornar AR, se o cartório estiver mais ou menos em dia, antes de ir para o correio pode demorar até 10 meses. Quanto ao retorno dos AR`s, estes têm demorado até 6 meses (mas a CGJ já encontrou varas com 20.000 AR acumulados para juntar). O "normal" seria a primeira etapa demorar uns 90 dias e a segunda etapa demorar uns 20 a 40 dias no formato antigo. Na Comarca de Chapecó, às citações por AR digital têm variado entre 30 e 60 dias, desde a sua emissão até a sua devolução. $\mathrm{O}$ impacto imediato foi a redução das atividades mecânicas dos servidores, permitindo que o tempo anteriormente utilizado possa ser utilizado na realização de outras tarefas. Dentre os respondentes, 79,41 \% entendem que o sistema deve realizar mais tarefas de forma automática, enquanto apenas $8.8 \%$ dos respondentes acreditam em parte que o sistema não deveria realizá-las.

\section{Indicador celeridade}

O avanço da tecnologia e da internet, a chamada revolução tecnológica, conquista novos espaços no mundo e fez com que os Tribunais buscassem a virtualização dos processos, cujo foco principal é reduzir os custos, promovendo celeridade e economia processuais. (ALVARES, 2011). Ocorreu um aprimoramento da prestação jurisdicional através do processo eletrônico e das tecnologias a ele inerentes, ressalvadas as peculiaridades do nosso país em termos de parte da população ser carente e não possuírem acesso à rede de energia, e menos ainda sabem manusear um computador ou possuem acesso à internet; por outro lado, os TICs são o pontapé inicial de uma reestruturação do sistema, buscando aprimorar e solucionar uma grande parte dos problemas jurídicos e sociais, bem como já se voltar para o futuro no qual todos possam ter acesso e dispor dos mesmos meios, buscando alternativas para melhorar não 
só o acesso à internet mas também ao governo dessa parcela da população considerada juridicamente pobre. Dessa forma, o Poder Judiciário, pensando em soluções para reduzir o volume de processos em trâmite e obter uma prestação jurisdicional menos defasada da atual, vem colocando em prática alguns projetos (ALVARES, 2011), como, por exemplo, a inovação normativa que diminua o trâmite do processo, incentivando acordos extrajudiciais, implementação de tecnologia para aprimorar seu funcionamento. $\mathrm{O}$ indicador celeridade foi descrito pelas variáveis velocidade de tramitação dos processos e eficiência.

Durante o estudo sobre a variável velocidade de tramitação dos processos, também se verificou o efetivo ganho de produtividade, redução de tempo morto, a redução dos períodos em que os processos ficam aguardando alguma providência, parados, sem andamentos, e a melhoria na qualidade do serviço prestado pelo Poder Judiciário. A avaliação em questão é considerada chave para verificação do sucesso do SAJ na visão dos usuários. Não significa dizer que as demais questões não sejam importantes, contudo, de nada adiantaria se o sistema fosse implementado e isso não ocasionasse uma maior celeridade processual e facilitação do trabalho. De todas as respostas obtidas dos usuários internos, essa foi a avaliação positiva com maior relevância. A grande maioria dos usuários considera que o sistema agilizou a tramitação processual. Os respondentes foram maioria: 64,71\% concordaram em reconhecer o efetivo ganho de desempenho na prestação jurisdicional com o uso do sistema de automação.

Ao se estudar a variável eficiência, de todos os respondentes a esta pergunta, $61,76 \%$ entendem que houve ganho de qualidade na prestação jurisdicional através da celeridade processual. O que é importante que seja tratado é que a celeridade no processamento das informações eletrônicas continuará dependendo da atuação humana, razão pela qual não adiantaria instalar um Processo Eletrônico com vistas à rapidez na prestação jurisdicional, sem profissionais capacitados para dar-lhe vazão. É razoável que o principal impacto é a celeridade processual, entretanto, para que exista esse ganho, há a necessidade de que o profissional do direito esteja alinhado com o uso da tecnologia. Isso significa maiores despesas com equipamentos e mesmo com qualificação. Por sua vez, pode significar uma grande barreira para aqueles profissionais ainda não familiarizados com os meios tecnológicos. É possível que o grande problema de nosso Poder Judiciário ainda seja a quase nenhuma habilitação de profissionais do direito na ciência da Informática. Todo profissional do direito, mesmo com todas as mudanças de procedimentos de realização de atos processuais impostas pelo caminho da tecnologia, deve ter em mente que o direito é acima de tudo contato humano e que informática é uma ferramenta de auxílio ao homem e não a solução para todos os problemas. 
Tal afirmação é reforçada pelas estatísticas nacionais que nos comprovam que somente computadores não suprem a inexistência de juízes, pois ainda não dispomos de um computador que sentencie. O CNJ (Justiça em números) aponta que, em 2013, para cada 100 mil habitantes nos estados de Amazonas, Alagoas, Bahia, Ceará, Piauí e Maranhão existe uma proporção menor que 4,4 magistrados. Nos Tribunais do Paraná, Goiás, Espírito Santo, Mato Grosso do Sul e Amapá, há mais de 10 magistrados para cada 100 mil habitantes.

\section{Discussão dos dados da dimensão comunicação}

A comunicação aqui avaliada deve ser considerada tanto no âmbito interno como externo ao Poder Judiciário. A elaboração de princípios para a comunicação das atividades, com fito de evitar as comunicações meramente publicitárias ou de cunho pessoal, denotam a elaboração de uma política que fere a tradicional cultura jurídica da exaltação e promoção pessoal. Nesse sentido, destacam-se os textos da Resolução no 79, no que concerne aos princípios da comunicação das atividades, conforme contexto realizado anteriormente. Para organizar essa temática esta dimensão organiza um único indicador, tramitação, que se abre em algumas variáveis.

\section{Indicador tramitação}

A implantação do processo eletrônico nas comarcas do Poder Judiciário brasileiro foi deflagrada há pouco mais de uma década; no entanto os avanços tecnológicos permitiram que somente agora o sistema pudesse ser inteiramente eletrônico. A eficiência na tramitação dos processos foi garantida também com a virtualização deles. A lei no 11.419/96, que dispõe sobre a informatização do processo judicial, permite o uso do meio eletrônico na tramitação dos processos judiciais, na comunicação de atos e na transmissão de peças processuais. A preocupação e reflexão sobre a importância da comunicação não só interna, mas com a sociedade (Resolução CNJ no 85/ 2009) demonstram os passos para uma maior transparência. As mudanças foram/são aceitas por todos os órgãos que passaram a usar o SAJ. O indicador tramitação foi descrito pelas vaiáveis banda e integração com outros órgãos.

Sobre a variável banda, tem-se que a velocidade da Internet é essencial para o funcionamento adequado dos sistemas de processo eletrônico. Apenas 1 respondente concorda que a velocidade de banda da internet é adequada para o funcionamento do sistema, enquanto 18 respondentes, isto é, 53\% entendem que a banda é inadequada para o funcionamento do sistema. Melhoramentos ocorreram, pois hoje o foro da Comarca de Chapecó conta com um 
link próprio para o funcionamento de seus serviços. Foi necessário quadruplicar a velocidade de internet e separar a banda para o funcionamento do SAJ das demais bandas para os demais sites.

Durante o estudo da variável integração com outros órgãos externos, verificou-se que a implantação do SAJ pode contribuir para a integração dos sistemas do Poder Judiciário com os sistemas informatizados de outros órgãos públicos, em níveis superiores aos existentes, atendendo ao objetivo de aumentar a eficiência e a eficácia na prestação de serviços jurisdicionais. O sistema já está integrado com a Secretaria da Receita Federal do Brasil - o que facilita o cadastramento das partes e evita a multiplicação de homônimos. Ao mesmo tempo, é essencial promover a integração com os órgãos do Judiciário estadual e federal, mais especificamente com o Conselho Nacional de Justiça - CNJ, bem como com os demais órgãos do setor público e privado. Inicialmente, após a implantação do SAJ, houve uma certa dificuldade com as Polícias Civil e Militar, pois não havia integração entre elas e as varas criminais para o envio de termos circunstanciados, inquéritos policiais, entre outros documentos, algo que hoje já está superado. Enfim, dos respondentes ao questionário, 58,82 \% concordam que as mudanças advindas com a implantação do SAJ podem contribuir para a integração dos sistemas do Poder Judiciário com os sistemas informatizados de outros órgãos públicos, em níveis superiores aos existentes, atendendo ao objetivo de aumentar a eficiência e a eficácia na prestação de serviços jurisdicionais.

\section{Discussão dos dados da dimensão infraestrutura}

Ao se tratar de reestruturação do Poder Judiciário, a infraestrutura é elemento balizado por resoluções do $\mathrm{CNJ}$, em que se estabelece um conjunto de elementos mínimos para que os instrumentos de processo judicial eletrônico possam ser organizados. Na opinião de Abrão (2009), para ter sucesso, o processo eletrônico necessita, fundamentalmente, de investimentos, e isso significa estar revestido de infraestrutura que responda à altura ao número das demandas. Assim, para que o processo eletrônico obtenha êxito, é indispensável que as unidades judiciais possam contar com conexões de banda larga, computadores com capacidade adequada, Data Centers estruturados corretamente, com capacidade de processamento e armazenamento adequados, além de pessoal técnico capacitado e em constante aperfeiçoamento. Neste estudo, esta dimensão gerou apenas um indicador, equipamentos. 


\section{Indicador equipamentos}

Ainda, consta entre os objetivos estratégicos do $\mathrm{CNJ}$, no que tange à Infraestrutura e Tecnologia, garantir a infraestrutura apropriada às atividades administrativas e judiciais; prover os recursos materiais e tecnológicos (instalações, mobiliários, equipamentos de informática) que permitam o bom desempenho das unidades do Judiciário, garantindo aos magistrados e servidores condições de trabalho com saúde e segurança, além da proteção e manutenção dos bens materiais e dos sistemas. A lei 11.419/06 determina ainda que os órgãos do Poder Judiciário mantenham equipamentos de digitalização e acesso à rede mundial de computadores à disposição dos interessados para distribuição de peças processuais. Essa infraestrutura é destinada aos advogados que não dispõem de acesso à internet ou de equipamentos para digitalização e que poderão elaborar suas peças processuais em casa ou escritório e fazer uso dos equipamentos no fórum/tribunal para acessar o sistema e realizar o andamento dos feitos em que atuam. Nessa direção vai a resolução 185/CNJ obrigando os órgãos do Poder Judiciário a manterem equipamentos à disposição das partes, advogados e interessados para consulta ao conteúdo dos autos digitais, digitalização e envio de peças processuais e documentos em meio eletrônico, devendo ainda providenciar auxílio técnico presencial às pessoas com deficiência e que comprovem idade igual ou superior a 60 (sessenta) anos. $\mathrm{O}$ indicador equipamentos foi explicado pela variável melhora dos equipamentos.

A variável melhora dos equipamentos expressa de forma completa este indicador. Do estudo de caso se verifica que a implantação do SAJ obrigou o Tribunal de Justiça a fazer substituição ou aquisição de novos equipamentos para o melhor funcionamento do sistema. Para a melhor adaptação à nova realidade tecnológica, os computadores, na Comarca de Chapecó, foram todos substituídos por equipamentos mais modernos e adicionado uma segunda tela de monitor, para facilitar o trabalho e aumentar o campo de visualização do processo eletrônico, além da aquisição de scanners para a digitalização dos processos, o que foi demonstrado no percentual de respondentes que concordaram com a melhora de equipamentos, representados por $94,12 \%$ dos respondentes.

\section{Discussão dos dados da dimensão segurança}

Questões atinentes à segurança da informação digital ainda são um desafio da atualidade, tendo em vista o risco de fraudes e manipulação de dados. Por essa razão merecem ser estudadas, principalmente quando se trata de informação processual. Segundo Silva (2012), 
no que consiste à segurança jurídica o processo informatizado traz consigo o sistema de certificação digital que, por meio da criptografia e assinatura digital, oferecerá segurança às informações contidas em banco de dados presente nos tribunais. A segurança dos atos processuais é importante desafio a ser enfrentado na prática judicial eletrônica, o que passa pelo desenvolvimento de recursos de informática, como a certificação digital e a assinatura eletrônica. Esses recursos já vinham sendo satisfatoriamente utilizados com o peticionamento eletrônico, cuja prática antecedeu o próprio processo eletrônico nos Tribunais brasileiros. Segundo Dondoerfer (2012), o processo eletrônico deve observar o princípio da obrigatoriedade do direito, o qual compõe a segurança jurídica e, portanto, o processo para ser útil à sociedade deve proporcionar segurança jurídica, desenvolver-se amparado de mecanismos de segurança que garantam a sua integridade, assim exalando confiabilidade. Neste estudo de caso, esta dimensão gerou apenas um indicador, certificação.

\section{Indicador certificação}

A Resolução Conjunta $n^{\circ}$ 04/2008, emitida em conjunto pelo Gabinete da Presidência e a Corregedoria Geral de Justiça, dispõe sobre o recebimento de petição eletrônica com certificação digital no âmbito do Poder Judiciário de Santa Catarina. Essa norma estabelece as regras e procedimentos relativos à utilização do Peticionamento Eletrônico disponível no Portal de Serviços do Sistema de Automação do Judiciário (Portal e-SAJ), criado para a prática de atos processuais que dependam de petição escrita para o Poder Judiciário do Estado de Santa Catarina. O indicador certificação foi descrito pelas variáveis autenticação e usuários.

Sobre a variável autenticação, tem-se nos meios virtuais, a autenticação como forma inequívoca de identificar uma pessoa, ser verificável por um terceiro, ser de fácil utilização, oferecer grande nível de dificuldade para a falsificação e permitir a associação da identidade à informação por ele gerada (SILVA, 2012). A autenticação busca essencialmente garantir que uma comunicação seja autêntica. Para o caso de uma mensagem, o objetivo da autenticação é garantir que a mensagem teve verdadeiramente origem na fonte informada. Entre os meios utilizados para a autenticação, temos o uso de $\log$ in/senha e a identificação biométrica. $\mathrm{O}$ primeiro consiste na utilização de um apelido, combinado com uma senha e não oferece segurança suficiente para as ações do processo eletrônico, pois os dados podem ser interceptados e reconhecidos com uso de softwares maliciosos, engenharia social. Observando as respostas entregues no questionário, verificamos que $94,12 \%$ dos respondentes manifestam concordância com o uso adequado de certificação, visando à segurança do sistema. No entanto, é sabido que a nossa legislação não obriga a todos os usuários a terem certificação digital para 
acessar os sistemas automatizados e obterem informações que lhes digam respeito. Basta apenas que tenham um cadastro de usuário e se identifiquem dentre as modalidades de usuários externos dispensados de certificação. No entanto, para que seja possível praticar algum ato processual através dos meios eletrônicos, a legislação obriga o usuário a ingressar no sistema via certificação digital emitida pelos órgãos oficiais de certificação.

Sobre a variável usuários, pode-se considerar que todos consideram ter condições de obter certificação para acessar o sistema. A forma pela qual se impôs a obrigatoriedade do armazenamento dos dados digitais e a vulnerabilidade de sistemas de proteção aos arquivos criou insegurança aos usuários do sistema eletrônico. A segurança a respeito do acesso ao sistema é fundamental, se ela não é gritante aos olhos dos servidores, talvez possa haver maior esclarecimento sobre a confiabilidade do sistema perante os servidores. Se os servidores não demonstrarem confiança absoluta na integridade do sistema, dificilmente a ideia passada aos usuários externos será boa nesse quesito. Cumpre ressaltar, tendo em vista as respostas dos usuários, é que dos respondentes, 27 desconhecem as restrições de acesso ao sistema de automação, pois a qualquer usuário é permitido o acesso ao sistema de automação, independentemente de certificação digital. Basta ao usuário preencher um cadastro no portal do TJSC para que possa ter acesso ter acesso às suas informações.

\section{Relação entre os elementos de gestão e de legalidade}

Feita a exposição e aplicação de todas as dimensões, indicadores e variáveis utilizadas na pesquisa de campo, faz-se enfim uma síntese buscando as inter-relações entre elas, apontando para os elementos de gestão e legalidade. Para isso, optou-se por desenvolver um quadro trazendo apenas as variáveis (Tabela 14). A comparação aqui desenvolvida auxiliará na visão geral do quadro conceitual e na identificação dos elementos presentes em cada variável, o que em última análise, é o que traz os conteúdos específicos e práticos tratados na pesquisa.

Assim, observa-se que a mudança de gestão do Poder Judiciário decorre muito da sua própria crise, notadamente pela morosidade na sua atuação. O processo eletrônico é uma das mais importantes e recentes iniciativas no sentido de mudar esse rumo. Fica claro que esse elemento de melhoria da gestão ocorra dentro da legalidade e assegure efetivo cumprimento das normas processuais e de gestão do Judiciário em geral. O quadro proposto, em última análise, consegue identificar elementos que definem critérios gerais de gestão e legalidade. Como parece óbvio na discussão, para cada movimento de gestão há uma ação de legalidade, de suma importância para a implantação dos sistemas de automação. 
A tabela a seguir traz mais detalhes da compreensão sobre a mudança ocorrida no caso proposto.

Tabela 1 - Elementos de legalidade e de gestão relativos às variáveis utilizadas.

\begin{tabular}{|c|c|c|}
\hline Variáveis & Elementos de Gestão & Elementos de Legalidade \\
\hline $\begin{array}{l}\text { Execução das } \\
\text { tarefas }\end{array}$ & $\begin{array}{l}\text { Conhecimento sobre a realização de } \\
\text { suas tarefas }\end{array}$ & $\begin{array}{l}\text { Cumprimento da legislação } \\
\text { processual; conhecimento dos } \\
\text { procedimentos no processo } \\
\text { judicial }\end{array}$ \\
\hline $\begin{array}{l}\text { Habilidades } \\
\text { prévias dos } \\
\text { usuários }\end{array}$ & $\begin{array}{l}\text { Exigência de habilidades específicas } \\
\text { para o cumprimento de rotinas; } \\
\text { identificação de habilidades prévias. }\end{array}$ & $\begin{array}{l}\text { Autorização exigida pela lei para } \\
\text { o acesso ao sistema de } \\
\text { automação }\end{array}$ \\
\hline $\begin{array}{l}\text { Realidade e } \\
\text { estrutura do foro }\end{array}$ & $\begin{array}{l}\text { Fatores contextuais que possam } \\
\text { afetar probabilidade de ocorrer } \\
\text { aprendizagem }\end{array}$ & \\
\hline $\begin{array}{l}\text { Interesse do } \\
\text { técnico }\end{array}$ & Mudança nas rotinas de trabalho & $\begin{array}{l}\text { Aprimoramento da atividade } \\
\text { jurisdicional }\end{array}$ \\
\hline $\begin{array}{l}\text { Estímulo para } \\
\text { qualificação }\end{array}$ & $\begin{array}{l}\text { Treinamento para uma visão geral } \\
\text { do SAJ; capacidade do } \\
\text { desenvolvimento de competências } \\
\text { técnicas e multiplicadores }\end{array}$ & $\begin{array}{l}\text { Conhecimento sobre a nova } \\
\text { ferramenta e suas } \\
\text { funcionalidades para cada perfil } \\
\text { de usuário, para procedimentos } \\
\text { cíveis ou criminais }\end{array}$ \\
\hline $\begin{array}{l}\text { Formação jurídica } \\
\text { dos técnicos }\end{array}$ & $\begin{array}{l}\text { Política interna do TJSC visando a } \\
\text { qualificação dos usuários. }\end{array}$ & $\begin{array}{l}\text { Exigência em razão da } \\
\text { necessidade de conhecer a } \\
\text { técnica jurídica }\end{array}$ \\
\hline Aposentadoria & $\begin{array}{l}\text { Estímulo a aposentadoria com o } \\
\text { implemento do novo sistema }\end{array}$ & \\
\hline $\begin{array}{l}\text { Capacidade para } \\
\text { mudar }\end{array}$ & $\begin{array}{l}\text { Formação tradicional que } \\
\text { dificultaria a adaptação à nova } \\
\text { tecnologia. Adequação para } \\
\text { manutenção da relação } \\
\text { organizacional }\end{array}$ & \\
\hline $\begin{array}{l}\text { Conhecimento } \\
\text { técnico }\end{array}$ & $\begin{array}{l}\text { Repasse das informações } \\
\text { necessárias para a capacitação dos } \\
\text { usuários }\end{array}$ & $\begin{array}{l}\text { Conhecimento das etapas do } \\
\text { processo de implantação do SAJ }\end{array}$ \\
\hline $\begin{array}{l}\text { Conhecimento da } \\
\text { realidade local }\end{array}$ & $\begin{array}{l}\text { Realização de workshops entre as } \\
\text { equipes. Acompanhamento em } \\
\text { produção. }\end{array}$ & $\begin{array}{l}\text { Conhecimento dos } \\
\text { procedimentos utilizados no } \\
\text { TJSC. Utilização dos } \\
\end{array}$ \\
\hline Atendimento & $\begin{array}{l}\text { Reorganização das estruturas físicas } \\
\text { dos foros. }\end{array}$ & $\begin{array}{l}\text { Modificação da forma de } \\
\text { atendimento. De atendimento } \\
\text { presencial para auto atendimento }\end{array}$ \\
\hline Presença da OAB & $\begin{array}{l}\text { A própria OAB capacitou os } \\
\text { advogados }\end{array}$ & Organização interna corporis \\
\hline
\end{tabular}




\begin{tabular}{|c|c|c|}
\hline Variáveis & Elementos de Gestão & Elementos de Legalidade \\
\hline Versões & $\begin{array}{l}\text { Várias versões do sistema visando } \\
\text { aprimorar o funcionamento do } \\
\text { sistema }\end{array}$ & $\begin{array}{l}\text { Atendimento ao art. } 14 \text { da Lei do } \\
\text { Proc. Jud. eletrônico }\end{array}$ \\
\hline Erros & Presença de erros de funcionamento & Não cumprimento das tarefas \\
\hline Ajustamento & $\begin{array}{l}\text { Fazer com que o sistema se torne de } \\
\text { fácil utilização }\end{array}$ & Realização correta das tarefas \\
\hline $\begin{array}{l}\text { Parcialidade } \\
\text { imparcialidade }\end{array}$ & $\begin{array}{l}\text { Dever de realizar as atividades com } \\
\text { rapidez, perfeição e rendimento }\end{array}$ & $\begin{array}{l}\text { Condições e limites autorizados } \\
\text { por lei }\end{array}$ \\
\hline Confiança & $\begin{array}{l}\text { Confiança na capacidade do sistema } \\
\text { em usar as informações de forma } \\
\text { saudável }\end{array}$ & $\begin{array}{l}\text { Conhecimento sobre as } \\
\text { funcionalidades do sistema }\end{array}$ \\
\hline Personalização & $\begin{array}{l}\text { Acompanhar o desempenho do } \\
\text { funcionário }\end{array}$ & $\begin{array}{l}\text { Rotinas e procedimentos } \\
\text { padronizados por normas } \\
\text { técnicas }\end{array}$ \\
\hline $\begin{array}{l}\text { Automatização de } \\
\text { tarefas }\end{array}$ & $\begin{array}{l}\text { Reorganização das atribuições } \\
\text { funcionais }\end{array}$ & $\begin{array}{l}\text { Tarefas automáticas que } \\
\text { atendam a legalidade }\end{array}$ \\
\hline $\begin{array}{l}\text { Velocidade de } \\
\text { tramitação dos } \\
\text { processos }\end{array}$ & Facilitação do trabalho & Celeridade processual \\
\hline Eficiência & Maior despesa com equipamentos & Celeridade processual \\
\hline Banda & Velocidade insuficiente & $\begin{array}{l}\text { Comunicação interna e com a } \\
\text { sociedade }\end{array}$ \\
\hline $\begin{array}{l}\text { Integração com } \\
\text { outros órgãos } \\
\text { externos }\end{array}$ & $\begin{array}{l}\text { Integração com órgãos federais, } \\
\text { estaduais e municipais }\end{array}$ & $\begin{array}{l}\text { Envio de termos } \\
\text { circunstanciados e inquéritos } \\
\text { policiais para as varas criminais }\end{array}$ \\
\hline $\begin{array}{l}\text { Melhora dos } \\
\text { equipamentos }\end{array}$ & $\begin{array}{l}\text { Substituição e renovação dos } \\
\text { equipamentos dos cartórios das } \\
\text { varas judiciais }\end{array}$ & $\begin{array}{l}\text { Equipamentos de digitalização e } \\
\text { acesso à rede mundial }\end{array}$ \\
\hline Autenticação & $\begin{array}{l}\text { Assegurar a autenticidade da } \\
\text { comunicação }\end{array}$ & $\begin{array}{l}\text { Acesso via identificação ou } \\
\text { certificação digital }\end{array}$ \\
\hline Usuários & $\begin{array}{l}\text { Confiabilidade do sistema perante } \\
\text { os servidores }\end{array}$ & Segurança no acesso ao sistema \\
\hline
\end{tabular}

Fonte: Elaborado pelos autores.

De maneira geral, fica claro que uma rede adequada de comunicação interna e entre os diferentes órgãos públicos é fundamental para melhorar a gestão pública do caso em discussão, o que não seria diferente para outras ações. Do mesmo modo, as peculiaridades do local são reconhecidas como fatores viabilizadores ou não da gestão do processo de mudança. Assim, nota-se que cada variável discutida possui seu peso de importância na construção de uma 
estrutura organizacional que permita o aprimoramento e mesmo a inovação nesse processo. A autonomia que a legalidade permite, para que todos os tribunais criem os seus próprios instrumentos digitais de gestão processual, tem sido fundamental, ao contrário do tradicional centralismo da administração pública nacional. Enfim, do estudo de caso fica claro que há uma relativa confiança dos servidores públicos, tanto do processo em si, como da utilização do sistema de processo eletrônico decorrentes de um adequado conhecimento técnico envolvido, bem como de uma regulamentação adequada para a situação.

Enfim, o estudo de caso permitiu levantar o conhecimento de aspectos que não são normalmente explicitado ou divulgado posteriormente à implantação de sistemas de automação do Judiciário. Isso poderá servir para que os Tribunais saibam quais as atividades no decurso da implantação precisam ser corrigidas e/ou aprimoradas para que surtam melhores efeitos em favor dos usuários internos dos sistemas. Assim, deve ser possível alcançar o máximo de satisfação desses usuários e que a população receba um serviço público cada vez melhor.

Ficaram explícitos e reconhecidos aspectos importantes referentes ao funcionamento dos sistemas de automação, a partir da opinião dos usuários internos no que diz respeito a importantes aspectos internos e externos relativos à gestão e a legalidade dos atos envolvidos.

\section{Conclusão}

Com o desenvolvimento desta pesquisa foi possível conhecer questões referentes ao sistema adotado para a automação judicial como aspectos de sua usabilidade em razão do número de versões adotadas durante a sua implantação, a ocorrência de erros de funcionamento e os necessários ajustes que precisam ser realizados para o aprimoramento de suas funcionalidades. Desse modo, pontos relevantes das funcionalidades do sistema como suas funcionalidades podem ser questionadas, como a confiança dos usuários na utilização do sistema para as atividades da justiça, o que pode gerar consequências importantes pelos resultados de seu funcionamento. Conhecer a capacidade ou não da automatização de tarefas cotidianas dos usuários, bem como se esta automatização leva a uma redução de tempo morto na tramitação dos processos na justiça com o efetivo ganho de qualidade no exercício da prestação jurisdicional pelo Estado é de fundamental importância. Com o interesse de conhecer os efeitos da implantação dos sistemas de automação judiciária pelo Estado de Santa Catarina, em especial na Comarca de Chapecó, este artigo buscou encontrar os elementos mais significativos e de efeitos diretamente ligados aos usuários desses sistemas, em atenção às metas do $\mathrm{CNJ}$, e ainda observando os elementos que visam a zelar pela legalidade de tais atividades. 
É importante ressaltar, neste contexto, que a legislação nacional trata das questões genéricas e que os aspectos particulares ficam a cargo dos Tribunais para criarem os seus regulamentos, pois o CNJ atribuiu autonomia para que todos os tribunais criem os seus próprios instrumentos digitais de gestão processual.

A análise dos dados de implantação do SAJ na Comarca de Chapecó nos mostra que os usuários do SAJ foram capacitados adequadamente para o exercício de suas atividades com o novo instrumento e nos fez entender se o usuário consegue realizar todas as tarefas possíveis para o seu perfil no sistema implantado. Conclui-se, por derradeiro, que a pesquisa trouxe importantes contribuições ao estudar a mudança ocorrida com a reestruturação de uma Comarca no Estado de Santa Catarina, descrevendo e analisando dimensões, indicadores e variáveis presentes neste processo de reestruturação.

\section{Referências bibliográficas}

ADORNO JUNIOR, Hélcio Luiz; SOARES, Marcele Carine dos Praseres. Processo Judicial Eletrônico. Acesso à justiça e inclusão digital: os desafios do uso da tecnologia na prestação jurisdicional. Universitas, [S. 1.], v. 6, p.65-86, jul. 2013. Semestral.

ALVARES, Nathalia Oliveira. A informatização do processo judicial e o acesso à justiça. 2011. 63 f. Monografia (Especialização) - Curso de Direito, Centro Universitário de Brasília, Brasília, 2011. Disponível em: <http://repositorio.uniceub.br/bitstream/123456789/506/3/ 20661449.pdf>. Acesso em: 20 out. 2014.

BARBOZA, Elza F.; NUNES, Eny M.; SENA, Nathália K. Websites governamentais, uma esplanada à parte. Brasília: Ciência da Informação, v. 29, n. 1, p. 118-25, jan./abr. 2000.

CALDAS, Claudete Magda Calderan; LOUZADA, Marcelle Cardoso. Os reflexos do processo judicial eletrônico nas condições de trabalho dos atores processuais. Anais do $\mathbf{2}^{\mathbf{o}}$ Congresso Internacional de Direito e Contemporaneidade: mídias e direitos da sociedade em rede, Universidade Federal de Santa Maria-RS, 2013. Disponível em: $<$ http://coral.ufsm.br/congressodireito/anais/2013/1-8.pdf $>$. Acesso em: 9 de maio 2015. 
justiça: processo eletrônico. 2011. 98 f. TCC (Graduação) - Curso de Direito, Universidade Federal de Santa Catarina, Florianópolis, 2011.

DONDOERFER, Crystian Josué. Princípio da segurança jurídica conjugado com o processo eletrônico. 14/2/2012. Disponível em: <http://www.egov.ufsc.br/portal/conteudo/oprinc $\% \mathrm{C} 3 \% \mathrm{AD}$ pio-da-seguran $\% \mathrm{C} 3 \% \mathrm{~A} 7$-jur\%C3\%ADdica-conjugado-com-o-processoeletr\%C3\%B4nico>. Acesso em: 4 jul. 2014.

ELLIS, David; ALLEN, David; WILSON, Tom. Information Science and Information Systems: conjunct subjects disjunct disciplines. Journal of the American Society for Information Science, v.50, n.12, p.1095-107, 1999.

FISCHMANN, Adalberto Américo; ALMEIDA, Martinho Isnard Ribeiro de. Planejamento estratégico na prática. 2.ed. São Paulo: Atlas, 2009.

GASPARINI, Diógenes. Direito administrativo. 11.ed. rev. e atual. São Paulo: Saraiva, 2006.

JANNUZZI, Paulo M. Indicadores para diagnóstico, monitoramento e avaliação de programas sociais no Brasil. Revista do Serviço Público, Brasília, v. 56, n. 2, p. 137-160, abr/jun. 2005.

SANTA CATARINA. Tribunal de Justiça de. André Alexandre Happke. Gabinete da Presidência do Tribunal de Justiça de Santa Catarina. Parecer. 2013. Disponível em: $<$ http://portal.tjsc.jus.br/c/document_library/get_file?uuid=9b0506e7-2ad1-458b-bbaabc9a0abcb08e\&groupId=101755>. Acesso em: 10 abr. 2016a.

.Processo eletrônico: implantação. 2015. Disponível em:

$<$ http://www.tjsc.jus.br/web/processo-eletronico/>. Acesso em: 21 abr. 2016 b.

Processo eletrônico: Implantação. 2015. Disponível em:

$<$ http://www.tjsc.jus.br/web/processo-eletronico/primeiro-grau/cronograma/>. Acesso em: 21 abr. 2016c.

SILVA, Marcelo Mesquita. Processo judicial eletrônico nacional: uma visão prática sobre o 
processo judicial eletrônico e seu fundamento tecnológico e legal (a certificação digital e a Lei 11.419/2006). Campinas, Millennium. 2012. s. p. 


\section{DESENVOLVIMENTO ECONÔMICO SUSTENTÁVEL, GLOBALIZAÇÃO E TRANSFORMAÇÕES NA ORDEM SOCIAL E ECONÔMICA}

\section{APRESENTAÇÃO}

Durante o período de 06 a 08 de setembro de 2018, foi realizado o VIII ENCONTRO INTERNACIONAL DO CONPEDI - Conselho Nacional de Pesquisa e Pós-Graduação em Direito com sede no Brasil, realizado na cidade de Zaragoza - Espanha em parceria com a Faculdade de Direito da Universidade de Zaragoza, com a participação de docentes e discentes dos Programas de Pós-Graduação em Direito dos dois países.

Os artigos apresentados no Grupo de Trabalho - 12 - Desenvolvimento Econômico Sustentável, Globalização e Transformações na Ordem Social e Econômica, e ora publicados, propiciaram importante debate em torno de questões teóricas e práticas, considerando as peculiaridades que envolvem a temática central sobre Direito, argumentação e comunicação: Desafios para o século XXI.

Neste Livro encontram-se publicados 11 (onze) artigos, rigorosamente selecionados por meio de avaliação por pares, objetivando a melhor qualidade e a imparcialidade na divulgação do conhecimento da área jurídica e áreas afins. Premiando a interdisciplinaridade, os artigos abordam assuntos que transitam pelo Direito do Trabalho, Direito Ambiental, Direito Tributário, Direito Constitucional, Direito Administrativo destacadamente, e, também outras áreas do conhecimento como economia e globalização e as respectivas implicações no processo do desenvolvimento global e sustentabilidade.

De forma abrangente a presente Coletânea examina os seguintes temas:

\section{A CONEXÃO INERENTE ENTRE OS DIREITOS HUMANOS E A AGENDA 2030 NO CONTEXTO DOS ESPAÇOS TRANSNACIONAIS FRENTE OS NEGÓCIOS INTERNACIONAIS}

Marcos Leite Garcia e Rafael Burlani Neves

Os autores demonstram a conexão entre os Direitos Humanos, os negócios internacionais, considerando os espaços transnacionais e a Agenda 2030 da ONU. Apresentam o entendimento 
de que os negócios internacionais realizados nos espaços transnacionais devem ser realizados nos limites da garantida dos Direitos Humanos. Analisam o conceito e as características dos objetivos do Desenvolvimento Sustentável, enquanto agenda de ação, para que os negócios internacionais possam estar legitimados no contexto dos Direitos Humanos bem como os fundamentos para o fenômeno de uma governança democrática e sustentável.

2. A PERDA DA INFLUÊNCIA ESTATAL NAS RELAÇÕES DE CONSUMO E A INVOLUÇÃO DA PROTEÇÃO ADMINISTRATIVA DAÍ DECORRENTE.

Dennis Verbicaro Soares e Gabriela Ohana Rocha Freire

Analisam a perda da influência estatal nas relações de consumo e seu impacto na involução da proteção administrativa do consumidor. Frente à crise de confiança no Poder Público, todavia, apresenta a real possibilidade de fortalecimento dos laços sociais e políticos entre consumidores.

3. A RESISTÊNCIA À REFORMA TRABALHISTA BRASILEIRA DE 2017: DESOBEDIENNCIA CIVIL DE MAGISTRADOS OU CONTROLE DE CONSTITUCIONALIDADE DIFUSO?

Cristiane Heredia Sousa e Adalberto Simão Filho

A Lei 13.467/17 (reforma trabalhista), introduziu substancial alteração da legislação laboral. Mesmo antes de sua entrada em vigor em 11/11/2017, houve grande repercussão no meio jurídico e de entidades sociais através de movimentos que defendiam a inconstitucionalidade de muitas das alterações legislativas por representarem retrocesso social, e outros que defendiam representar avanço nas relações de emprego. $O$ artigo analisa a posição de magistrados que resistem à essas alterações, na investigação de poder ser esta postura uma conduta de desobediência civil ou ato jurisdicional.

\section{ANÁLISE DE IMPACTO REGULATÓRIO (AIR) E SUAS ETAPAS}

Gabriel Fliege de Lucena Stuckert

Quais etapas ou elementos seriam necessários e capazes de imprimir um diferencial analítico para esta ferramenta? É o que pretende responder o autor, passando pelo conceito do Impacto Regulatório, explorando as principais etapas que por ela devem ser utilizadas. 
5. APLICATIVOS DE ECONOMIA COLABORATIVA: O CASO DO UBER E AIRBNB NO BRASIL

Handerson Gleber e Arnaldo Sobrinho de Morais Neto

A economia de compartilhamento é formada por um sistema socioeconômico construído em torno do compartilhamento de recursos humanos, físicos e intelectuais, através de novos instrumentos tecnológicos. Por meio dos novos modelos de compartilhamentos, o acesso aos bens e aos serviços tradicionais, passa a ser compartilhado ao invés de adquiridos, o que vem gerando em alguns países conflitos entre usuários e os prestadores de serviço tradicionais. A proposta analisa a situação atual no Brasil sobre os aplicativos Uber e o Airbnb.

6. FUNDAMENTO EXISTENCIAL E CONTRATUAL DA PROTEÇÃO CONTRA O SUPERENDIVIDAMENTO NA SOCIEDADE DA INFORMAÇÃO

Maíra Matsue Shimizu de Sousa e Roberto Senise Lisboa

Estabelece a noção introdutória ao estudo do superendividamento e traça breves comparações entre o modelo francês e o brasileiro, prestando-se a tratar do fundamento existencial e contratual da proteção do consumidor contra o superendividamento na sociedade da informação.

7. HERMETISMO NO PROCESSO DE RECALL DE MEDICAMENTOS NO BRASIL: AFRONTA AO DIREITO À INFORMAÇÃO E CONSEQUENTE AMEAÇA À SAÚDE E SEGURANÇA DO CONSUMIDOR

Juliana Barbalho Brasileiro e Carolina Valença Ferraz

Estes escritos buscam desvelar e compreender o processo de recall de medicamentos no Brasil e verificar até que ponto este instituto vêm efetivamente cumprindo o seu papel em proteger a saúde e segurança dos consumidores. Analisou-se o Código do Consumidor, a Portaria $\mathrm{n}^{\circ}$ 487/2012 do Ministério da Justiça e a RDC n 55/2012 da ANVISA bem como dados abertos de recalls de medicamentos extraídos da ANVISA e da SENACON e de procedimentos instaurados na $1^{\text {a }}$ Promotoria do Consumidor de João Pessoa, buscando fundamentar a discussão empiricamente.

\section{O DIREITO AO DESENVOLVIMENTO SUSTENTÁVEL DA ZONA COSTEIRA} Lair da Silva Loureiro Filho 
$\mathrm{Na}$ zona costeira brasileira encontra-se grande parte da atividade econômica, significativas referências da identidade nacional, bem como áreas de interesse turístico, de recreação e de lazer, atividades que proporcionaram uma segunda fase na sua ocupação, agora às voltas com as descobertas de expressivas jazidas de petróleo e gás, que por certo darão nova moldura à região. Referido artigo analisa que, mesmo a inserção no art. 225 da CF/888, como área de patrimônio nacional, até o momento, o Estado Brasileiro não promoveu o desenvolvimento sustentável da região costeira e de atender à demanda por serviços públicos básicos.

\section{O FENÔMENO DA ECONOMIA DE COMPARTILHAMENTO: NOVOS PARADIGMAS} SOCIAIS, ECONÔMICOS E TECNOLÓGICOS

Kerolinne Barboza da Silva e Fernando Antônio de Vasconcelos

O fenômeno da economia de compartilhamento ou economia colaborativa pode ser entendido como um sistema socioeconômico construído em torno do compartilhamento de recursos, tornando acessível aos bens e serviços sem a necessidade de sua aquisição. Os autores apresentam que tal sistema crescente e inovador, diante da era informacional e da tecnologia, faz-se necessário o estudo conceitual sobre esse fato, em razão de seus impactos socioeconômicos, tendo em vista suas interferências nas relações pessoais.

\section{O PAPEL DA EMPRESA NO DESENVOLVIMENTO SUSTENTÁVEL: DA FUNÇÃO} SOCIAL DA EMPRESA AOS VALORES SOCIAIS PARA O MERCADO E A SOCIEDADE Hertha Urquiza Baracho e Emília Paranhos Santos Marcelino

Analisa a relação entre o papel da empresa e o desenvolvimento sustentável. A necessidade de estudo deste trabalho surgiu com o estabelecimento da função social das empresas e o advento de uma nova ordem econômica mais voltada para as questões sociais. Diante da importância do segmento empresarial, analisamos a função social e os valores da empresa para o desenvolvimento sustentável.

\section{O PAPEL REGULATÓRIO DA TRIBUTAÇÃO EXTRAFISCAL AMBIENTAL E SEU IMPACTO PARA A FUNÇÃO SOCIAL DA EMPRESA}

Regina Célia de Carvalho Martins e Maria de Fatima Ribeiro 
A Constituição brasileira no artigo 170 estabelece determinantes norteadoras do desenvolvimento econômico onde a empresa deve atender a diversos critérios. Entre eles a livre iniciativa, respeitando a soberania nacional e promovendo a redução de desigualdades sociais, às determinações das relações de consumo e a necessidade de preservar o meio ambiente. Assim, as regulações estatais através de normas tributárias extrafiscais podem ser utilizadas como instrumentos estimuladores do desenvolvimento sustentável e também como agentes desestimuladores de condutas degradantes ambientais. Tais normas propiciam que a empresa cumpra sua função social nas premissas da sustentabilidade ambiental que deve respeitar.

\section{TRIBUTAÇÃO E DESIGUALDADES REGIONAIS: NECESSIDADE DE INTERLOCUÇÃO ENTRE ECONOMIA E DIREITO PARA A CONCRETIZAÇÃO DO DESENVOLVIMENTO SUSTENTÁVEL}

Maria Marconiete Fernandes Pereira e Flavia de Paiva Medeiros de Oliveira

O artigo analisa as normas tributárias indutoras como instrumentos hábeis a fomentar a redução das desigualdades regionais e, por conseguinte, concretizar o princípio do desenvolvimento sustentável, a partir de um diálogo entre economia e direito, o que, à guisa de conclusão, viabiliza a sustentabilidade pelo prisma social.

O CONPEDI, com as publicações dos Anais dos Encontros e dos Congressos, mantendo sua proposta editorial, apresenta semestralmente os volumes temáticos, com o objetivo de disseminar, de forma sistematizada, os artigos científicos que resultam dos eventos que organiza, mantendo a qualidade das publicações e reforçando o intercâmbio de ideias, com vistas ao desenvolvimento e ao desenvolvimento econômico, considerando também a realidade econômica e financeira internacional que estamos vivenciando, com possibilidades abertas para discussões.

Agradecemos aos autores pelas exposições, debates e publicações de suas produções.

Coordenadores do GT:

Profa. Dra. MARIA DE FATIMA RIBEIRO - Universidade de Marilia - UNIMAR

Prof. Dr. MARCOS LEITE GARCIA - Universidade do Vale do Itajaí - UNIVALI 


\title{
A CONEXÃO INERENTE ENTRE OS DIREITOS HUMANOS E A AGENDA 2030 NO CONTEXTO DOS ESPAÇOS TRANSNACIONAIS FRENTE OS NEGÓCIOS INTERNACIONAIS
}

\author{
Rafael Burlani \\ Universidade do Vale do Itajaí - UNIVALi \\ Marcos Leite Garcia \\ Universidade do Vale do Itajai - UNIVALI
}

\begin{abstract}
Resumo
O presente artigo procura demonstrar a conexão existente entre os Direitos Humanos, os negócios internacionais, considerando os espaços transnacionais e a Agenda 2030 da ONU. Determina que o link inicia com o entendimento de que os negócios internacionais realizados nos espaços transnacionais devem ser realizados nos limites da garantida dos Direitos Humanos. Analisa o conceito e as características dos Objetivos dos Desenvolvimento Sustentável, enquanto agenda de ação, para que os negócios internacionais possam estar legitimados no contexto dos Direitos Humanos, ou seja, desenvolvidos de forma sustentável. Por fim, apresenta fundamentos para o fenômeno de uma governança democrática e sustentável.
\end{abstract}

Palavras-chave: Direitos Humanos, Negócios Internacionais, Transnacionalização, Desenvolvimento Sustentável.

\section{Abstract/Resumen/Résumé}

This article seeks to demonstrate the connection between human rights and international affairs, considering transnational spaces and the UN Agenda 2030. It determines that the link begins with the understanding that international business carried out in transnational areas must be carried out within the limits of the guarantee of Human Rights. It also analyzes the concept and characteristics of the Sustainable Development Goals, as an agenda for action, so that international business can be legitimized in the context of Human Rights, that is, developed in a sustainable way. Finally, it presents some fundamentals for the governance phenomenon for sustainability. 
Keywords/Palabras-claves/Mots-clés: Human Rights, International Business, Transnationalization, Sustainable Development.

\section{Introdução}

O presente artigo tem como objetivo principal explicitar uma necessária conexão na operação dos negócios internacionais com os Direitos Humanos. É feita a reflexão sobre a Agenda 2030 - ODS ${ }^{1}$, no contexto de um espaço transnacional. Espaço este que gradativamente está se tornando cada vez mais imprescindível para tratar de temas fundamentais de direitos difusos e transfronteiriços como o direito à segurança na produção e consumo de bens através de uma economia globalizada, direito à paz, direito a um meio ambiente saudável, entre outros.

É pressuposto para a edificação destes espaços, em que demandas de interesses globais são tratadas, a necessária qualidade da sustentabilidade, desde que sejam contextualizados na plena garantia dos Direitos Humanos.

Por suposto, há uma mudança peremptória no cenário global, tendo em vista a aceleração crescente das transformações tecnologias, jurídicas, de negócios e políticas, sobretudo, no que impacta os Direitos Humanos, isto porque, com o advento da velocidade das comunicações e da mobilidade global, a comunidade comum reclama medidas concretas para a garantia destes direitos, de modo a viabilizar a sustentabilidade do desenvolvimento humano, social e ambiental.

Neste contexto em que o novo se instala e traz um cenário de instabilidade e, porque não, de caos, no plano internacional, há que se determinar pressupostos de convergência entre todos o atores no plano político, jurídico e de negócios - para que os abusos sejam evitados, no caso deste estudo, no cenário particular da globalização dos negócios. A hipótese é a de que a sustentabilidade dos negócios internacionais, no espaço transnacional, vincula-se com a plena conexão com a garantia dos Direitos Humanos, em que, a hipótese de construção deste espaço negocial sem a garantia dos Direitos Humanos - ou seja, fora de uma sociedade plenamente democrática e sustentável - deslegitima o processo dos negócios internacionais.

O filósofo alemão Jürgen Habermas no livro Era das Transformações prevê a construção de novos espaços a partir da perspectiva de ampliação da esfera da influência da

1Os Objetivos do Desenvolvimento Sustentável - ODS estão configurados como uma agenda mundial adotada durante a Cúpula das Nações Unidas sobre o Desenvolvimento Sustentável no intuito de ações para a erradicação da pobreza, segurança alimentar, saúde, educação, igualdade de gênero, economia, cultura, meio ambiente, entre outros. 
experiência das sociedades democráticas para além das fronteiras nacionais. No entender de Habermas tal processo de democratização pode ser reproduzido no que chama de constelação pós-nacional (Die postnationale Konstellation) pelos caminhos de uma política interna voltada para o mundo em geral, ou seja, aberta a uma ordem jurídica cosmopolita (HABERMAS, 2003, p. 37), capaz de funcionar sem a estrutura de um governo mundial (HABERMAS, 2001, p. 175).

É sabido que a evolução dos Direitos Humanos constitui um momento de discussão e reflexão da dignidade da vida humana em todos os cenários de conexões, seja nacional, como internacional.

A história recente da economia mundial indica cautela em afirmar como serão as instituições e as relações entre os diferentes blocos de nações que irão compor a Comunidade Internacional. Mesmo assim é inevitável e evidente a necessidade de abordar questões relacionadas ao fenômeno da transnacionalidade, dito de forma mais radical, sem receio a cometer exageros: faz-se vital para o futuro da raça humana tratar das questões que intitulamos de demandas transnacionais, na abordagem deste artigo, a demanda por negócios visando a produção de bens e serviços.

O fenômeno da transnacionalidade dá-se a partir das chamadas demandas transnacionais que a sua vez estão relacionadas com a questão da efetividade dos chamados direitos difusos e transfronteiriços. Desta maneira, as demandas transnacionais são questões fundamentais para o ser humano e que vêm sendo classificadas pela doutrina como "novos" direitos. Um fato é impossível de se evitar: as questões transnacionais devem ser abordadas e enfrentadas por toda a Comunidade Internacional de forma diferente da prevista nas legislações interna e internacional existente.

A discussão sobre as demandas transnacionais em primeiro lugar gira em torno da questão da guerra e da paz. Esta certamente é a primeira grande questão transnacional e difusa da humanidade. Os Direitos Humanos são um fenômeno do mundo moderno e são concebidos e teorizados primeiramente como Direito Natural Racionalista e será exatamente em um debate sobre o tema de guerra e da paz que Hugo Grotius dará partida ao mesmo. O direito à paz segue sendo, principalmente após o processo de internacionalização dos direitos humanos demanda oriunda, sobretudo do horror da Segunda Guerra Mundial, um tema ainda em debate e agora classificado como um direito difuso (e transfronteriço mesmo em sua modalidade quando trata de conflitos internos) ou como pelo menos uma questão difusa, já que existe uma polêmica quanto a classificar a paz como um direito fundamental. As seguintes serão todas demandas mais recentes como a questão do meio ambiente, do direto dos consumidores, do direito ao desenvolvimento dos povos etc. 
Já os negócios internacionais são projetados como um desdobramento do pensamento econômico, muitas vezes acrítico, em que não são poucos os relatos de práticas pouco dignas, como o fato de que algumas multinacionais estrangeiras terem trazido para o Brasil parques fabris altamennte nocivos ao meio ambiente, a saúde pública e aos seus trabalhadores, assim, então proibidas na Europa e nos EUA nos anos 1970 e suas operações serem causadoras dos mais diversos tipos de danos, tanto sociais, ambientais e culturais, inclusive, considerados irreversíveis, como a morte de trabalhadores (RODRIGUES, 2013).

O método de abordagem utilizado será o Dedutivo ${ }^{2}$, cuja premissa maior é a existência das novas demandas de Direitos Fundamentais, que são as novas reivindicações da sociedade atual, e sua conexão com a Agenda de 2030 no âmbito dos negócios internacionais. As técnicas selecionadas ao cumprimento do método eleito são a Pesquisa Bibliográfica e Documental ${ }^{3}$, a Categoria $^{4}$ e o Conceito Operacional ${ }^{5}$, quando necessários.

Este estudo situa-se no entendimento de que há um vácuo imenso nos espaços transnacionais quanto a necessidade das multinacionais de mercado e financeiras, no contexto dos negócios internacionais, em garantirem de forma efetiva o cumprimento dos Direitos Humanos. ${ }^{6}$ Há a falta de uma agenda propositiva para tal. Este artigo situa a agenda 2030 como o ponto de inflexão para a mudança neste cenário.

\section{Demandas transnacionais e os novos dirietos}

As demandas transnacionais se justificam a partir da necessidade de criação de espaços públicos para tratar de questões referentes a fenômenos novos que serão ineficazes se tratados somente dentro do espaço do tradicional Estado nacional. Estes fenômenos novos se identificam com os chamados "novos" direitos, ou "novos" direitos fundamentais. Para evitar equívocos de fundo meramente ideológico, certamente que se faz necessário afirmar que as demandas transnacionais não tratam somente de questões relacionadas com a globalização econômica como alguns autores pretendem, e sim com fundamentais questões de direitos relacionadas com a sobrevivência do ser humano no planeta. A globalização econômica pode estar na base de

2“[...] base lógica da dinâmica da Pesquisa Científica que consiste em estabelecer uma formulação geral e, em seguida, buscar as partes do fenômeno de modo a sustentar a formulação geral". PASOLD, Cesar Luiz. Metodologia da pesquisa jurídica: teoria e prática. 13. ed. Florianópolis: Conceito Editorial, 2015, p. 213.

3“[...] Técnica de investigação em livros, repertórios jurisprudenciais e coletâneas legais” (PASOLD, 2015, p. 215). 4“[...] palavra ou expressão estratégica à elaboração e/ou à expressão de uma idéia” (PASOLD, 2015, p. 205).

5“[...] definição estabelecida ou proposta para uma palavra ou expressão, com o propósito de que tal definição seja aceita para os efeitos da ideia exposta" (PASOLD, 2015, p. 205).

6Esta afirmação dos autores sem qualquer receio de cair na impropriedade da generalidade, na qual, a exceção, é ínfima. Vide sistema das maquiladoras no México e no Paraguai. 
algumas questões transnacionais, mas não é sua principal fonte e fundamentação, a principal justificativa da necessidade de transnacionalização do direito é a necessidade de proteção do ser humano e dentro dessa perspectiva também se encontra a proteção de seu entorno natural.

Os direitos fundamentais são um fenômeno da Modernidade, pois as condições para o seu florescimento se dão no chamado trânsito à modernidade (PECES-BARBA, 1995, p 146). Assim depois do primeiro processo de positivação que será marcado pelas revoluções burguesas e pela ideologia liberal, através da história dos dois séculos seguintes os direitos fundamentais irão se modificando e incluindo novas demandas da sociedade em transformação. Os direitos fundamentais não são um conceito estático no tempo e sua transformação acompanha a sociedade humana e conseqüentemente suas necessidades de proteção.

Cabe frisar que na Modernidade os Direitos Humanos nascem como direitos fundamentais, ou seja, primeiramente são concebidos como direito interno (PECES-BARBA, 1995, p. 113), como direitos do cidadão, mas ainda que direito nacional-interno com ampla vocação e pretensão universal como direitos do homem genérico, se referindo a todos os seres humanos. O fenômeno da universalidade dos Direitos Humanos é diferente do fenômeno da internacionalização dos mesmos. A universalização é anterior aos mesmos, pois se dá já na construção teórica dos direitos, ainda como Direito Natural Racionalista, e segue seu curso desde as primeiras declarações de direitos ${ }^{7}$. Já a internacionalização dos Direitos Humanos é um processo muito mais recente, pois se dá basicamente como resultado da barbárie da guerra, do desejo do nunca mais da Segunda Guerra Mundial, com o advento da Organização das Nações Unidas (ONU) e com a construção de pelo menos três sistemas internacionais de proteção de Direitos Humanos (ONU, Organização dos Estados Americanos e Conselho da Europa) e tem como marco documental inicial a fundamental Declaração Universal de Direitos Humanos de 1948 Não resta a menor dúvida de que a manutenção da paz e a defesa dos direitos humanos, objetivos plasmados no art. $1^{\circ}$ da Carta de São Francisco de 1945, decisivamente são os principais motivos da criação da ONU. Da mesma forma que essas foram também as principais preocupações tanto da Comunidade Interamericana como Européia. Não resta dúvida que a questão da universalidade do conceito ocidental dos direitos humanos/direitos fundamentais é uma discussão prévia ao tema da transnacionalidade dos mesmos.

A transnacionalização dos direitos fundamentais é um processo diferente e posterior ao da internacionalização dos mesmos. Na teoria geral dos direitos fundamentais do professor

\footnotetext{
7Veja por exemplo as declarações resultantes das revoluções burguesas, uma vez que tanto a Declaração dos Direitos do Homem e do Cidadão de 1789, assim como a Declaração de Independência Americana de 1776, se referem a um cidadão universal.
} 
Gregorio Peces-Barba uma das mais importantes de suas teses consiste nas já mencionadas linhas de evolução dos direitos que são relatadas nos seguintes processos, entre os quais incluímos didaticamente em um outro escrito chamado de processo de formação do ideal dos direitos fundamentais (GARCIA, 2005, p.309). Resumidamente as linhas ou processos evolutivos dos direitos fundamentais em Peces-Barba se dão em quatro processos históricos: 1. processo de positivação: a passagem da discussão filosófica do Direito Natural Racionalista ao Direito positivo realizada a partir das revoluções liberais burguesas (característica principal: positivação da primeira geração dos direitos fundamentais: direitos de liberdade); 2. processo de generalização: significa a extensão do reconhecimento e proteção dos direitos de uma classe a todos os membros de uma comunidade como conseqüência da luta pela igualdade real (característica principal: a luta e a conseqüente positivação dos direitos sociais ou de segunda geração e de algumas outras liberdades como a de associação e a de reunião e a ampliação da cidadania com a universalização do sufrágio); 3. processo de internacionalização: louvável tentativa de internacionalizar os Direitos Humanos e criar sistemas de proteção internacional dos mesmo que estejam por cima das fronteiras e abarquem toda a Comunidade Internacional ou regional dependendo do sistema. Infelizmente trata-se de um processo estagnado por vários problemas que caracterizam o Direito Humanos e de difícil realização prática (Principal característica: tentativa de efetivar a universalização dos direitos ao positivar os direitos humanos no plano internacional). 4. processo de especificação: atualíssimo processo pelo qual se considera a pessoa em situação concreta para atribuir-lhe direitos seja: como titular de direitos como criança, idoso, mulher, consumidor, etc., ou como alvo de direitos como o de um meio ambiente saudável ou à paz (principal características: positivar e mudar a mentalidade da sociedade na direção dos chamados direitos de solidariedade, difusos ou de terceira geração).

A internacionalização dos direitos fundamentais em direitos humanos é um fenômeno ainda incompleto e para muitos um falido processo de tentativa de internacionalizar a questão. Sua principal crítica situa-se na falta de um poder coercitivo acima dos Estados e na falta de homogeneidade entre os países e os seus interesses, que leva a uma carência de democracia no contexto da Comunidade Internacional: o que deixa infelizmente prevalecer a situação da tradicional, primitiva e selvagem lei do mais forte que impõe sua vontade. Este processo incompleto situa-se exatamente em um âmbito jurídico que carece de um Poder político que garanta plenamente a eficácia do ordenamento internacional dos diferentes sistemas de proteção dos Direitos Humanos, ainda que as tentativas são válidas e muito interessantes ${ }^{8}$. Difícil positivos, com uma visível autoridade supranacional, tenha sido no marco do sistema de proteção do Conselho de 
conceber o Direito sem força, sem coerção. Mesmo assim, inegável é a existência de um Direito Internacional dos Direitos Humanos, como nos mostra a prática e a jurisprudência interna e internacional e como admite majoritariamente a doutrina. Não se pode negar a existência de normas internacionais de Direitos Humanos, ainda que é facilmente constatado exatamente pelos problemas apontados um absurdo e completo descaso com este ordenamento muito menos considerado e obedecido que os ordenamentos internos.

\section{Os negócios internacionais}

Os negócios internacionais é o processo de finalaidade comercial no qual uma determinada atividade de negócio decide expandir suas atividades para além do Estado nacional em que ela foi concebida. É um movimento que acompanha a globalização, entretanto a evolução do seu tratamento no pensamento científico tem se desenvolvido puramente sob um olhar funcionalista, com forte tendência em desconsiderar questões de poder e a face repugnante das organizações (SPOHR; ALCADIPANI, 2013).

Tanto é firme esta concepção, que estudos mais atualizados propõem que agenda de investigação para o desenvolvimento do conhecimento e consolidação da pesquisa em termos de nogócios internacionais é proposta em algumas etapas, tais como motivos para internacionalização, seleção de mercados de destino e padrões de operação (GOMES, CARNEIRO \& KOGUT, 2017).

Ou seja, os aspectos obscuros, nefastos e custosos para os espaços transnacionais em que há a presença de multinacionais de mercado e de finanças, são negligenciados, como se não fossem temas oportunos a serem tratados. ${ }^{9}$

Ora evidente que os temas de poder, de controle, de exploração, de dominação e de degradação, precisam ganhar contornos de apontamento na medida em que, no contexto dos negócios internacionais, as ações destas multinacionais de mercado e de finanças - que eminentemente realizam negócios internacionais - devem ser tratados, questionados, criticados e dimensionados. É fato que as pesquisas em negócios internacionais tem negligenciado, por exemplo, os fatos obscuros que ocorrem entre multinacionais e governos corruptos (SPOHR; ALCADIPANI, 2013).

Europa, devido a que são sociedades mais homogêneas em sua cultura política e jurídica.

9Se crê que isto ocorra por uma falta de agenda padrão para determinar a conduta social, ambiental, cultural e comercial nestes espaços. 
Disto, têm-se que o estudo sobre os negócios internacionais possuem oportunidade para que haja uma discussão além dos aspecto meramente operacional, mas também com carga para que haja uma análise sobre os impactos das estratégias dos negócios internacionais, considerando a atuação de multinacionais de mercado e de finanças, também sobre a premissa da análise de afetação cultural, social e ambiental das comunidades, tanto regional, como global.

Defende-se que o desenvolvimento de negócios internacionais devem ser legitimados nos firmes contornos dos Direitos Humanos, inclusive, sem receio de apontar, que a "ética" de mercado na atuação das ativdades de negócio internacional é a garantia dos Direitos Humanos. No entanto, sabe-se que, há uma falta de uma política, uma agenda, norteadora. Este estudo coloca a Agenda 2030 como o elemento norteador da atuação empresarial - e também estatal nos negócios internacionais, para que estes estejam legitimados frente aos Direitos Humanos.

\section{A agenda 2030 como modelo de governança aos negócios internacionais considerando os espaços transnacionais}

A discussão sobre sustentabilidade vem assumindo um papel importante no mundo contemporâneo sendo notável que todos os setores atuem na transição para uma sociedade sustentável. A sustentabilidade é uma qualidade inerente a todos os processos sociais. As estruturas desta qualidade para às operações dos negócios internacionais em razão dos aspectos de poder, são os Direitos Humanos.

Neste contexto, o mundo tem desafios específicos para alcançar o desenvolvimento sustentável, para este trabalho, consolidar os negócios internacionais na estrutura dos Direitos Humanos, por isso à importância de pensarmos no todo, que o planeta Terra e seus ecossistemas são a nossa casa comum, e com estratégias globais o mundo poderá alcançar as metas estabelecidas (PROGRAMA DAS NAÇÕES UNIDAS PARA O DESENVOLVIMENTO PNUD, 2017).

A ação para a sustentabilidade, então, impôs a necessidade de medidas. Dentre estas, uma de significativa importância foi a definição de Objetivos para o Desenvolvimento Sustentável. Esta proposta foi concebida como uma agenda, no caso, a agenda 2030 da ONU (Transformando Nosso Mundo: a Agenda 2030 para o Desenvolvimento Sustentável), os chamados Objetivos do Desenvolvimento Sustentável - ODS. Eles estão configurados como uma agenda mundial adotada durante a Cúpula das Nações Unidas sobre o Desenvolvimento Sustentável no intuito de ações na erradicação da pobreza, segurança alimentar, saúde, educação, igualdade de gênero, entre outros. Esta foi legitimada pelos 193 Estados-membros da ONU e 
consiste numa Declaração, no estabelecimento de 17 Objetivos de Desenvolvimento Sustentável, os quais englobam mais 169 metas específicas, uma seção sobre meios de implementação e uma renovada parceria mundial, além de um mecanismo para avaliação e acompanhamento (ORGANIZAÇÕES DAS NAÇÕES UNIDAS / ESCRITÓRIO BRASIL ONUBR, [s.d.]a.)

Ela é fruto da evolução dos ODMS - Objetivos do Milênio, estabelecido pela ONU nos anos 2000. A convergência dos ODMS com a Sustentabilidade já era apontada por Ferrer (2008, p.5), inclusive, no que tange as dificuldades de implementação dos ODMS, veja-se:

\begin{abstract}
La sostenibilidad se encuentra más bien relacionada com los Objetivos del Milenio, que son la guía de acción de la humanidad. El objetivo de lo ambiental es asegurarlas condiciones que hacen posible la vida humana em el planeta. En cambio, los otros dos aspectos de la sostenibilidad, los sociales que tienen que ver com la inclusión, con evitar la marginalidad, com incorporar nuevos modelos del gobernanza, etcétera, y los aspectos económicos, que tienen que ver com el crecimiento y la distribución de la riqueza. Tienen que ver con dignificar la vida. La sostenibilidad nos dice que no basta asegurar la subsistencia, sino que la condición humana exige asegurar unas las condiciones dignas de vida.
\end{abstract}

A implementação dos ODS iniciou em $1^{\circ}$ de janeiro de 2016 e se constitui como um desafio de amplitude mundial, que busca seguir as diretrizes definidas pelos 17 objetivos e suas respectivas metas, cuja principal atuação incide sob a pobreza e a proteção do planeta, adotando para isso medidas sustentáveis apoiadas nas dimensões econômica, social e ambiental, visando sobretudo o bem comum. Trata-se de um compromisso global que inclui não apenas os governos dos Estados-Membros, mas exige uma atuação universal que envolve a participação da sociedade civil, da iniciativa privada, da academia nas mais variadas áreas do conhecimento, da mídia, demais grupos interessados e de todas as pessoas do planeta. Este plano comprometese a não deixar ninguém para trás.

Como estratégia de sistematização dos ODS, foram definidos os 5P's: pessoas, planeta, prosperidade, parcerias e paz. Através dos 5P's, os ODS comprometem-se com as pessoas - a erradicar a pobreza e garantir dignidade e igualdade; o planeta - a proteger os recursos naturais e o clima da Terra; a prosperidade - a garantir vidas prósperas e plenas em harmonia com a natureza; a parcerias - implementar a agenda por meio de parcerias globais e sólidas e a paz promovendo uma sociedade pacífica, justa e inclusiva (MINISTÉRIO DAS RELAÇÕES EXTERIORES DO BRASIL - MRE. ORGANIZAÇÕES DA NAÇÕES UNIDAS - ONU, 2016).

A construção dos ODS sob a organização da ONU representa um momento ímpar na história da humanidade, pois convoca as nações para a construção de um espaço de discussão 
e reflexão sob os problemas que assolam a humanidade e consolidam uma agenda única, onde todos são convidados a participar e todos são responsáveis pelas mudanças na construção de um mundo melhor para se viver, buscando sobretudo sedimentar uma sociedade igualitária e justa. Talvez esta ação seja algo inédito na história.

No entanto, é necessário atentar-se para que os possíveis interesses distintos que possam estar enrustidos nesta agenda não venham a comprometê-la. Os sujeitos envolvidos neste processo podem conduzi-lo de modo a direcionar os ODS de forma a atender os seus interesses individuais e/ou corporativos, buscando sobretudo um proveito econômico, político, intelectual, cultural, entre outros. Frente a esta possibilidade, a agenda 2030 pode reforçar ainda mais os preceitos da desigualdade, da exclusão, da competitividade exacerbada que em nada colaboram para erradicação da pobreza e da fome no planeta e que muito menos contribuem para a libertação do homem.

Neste sentido, o desenvolvimento de diretrizes institucionais - de direito e orgânicas, no que se refere aos ODS, refletiria na governança para o exercício de um gerenciamento, que tende a garantir a gestão dos sujeitos a uma autoridade que age sobre estas ações, sendo esta relação de poder um processo dinâmico ao longo do tempo.

A proeminência dos ODS, como uma agenda a ser implantada até 2030 tem se apresentado com desafios para a gestão contemporânea. Todos os setores são penetrados por variáveis ambientais ou socioambientais, cujas implicações não podem ser sonegadas sem implicarem em custos para as futuras gerações. Dentre estes desafios a harmonização da relação comercial internacional à garantir a efetividade dos direitos humanos, logo, elementos jurídicos e de governança precisam ser investigados e propostos.

Quanto aos modelos de governança, o desafio consiste em estabelecer instituições para avançar no novo paradigma de sustentabilidade através de formas de associação entre diferentes partes intervenientes e sistemas em nível local, nacional e global. Enquanto as estruturas específicas forem objeto de adaptação e debate, cabe esperar a proliferação de novas formas de participação que complementem e desafiem o sistema governamental tradicional. No novo paradigma, o Estado encontra-se imerso na sociedade civil e a nação inserta na sociedade planetária (CEPAL, 2006, p. 128).

Ainda sobre a governança, haverá uma adequação de paradigmas às finalidades das instituições em âmbito global. A soberania dará espaço para a gestão política cooperada, coordenada e convencionada, haja vista os desafios em sustentabilidade que escapam a ação dos Estados Nacionais, sejam eles, ricos ou pobres. Logo a implementação dos negócios internacionais não pode se omitir este vies mundial. 
Também, no que tange aos primados para um governança global que impactaria nos negócios internacionais, de acordo Giménez-Candela (2011, p.32) há um entendimento de que é necessário uma adaptação do sistema legal frente aos desafios globais, havendo a necessidade de um quadro comum de conceitos, no contexto de uma nova linguagem jurídica, buscando um consenso na base de uma nova unidade intelectual. Assim, ela cita:

to understand the necessary adaptation of our legal systems to the challenges of globalisation, legal history could help us by contributing a common framework of concepts, a common juridical language, a consensus in te basis of a new intellectual unity .

A sustentabilidade trabalha seu objeto temático de modo transversal às demais políticas sociais, pressupondo novas dimensões para a formulação de programas, planos e projetos de desenvolvimento local e regional. Dentro desta perspectiva - e considerando as especificidades socioambientais dos negócios internacionais - a efetividade das políticas sociais para a garantida dos Direitos Humanos pressupõe geração de emprego e renda (combate à exclusão social), justa distribuição das condições de apropriação dos espaços urbanos e rurais (inclusão territorial) em conjunto com a eficiência da infraestrutura de produção (combate ao desperdício de recursos naturais e humanos), e com a proteção da integridade dos ecossistemas, além da qualidade de vida das populações, especialmente das mais vulneráveis. A sustentabilidade compreende não somente na relação entre econômico e ambiental, mas do equilíbrio humano frente às demais problemáticas (FERRER, 2012, p. 319).

Nesta concepção está implícita a adequação de postura dos negócios internacionais, na qual variáveis culturais, jurídicas, políticas, econômicas e físico-espaciais devem ser respeitadas e garantidas.

Para tanto, os negócios internacionais terão que se alinhar a premissa da colaboração e da solidariedade transnacionais visando a sustentabilidade global na premissa da garantia dos Direitos Humanos. Isto porque, a intensificação do fenômeno da globalização apresenta desafios importantes aos Estados e exige uma readequação qualitativa e estratégica do Direito, pois este apresenta-se como instrumento de controle social estatal. Emanado de um ente soberanamente isolado no planeta, já não produz mais respostas eficazes para assegurar um futuro com sustentabilidade progressiva para toda a comunidade de vida e em escala global. Necessita-se da construção e consolidação de uma nova concepção de sustentabilidade transnacional, como paradigma de aproximação entre os povos e culturas, e na participação do cidadão de forma consciente e reflexiva na gestão política, econômica e social (CRUZ; 
FERRER, 2015).

Nesta senda, a governança para os Direitos Humanos nos espaços transnacionais, seja condicionada pelas pressões da sociedade global ou seja tocada pelas pressões do capitalismo global, ganham com os ODS uma agenda para constituírem e formularem políticas em qualquer escopo, sejam macroestruturais, ambientais ou sociais.

A nova era global implica em mudanças em que a Terra como um sistema irá impor o seu domínio geológico, considerando uma escala do presente para com as gerações futuras. Ainda, os tempos que se avizinham consolidam uma população mundial de 9 bilhões de habitantes (até 2050), comportando uma "sociedade mundial" com vulnerabilidades igualitárias numa sociedade que necessitará criar riqueza em um contexto de vida tecnológico e de inovação (MESSNER, 2011, p. 244).

\section{Conclusão}

Os negócios internacionais são daqueles fenômenos com forte tendência de progressão - ou seja, mais negócios - entretanto, é fato que, para que eles sejam sustentáveis haverá a necessidade de um arranjo crítico para eles. O seu desenvolvimento, considerando um espaço transnacional, deve ocorre na garantia dos Direitos Humanos. Esta dependência dos negócios internacionais para com a a garantia dos Direitos Humanos alcança na agenda 2030 uma plataforma estratégica para que possa então ser realizada. É pressuposto que os negócios internacionais devem ser desenvolvidos em um espaço transnacional para que a Comunidade Internacional possa tratar de questões tão urgentes para o ser humano como a paz entre as nações, a defesa do consumidor global, o comércio internacional, o meio ambiente para a atual e as futuras gerações, o crime organizado internacionalmente e outras novíssimas questões relacionadas com novas tecnologias como a biotecnologia evolução da medicina e o ciberespaço mundial.

Os Direitos Humanos também são reivindicações necessárias para os negócios internacionais, quando vemos que questões como a paz, o meio ambiente, o consumo, a proteção da criança e do adolescente, do idoso etc., são mais débeis que os interesses econômicos das grandes corporações e dos Estados centrais. Quando estão em jogo interesses econômicos dos mais poderosos sabemos que prevalecem quase sempre a vontade dos de sempre. Como o vulnerável súdito do estado absoluto, como o desprotegido trabalhador no estado liberal de direito do século XIX, o cidadão atual tem a necessidade de ver suas demandas fortalecidas, sendo a Agenda 2030 uma plataforma estratégica para tais demandas. 
No mais, a evidente crise da democracia, da falta de efetividade do fenômeno jurídico no âmbito global e da falta de vigor do Estado nacional para tratar de temos comuns a todos o seres humanos, leva a que devam ser pensadas novas possibilidades para regular e renovar as questões de cidadania. A União Européia certamente é o exemplo de transnacionalização que superou a questão puramente econômica e com respeito à decisão das maiorias e de uma sublime invocação, consideração e respeito aos direitos fundamentais mudou o rumo de futuras alianças transnacionais.

\section{Referências bibliográficas}

ALMEIDA BASTOS GOMES, Renata Maria de; CARNEIRO, Jorge; KOGUT, Clarice Secches. Estudos de caso na internacionalização varejista: uma revisão de literatura. Internext, Brasil, v. 12, n. 1, p. 16-32, abr. 2017. ISSN 1980-4865. Disponível em: $<$ http://internext.espm.br/index.php/internext/article/view/337/296>. Acesso em: 25 mar. 2018. doi:http://dx.doi.org/10.18568/1980-4865.12116-32.

BARRANCO, Maria del Carmen, El discurso de los derechos: Del problema terminológico al debate conceptual. Madrid: Dykinson, 1992.

BRASIL. Ministério das Relações Exteriores do Brasil. Organização das Nações Unidas (ONU) (Comp.).Transformando Nosso Mundo: A Agenda 2030 para o Desenvolvimento Sustentável. Brasília: CGDES, 2016. 42 p. Tradução: Centro de Informação das Nações Unidas para o Brasil (UNIC Rio). Disponível em: <http://www.br.undp.org/content/dam/ brazil/docs/agenda2030/undp-br-Agenda2030-completo-pt-br-2016.pdf $>$. Acesso em: 18 dez 2017.

CRUZ, Paulo Márcio; REAL FERRER, Gabriel. Direito, Sustentabilidade e a Premissa Tecnológica como Ampliação de seus Fundamentos. Seqüência: Estudos Jurídicos e Políticos, Florianópolis, v. 36, n. 71, p. 239, dez. 2015. ISSN 2177-7055. Disponível em: $<$ https://periodicos.ufsc.br/index.php/sequencia/article/view/2177-7055.2015v36n71p239>. Acesso em: 26 dez. 2017. doi:http://dx.doi.org/10.5007/2177-7055.2015v36n71p239

COMPARATO, Fábio Konder. A afirmação histórica dos Direitos Humanos. 5.ed. São Paulo: Saraiva, 2007. 
GARCIA, Marcos Leite. A contribuição de Christian Thomasius ao processo de formação do ideal dos direitos fundamentais. In: MARTEL, Letícia de Campos Velho (Org.). Estudos Contemporâneos de Direitos Fundamentais. Rio de Janeiro: Lumen Juris, 2009. p. 3-26.

GARCIA, Marcos Leite. O processo de formação do ideal dos direitos fundamentais: alguns aspectos destacados da gênese do conceito. In: XIV Congresso Nacional do Conpedi, 2005, Fortaleza, CE. Anais. Disponível em:

http://www.org/manaus/arquivos/Anais/Marcos\%20Leite\%20Garcia.pdf $>$. Acesso em: 27 mar. 2018.

GLOBAL SCENARIO GROUP; NU. CEPAL; Stockholm Environment Institute. La gran transición: La promesa y la atracción del futuro. Santiago de Chile: Cepal, 2006.

GIMÉNEZ-CANDELA, Teresa. Global Legal Theory: Drawing the Line. In: MOZETIC, Vinícus Almada; RESINA, Judith Solé (Orgs.). Reflexões e dimensões do direito: uma cooperação internacional entre Brasil e Espanha. Curitiba: Multideia, 2011.

GONZÁLEZ AMUCHASTEGUI, Jesús. Autonomía, dignidad y ciudadanía: Una teoría de los derechos humanos. Valencia: Tirant lo Blanch, 2004.

HABERMAS, Jürgen. A constelação nacional: Ensaios políticos. Tradução de Marcio Seligmann Silva. São Paulo: Littera Mundi, 2001. Título original: Die postnationale Konstellation: Politischen Essays.

HABERMAS, Jürgen. Era das transformações. Rio de Janeiro: Tempo Brasileiro, 2003. Título original: Zeit der Übergänge.

HERRERA FLORES, Joaquín. Los derechos humanos como productos culturales: crítica al humanismo abstracto. Madrid: Catarata, 2005.

MESSNER, Dirk (2011): Three waves of global change - The dynamics of global governance in the first half of the 21st century, in: Thomas Fues/LIU Youfa (eds.), Global governance and building a harmonious world: a comparison of European and 
Chinese concepts for international affairs (Bonn: Deutsches Institut für Entwicklungspolitik / German Development Institute, Studies 62) p. 9-38.

ONUBR. Cúpula das Nações Unidas sobre o Desenvolvimento Sustentável. Nova agenda de desenvolvimento sustentável: não deixando ninguém para trás. [S.1.], [s.d.]a. Disponível em: <https://nacoesunidas.org/pos2015/cupula/>. Acesso em: 05 dez. 2017

PALOP, María Eugenia. El derecho a la paz: un cambio de paradigma. In: CAMPOY CERVERA, Ignacio; REY PÉREZ; José Luis; (Orgs.). Desafíos actuales de los derechos humanos: reflexiones sobre el derecho a la paz. Madrid: Dykinson, 2006.

PASOLD, Cesar Luiz. Metodologia da pesquisa jurídica: teoria e prática. 13. ed. Florianópolis: Conceito Editorial, 2015.

PECES-BARBA, Gregorio. Curso de Derechos Fundamentales: teoría general. Madrid: Universidad Carlos III de Madrid, 1995.

PEREZ LUÑO, Antonio-Enrique. Derechos Humanos, Estado de Derecho y Constitución. 9. ed. Madrid: Tecnos, 2005.

PÉREZ LUÑO. Antonio Enrique. La Universalidad de los Derechos Humanos y el Estado Constitucional. Bogotá: Universidad Externado de Colombia. 2002.

PROGRAMA DAS NAÇÕES UNIDAS PARA O DESENVOLVIMENTO - PNUD (Brasil). Organização das Nações Unidas - ONU (Ed.).Os Objetivos do Desenvolvimento

Sustentável. 2017. Disponível em: $<$ http://www.br.undp.org/content/brazil/pt/home/post2015.html>. Acesso em: 23 dez. 2017.

REAL FERRER, Gabriel Real. Calidad de vida, medio ambiente, sostenibilidad y ciudadanía. Construímos juntos el futuro? Revista NEJ - Eletrônica, Vol. 17 - n. 3 - / set-dez 2012 . Disponível em: www.univali.br/periodicos. Acesso em 20 de novembro de 2017.

FERRER, Gabriel Real. El derecho ambiental y el derecho de la sostenibilidad. In: 
PNUMA. Programa regional de capacitacion em derecho y políticas

ambientales. 2008. Disponível em: <http://www.pnuma.org/deramb/documentos>.

Acesso em: 20 dezembro de 2017.

RODRIGUES, C. Inimigos públicos: crimes corporativos e necrocorporações. Tese

(Doutorado em Administração) - Escola de Administração de Empresas, Fundação Getulio Vargas, 2013.

RUIZ MIGUEL, Alfonso. Tenemos derecho a la paz? Anuario de Derechos Humanos, n. 3, 1985 , p. 397-434.

SARLET, Ingo Wolfgang. A eficácia dos direitos fundamentais. Porto Alegre: Livraria do Advogado, 2001.

SEN, Amartya. Desenvolvimento como Liberdade. São Paulo: Companhia das Letras. 2000.

SPOHR, Nicole; ALCADIPANI, Rafael. Estudos críticos em negócios internacionais: uma proposta de diálogo. Internext, Brasil, v. 8, n. 3, p. 1-19, nov. 2013. ISSN 1980-4865.

Disponível em: <http://internext.espm.br/index.php/internext/article/view/201>. Acesso em: 25 mar. 2018. doi:http://dx.doi.org/10.18568/1980-4865.831-19.

WALLERSTEIN. Immanuel. O universalismo Europeu: a retórica do poder. São Paulo: Boitempo, 2007. 


\title{
A PERDA DA INFLUÊNCIA ESTATAL NAS RELAÇÕES DE CONSUMO E A INVOLUÇÃO DA PROTEÇÃO ADMINISTRATIVA DAÍ DECORRENTE
}

\author{
Dennis Verbicaro \\ UFPA e CESUPA e Procuradoria do Estado do Pará \\ Gabriela Ohana Rocha Freire \\ Universidade Federal do Pará -UFPA. Bolsista CAPES - Código de Financiamento 001
}

\begin{abstract}
Resumo
O artigo propõe-se a analisar a perda da influência estatal nas relações de consumo e seu impacto na involução da proteção administrativa do consumidor. Frente à crise de confiança no Poder Público, todavia, surge também a real possibilidade de fortalecimento dos laços sociais e políticos entre consumidores. Utilizou-se o método dedutivo de investigação, a partir de pesquisa bibliográfica nacional e estrangeira.
\end{abstract}

Palavras-Chave: Tutela Administrativa da relação de consumo, Perda da influência estatal, Espaços de atuação política do consumidor, Crise de confiança, Direito do Consumidor.

\begin{abstract}
Resumen/Résumé
The article proposes to analyze the loss of state influence in consumer relations and its impact on the involution of the administrative protection of the consumer. Faced with the crisis of confidence in the Public Power, however, there is also the real possibility of strengthening social and political ties between consumers. We used the deductive method of investigation, based on national and foreign bibliographic research.
\end{abstract}

Keywords/Palabras-claves/Mots-clés: Administrative control of the consumption relationship, Loss of state influence, Spaces of consumer political action, Crisis of confidence, Consumer Law. 


\section{Introdução}

A globalização e a mudança de paradigmas no Direito do Consumidor exigiram do Estado um nível de dirigismo administrativo incompatível com seu atual perfil liberal e abstencionista, pois a evolução tecnológica do comércio eletrônico, a propagação do assédio de consumo e de meios comerciais coercitivos, bem como o esvaziamento de suas competências regulatórias no âmbito dos serviços públicos exigem uma reflexão mais profunda acerca da tutela administrativa do consumidor e do papel desempenhado pelo Estado nesse contexto.

Outrora, devotava-se ao Estado a função de redentor dos problemas sociais e fiel depositário das muitas expectativas criadas em torno de um sofisticado microssistema normativo de proteção do consumidor, concebido a partir da Constituição Federal de 1988 e sistematizado pela Lei 8.078/90 (Código de Defesa do Consumidor). Esse aparente protagonismo estatal decorria de sua Potestade Pública e da necessidade efetivar as desigualdades jurídicas de tratamento em favor do consumidor diante dos abusos praticados pelos agentes econômicos de mercado, criando condições para um debate político qualificado entre os sujeitos da relação de consumo.

O empoderamento cívico do consumidor seria a melhor a resposta à crise do "Estado Providência", do "Estado Paternalista", ou mesmo do "Estado Mediador", impondo uma reflexão mais profunda acerca do discutível "bem-estar" que aquelas diferentes acepções de Estado se propuseram a garantir, bem como da necessidade premente de modulação das expectativas de consumo indefinidamente crescentes a partir de bases mais racionais, sendo o despertar para um sentimento de participação e de responsabilidade individual e coletiva, um importante ponto de partida nesse contexto.

À luz deste contexto, a presente pesquisa destina-se a problematizar em que medida a menor influência estatal tem contribuído para a involução da proteção administrativa do consumidor e consequente perda da eficácia de seus direitos. Por outro lado, a crise de confiança no Estado estimula o fortalecimento da empatia e dos laços sociais entre os consumidores que, atuando sob a perspectiva de grupo, e com um maior nível de consciência acerca de seus direitos, podem construir soluções autônomas para os conflitos de consumo, aprimorando a ideia de que as ações políticas coletivas são a melhor forma de se exercitar uma força contra majoritária em relação aos abusos dos agentes econômicos do mercado.

$\mathrm{O}$ artigo, através de estudo teórico e pesquisa bibliográfica nacional e estrangeira, seguindo o método dedutivo, se propõe a compreender os espaços políticos de atuação do Estado e da sociedade civil e de que modo seria possível resgatar a influência do Poder Público 
nesse contexto, sem comprometer o desenvolvimento de novas habilidades cívicas do consumidor, a partir do exercício permanente, independente e qualificado de sua vontade política.

\section{As relações de consumo na perspectiva educacional da Política Nacional de Consumo}

Martins (2015, p. 102) aponta três projeções reflexivas ao envolvimento político e ideológico na permanente construção do direito do consumidor, quais sejam " a participação da sociedade civil na realizabilidade da legislação pertinente", a "expansão do número de pessoas consumidoras pela adoção de políticas públicas e a necessidade de promovê-las neste estágio" e o "enfrentar posições institucionais-normativas do Estado no cumprimento de deveres constitucionais".

Eis que nesse cenário a Política Nacional das Relações de Consumo, prevista no art. $4^{\circ}$ do CDC, surge a partir de uma obrigação internacional para ratificar a preocupação com o princípio da harmonia da relação de consumo, uma vez que se refere justamente à compatibilidade da proteção do consumidor com o desenvolvimento econômico e tecnológico que, em última análise, limitará a livre iniciativa.

Ademais, insurge-se, também, a educação como princípio-diretriz, que pode ser analisado sob a ótica de dois aspectos, quais sejam o formal e o informal.

A educação formal visa garantir ao consumidor o conhecimento de seus direitos e deveres na ordem jurídica de consumo, através de uma melhor difusão da sua tutela material e processual. Ora, à título de ilustração, é possível estimular a inserção do direito do consumidor nas escolas de ensino médio, não como uma disciplina autônoma, mas através de lições básicas sobre consumo consciente e responsável, além de noções preliminares sobre os principais institutos da disciplina. Contudo, há outra educação que é informal, decorrente do grau de comprometimento ético do fornecedor e do próprio consumidor, ou seja decorre do cumprimento.

Já no que pertine ao consumidor, a educação decorre do sentimento de confiança e pertença ao grupo, acreditando ser ele um instrumento de transformações concretas no mercado de consumo. Quanto maior o seu envolvimento no debate político, mais consciente de seu poder transformador ele ficará, permitindo sua maior interação social com os outros agentes, favorecendo seu bem estar político.

Em outras palavras, a participação maior do consumidor no debate político, reafirmando o ideal de cidadania, seria fruto de seu maior nível de educação para um consumo 
consciente e responsável, o que provocaria o constante aprimoramento do sistema consumerista. A participação direta seria fonte de aprendizado político.

\section{O Sistema Nacional de Proteção Consumerista e a tutela administrativa do consumidor: um modelo gerencial eficiente?}

$\mathrm{O}$ art. $5^{\circ}$ do CDC nos remete aos órgãos integrantes do Sistema Nacional de Defesa do Consumidor - SNDC, quando acena para as entidades que prestarão assistência gratuita ao consumidor. Assim, se refere ao papel desempenhado por instituições como o PROCONS, Entidades civis de defesa do consumidor, Ministérios Públicos e Defensorias Públicas, que no âmbito de suas atuações agem de forma integrada a Secretaria Nacional do Consumidor SENACON.

Tal Sistema objetiva a defesa e proteção do consumidor frente as adversidades do mercado, quando este não desempenha suas atividades dentro do permitido legalmente, desta forma, compete ao SNDC o recebimento de denúncias, a apuração sobre as irregularidades, fiscalizações regulatórias e elaboração de políticas públicas que prezem pelo fidedigno cumprimento do CDC.

Em se tratando de PROCON e, particularizando no Estado do Pará, este é uma entidade governamental que integra a estrutura da Secretaria Executiva de Justiça, ficando responsável pela fiscalização e aplicação das sanções administrativas previstas no art. 56 CDC.

As sanções administrativas podem se referir ao aspecto objetivo, seja na apreensão do produto, impedimento quanto à continuidade daquele serviço, etc. ou de natureza subjetiva, seja na cassação do alvará de funcionamento da empresa, intervenção administrativa, dentre outras. Há um universo muito grande de sanções, dando ao PROCON o status de polícia fiscalizatória da relação de consumo, assim, pode-se afirmar que é um órgão executivo da Política Nacional da Relação de Consumo que presta esse tipo de atendimento e tenta, na medida do possível, mediar e conciliar os conflitos de interesses, antes de encaminhá-los à via judicial.

Sob esse aspecto, remetendo à doutrina administrativista, Di Pietro explana:

O princípio da legalidade não impede que o Poder Executivo, no exercício de sua parcela do poder de polícia, regulamente as leis por meio de atos normativos. Além disso, a Administração Pública, ainda dentro da atividade de polícia, controla a sua aplicação, seja preventivamente (por meio de ordens, notificações, licenças ou autorizações) seja repressivamente (mediante imposição de medidas coercitivas) (DI PIETRO, 2009, p. 27). 
Além do PROCON, podemos citar o INMETRO ${ }^{1}$ que tem por finalidade a aferição do grau de pertinência técnica de determinado produto com as normas específicas, onde é muito comum a utilização das normas da Associação Brasileira de Normas Técnicas - ABNT, assim, a atuação desse instituto está na verificação do produto ou da execução do serviço para que este atenda à expectativas do consumidor, sem submetê-lo a uma situação de risco ou de insegurança, determinando se está ou não dentro dos padrões de segurança mínimos, bem como daqueles padrões de adequação, prestabilidade e servibilidade.

O Departamento Intersindical de Estatísticas e Estudos Socioeconômicos - DIEESE, por sua vez, tem um papel muito importante no que diz respeito ao controle estatístico dos índices que são utilizados para se apurar o aumento de preços, das tarifas públicas, viabilizando, também, a partir de suas pesquisas, um arsenal técnico para instruir as respectivas demandas judiciais.

Há, também, as associações representativas, que haja vista a impossibilidade material estatal de implementação isolada da Política Nacional de Consumo, será uma espécie de divisor da responsabilidade fiscalizatória em prol dos direitos do consumidor de forma coletiva, bem como auxiliam de forma como ponte para a participação cidadã na economia de mercado.

Muito embora as associações cívicas sejam um marco, a sociedade civil não conseguiu incorporar o aspecto de cidadania participativa de modo efetivo, atualmente raras são as associações instituídas e com poder de convencimento e influência na relação jurídica consumerista, assim a considerar a deficiência de efetividade de muitas normas, o consumidor não consegue visualizar outra figura senão o Estado de modo isolado (Executivo, Legislativo e Judiciário) tentando atender às necessidades coletivas.

O Ministério Público, embora não integre o executivo, pode ser considerado um órgão do SNDC, tendo em vista que assume, muitas vezes, o controle judicial das condutas irregulares, através das suas Promotorias de Defesa do Consumidor, contribuindo, ao lado dos demais legitimados extraordinários previstos no artigo 82 do CDC, para a efetivação de novos deveres para o fornecedor, através da cominação de obrigações de fazer, não fazer, assim como através da sua responsabilização no âmbito coletivo da tutela, sem prejuízo de campanhas de divulgação e orientação para um consumo responsável.

\footnotetext{
${ }^{1} \mathrm{O}$ Instituto Nacional de Metrologia, Normalização e Qualidade Industrial-Inmetro- é uma autarquia federal, vinculada ao Ministério do Desenvolvimento, Indústria e Comércio Exterior, que atua como secretaria Executiva do Conselho Nacional de Metrologia, Normalização e Qualidade Industrial (Conmetro), colegiado interministerial, que é órgão normativo do Sistema Nacional de Metrologia, Normalização e Qualidade Industrial (Sinmetro).
} 
No âmbito federal, a tutela administrativa estratégica do consumidor, em razão de sua gradual evolução e reconhecimento políticos, teve a coordenação das respectivas políticas públicas a cargo da Secretaria Nacional de Direito Econômico e, sucessivamente, pelo Departamento Nacional de Proteção e Defesa do Consumidor-DPDC e, mais tarde, por força do Decreto $\mathrm{n}^{\mathrm{o}} 7.963$, de 15/03/2013, foi aprovado o Plano Nacional de Consumo e Cidadania, que instituiu a Secretaria Nacional do Consumidor, órgão executivo e integrante do Ministério da Justiça.

Para Miragem (2013, p. 281), a partir do Plano Nacional de Consumo e Cidadania, foi possível corrigir o direcionamento das políticas públicas na defesa do consumidor, em especial o problema relacionado à atuação desconcertada e, muitas vezes, atomizada de um ou outro órgão nas três instâncias federativas, sob a premissa equivocada de que a competência específica de uns era excludente da autuação dos demais.

O Plano Nacional de Consumo e Cidadania, sob a execução da Secretaria Nacional do Consumidor, atua na prevenção e redução de conflitos, regulação, fiscalização e fortalecimento do Sistema Nacional de Defesa do Consumidor, conforme definido pelo artigo $4^{\mathrm{o}}$ do Decreto $\mathrm{n}^{\mathrm{o}} 7.963$, de 15/03/2013.

No atinente à prevenção e redução de conflitos, o artigo $5^{\circ}$ do decreto estabelece as seguintes ações: a) aprimoramento dos procedimentos de atendimento ao consumidor no pósvenda de produtos e serviços; b) criação de indicadores e índices de qualidade das relações de consumo e; c) promoção da educação para o consumo, incluída a qualificação e capacitação profissional na defesa do consumidor.

Vê-se, portanto, que o diagnóstico da realidade social implícito no decreto foi preciso, ao fortalecer o controle preventivo de conflitos de consumo, através da difusão da informação qualificada ao consumidor acerca da qualidade e segurança dos bens de consumo como um trunfo determinante para a redução desse natural antagonismo entre a livre iniciativa e a proteção do destinatário final, permitindo ao consumidor, com base nos indicadores estatísticos e padrões de qualidade, prévia e amplamente difundidos no mercado, exercer sua liberdade de escolha de maneira fundamentada.

Neste particular, explica-se:

De fato, em um mercado de consumo massificado e em constante transformação, e especialmente em vista da realidade brasileira de inclusão de consumidores mediante elevação do nível de renda de grandes contingentes da população, a concentração da atuação administrativa no exercício do poder de polícia para a fiscalização e repressão de infrações a direitos dos consumidores revela-se insuficiente. A prevenção e redução de conflitos vêm se afirmando, aliás, como uma das grandes linhas de compreensão do direito contemporâneo. O custo e o tempo dos conflitos revelam-se 
como fatores que comprometem a satisfação dos interessados com a decisão jurídica que deles resulta, tanto no âmbito administrativo, quanto judicial (MIRAGEM, 2013, p. 283).

Prossegue o autor questionando o modelo de atuação repressiva do Estado como insuficiente:

\begin{abstract}
Por outro lado, a exclusividade ou preponderância do modelo de atuação a posteriori do Estado, no domínio das relações de consumo, revela-se ineficiente. Permite aos infratores a padronização da conduta infratora e a internalização de seus custos de acordo com o tempo que separa a obtenção de vantagens indevidas e o de que, em situações proporcionalmente muito reduzidas frente ao contingente de lesões cometidas, são obrigados a restituir, indenizar ou ainda, submetem-se a sanções administrativas decorrentes do ilícito (MIRAGEM, 2013, p. 283).
\end{abstract}

Isso revela as virtudes da prevenção, redução e dos meios alternativos à solução de conflitos, pois embora estes últimos não sejam tratados diretamente no decreto, acabam sendo incentivados por força na nova filosofia de atuação pacificadora do Estado no âmbito das relações de consumo, através de sua intermediação entre os agentes do mercado, através, por exemplo, de estímulos aos canais de atendimento das próprias empresas, das agências reguladoras e, principalmente, do resgate da importância da convenção coletiva de consumo.

Quanto ao eixo regulatório e fiscalizatório estatal, hoje considerados graves pontos de estrangulamento do SNDC, é proposta uma permanente avaliação no mercado quanto ao impacto regulatório sob a perspectiva dos direitos do consumidor, bem como a criação e o aperfeiçoamento dos mecanismos já existentes de garantia dos seus direitos e, também, maior efetividade do poder fiscalizatório, através do aprimoramento do procedimento de cobrança e exigibilidade das sanções administrativas, em especial, das multas, pois quando não impugnadas formalmente na instância administrativa, são suspensas e, consequentemente, canceladas pelo Judiciário, seja por vício legislativo ou material, havendo, ainda, o instituto da prescrição administrativa para aniquilar as multas remanescentes.

Quanto à meta de fortalecimento do Sistema Nacional de Defesa do Consumidor, houve um estímulo à interiorização e ampliação do atendimento ao consumidor, com especial enfoque à municipalização e fortalecimentos dos PROCONS, bem como o incentivo à participação social. A partir do Decreto 7.963/2013, criou-se a Câmara Nacional das Relações de Consumo, no âmbito do Conselho de Governo, formada por um Conselho de Ministros e um Observatório Nacional das Relações de Consumo.

O Observatório Nacional das Relações de Consumo tem funções estratégicas de promover estudos e formular propostas para consecução dos objetivos do Plano Nacional de Consumo e Cidadania e acompanhar a execução das políticas públicas, programas e ações do 
Plano Nacional de Consumo e Cidadania, sendo composto, conforme previsão no parágrafo $1^{\circ}$ do artigo 11, por uma Secretaria Executiva e de Comitês Técnicos divididos pelos assuntos Consumo e Regulação, Consumo e Turismo e Consumo e Pós-Venda.

Os objetivos, metas, novos órgãos e competências insculpidos no Decreto $\mathrm{n}^{\circ}$ 7.963/2013 traduziram antigas angústias e reinvidicações do consumidor, porquanto na particularidade do Estado do Pará são equivalentes às metas consagradas na definição das Políticas Públicas do Estado em matéria de consumo, consolidadas na I Conferência Estadual de Defesa do Consumidor, realizada em Belém no ano de 2008, na qual se pôde definir as metas governamentais para a efetivação da presença do Estado e sociedade civil nas relações de consumo, em permanente diálogo construtivo com o segmento empresarial.

Dentre as principais metas consolidadas a partir das audiências públicas em vários municípios paraenses tornou-se possível destacar: a criação e veiculação de campanhas publicitárias e de educação para a melhor conscientização do consumidor, investimentos na municipalização do PROCON, ficando o órgão estadual como coordenador do sistema; incentivo ao consumo sustentável, implantação de Juizados Especiais do consumidor nos municípios de maior demanda de consumo; a criação de cadastros de fornecedores com ampla divulgação; a aprovação de lei que impeça a Administração Pública de comprar ou contratar fornecedores inscritos nos cadastros negativos; a criação de Delegacias especializadas no atendimento do consumidor; a maior divulgação das competências e canais de atendimento das agências reguladoras; o fomento da articulação civil de associações e cooperativas para a defesa do consumidor; a celebração de convênios e termos de ajustamento de conduta para a modulação das pretensões coletivas do consumidor no estado, em especial no âmbito dos serviços públicos e o incentivo a criação de canais alternativos de atendimento ao consumidor e de solução extrajudicial de conflitos de consumo, dentre outros.

$\mathrm{Na}$ linha de fortalecimento da tutela administrativa do consumidor, de modo a otimizar e profissionalizar a atuação dos órgãos integrantes do Sistema Nacional de Defesa do Consumidor, em especial o PROCON, através de ações estratégicas e que gozem de maior nível de efetividade, a prevenir e reduzir conflitos no âmbito das relações de consumo, é notável o esforço legislativo corporificado no Projeto de Lei $n^{\circ}$ 5.196/2013, que pretende acrescer o Capítulo VIII ao Título I da Lei 8.078/90 (CDC) e parágrafo único ao artigo 16 da Lei 9.099/1995 (Juizados Especiais).

O referido Projeto de Lei, que ainda tramita na Câmara dos Deputados, tem a ambição de resolver problema histórico no âmbito do atendimento às pretensões individuais do 
consumidor por meio de medidas corretivas e com maior força coercitiva junto aos fornecedores, ultrapassando, em muito, a mera e precária função conciliatória.

O novel artigo 60-A prevê, sem prejuízo das demais sanções previstas no Capítulo VII, a aplicação cumulativa ou isolada das seguintes medidas corretivas, que serão verdadeiras obrigações de fazer blindadas pelo poder de polícia: a) substituição ou reparação do produto (em equiparação com as prerrogativas do artigo 18 do CDC); b) devolução ou contraprestação paga pelo consumidor em razão de cobrança indevida (em equiparação ao artigo 42 do CDC; c) cumprimento da oferta pelo fornecedor, sempre que manifestada pela via escrita e de forma expressa (em sintonia com a proteção pré-contratual dos artigos 30, 31 e 35 do CDC); d) devolução ou estorno da quantia paga nas hipóteses de descumprimento contratual (em sintonia com o dirigismo contratual do CDC, em especial no que pertine aos tipos legais abusivos do artigo 51, I, II e 53 do $\mathrm{CDC}$ ); e) prestação adequada das informações requeridas pelo consumidor (em observância à obsessão protetiva ao direito básico da informação constante nos artigos $4^{\circ}, \mathrm{IV}, 6^{\circ}$, III e em diversas outras passagens do CDC).

O legislador reproduziu para o âmbito da tutela administrativa do consumidor as mesmas prerrogativas que, até então, só poderiam ser instrumentalizadas na via judicial e foi além, ao considerar no parágrafo $1^{\circ}$ do referido dispositivo, a possibilidade de aplicação de multa diária ao infrator, graduada de acordo com a gravidade da infração, a vantagem auferida e a condição econômica do fornecedor. Em outras palavras, o Projeto de Lei cria a figura da "astreinte administrativa".

A astreinte administrativa, como fruto do poder de polícia e com o mesmo intuito de vencer a obstinação do infrator em cumprir a ordem da autoridade será sempre revertida em favor do Fundo de Defesa dos Direitos Difusos ou aos fundos estaduais ou municipais de proteção ao consumidor, ou seja, neste particular, segue sistemática diversa de sua congênere judicial do parágrafo $4^{\circ}$ do artigo 84 do CDC, sempre destinada ao credor da obrigação inadimplida.

Aliás, em relação a este aspecto do beneficiário da multa, almeja-se que a autoridade pública, bem como em razão de eventual controle judicial da multa administrativa, seja mantida a sua força psicológica da constrição patrimonial através da manutenção dos valores, mesmo que elevados pela contumácia do devedor, para que haja uma sujeição mais rápida e efetiva à ordem de cumprimento.

Outra inovação do projeto está no artigo 60-B e corresponde à possibilidade de constituição das decisões administrativas em título executivo extrajudicial e, o que é melhor, permitindo, no seu parágrafo único, a possibilidade de execução individual do compromisso na 
via judicial, naturalmente na hipótese do objeto do acordo contemplar interesse individual subjetivo, eliminando ou restringindo a necessidade de cognição da matéria pelo juízo, restando ao infrator a estreita via dos embargos exclusivamente para questionar a validade formal do título.

Tem-se que o projeto visa resgatar a confiança dos consumidores na presença efetiva do Estado como órgão estratégico da Política Nacional das Relações de Consumo, há muito marginalizado por direcionamentos políticos titubeantes e, em alguns casos, comprometidos com uma liberdade promíscua dos agentes econômicos do mercado, assim como pela falta de um instrumental humano e orçamento adequados a tão grande missão. Nesse sentido:

\begin{abstract}
Prioriza-se, assim a resolutividade de demandas individuais deduzidas em reclamações aos órgãos administrativos, o que claramente repercute no sistema de defesa do consumidor em diferentes dimensões: (a) reforça a confiança dos consumidores na efetividade e capacidade de resolução dos Procons; (b) previne e reduz litígios judiciais decorrentes destas situações, em especial dos juizados de pequenas causas; (c) interfere em eventual juízo do fornecedor quanto à conveniência de estruturar sua ação ou admitir como característica de sua prática negocial o cometimento de práticas infrativas, considerando a perda econômica representada pela possibilidade de imposição de multa diária pela via administrativa (MIRAGEM, 2013, p. 305).
\end{abstract}

Por fim, o projeto insere o parágrafo único no artigo 16 da Lei 9.099/95, que versa sobre a sistemática dos Juizados Especiais, através do qual se permite a supressão de audiência preliminar de conciliação, caso o consumidor comprove que já houvera se submetido à audiência de conciliação em órgão administrativo, sem sucesso, ocasião em que será, desde logo, designada audiência de instrução e julgamento, resultando em grande economia de tempo no processo.

A esse respeito, não obstante essa possibilidade de aproveitamento judicial da tentativa de conciliação administrativa seja positiva, não se pode perder de vista que o próprio artigo 27 da referida lei, em pleno vigor, já faculta ao autor da ação requerer expressamente a realização de audiência una, em que através de um único ato processual poderão ser realizadas a conciliação e a instrução no processo, favorecendo, do mesmo modo, a celeridade processual.

Sob um panorama geral do Sistema Nacional de Defesa do Consumidor e a tutela administrativa têm-se que o Estado, mesmo com os mecanismos a postos que detém, ainda age como se isolado fosse nos assuntos referentes a maior efetividade e fiscalização das normas protetivas consumeristas. Percebe-se que mesmo com os órgãos como PROCONS, INMETRO, Ministérios Públicos e Defensorias Públicas não há um aparato onipresente capaz de 
acompanhar a progressão agressiva do mercado de consumo, assim havendo uma forte perda da influência estatal quanto à defesa dos vulneráveis.

Ademais, com a ausência educacional de forma a conscientizar os consumidores de forma preventiva pré-processual faz com que cada vez mais seja difundida a cultura da litigiosidade judicial, pois no exercício de cidadania consumerista pouco se observa o questionamento político das medidas protetivas e reparatórias consumeristas, bem como o acompanhamento se as fiscalizações e penalidades por meio dos órgãos do SNDC são realmente efetivas, entretanto facilmente é possível constatar o alto índice de demandas no Judiciário.

Deste modo, acerca do ângulo da tutela administrativa nas relações de consumo têmse que o exaurimento da via administrativa e a prévia resolução extrajudicial de conflitos não tem sido um plano de gerenciamento operacional diferenciado priorizando pela proteção que tanto almejou a legislação do CDC, e sim tem sido apenas mais uma desconcentração estatal que deixa transparecer uma mascarada democracia representativa que mais se alinha impropriamente ao segmento econômico do que com ao consumidor.

\section{A crescente perda de influência do Estado na seara consumerista}

No contexto Estado, Sociedade e Direito do consumidor para que se tenha uma tutela jurídica efetiva há a necessidade de haja uma harmonização da relação de consumo por meio da Política Nacional de Consumo e do exato funcionamento do Sistema Nacional de Defesa do Consumidor, ambos previstos no âmbito do CDC.

Entretanto, como já exposto anteriormente a máquina estatal no seu atual gerenciamento, talvez por grande parte dos efeitos de globalização de redução de fronteiras e ampliação da abertura a grandes empresas e multinacionais, tem hodiernamente perdido seu poder persuasivo e cada vez menos formulando estratégias ou políticas públicas, assim, recaindo sobre entraves que inviabilizam a efetiva proteção de direitos na seara do consumidor.

Elencam-se como alguns desses entraves a falta de investimentos e a gestão de qualidade, o gerenciamento político das agências reguladoras e o modelo político liberal nas relações consumeristas.

\subsection{A falta de investimentos e a gestão de qualidade}

No inciso $\mathrm{V}$ do art. $4^{\circ}$, do Código, tem-se uma preocupação com o controle de qualidade dos produtos e serviços disponibilizados no mercado de consumo, tratando-se de uma obrigatoriedade e não de mera liberalidade. Hoje, a empresa que queira ter uma certificação, e 
queira ser reconhecida como idônea, tem, necessariamente, que possuir um setor de qualidade, ao qual ficará responsável pelo controle da produção, da adequação técnica, qualidade e segurança do produto ou serviço.

Além disso, as empresas têm que garantir um mecanismo eficiente e gratuito de atendimento ao consumidor, como um instrumento prévio para a solução do com flito, evitando a formação de uma demanda na via administrativa ou judicial; estando preparada para ouvir o que o consumidor tem a dizer, facilitando o recebimento de suas sugestões e reclamações.

Até bem pouco tempo atrás, as empresas disponibilizavam serviços de atendimento gratuitos de comunicação, porém o que se percebe hoje é uma migração irregular para os canais que transferem o ônus desse serviço ao consumidor do serviço (Centrais 0300), no qual o consumidor é obrigado a pagar para exercer sua cidadania, em outros termos, a parte mais vulnerável da relação acaba pagando para reclamar, tirar dúvidas e etc. Isso constitui prática abusiva e é passível de sanções judiciais e administrativas.

Com efeito, esse procedimento irregular acaba por macular alguns dos direitos básicos do consumidor, como a informação, transparência e o direito à reclamação, impondo-se, portanto, a repressão legal. Nesse sentido, no art. $6^{\circ}$ do $\mathrm{CDC}$, onde estão estabelecidos os direitos básicos do consumidor, tem-se nos incisos III e IV, as seguintes disposições:

III- a informação adequada e clara sobre os diferentes produtos e serviços, com especificação correta de quantidade, características, composição, qualidade e preço, bem como sobre os riscos que apresentem;

IV- A proteção contra a publicidade enganosa e abusiva, métodos comerciais coercitivos ou desleais, bem como outras práticas e cláusulas abusivas ou impostas ao fornecimento de produtos e serviços.

Assim sendo, revela-se imperiosa a atuação dos órgãos integrantes da Política Nacional das Relações de Consumo, assim como dos entes federativos e Ministério Público, no sentido de promoverem a legítima responsabilização das empresas que repassam esse custo operacional aos consumidores; ressalte-se tal defesa deve ser feita no plano da coletividade e não meramente individual, pois tal falta de gestão afeta uma grande maioria na seara consumerista.$^{2}$

\footnotetext{
${ }^{2}$ A propósito, foi proposta, através da Procuradoria Geral do Estado do Pará, uma Ação Civil Pública com preceito cominatório de obrigação de fazer e tutela antecipada em face das Companhias Aéreas que atuam no Estado, por conta da migração ilegal do serviço de atendimento gratuito para o pago (Processo n. ${ }^{\circ} 2004.1 .009803-9$ ), que teve a tutela antecipada deferida pela Juíza da $21^{\text {a }}$ Vara Cível da Capital, cominando a obrigação de imediata reabertura do serviço de atendimento gratuito do consumidor paraense, decisão essa publicada no Diário de Justiça do Estado, que circulou no dia 09/03/2004.
} 
Ademais, é perceptível que o Estado pouco investe recursos no tocante a prevenção e compartilhamento de informações ao consumidor referente a atuação dos órgãos pertencentes ao SNDC; no Estado do Pará, por exemplo, em consulta aos sites dos órgãos e entidades de defesa consumerista, constatou-se que somente o PROCON disponibilizou no ano de 2018 o relatório referente ao cadastro de reclamações fundamentadas, aliás, frise-se que o cadastro menciona apenas termos quantitativos das demandas dos "bons e maus" fornecedores, não explicitando as soluções que foram tomadas na maioria das demandas e sequer explicitando o efetivo pagamento das multas que foram ou vieram a ser cominadas.

Tal entrave afronta diretamente e coloca em pleno desuso o disposto no art.44 do CDC, ao qual se refere ao dever dos órgãos públicos de defesa do consumidor de manter atualizado os cadastros de reclamações fundamentadas contra fornecedores de produtos e serviços, devendo divulgá-los pública e anualmente, e ainda a Lei de Acesso à Informações Públicas $12.527 / 2011$.

\subsection{O gerenciamento político das Agências Reguladoras}

Compreende-se que a prestação dos serviços públicos encontra-se interligada a matéria administrativa, sendo também submetida aos parâmetros descritos no Código de Defesa do Consumidor - CDC. Entretanto, em se tratando de serviços públicos, muito embora o país tenha vivido um crescente fenômeno relativo à privatização desses serviços, a capacidade do Estado de fiscalizá-los e melhor adaptá-los às necessidades coletivas não evoluiu da mesma maneira, porquanto os princípio da qualidade, segurança e continuidade foram completamente ignorados pelas concessionárias com a injustificável chancela do poder público.

Com a privatização, surgiu o modelo regulatório estatal por meio das agências reguladoras, em que o poder público assume o compromisso de acompanhar a adequada e eficaz prestação dos serviços. Acerca do modelo regulatório estatal, suas dificuldades são possíveis de serem compreendidas a partir dos momentos em que foram idealizadas, assim na primeira geração as agências reguladoras relacionadas com a privatização e a quebra do monopólio do Estado, como no caso da Agência Nacional de Energia Elétrica - Aneel, posteriormente na segunda geração está mais relacionada à busca de melhor eficiência e modernização do aparelho de Estado, ocorrendo em meados de 1999/2000 e por fim terceira geração, a qual ainda nos encontramos, houve uma grande mistura de finalidades e áreas de atuação, perdendo então as agências reguladoras o foco na regulação de mercados, a exemplo a Agência Nacional de Cinema - Ancine ( PÓ; ABRUCIO, 2006, p. 684). 
Criadas com natureza jurídica de autarquias em regime especial, nas agências reguladoras as nomeações para sua gestão são decorrentes de ato composto, qual seja das indicações políticas e convalidação do Senado, fator que possivelmente implica no mal funcionamento, deste modo:

\begin{abstract}
Os problemas do setor, os desejos e negociações dos representantes políticos, a existência de grupos e interesses organizados afetam a configuração institucional e as regras a que uma agência pode estar submetida. A argumentação deste artigo mostra que essa uniformidade é, em grande medida, aparente e esconde diferenças significativas no funcionamento das agências. Assim, a diversidade dos setores já estaria incorporada no funcionamento, mais que no desenho, das agências, o que matiza a argumentação de Mueller e Pereira (2002:68) no sentido de que as diferenças entre os reguladores serão provocadas depois da sua instalação devido à ação dos atores políticos, sociais e econômicos envolvidos em cada setor (PÓ;ABRUCIO, 2006, p. 688).
\end{abstract}

Constata-se uma total inoperância e conivência com as práticas irregulares dos fornecedores, pois basta citar o problema crônico da telefonia fixa e energia elétrica que na maioria dos Estados são disponibilizados em regime de monopólio, limitando por completo o poder de escolha e as alternativas do consumidor.

A supervalorização das tarifas, por sua vez, inviabiliza o próprio acesso ao serviço, que, na maioria das vezes, não é disponibilizado de maneira adequada, segura e nem tampouco contínua, como estabelece o próprio art. 22 do CDC.

Diante desse fato, exsurgem as seguintes indagações: será que a agência reguladora não tem o compromisso de aferir se realmente aquele parâmetro de indexação era o mais consentâneo com a realidade econômica? Em sendo o índice mais gravoso para o consumidor, não poderia ser revisto pela atuação de direta do Estado no seu papel regulador?

Enquanto na condição de cidadãos e consumidores se torna inadmissível compreender a conivência do Estado com a aplicação de um índice que ultrapasse, por vezes mais de dez pontos percentuais, os próprios índices inflacionários oficiais. Esse descaso revela marcantemente a ineficiência do modelo regulador brasileiro que prejudica sobremaneira o consumidor-usuário dos serviços.

Nessa mesma linha de pensamento, considerando ainda as relações de consumo decorrentes do fornecimento de energia elétrica, cada vez tem sido mais frequentes na sociedade as cobranças por supostas fraudes aos medidores das unidades consumidoras imputados na grande maioria das vezes, de maneira unilateral ao consumidor; e este que frente a imprudência apuratória das alterações de medidores por parte das concessionárias de energia acaba sendo lesado gravemente, por exemplo, com a suspensão no fornecimento de energia e a inscrição do 
nome do usuário nos cadastros de proteção de crédito.

A situação de tais cobranças abusivas não é uma situação apenas adstrita a região norte do País, uma vez que analisando os estudos sobre a matéria e os julgados dos Tribunais é nitidamente perceptível a veiculação de decisões de localidades diversas posicionando-se a favor do consumidor, transparecendo a nítida decadência estatal e a imediata necessidade de maior fiscalização por parte das agências reguladoras.

\subsection{O modelo político liberal na proteção consumerista}

A deficiência estatal no trato das relações econômicas consumeristas exigiu transições entre paradigmas sociais do conhecimento e da emancipação, retirando o Estado da posição de espectador que não intervinha no processo econômico da sociedade, tutelando apenas a validade dos contratos, e tampouco reconhecia direitos consumeristas aos cidadãos, uma vez que antes não eram considerados consumidores.

Sob esse prisma, foram rompidas as bases do direito individualista e da sociedade indolente, passando a consolidar novas bases vinculadas à proteção da metaindividualidade ligada direta e, proporcionalmente, à participação política social, à solidariedade, aos direitos e deveres de um direito plural e à transparência nas relações de consumo.

De fato, na linha do tempo o Estado Liberal evoluiu, apresentando-se sob uma nova perspectiva de Estado Democrático de Direito, que agrega ao perfil mercadológico e à relação consumerista outros valores nos quais, por meio do microssistema de proteção implementado, quebrou-se o padrão do individualismo jurídico em prol apenas do fornecedor, levando em consideração os fatores advindos da globalização, o aumento do número de consumidores e da quantidade de produtos, serviços e meios de produção.

Frise-se que o objetivo protecional consumerista não se destina a limitar o mercado e onerar para os comerciantes o exercício regular de suas atividades, ao passo de torná-las inviáveis, mas almeja delimitar diretrizes para que as práticas comerciais ocorram em concordância com a boa-fé e a Política Nacional das Relações de Consumo em relação ao tratamento sobre a responsabilidade pelo livre comércio.

Tomando por base a nova vertente sedimentada pelo Estado, a sociedade, cumprindo de certo modo a intenção do legislador, tornou-se mais participativa à medida que a própria Lei 8.078/90 - CDC (BRASIL, 1990) estabelece condições em que Estado, agentes econômicos e sociedade são a tríplice harmônica para zelar quanto à responsabilização nas relações de consumo. 
Não obstante a toda essa evolução e compatibilização entre a proteção do consumidor e a livre iniciativa, tanto o Estado-Administração como o Estado-Judiciário tem emitidos sinais erráticos quanto ao ponto de equilíbrio entre os aludidos princípios.

A título de exemplo, recente decisão proferida no Recurso Especial 1712504/PR, julgado pelo Superior Tribunal de Justiça - STJ, na Ação Coletiva proposta pelo Instituto de Defesa do Cidadão, em sede de recurso, permitiu a diminuição expressiva do valor condenatório do Banco Itaú, do montante de R\$ 160 milhões, para R\$ 160 mil, no caso de oferta agressiva e irresponsável do crédito, contribuindo para o superendividamento de uma grande quantidade de clientes.

Isso revela um distanciamento cada vez maior do Estado em relação ao consumidor, mas que pode ser canalizado para uma perspectiva de empoderamento cívico, através do fortalecimento de seus vínculos sociais e políticos com outros consumidores.

\section{A lacuna deixada pelo estado favorece a empatia e os laços sociais e políticos entre os consumidores}

Não há dúvida de que o Estado vem se tornando cada vez mais dependente das grandes empresas multinacionais e corporações internacionais e, em razão disso, vem perdendo seu poder de persuasão, hoje inevitavelmente limitado, mesmo no âmbito territorial doméstico, pois não tem mais o monopólio das decisões políticas, uma vez que estas, como nas palavras de Canclini (2010, p. 33) " são tomadas em função das seduções imediatistas do consumo, o livre comércio sem memória de seus erros, a importação afobada [...], no endividamento e na crise de balança de pagamentos".

Nesse contexto, muito embora existam espaços participativos nacionais, e estes sejam mais propícios à participação plural de grupos representativos estatais do SNDC, tais como as Associações Civis de Defesa do Consumidor, não se pode ignorar que a participação individual ou através de outros mecanismos de inserção política, atualmente são igualmente relevantes frente a perda de influência do Estado, podendo tal inserção ser viabilizada, através de conferências, conselhos, audiências públicas e das Convenções Coletivas de Consumo.

Neste particular, Gurutz Jáuregui afirma:

En la medida en que el poder se halla disperso en la própria sociedad, y en la medida en que existe una pluralidad de centros de presión, surge una variada panoplia competitiva de formulaciones políticas y de centros de decisión. La política del gobierno es el resultado de un proceso de oferta y demanda, negociación, regateo y compromiso entre los diversos grupos de poder (JÁUREGUI, 1994, p. 108). 
As conferências podem ser compreendidas como espaços participativos, convocados pelo poder Executivo com certa periodicidade para a interlocução racional entre representantes do Estado, mercado e da sociedade com o objetivo de discutir e consolidar propostas para determinada política pública, sempre de modo transitório embora não pontual. Essa transitoriedade sugere que são convocadas com finalidades específicas por um período determinado (TEIXEIRA; SOUZA; LIMA, 2012, p. 14,15).

Por sua vez, em se tratando de conselhos, estes são espaços participativos, que podem assumir tanto a função consultiva, como deliberativa, pressupondo certa constância no tempo, compostos por representantes do poder público e da sociedade civil, de modo a favorecer um maior nível de intervenção nas políticas públicas. São, portanto, órgãos de manifestação política colegiada que trazem como traço característico marcante a intencionalidade de um debate contínuo. Cada reunião não pode ser concebida como um evento aleatório, mas sim integrante de um processo sistemático de construção de políticas públicas (TEIXEIRA; SOUZA; LIMA, 2012, p. 14-15).

Nesses conselhos, a participação política ficará adstrita aos representantes eleitos ou indicados, sendo limitada a participação de terceiros, vedado para estes o direito a voto, diferentemente do que ocorre nas conferências e audiências públicas em que a democratização do debate é muito maior. Da mesma forma, no âmbito dos conselhos, a manifestação pública é qualificada, ou seja, a pessoa que fala deverá demonstrar conhecimento técnico, o que não se exige nas conferências e audiências (TEIXEIRA; SOUZA; LIMA, 2012, p. 14-15).

As audiências ou consultas públicas são exemplos de participação política ocasional, convocados de acordo com circunstâncias e temas específicos de interesse comum ao grupo, seja no âmbito de processos administrativos, como, por exemplo, nas hipóteses de estudos de impacto ambiental, seja para alinhavar planos diretores para as cidades, ou na instrução de processos judiciais complexos e de relevância social, como verificado nos últimos anos no âmbito do Supremo Tribunal Federal, pioneiro na utilização deste recurso.

Nesse cenário de falência/perda da influência estatal e involução da tutela administrativa na seara consumerista, quando se menciona em alternativas de resgate do debate político qualificado com o cidadão, não se pode olvidar discorrer sobre a Convenção Coletiva de Consumo, prevista no art.107 do CDC, a qual tem o papel de formatar juridicamente o debate político qualificado entre consumidor e fornecedor com a responsável mediação do Estado, produzindo um círculo virtuoso no monitoramento preventivo dos conflitos de consumo e envolvimento cívico do indivíduo na constituição de padrões de comportamentos desejáveis 
para o aprimoramento das relações de consumo (VERBICARO, 2017, p. 296).

Em outros termos, destina-se a Convenção Coletiva a busca de soluções de modo antecipado aos conflitos consumeristas, discutindo assuntos relacionados à preço, à qualidade, à garantia, características e ainda sobre a resolução de litígios; é um mecanismo pelo qual o individualismo é deixado de lado, reestruturando o cidadão a pensar, no plano coletivo, de forma consciente e responsável, tornando-o não dependente apenas do amparo burocratizado estatal.

É imperioso ressaltar que a participação do consumidor nesse contexto é fundamental, seja porque revela uma espiral virtuosa de comprometimento pessoal, exercício da liberdade positiva e engajamento cívico para com o grupo no contexto político de sua proteção jurídica, mas também porque estimula, através do permanente debate, a construção de estratégias e difusão de expectativas pelos próprios sujeitos, sob a intermediação do Estado, para a transversalização de demandas ligadas aos seus mais legítimos interesses, enquanto categoria economicamente marginalizada pelos agentes econômicos do mercado.

Todavia, no âmbito das relações de consumo, as experiências concretas quanto à ocupação desses espaços políticos de participação, conquanto tenham sido positivas, ainda são escassas, à exceção de algumas audiências públicas em matéria de consumo, carecemos no âmbito federal e estadual de conselhos com atuação específica na programação das metas governamentais, aperfeiçoamento de direitos e mesmo no que pertine a melhor gestão do fundo dos direitos difusos e coletivos.

\section{Conclusão}

Com o advento do Código de Defesa do Consumidor - CDC, a Política Nacional de Consumo e o Sistema Nacional de Defesa do Consumidor se fortaleceram, aparentemente deixando transparecer que seria naquela oportunidade que o Estado tomaria a frente e daria a tutela consumerista um patamar de fiel e estrito cumprimento. Entretanto, a tutela administrativa estatal cada vez mais tem se demonstrado falha, no decorrer desses quase 28 anos de vigência do CDC.

O modelo da tutela administrativa atual, seja o padrão das agências reguladoras, tem se demonstrado decadente e cada vez menos eficaz, contribuindo apenas para a manutenção desconcentrada dos poderes da administração e não priorizando pela defesa dos vulneráveis, justamente porque existem interesses econômicos e políticos que dão margem ao entendimento 
de que são superiores ao interesse de uma coletividade (sociedade civil consumerista).

Há poucos anos atrás, ainda era perceptível um certo entusiasmo com o nível diferenciado da proteção jurídica dispensada ao consumidor brasileiro e se admitia, como algo inevitável, o aperfeiçoamento do sistema normativo com a provável aprovação dos projetos de lei em tramitação no Congresso Nacional sobre o superendividamento e o comércio eletrônico, os quais tinham como ponto em comum o fortalecimento do controle pré-contratual da Lei 8.078/90 (CDC) e a adequação do Direito do Consumidor às novas tecnologias virtuais, diante da maior sofisticação das práticas abusivas.

Todavia, num curto intervalo de tempo, a realidade política brasileira sofreu grandes rupturas, arrastando as expectativas de aprimoramento da legislação para a zona da incerteza. A reforma normativa que se revelava provável, hoje, tende a permanecer estagnada, tendo o debate jurídico se limitado a defender a manutenção da proteção já existente. Desde que não haja retrocesso, o consumidor brasileiro já estaria "em vantagem".

Com o fortalecimento de uma onda liberal no contexto político, o Estado brasileiro que, há muito, já havia perdido o protagonismo no âmbito da proteção do consumidor, hoje sequer consegue cumprir a função de mediador minimamente responsável na condução do debate deliberativo entre os agentes econômicos do mercado e a sociedade de consumidores.

O modelo regulatório brasileiro, através das recentes medidas administrativas aprovadas pelas Agências Reguladoras como a ANAC, ANATEL e outras, denota um flagrante descompasso com a proteção de direitos básicos do consumidor, tais como as Resoluções $\mathrm{n}^{\circ} 400 / 2016$ (ANAC) que liberaram a cobrança avulsa de bagagens e restringiram o direito de arrependimento do consumidor, Resolução n. ${ }^{\circ}$ 680/2017 (ANATEL) que permitiu o bloqueio da internet móvel nos celulares, quando superada a franquia contratada, apenas como alguns exemplos.

Da mesma forma, o Judiciário que, até então, a última fronteira da preservação dos direitos do consumidor, tem emitido mensagens contraditórias, erráticas e, algumas, até diretas, todas em detrimento da proteção consumerista, como verificado no julgamento do RE 636.331 pelo Supremo Tribunal Federal, através do qual considerou o Pacto de Varsóvia como fonte normativa prevalente em relação ao $\mathrm{CDC}$, em matéria de transporte aéreo, em franco menosprezo ao princípio da ampla e efetiva reparação aos danos, positivado no artigo $6^{\circ}$, VI do CDC.

Nessa mesma lógica, tem-se a recente decisão do Superior Tribunal de Justiça, no julgamento do tema repetitivo 952 e com base no REsp 1.568.244/RJ, que a pretexto de padronizar a interpretação judicial acerca dos reajustes abusivos nas mensalidades dos planos 
de saúde do idoso, importou em grave retrocesso à tutela do consumidor, na medida em que convalidou o vetusto princípio do pacta sunt servanda nas relações de consumo. E, ainda, atribuiu autoridade decisória irrecorrível à Agência Nacional de Saúde quanto ao reajuste das mensalidades, deixando para uma improvável revisão judicial o conceito de onerosidade excessiva na análise do caso concreto.

Portanto, o sensível enfraquecimento da máquina gerencial demonstra a postura errática do Estado brasileiro no âmbito do Sistema Nacional de Proteção Consumerista, mas por outro lado provoca o consumidor a buscar novas alternativas, sobretudo a ocupar os espaços políticos de deliberação no âmbito da Política Nacional das Relações de Consumo, a partir do fortalecimento da empatia e dos laços sociais com os demais consumidores, criando um círculo virtuoso de independência e maior protagonismo cívico em relação ao combalido EstadoAdministração.

\section{Referências Bibliográficas}

BRASIL. Constituição da República Federativa do Brasil de 1988. Diário Oficial [da] União, Brasília, DF, 05 de outubro de 1988. Disponível em:

$<$ http://www.planalto.gov.br/ccivil_03/constituicao/constituicaocompilado.htm>. Acesso em: 03 mai. 2018.

. Decreto no 7.963, de 15 de março de 2013. Institui o Plano Nacional de Consumo e Cidadania e cria a Câmara Nacional das Relações de Consumo. Diário Oficial [da] União, Brasília, DF, 16 mar. 2013. Disponível em: < http://www.planalto.gov.br/ccivil_03/_ato20112014/2013/decreto/d7963.htm>. Acesso em: 03 mai. 2018.

. Lei ${ }^{\circ} 8.078$, de 11 de setembro de 1990. Dispõe sobre a proteção do consumidor e dá outras providências. Diário Oficial [da] União, Brasília, DF, 12 set. 1990. Disponível em: $<$ http://www.planalto.gov.br/ccivil_03/leis/L8078.htm>. Acesso em: 03 mai. 2018.

. Projeto de Lei $\mathbf{n}^{0}$ 5.196, de 20 de março de 2013. Acresce Capítulo VIII ao Título I da Lei $n^{\circ} 8.078$, de 11 de setembro de 1990, que dispõe sobre a proteção do consumidor; e parágrafo único ao art. 16 da Lei n ${ }^{\circ} 9.099$, de 26 de setembro de 1995, que dispõe sobre os 
Juizados Especiais Cíveis e Criminais. Brasília, DF, 2013. Disponível em: <http://www. camara.gov.br/proposicoesWeb/fichadetramitacao?idProposicao=568597>. Acesso em: 25 abr. 2018.

Agência Nacional de Aviação Civil - ANAC. Resolução nº 400, de 13 de dezembro de 2016. Dispõe sobre as Condições Gerais de Transporte Aéreo. Diário Oficial [da] União, Brasília, DF, 14 dez. 2016. Disponível em: <http://www.anac.gov.br/assuntos/legislacao/ legislacao-1/resolucoes/resolucoes-2016/resolucao-no-400-13-12-2016>. Acesso em: 03 mai. 2018.

. Agência Nacional de Telecomunicações - ANATEL. Resolução nº 680, de 27 de junho de 2017. Aprova o Regulamento sobre Equipamentos de Radiocomunicação de Radiação Restrita e altera o Regulamento dos Serviços de Telecomunicações, o Regulamento de Gestão da Qualidade do Serviço de Comunicação Multimídia, o Regulamento do Serviço de Comunicação Multimídia e o Regulamento do Serviço Limitado Privado. Diário Oficial [da] União, Brasília, DF, 29 jun. 2017. Disponível em: <http://www.anatel.gov.br/ legislacao/resolucoes/2017/936-resolucao-680>. Acesso em: 03 mai. 2018.

. Superior Tribunal Federal- STF. Apelação Civil. Responsabilidade Civil. Transporte Aéreo. Extravio De Bagagem. Inaplicabilidade da Convenção de Varsóvia. Relação de Consumo. Código de Defesa do Consumidor. Indenização Ampla. Danos Materiais e Morais. Viagem realizada por companhia aérea com conexão em País Europeu. Verossimilhança das Alegações e hipossuficiência. Possibilidade de Inversão do Ônus da Prova. Recurso Extraordinário 636.331 - RJ. Rio de Janeiro, 2017. Relator: Min. Gilmar Mendes. Disponível em: < www.stf.jus.br/portal/processo/verProcessoPeca.asp?id=313246068\&tipo $\mathrm{App}=. \mathrm{pdf}>$. Acesso em: 01 mai. 2018.

. Superior Tribunal de Justiça - STJ. Recurso Especial Repetitivo. Negativa de Prestação Jurisdicional. Não Ocorrência. Civil. Plano de Saúde. Modalidade individual ou familiar. Cláusula de Reajuste de mensalidade por mudança de faixa etária. Legalidade. Último grupo de risco. percentual de reajuste. Definição de parâmetros. Abusividade. Não caracterização. Equilíbrio financeiro-atuarial do contrato. Recurso Especial no 1.568.244 RJ (2015/0297278-0). Rio de Janeiro, 2017. Relator: Min. Ricardo Villas Bôas Cueva. Disponível em: < https://stj.jusbrasil.com.br/jurisprudencia/416939208/recurso-especial-resp- 
1568244-rj-2015-0297278-0/inteiro-teor-416939214?ref=juris-tabs > . Acesso em: 03 mai. 2018.

CANCLINI, Néstor Garcia. Consumidores e Cidadão: conflitos multiculturais da globalização. $8^{\text {a }}$ edição. $1^{\text {a }}$ Reimpressão. Rio de Janeiro: UFRJ, 2010.

DI PIETRO, Maria Sylvia Zanella. Direito regulatório: Temas polêmicos. Coordenado por Maria Sylvia Zanella Di Pietro. 2 ${ }^{\mathrm{a}}$. edição. Rev. e ampl. 1ª reimpressão. Belo Horizonte: Fórum, 2009.

JÁUREGUI, Gurutz. La democracia en la encrucijada. Barcelona: Editorial Anagrama SA., 1994.

MARTINS, Fernando Rodrigues. Os lugares do Direito do Consumidor na Pauta Humanitária: em busca do modelo-global de promoção aos vulneráveis. In: MARQUES, Claudia Lima; GSELL, Beate (Org.). Novas Tendências do Direito do Consumidor. São Paulo: Revista dos Tribunais, 2015. p. 88 - 119.

MIRAGEM, Bruno. “O Plano Nacional de Consumo e Cidadania: comentários ao Dec. 7.963, de 15.03.2013”. Revista de Direito do Consumidor. São Paulo, ano 22, vol. 86, marçoabril/2013.

MUNIZ, Mariana. STJ reduz de R\$ 160 milhões para R\$ 160 mil valor de ação coletiva contra Itaú. JOTA. Brasília, 10 abr. 2018. Disponível em: $<$ https://www.jota.info/justica/stjreduz-160-milhoes-160-mil-condenacao-itau-acao-coletiva-10042018>. Acesso em: 01 mai. 2018.

PÓ, Marcos Vinicius; ABRUCIO, Fernando Luiz. Desenho e funcionamento dos mecanismos de controle e accountability das agências reguladoras brasileiras: semelhanças e diferenças. RAP. Rio de Janeiro. 40(4):679-98. Jul./Ago. 2006. Disponível em: < http://www.scielo.br/ pdf/rap/v40n4/31601>. Acesso em: 01 mai. 2018.

TEIXEIRA, Ana Cláudia Chaves; SOUZA, Clóvis Henrique Leite; LIMA, Paula Pompeu Fiúza. Arquitetura da Participação no Brasil: uma leitura das representações políticas em 
espaços participativos nacionais. Texto para discussão 1735. Rio de Janeiro: IPEA, 2012.

VERBICARO, Dennis. Consumo e cidadania: identificando os espaços políticos de atuação qualificada do consumidor. Rio de Janeiro: Lumen Juris, 2017.

VERBICARO, Dennis; ATAÍDE, Camille; ACIOLI (Coord.). Provocações Contemporâneas no Direito do Consumidor. Rio de Janeiro: Lumen Juris, 2018. 


\title{
A RESISTÊNCIA À REFORMA TRABALHISTA BRASILEIRA DE 2017: \\ Desobediência Civil de Magistrados ou Controle de Constitucionalidade Difuso?
}

\author{
Cristiane Heredia Sousa
}

Universidade de Ribeirão Preto - UNAERP

Adalberto Simão Filho

Universidade de Ribeirão Preto - UNAERP

\begin{abstract}
Resumo
No dia 11 de novembro de 2017 entrou em vigor a Lei 13.467/17, a chamada "reforma trabalhista", que introduziu substancial alteração da legislação laboral. Porém, desde muito antes de sua entrada em vigor, houve grande repercussão no meio jurídico e de entidades sociais através de movimentos que defendiam a inconstitucionalidade de muitas das alterações legislativas por representarem retrocesso social, e outros que defendiam representar avanço nas relações de emprego. O presente estudo tem por finalidade analisar a posição de magistrados que resistem à essas alterações, na investigação de poder ser esta postura uma conduta de desobediência civil ou ato jurisdicional.
\end{abstract}

Palavras-chave: Reforma trabalhista, desobediência civil, retrocesso social, direito coletivo, resistência de juízes.

\section{Abstract/Resumen/Résumé}

On November 11, 2017 came into force Law 13.467/17, the called "labor reform", which introduced a substantial change in labor legislation. However, long before its validity, there was a great repercussion in the juridical environment and of social entities through movements that warn about the unconstitutionality of many of the legislative changes because they represent social retrogression. The purpose of the present study is to analyze the position of magistrates who resist such changes in the investigation of whether this position is a conduct of civil disobedience or a jurisdictional act.

Keywords/Palabras-claves/Mots-clés: labor reform, civil disobedience, social retraction, collective law, resistance of judges. 


\section{Introdução}

Em meio a uma das maiores crises políticas, éticas e econômicas do Brasil, o até então Vice-Presidente da República Michel Temer, ao assumir a Presidência da República após a realização do impeachment de Dilma Roussef, enviou para votação do Congresso Nacional projeto de lei $\mathrm{n}^{\mathrm{o}}$ 6.878/2016, propondo substancial reforma na legislação trabalhista, justificando-a com a necessidade de adequação da Consolidação das Leis do Trabalho às novas e atuais relações de trabalho.

Referido projeto foi aprovado em ambas as casas do Congresso Nacional, se transformado na Lei Ordinária $\mathrm{n}^{\mathrm{o}}$ 13.467/2017. Ainda durante a tramitação legislativa, inúmeros foram os manifestos públicos a favor e contra à reforma.

Parte da população composta por empresários, juízes do trabalho e outros, apoiou a proposta de reforma por ser necessária à modernização das normas laborais, a exemplo do que aconteceu em inúmeros países frente à globalização, e por estarem superadas pelo tempo as normas existentes na CLT que datava de 1943, quando o Brasil ainda era predominantemente rural e com extrema dificuldade de difusão de informações, o que hoje não é mais.

Para Martins Filho (2017), então Presidente do Tribunal Superior do Trabalho (TST), as reformas propostas na legislação trabalhista permitirão melhores negociações coletivas, notadamente em período de crise econômica, diminuindo os impactos de desemprego.

Por seu turno, parte dos juízes do trabalho da vários estados da Federação, e parte dos operadores do direito, além de entidades sindicais, se manifestaram publicamente contra a reforma trabalhista, alegando que tamanha modificação necessitava de maior debate com a população; que estavam sendo retirados direitos conquistados ao longo de décadas, e que isso representava retrocesso social, o que é vedado por princípio laboral e constitucional.

Exemplo desta manifestação, é a petição pública firmada por mais de 6.400 pessoas, dentre eles juízes e desembargadores do trabalho de vários Tribunais do Trabalho do Brasil, que afirmam em referido documento, dentre outros:

O PL 6.787/2016 representa uma mudança profunda no sistema de relações de trabalho brasileiro ao introduzir o princípio de que a lei possa ser rebaixada pela negociação coletiva. O negociado prevalecer sobre o legislado significará que as contratações dos trabalhadores poderão ser em patamares inferiores aos estabelecidos pela legislação, ou seja, com redução de direitos. (MANIFESTO, 2016)

Esse embate, contudo, não se encerrou com a aprovação e entrada em vigor da Reforma Trabalhista em novembro de 2017 (Lei n 13.467/17), tendo havido, na verdade, apenas modificação do plano onde esta batalha continua a ser tratava, que saiu das ruas e migrou para os tribunais, por juízes e outro operadores do direito que se mantém contrários à reforma. 
Diante desse cenário, cabe uma reflexão acerca da natureza desses atos de resistência dos magistrados, posto que esses operadores do direito serão responsáveis pelas sentenças judiciais que serão proferidas, quando da análise da regularidade ou não de uma conduta praticada pelos jurisdicionados com apoio nas novas determinações legais.

A metodologia aplicada neste estudo foi realizada através de levantamento bibliográfico, de manifestações públicas documentadas, busca de julgamentos realizados em processos judiciais, e também por reportagens e entrevistas concedidas à imprensa que promoveram o debate sobre o tema da reforma trabalhista, com posições favoráveis e contrárias defendidas por juízes, desembargadores e ministros do trabalho.

O referencial teórico parte dos estudos de Maria Garcia (1994), que propõe que os atos de resistência contra normas injustas, são atos de Desobediência Civil,

Este referencial nos parece ser adequado para o enfrentamento da questão posta, qual seja, da análise dos atos contrários à Reforma Trabalhista por magistrados do trabalho, como sendo atos de Controle Difuso de Constitucionalidade legítima, ou se, de fato, podem constituir típica Desobediência Civil.

\section{A proteção normativa do trabalho como direito fundamental ao longo da história}

O direito do trabalho no Brasil é um dos ramos jurídicos em que o embate por questões econômico-sociais fica mais evidenciado, e a história das conquistas desse ramo especializado é que basicamente fundamenta a posição dos que são contra a reforma.

As relações sobre o trabalho humano (em seu sentido amplo) foram negligenciadas ao longo da história, do ponto de vista de importância como direito fundamental, e por muitos séculos, especialmente nos períodos de servidão e escravidão o homem chegou a ser tratado como res, sendo as relações jurídicas aplicáveis à sua força de trabalho as de natureza civil de propriedade.

Mesmo quando o homem passou a ser "livre" e tratado como assalariado, a exploração não cessou, quer em relação às condições de trabalho que permaneciam desumanas e degradantes, quer em relação à paga que era oferecida, sendo esse, na ampla maioria dos casos, a única fonte de sobrevivência dos trabalhadores.

Segundo Delgado, o Direito do Trabalho é fruto da conjunção de fatores e condições econômicas, sociais e jurídicas, a partir da sociedade moderna: 
Nas sociedades feudais e antigas, a categoria do trabalho subordinado pode, eventualmente, ter surgido, como singular exceção - mas jamais foi uma categoria relevante do ponto de vista socioeconômico. Muito menos erigiu-se em categoria socialmente dominante, a ponto de poder gerar um fenômeno de normatização jurídica abrangente como o Direito do Trabalho. (DELGADO, M. 2014, p. 88)

Destaque-se que na Revolução Francesa (1789), inspirada no Iluminismo, houve basicamente enfoque na aquisição de direitos civis com desenvolvimento da concepção de dignidade da pessoa humana, visando diminuiçãoda situação de miséria e profunda desigualdade em relação aos privilégios existentes então, o que não ocorreu de fato.

$\mathrm{O}$ trabalhador, que não pertencia à burguesia e nema famílias financeiramente abastadas, por muito tempo ainda permaneceu à margem da proteção jurídica, sequer sendo pensada a condição de dignidade humana nas relações laborais.

A primeira lei voltada a regular o trabalho operário, é registrada como sendo o Moral and Health Act, promulgada na Inglaterra em 1802que trouxe tímidas inovações, que hoje seriam consideradas inaceitáveis, tais como o limite para a jornada diária de trabalho infantil em 12 horas.

Oportuno mencionar que, nesse período da história, o Estado se mantinha distante das relações de capital-trabalho e, como consequência, as relações de trabalho eram basicamente reguladas pela "lei de mercado", não havendo mínimo de pagamento a ser observado, mulheres e homens e até crianças impúberes trabalhavam em jornadas exaustivas e sem qualquer proteção contra acidentes de trabalho ou garantia em caso de lesão no ambiente de trabalho.

Esses abusos cometidos insuflaram a criação de movimento que uniu os trabalhadores, com fincas a impor limites ao poder econômico nessa formação de novos operários:

Em termos de relações coletivas ou sindicais, a questão social sobre a condição do trabalhador esteve vinculada às injustiças praticadas contra estes no interior das organizações produtivas. Do mesmo modo, as principais correntes teóricas e ideológicas das doutrinas sindicais foram elaboradas em função dos trabalhadores e seus conflitos nas fábricas - como atores e cenários privilegiados - onde se deram as batalhas pela humanização do trabalho ou pelo nascimento de um outro homem - livre do poder econômico e do poder político -, ou para a tomada do próprio poder por meio de uma luta simultaneamente econômica e política. (ANDRADE, 2008, p.111)

Nesse fértil campo de conflito latente, foi publicado o Manifesto Comunista, conclamando os operários a se voltarem contra a opressão imposta pela burguesia, que seria apenas uma transmutação do anterior sistema feudal, e criticando a situação de submissão necessária dos trabalhadores, sob pena de não terem meios de sobrevivência pela inércia do Estado. (MARX e ENGELS, 1848) 
A Europa vivenciava exponencial crescimento econômico e industrial, enquanto no Brasil, mesmo após a proclamação da sua independência, a escravidão ainda foi mantida até 1888, com a promulgação da Lei Áurea, em um país que era essencialmente agrícola.

Com a promulgação da Lei $\mathrm{n}^{\circ}$ 581, de 4 de Setembro de 1850 , conhecida por Lei Euzébio de Queiróz, por pressão Inglesa, foi proibido o tráfico de escravos para o Brasil, tendo como consequência a intensificação da vinda de imigrantes para o Brasil em busca de trabalho na lavoura e no comércio.(CAVALCANTE, 2005).

Sobre esse importante período histórico no Brasil, e a transição para o trabalho livre, em grande parte por imigrantes, oportuna a análise do não aproveitamento total da mão-de-obra disponível no Brasil constituída por homens brancos pobres e livres:

O recurso do trabalho do imigrante, a partir de 1840, intensificado a partir de 1850 , e mais ainda no final do século, não se deu por uma mera questão quantitativa ou por uma suposta não adaptação do brasileiro, branco livre, ao trabalho, mas porque havia uma distensão muito forte entre a classe dominante conservadora e a massa popular, em razão da forma como se concretizou a independência, sendo que, por conta disso, também os senhores de escravos não queriam se relacionar com essa massa, considerando-a perigosa. (MAIOR, 2017, p.69)

No período da Revolução Industrial (meados do século XVIII), notadamente na Inglaterra, a otimização da produção industrial em série teve como consequência a exacerbada exploração da força de trabalho humano, com a realização de jornadas de trabalho que chegavam a atingir de 12 a 16 diárias, mesmo para crianças (VON AMMON, 2017)

Sobre o tema, a Encíclica Rerun Novarum (1891) do Papa Leão XIII buscava difundir a ideia da dignidade humana dos operários e da conscientização de direitos e deveres entre operários e patrões, propondo:

\footnotetext{
Obrigações dos operários e dos patrões

Entre estes deveres, eis os que dizem respeito ao pobre e ao operário: deve fornecer integral e fielmente todo o trabalho a que se comprometeu por contrato livre e conforme à equidade; não deve lesar o seu patrão, nem nos seus bens, nem na sua pessoa; [.. ]

Quanto aos ricos e aos patrões, não devem tratar o operário como escravo, mas respeitar nele a dignidade do homem,[...] O trabalho do corpo, pelo testemunho comum da razão e da filosofia cristã, longe de ser um objecto de vergonha, honra o homem, porque lhe fornece um nobre meio de sustentar a sua vida. O que é vergonhoso e desumano é usar dos homens como de vis instrumentos de lucro, e não os estimar senão na proporção do vigor dos seus braços.
}

No decorrer dos anos, a busca por uma legislação minimamente protetiva aos trabalhadores foi objeto de lutas em vários países, com forma e intensidade diferentes.

$\mathrm{Na}$ esteira da compreensão de que o trabalho é parte essencial da vida do homem, e que merece a proteção do Estado na regulação das relações entre o capital e trabalho como 
política pública, o México, em 1917, foi o primeiro país no mundo a prever em sua Constituição, direitos relativos ao trabalho (DELGADO, M. 2014 p.77)

Seguindo o rumo de ampliar a rede de princípios e normas especialmente dirigidas ao trabalho, após a I Guerra Mundial, em 1919 foi criada através do Tratado de Versalhes a OIT (Organização Internacional do Trabalho), agência da Nações Unidas voltada exclusivamente a cuidar de assuntos relacionados ao trabalho humano, criando tratados e recomendações a serem observados pelos países signatários (LIMA FILHO, 2013) Nesse período o Brasil vivia seus problemas internos em relações laborais. Em 1912 foi organizado por anarquistas e socialistas o ato Primeiro de Maio, que se seguiu de greves em empresas têxteis e de calçados, levando os empresários a cederem às reivindicações de diminuição da jornada diária para oito hora e meia e aumento de salário (MAIOR, 2017, p.117).

Em maio de 1919, foi instaurada a Comissão Especial de Legislação Social da Câmara dos Deputados, em razão do compromisso assumido pelo Brasil no Tratado de Versalhes, não tendo havido rápido progresso ou efetividade da comissão.

Leis esparsas foram criadas ao longo dos anos, mas normalmente direcionadas a determinadas categorias e não se aplicando a todos os trabalhadores brasileiros, sendo grande preocupação do primeiro governo Vargas reprimir o movimento sindical.

O advento da II Guerra Mundial (1939 - 1945) e as atrocidades cometidas, obrigou as nações a repensarem seus valores e o próprio homem.

A partir de 1942, no período da ditadura de Vargas, houve grande pressão internacional sobre o governo brasileiro, tendo o então presidente Getúlio Vargas buscado o apoio interno para legitimar sua permanência no poder, criando o movimento que ficou conhecido como Trabalhismo, como resultado da estratégia de Vargas para angariar o apoio popular sob a promessa de concessão de direitos trabalhistas (MAIOR, 2017, p. 253).

O resultado dessa estratégia política foi a promulgação da CLT (Consolidação das Leis do Trabalho) em $1^{\circ}$ de maio de 1943, em ato público com enorme participação popular no Estádio São Januário, no Rio de Janeiro, sem que a população se notasse que esse "código" era basicamente o agrupamento de leis já existentes.

Nessa seara, em 1944 foi adotada a Declaração da Filadélfia pelos delegados da OIT que passou a ser anexo da Constituição da organização, e que é a sua carta de princípios, anterior, portanto, à Carta das Nações Unidas (1946) e à própria Declaração dos direitos Humanos (1948), de onde se extraem princípios basilares da Organização: 
A Conferência afirma novamente os princípios fundamentais sobre os quais se funda a Organização, isto é:

a) o trabalho não é uma mercadoria;

b) a liberdade de expressão e de associação é uma condição indispensável para um progresso constante;

c) a pobreza, onde quer que exista, constitui um perigo para a prosperidade de todos; d) a luta contra a necessidade deve ser conduzida com uma energia inesgotável por cada nação e através de um esforço internacional contínuo e organizado pelo qual os representantes dos trabalhadores e dos empregadores, colaborando em pé de igualdade com os dos Governos, participem em discussões livres e em decisões de carácter democrático tendo em vista promover o bem comum.

[...]

II

A Conferência, convencida de ter a experiência plenamente demonstrado a verdade da declaração contida na Constituição da Organização Internacional do Trabalho, que a paz, para ser duradoura, deve assentar sobre a justiça social, afirma que:

a) todos os seres humanos de qualquer raça, crença ou sexo, têm o direito de assegurar o bem-estar material e o desenvolvimento espiritual dentro da liberdade e da dignidade, da tranquilidade econômica e com as mesmas possibilidades;

.A dignidade humana, há muito bradada, é desde a Declaração Universal dos Direitos Humanos (1948) direito fundamental, com proposta de universalidade, expresso em documento internacional, inclusive para as relações laborais, conforme se infere do contido no artigo XXIII:

3. Todo ser humano que trabalha tem direito a uma remuneração justa e satisfatória, que lhe assegure, assim como à sua família, uma existência compatível com a dignidade humana e a que se acrescentarão, se necessário, outros meios de proteção social.

Após longo período, finalmente o Constituinte brasileiro consagrou o valor social do trabalho e da livre iniciativa, como fundamentos da república, previstos já no artigo $1^{\mathrm{a}}$, em situação de igualdade linear, na Carta da República, embora seja inegável que na realidade sejam forças antagônicas e que muitas vezes se contraponham e entrem em conflito, sem que possa ser negada a evolução de proteção normativa e principiológica do direito laboral.

Ademais, foram alçados à proteção Constitucional, os direitos sociais do trabalho previstos especialmente no art. $7^{\circ}$ da Constituição de 1988.

Em estudo jurídico-filosófico sobre a formação dos direitos, Norberto Bobbio assim assevera:

Do ponto de vista teórico, sempre defendi - e continuo a defender, fortalecido por novos argumentos - que os direitos do homem, por mais fundamentais que sejam, são direitos históricos, ou seja, nascidos em certas circunstâncias, caracterizadas por lutas em defesa de novas liberdades contra velhos poderes, e nascidos de modo gradual, não todos de uma vez e nem de uma vez por todas. (Bobbio, 2004, p.5)

E, também é desta forma em relação aos direitos sob a perspectiva do Direito do Trabalho, cujas normas, princípios e posicionamentos jurisprudenciais vão sendo construídos e lapidados ao longo da história.

A CLT sofreu alterações desde sua promulgação, porém sempre no sentido de conceder maiores direitos. 
Cumpre informar, por oportuno ao debate, que dentre os vários princípios do direito trabalho, três se destacam: a) o princípio protetivo, b) o princípio da norma mais favorável e c) o princípio da vedação ao retrocesso social.

O primeiro tem por escopo lógico, a proteção do trabalhador em razão de sua hipossuficiência frente ao poderio econômico de seu empregador.

O princípio da norma mais favorável tem uma característica muito peculiar. Utilizando como metáfora a pirâmide atribuída à Kelsen (MASCARO, 2016), o topo desta pirâmide para o Direito do Trabalho é flexível e não é necessariamente ocupado pela Constituição Federal, mas sim pela norma que atribua maiores direitos aos trabalhadores, podendo inclusive ser uma norma negociada por sindicatos e empregadores chamadas Convenções Coletivas do Trabalho ou Acordos Coletivos do Trabalho.

E por fim, o princípio do não retrocesso, tem suas bases na ideia de que conquistas jurídico-sociais são pautadas na melhora da condição da dignidade humana, e por isso não é aceitável que haja supressão de direitos, apenas avanços (SARLET, 2014).

\section{A resistência apresentada por parte dos juízes do trabalho: desobediência civil ou controle difuso de constitucionalidade?}

Como já mencionado, desde a fase de tramitação legislativa houve resistência por grande parte dos magistrados com jurisdição na seara trabalhista, basicamente sob o argumento de que a maioria das alterações legislativas propostas representavam a perda de direitos sociais conquistados, e que isso atentava contra o princípio do não retrocesso social.

Dentre as justificativas apresentadas, está ainda a de que tais modificações que retiram direitos dos trabalhadores seriam inconstitucionais, já que ferem a previsão de que a lei só pode melhorar os direitos dos trabalhadores e não retirar, conforme disposto no caput do $\operatorname{art} .7^{\circ} \mathrm{da}$ CRFB: "São direitos dos trabalhadores urbanos e rurais, além de outros que visem à melhoria de sua condição social”.

Não se pretende aqui analisar o conteúdo das alterações normativas aprovadas, mas sim, - tendo em vista a modificação da arena do embate para os tribunais - analisar a condição dos juízes, individualmente ou organizados em associações, que se opõem à essa reforma, visando perquirir se estariam em legítimo ato jurisdicional ou em ato de desobediência civil. 


\title{
3.1 Análise da Atuação jurisdicional
}

Em nosso sistema jurídico, o ato de posse de um juiz o habilita a praticar atos de judicatura, decorrente do poder exclusivo do Estado, dentro da competência estabelecida constitucionalmente.

Possui ainda o juiz uma série de deveres e compromissos, inclusive em sua vida privada, a que passa a ser obrigado a observar quando empossado.

Sobre isso, destaca-se o teor do disposto no inciso I art. 35 da Lei Orgânica da Magistratura Nacional (LC 35/1979), a que está submetido o juíz: “I - Cumprir e fazer cumprir, com independência, serenidade e exatidão, as disposições legais e os atos de ofício;"

Ademais, no ato de posse solene os juízes fazem um juramento de "respeitar, cumprir e aplicar as leis e a Constituição da República Federativa do Brasil”".

Isso significa, então, que não poderiam os juízes do trabalho se oporem à reforma trabalhista? Não exatamente.

Em matéria denominada "O dever de aplicar a lei”, publicada pelo jornal O Globo, em 30/09/2017, disponível no site do referido meio de imprensa, o então presidente da Associação dos Juízes do Trabalho, Otávio Amaral Calvet assevera que:

\begin{abstract}
$[\ldots]$
O problema começa quando a sociedade questiona a atuação dos juízes do Trabalho, se eles vão ou não aplicar a nova lei. Será que a Justiça do Trabalho vai impedir a reforma trabalhista?

Ao contrário de demonizar a sociedade, como se nós, juízes, estivéssemos em patamar superior de entendimento acerca do melhor caminho para o futuro, cabe-nos refletir e reconhecer que, diante de várias manifestações pautadas por ideologia (de todos os matizes), nosso papel é simplesmente nos voltar para nosso mister: aplicar a lei.

Juiz não defende esta ou aquela mudança na lei, juiz não aplica a lei conforme preferências pessoais, juiz não submete a lei a um programa ideológico, juiz não é tendencioso na interpretação para afastar a lei com a qual não concorda, juiz não possui atuação político-partidária, juiz não se imiscui no Poder Legislativo. Juiz atua como juiz.
\end{abstract}

[...] (CALVET, 2017)

Numa leitura singela com interpretação literal, poderiam ser (equivocadamente) entendidas essas palavras como uma certeza de atuação jurisdicional seguindo exatamente o que está estabelecido na alteração legislativa, mas não é tão simples assim.

Não há mais dúvidas acerca da constitucionalização de todas as normas e atos jurídicos no Brasil, em que a validade de qualquer norma é aferida frente aos preceitos contido na Magna Carta, e nos princípios que inspiram e apontam o caminho em uma república democrática.

De forma a que o sistema jurídico se mantenha hígido, é necessário que haja, então, o controle de constitucionalidade das normas, que pode ser realizado de forma concentrada, 
através das ações cabíveis perante o Supremo Tribunal Federal, conforme previsão nos arts. 102 e 103 da CF/88, que possui a função nomofilácica de guarda da Constituição e a palavra final na interpretação desta.

É possível, ainda, o controle difuso de constitucionalidade de normas infraconstitucionais, inclusive por juízes de primeiro grau, quando esses decidem incidentalmente pela inadequação/compatibilidade de uma norma em confronto com o denominado bloco de constitucionalidade, sendo, pois, caso de ação subjetiva e não objetiva, e com efeitos limitados ao caso concreto em análise.

Desde a revolução provocada pelo neoconstitucionalismo, que o Poder Judiciário não é apenas mero aplicador da letra fria da lei.

Neste sentido, destacou Marinoni:

O juiz não é mais a boca da lei, como queria Montesquieu, mas o projetor de um direito que toma em consideração a lei à luz da Constituição e, assim, faz os devidos ajustes para suprir as suas imperfeições ou encontrar uma interpretação adequada, podendo chegar a considerá-la inconstitucional no caso em que a sua aplicação não é possível diante dos princípios da justiça e dos direitos fundamentais.(MARINONI, 2016; p. 67).

Esta possibilidade está assentada em nossa jurisprudência, após várias discussões acerca da competência para tanto, em relação ao disposto no art. 97 da CF.

Aliás, sobre esse tema, Mendes e Branco (2017, p. 1207) citando Martins de Oliveira e Carlos Lucio Bittencourt, assim leciona:

A exigência de maioria absoluta dos votos para a declaração de inconstitucionalidade de leis pelos tribunais, introduzida pela Carta de 1934 (art. 179) e reproduzida nas subsequentes (CF de 1937, art.96; CF de 1946, art. 200; CF de 1967/69, art. 116; CF de 1988, art. 97), ensejou polêmica sobre a possibilidade de o juiz singular pronunciarse sobre a inconstitucionalidade. Prevaleceu todavia o entendimento que afirmada a competência do juiz singular para apreciar a controvérsia constitucional.

Destaque-se, ainda, que não é necessária a provocação de qualquer parte acerca da inconstitucionalidade de determinada norma como matéria prévia do mérito e não como objeto de pedido, podendo ser essa declarada ex oficio.

Resta, assim, que ao julgar caso concreto, poderá o juiz do trabalho singular declarar incidentalmente a inconstitucionalidade de qualquer das normas contidas na reforma trabalhista, afastando sua incidência ao caso sub judice, desde que, é claro, fundamente sua decisão, quaisquer que sejam seus jurídicos argumentos a embasar tal decisão.

Este ato é, por óbvio, um ato típico jurisdicional, e não de desobediência civil, já que está entre suas funções a obrigação de observar a Constituição em cada decisão que proferir. 
Mas, há situações em que o juiz ao se pronunciar publicamente em sua vida pessoal e até mesmo em julgamentos, pode sugerir ato de desobediência civil.

\section{2 É possivel a desobediência civil por juizes}

Necessário, a princípio, brevemente revisitar o conceito e caracterização da desobediência civil.

O exercício pleno da cidadania, em qualquer sociedade democrática do mundo, passa não apenas pela concessão (em tese) de direitos à liberdade e à vida, etc., mas essencialmente pela qualidade do exercício dos direitos à liberdade em seus vários aspectos, inclusive políticos e religiosos, e também em, de fato, se sentir a igualdade, o respeito pelos direitos fundamentais, e a atuação positiva do Estado em promover o bem estar social em uma sociedade nas suas relações mais cotidianas.

A compreensão de que a cidadania é realmente exercida quando a postura do cidadão não é de mero espectador frente a atos da Administração que vão de encontro à opção social de um país, é uma das pedras fundantes desse tema, e bem analisada na proposta feita por

\section{LEHFELD:}

[...] Parte-se, para tanto, de uma visão de cidadania como caráter eminentemente político da liberdade - a possibilidade efetiva do agir individual - para se chegar à resistência à opressão (por meio de instrumentos previstos implícita ou expressamente no ordenamento constitucional) como princípio legitimador de uma substancial representação democrática por parte dos administrados na condução das políticas públicas. (2005, p.160-161)

Analisando o Poder e a possibilidade de resistência, Garcia, citando Leviatã, assim

leciona:

Mais: o soberano hobbesiano tem direitos ilimitados, mas não pode usá-los ao seu capricho. Além da ideia de racionalidade desse governo, "a arbitrariedade nas condenações, o abuso na repressão devolvem a liberdade aos homens, contra um Estado que já não é deles: pois deixo de me reconhecer na máscara do soberano que me fere u prende. [..]" (GARCIA, 2004, p.135)

Segundo a mesma autora, o $\S 2^{\circ}$ do art. $5^{\circ}$ da CF possibilita aos administrados a insurgência contra norma infraconstitucional que contrarie tratados internacionais dos quais o Brasil seja signatário.

Nem se discuta que tratados e convenções são normas internacionais diferentes, e o texto previsto no $\S 2^{\circ}$ do art. $5^{\circ}$ trata expressamente de tratados internacionais.

Porém, para efeito da compreensão da motivação à resistência, as Convenções internacionais da OIT possuem natureza jurídica de norma supralegal ao qual o Brasil se 
obrigou a cumprir ao firmar o Tratado de Versalles.

Se na análise do conjunto de regras e princípios (nacionais e internacionais) que norteiam o direito do trabalho houver a compreensão de que determinadas regras contidas na reforma trabalhista leva à conclusão de abuso por parte do poder Público que a editou, votou, aprovou e promulgou as alterações legislativas, o administrado pode não mais se perceber na "máscara" de seu governante, isentando-se, pois, da obrigatoriedade de cumpri-la.

Porém, a desobediência civil não é o simples não cumprimento de norma jurídica, sob pena de poder sofrer sanções, já que não vivemos sob os auspícios de regime anárquico.

A desobediência civil, a exemplo da resistência, deve se utilizar de ferramentas que o próprio sistema jurídico coloca à disposição, pois a desobediência civil é, no fundo, a preservação da essência verdadeira do regime democrático.

Pois bem, feitas essas breves considerações, retomemos a perquirição de poder ou não um juiz do trabalho praticar a desobediência civil.

Na hipotética situação de o juiz, em suas redes sociais, se manifestar contra a reforma trabalhista por entendê-la como prejudicial aos trabalhadores, conclamando a que as outras pessoas ponderem sobre tais fatos, estar-se-ia, sim, diante de atos de desobediência civil, porém não serão de um juiz, mas sim da pessoa física.

Cabe ressaltar, todavia, que esse mesmo magistrado, hipoteticamente considerado, quando está na situação de empregador de algum trabalhador doméstico, e opta por não aplicar a legislação trabalhista recém modificada (Lei 13.467/2017), mantendo benefícios ao trabalhador em sua relação jurídica privada, não é caso de desobediência civil, posto que conforme se infere do art. $7^{\circ}$ da $\mathrm{CF} / 88^{1}$, a previsão normativa de direitos não impede a concessão de melhores condições de trabalho.

$\mathrm{O}$ ato da desobediência civil é ato que pode ser individual ou coletivo, e a influência que terá na coletividade possui inúmeras variáveis, não conduzindo, automaticamente, à uma situação de insegurança jurídica em proporções que abalem o sistema jurídico de um país.

Porém, neste estudo, é essencial que duas situações concretas sejam trazidas à discussão, já que, em tese, sugerem a prática de ato que pode ser caracterizado como Desobediência Civil.

O primeiro a ser mencionado, é a propositura da Ação Direta de Inconstitucionalidade ADI-5870, pela Associação Nacional dos Magistrados da Justiça do Trabalho (ANAMATRA) em 21/12/2017, que tramita perante o STF, que demonstra inegavelmente resistência aos pontos

\footnotetext{
${ }^{1}$ Art. $7^{\circ}$ São direitos dos trabalhadores urbanos e rurais, além de outros que visem à melhoria de sua condição social
} 
da reforma trabalhista que são objeto da ação.

O segundo, tem base em levantamento realizado pelo TST que demonstra que $1 \mathrm{em}$ cada 4 acordos de rescisão contratual realizados entre empregadores e empregados não são homologados pela Justiça do Trabalho, conforme matéria veiculada por meio eletrônico do jornal Folha de São Paulo de 06 de maio de 2018 (FOLHA, 2018).

Essa possibilidade de rescisão direta entre as partes na empresa, ou submetida à homologação judicial, caso queiram as partes, dispensando a participação de Sindicatos,é uma das inovações trazidas pela Reforma Trabalhista.

Os juízes que não homologam essas rescisões, partem não de recusa do empregado à homologação, mas sim das convicções pessoais de que uma vez homologado acordo com quitação geral, o empregado estará impedido de no futuro buscar os recebimentos de outras verbas. Ou seja, mesmo que empregado e empregador desejem e estejam cientes do teor do pacto, o juiz não o homologa, num ato e hiperproteção pautado em suas convicções pessoais.

Nos parece, assim, que estas duas situações citadas são casos de desobediência civil estudado por Garcia.

O posicionamento contrário à reforma de um juiz em uma comarca com 100 vara do trabalho, por exemplo, é menos impactante do que esse mesmo posicionamento em uma comarca com duas ou apenas uma vara.

Por questão de coerência, é fácil supor que um juiz que pratica atos considerados de desobediência civil em suas relações particulares, possivelmente agirá processualmente com essa resistência às alterações legislativas.

É fato que até que haja pronunciamento do STF acerca da constitucionalidade ou não das normas contidas na reforma trabalhista, inúmeros questionamentos ainda existirão, e muitos julgamentos contraditórios sobre um mesmo artigo da CLT certamente ocorrerão.

Até o momento da elaboração do presente artigo, já haviam sido distribuídas mais de 30 Ações Diretas de Inconstitucionalidade (ADI) junto ao STF, questionando pontos das reformas trabalhistas.

Resta, pois, aguardar que haja célere pronunciamento do STF sobre o tema da constitucionalidade ou não da reforma trabalhista, de forma a que haja mais segurança jurídica para aplicação (ou não) das novas normas, pois é indubitável que a sociedade está num verdadeiro "limbo jurídico" apesar da vigência da norma, correndo o risco de ser punida em caso de observância de lei que poderá vir a ser considerada, em pontos importantes, como inconstitucional. 


\section{Conclusão}

A promulgação da Lei federal13.467 de 13 de julho de 2017, denominada Reforma Trabalhista, trouxe com as alterações da legislação laboral, profundo debate social sobre serem estas modificações benéficas ou prejudiciais à coletividade dos trabalhadores.

Parte da sociedade entende que referidas modificações de fato vieram a modernizar as relações trabalhistas, que estavam estagnadas por legislação basicamente formada na década de 30 e 40 quando o Brasil era ainda um país predominantemente rural, tais como a possibilidade de terceirização inclusive de atividade ligada à finalidade da empresa; a fruição de férias em períodos distintos, caso assim deseje o trabalhador, a previsão de sucumbência processual, a possibilidade de rescisão contratual de comum acordo e sem a necessidade de homologação sindical, etc.

Por outro lado, os que se opõem à reforma, defendem que as modificações introduzidas representam retirada de direitos dos trabalhadores que foram conquistados ao longo de séculos de luta, tais como: o amplo acesso à justiça, a possibilidade de gestantes trabalhares em atividades insalubres, o trabalho intermitente, a desproteção sindical na homologação das rescisões de contratos, etc.

Argumentam, ainda, que se trata de claro retrocesso social, o que é vedado por nosso sistema jurídico, existindo, dentre elas, regras incompatíveis com os preceitos traçados na Carta Magna, contaminando referidos dispositivos com a inconstitucionalidade.

Dentre esses, não raro encontram-se juízes do trabalho que se colocam ostensivamente contrários à boa parte das modificações que entraram em vigor em novembro de 2017.

Analisada a postura destes magistrados, resta óbvio que a declaração incidental de inconstitucionalidade de determinado dispositivo legal modificado, realizada em julgamento de caso concreto, ainda que por juiz singular, é típico ato jurisdicional.

Quanto, todavia, esse magistrado se posiciona de forma contrária à reforma, por exemplo, quando ministra palestras, em suas redes sociais, quando se nega a homologar acordos de rescisão contratual direto entre as partes (como previsto na nova legislação em vigor), é possível, sim, a ocorrência de ato de desobediência civil, pautada na compreensão pessoal de que a reforma trabalhista é um ato contrário às pautas esperadas num regime social democrático.

Compreendida sob esse prisma, a desobediência civil é ato de exercício de cidadania, com fundamento de que, quem o pratica, entende que resiste à uma violência injusta.

Ainda há na sociedade, grande conflito interpretativo sobre a aplicabilidade das novas 
regras, notadamente pelo posicionamento dos magistrados do trabalho que, por óbvio, serão os que julgarão as causas que discutam relações trabalhistas, cabendo ao STF julgar, com a maior celeridade possível, as inúmeras ADI já propostas, como forma de pacificar as relações sociais e trazer mais segurança jurídica aos jurisdicionados.

\section{Referências bibliográficas}

ANDRADE, Everaldo Gaspar Lopes de. Princípios do Direito do Trabalho: Fundamentos teóricos-Filosóficos. São Paulo: Ltr, 2008. 287 p.

BOBBIO, Norberto. A Era dos Direitos. $8^{a}$ ed., Rio de Janeiro: Elsevier, 2004,

BOBBIO, Norberto. Teoria da Norma Jurídica. $6^{\text {a }}$ ed. São Paulo: Edipro, 2016. Tradução de Arani Bueno Sudatti e Fernando Pavan Baptista.

BRASIL. Constituição (1988). Constituição Federal nº 1, de 1988. Constituição Federal.

BRASIL. Decreto-lei n ${ }^{0} 5.452$, de 01 de maio de 1943. CLT

BRASIL. Associação Nacional dos Magistrados da Justiça do Trabalho. STF. ADI - 5870. 2017. Andamento processual. Disponível em:

$<$ http://portal.stf.jus.br/processos/detalhe.asp?incidente=5335465>. Acesso em: 30 abr. 2018.

CALVET, Otávio Amaral. O dever de aplicar a lei. O Globo. Rio de Janeiro, p. 1-1. 30 set. 2017. Disponível em: <https:/oglobo.globo.com/opiniao/o-dever-de-aplicar-lei-21890141>. Acesso em: 14 out. 2017.

CAVALCANTE, José Luiz. A Lei de Terras de 1850: e a reafirmação do poder básico do Estado sobre a terra. 2005. Disponível em:

$<$ http://www.historica.arquivoestado.sp.gov.br/materias/anteriores/edicao02/materia02/>. Acesso em: 08 out. 2017.

DELGADO, Gabriela Neves et al. Trabalho, Constituição e Cidadania: A Dimensão Coletiva 
dos Direitos Sociais Trabalhistas. São Paulo: Ltr, 2014.

DELGADO, Gabriela Neves. Direito Fundamental ao Trabalho Digno. 2. ed. São Paulo: Ltr, 2015. 224 p.

DELGADO, Maurício Godinho. Curso de Direito do Trabalho. 13. ed. São Paulo: Ltr, 2014. $1536 \mathrm{p}$.

GARCIA, Maria. Desobediência Civil: Direito Fundamental. 2. ed. São Paulo: Revista dos Tribunais, 2004. $336 \mathrm{p}$.

GEMIGNANI, Tereza Aparecida Asta; GEMIGNANI, Daniel. Direito Constitucional do Trabalho: da análise dogmática à concretização de questões polêmicas. São Paulo: Ltr, 2014. $143 \mathrm{p}$.

LEHFELD, Lucas de Souza. Modalidades de Participação-Cidadã no Horizonte de Concreção do Direito. In: FERREIRA, Luiz Alexandre Cruz et al (Org.). Hermenêutica, Cidadania e Direito. Campinas: Millenium, 2005. Cap. 6, p. 160.

LIMA FILHO, Claudio Dias. Por Uma Interpretação Não Restritiva dos Direitos Fundamentais do Trabalhador Reconhecidos na Constituição. In: MIESSA, Élisson; CORREIA, Henrique (Org.). Estudos Aprofundados Ministério Público do Trabalho. 2. ed. Salvador: Jus Podivum, 2013. Cap. 8, p. 238.

MAIOR, Jorge Luiz Souto. História do Direito do Trabalho no Brasil. São Paulo: Ltr, 2017. 723 p. (Vol. I - Parte II).

MANIFESTO contra a reforma trabalhista.: Petição Pública. 2016. Disponível em: $<$ http://www.peticaopublica.com.br/pview.aspx?pi=BR98485>. Acesso em: 26 abr. 2018.

MARINONI, Luiz Guilherme. Novo curso de processo civil, volume 1 - 2a edição revisada, atualizada e ampliada. São Paulo: Editora Revista dos Tribunais, 2016.

MARTINS FILHO, Ives Gandra da Silva. É preciso flexibilizar direitos sociais para haver 
emprego. Folha de São Paulo: Economia. Brasília, 06 nov. 2017. p. 1-1. Disponível em: $<$ http://www1.folha.uol.com.br/mercado/2017/11/1933111-e-preciso-flexibilizar-direitossociais-para-haver-emprego-diz-chefe-do-tst.shtml>. Acesso em: 25 abr. 2018.

MARX, Karl Heinrich; ENGELS, Friedrich. O Manifesto Comunista. 1848. Disponível em: $<$ http://www.ebooksbrasil.org/adobeebook/manifestocomunista.pdf $>$. Acesso em: 12 out. 2017.

MASCARO, Alysson Leandro. Filosofia do Direito. 5. ed. São Paulo: Atlas, 2016. 610 p.

MENDES, Gilmar Ferreira; BRANCO, Paulo Gustavo Gonet. Curso de Direito

Constitucional. 12. ed. São Paulo: Saraiva, 2017. 1576 p.

MORAES, Guilherme Peña de. Curso de Direito Constitucional. 8. ed. São Paulo: Gen Atlas, 2016. 911 p.

PEDUZZI, Maria Cristina Irigoyen. O Princípio da Dignidade da Pessoa Humana: Na perspectiva do Direito como Integridade. São Paulo: Ltr, 2009. 111 p.

PIOVESAN, Flavia (Org.). Direito ao Trabalho e a Proteção dos Direitos Sociais nos Planos Internacional e Constitucional. In: PIOVESA, Flávia et al (Org.). Direitos Humanos e Direito do Trabalho. São Paulo: Atlas, 2010. Cap. 1, p. 6.

SARLET, Ingo Wolfgang. Os direitos fundamentais (sociais) e a assim chamada proibição de retrocesso: contributo para uma discussão. In: DELGADO, Gabriela Neves; PEREIRA, Ricardo José Macedo de Britto (Org.). Trabalho, Constituição e Cidadania: A dimensão coletiva dos direitos sociais trabalhistas. São Paulo: Ltr, 2014. Cap. 12, p. 176.

VON AMMON, Cinthia Passari. Trabalho Extraordinário: Submissão em descompasso com as normas que limitam o tempo de trabalho e seus reflexos na saúde do trabalhador. In: BARBOSA, Amanda et al (Org.). Atualidades e Tendências do Direito e Processo do Trabalho. São Paulo: Ltr, 2017.p. 47. 


\section{ANÁLISE DE IMPACTO REGULATÓRIO (AIR) E SUAS ETAPAS}

Gabriel Fliege de Lucena Stuckert

Universidade Federal do Estado do Rio de Janeiro

\section{Resumo}

As Análises de Impacto Regulatório (AIR) tem sido um instrumento incorporado pelas Agências Reguladoras como uma ferramenta para a melhoria da regulação. Quais etapas ou elementos são seriam necessários e capazes de imprimir um diferencial analítico para esta ferramenta? Este artigo pretende responder à pergunta proposta, passando pelo conceito de uma Análises de Impacto Regulatório, para em seguida explorar mais detidamente as principais etapas que por ela devem ser utilizadas.

Palavras-Chave: Análise de impacto regulatório (AIR), direito, políticas públicas, economia, processo

\section{Abstract/Resumen/Résumé}

Regulatory Impact Assessment (RIA) has been adopted by Regulatory agencies as a tool to improve regulatory quality. Which are the steps or elements that are necessary to print an analytical advantage for this tool? This article aims to answer the question posed, going through the concept of RIA as tool, to then further explore the main steps or elements used by RIA.

Keywords/Palabras-claves/Mots-clés: Regulatory impact assessment (RIA), law, public policies, economics, process. 


\section{Introdução}

As Análises de Impacto Regulatório podem ser um instrumento para a análise e avaliação das políticas públicas no âmbito da regulação, de forma a auxiliar na fundamentação e na racionalidade das opções tomadas pelos reguladores, como um instrumento de melhoria da qualidade regulatória.

AIR não pretende ser apenas mais um procedimento meramente justificador de decisões já postas em processos administrativos, incapaz de produzir qualquer alteração na tomada de decisões. Nesse sentido, o uso e a compreensão das metodologias disponíveis para esta ferramenta merecem especial atenção.

O tema da Análise de Impacto Regulatório - AIR é bastante atual e de grande importância no contexto das Agências Reguladora enquanto agentes produtores (seja na formulação ou implementação) de políticas públicas.

Este artigo pretende explorar as principais etapas ou elementos que constituem esta ferramenta, buscando contribuir para uma compreensão mais específica das Análises de Impacto Regulatório, e as razões para as quais estas subdivisões metodológicas seria potencialmente relevante para que este instrumento possa alcançar em termos práticos, os resultados teóricos dele esperados.

Procuraremos também verificar a relação entre esses elementos com as etapas do modelo conceitual de processos, ou ciclos de políticas públicas, bastante utilizados nos estudos de políticas públicas e em suas análises.

Ao final esperamos poder contribuir com os debates relativos a esse tema, tentando encurtar a distância entre aquilo que é idealmente proposto em termos teóricos e acadêmicos, daquilo que se espera em termos práticos da atuação dos agentes públicos diante das complexidades das questões e das dinâmicas da atualidade e dos anseios da sociedade por uma atuação com maior eficiência, eficácia, racionalidade e sustentabilidade.

\section{AIR}

Análise de Impacto Regulatório, pela definição da OCDE seria “(...) ao mesmo tempo, uma ferramenta e um processo para instruir a autoridade política sobre "se" e "como" regular para atingir as metas de políticas públicas." "Por isso, AIR é recomendada pela OCDE, como

\footnotetext{
${ }^{1}$ Tradução livre de trecho de: Recommendation of the Council of the OECD on Regulatory Policy and Governance, 2012, p. 25, disponível em: http://www.oecd.org/gov/regulatory-policy/49990817.pdf; acesso em: 17/10/2013;
} 
um instrumento de boas práticas regulatórias e um mecanismo de aumento da eficiência e da eficácia da intervenção do Estado nas atividades reguladas.

Para Patricia Pessôa Valente (2013, p. 35), AIR seria "um procedimento ordenado de tomada de decisão no âmbito da atividade regulatória estatal, baseado no uso sistemático de análises sobre possíveis efeitos de uma dada decisão."

Alketa Peci (2010, p. 8) adverte que AIR é derivada do referencial teórico de policy analysis, e que "consiste na análise e avaliação dos possíveis benefícios, custos e impactos de regulamentações novas ou já existentes.”

Pode-se entender AIR como um processo, ou procedimento que deve possuir etapas determinadas e que, ao final, deve ser concluído com a produção de um relatório, que por sua vez, deve possuir uma estrutura com elementos determinados ${ }^{2}$.

Claudio Radaelli (2008, p.2) também aponta a qualidade sistêmica do processo de AIR, advinda da necessidade de coerência, alertando que sua sofisticação e abrangência analítica irão variar, dependendo das questões em jogo e dos recursos disponíveis, e que o grau de sofisticação deveria ser proporcional aos efeitos esperados da regulação. A ferramenta poderia ser usada tanto para propostas de novas regulações, quanto para a avaliação de regulações já em vigor. Esse autor também aponta a utilidade desta ferramenta enquanto instrumento de controle ${ }^{3}$ da produção normativa delegada para as agências reguladoras ${ }^{4}$.

No mesmo sentido, de que é um método sistêmico para analisar impactos positivos e negativos, de regulação já existente ou de propostas de nova regulação, aponta Colin Jacobs (2005, p.2), que acrescenta o propósito de esclarecer (ou explicar) os objetivos da regulação proposta, deixando transparentes tanto os custos quantos os benefícios das opções para todas as partes envolvidas (governo, agentes econômicos), sublinhando ainda o caráter multidisciplinar que deve ser perseguido tanto quanto for possível (incluindo questões sociais, ambientais, econômicas, por exemplo).

Colin Kirkpatrick (2004, p.4), em artigo onde apresenta o resultado de uma pesquisa a respeito do uso da AIR em países com economia em desenvolvimento, apresenta três dimensões desta ferramenta: pode ser verificada como método de avaliação; como processo; ou ainda como parte de uma estratégia mais geral para a reforma regulatória (Idem, p.4). Quanto

realizada pelo autor.

${ }^{2}$ Nesse sentido: SAMPAIO, 2010, p. 21 a 24

${ }^{3}$ Alertando para que esse papel de controle deveria ser gerenciado com cautela, de modo que modelos excessivamente detalhados não gerem parâmetros que se sobreponham a princípios, ver: BLACK, 2001, p. 29.

${ }^{4}$ Nos EUA, esse controle seria exercido pelo Poder Executivo, através do OIRA (Office for Information and Regulatory Affairs), ligado ao OMB (Office for Management and Budget). 
a uma definição, este autor esclarece que a AIR teria sido originalmente concebida como um instrumento para identificar os custos de regulação sobre setores empresariais, e que seria seguido por um processo de des-regulação visando reduzir o "peso" da regulação e melhorando assim a competitividade. Ao longo do tempo, a definição teria sido ampliada e refinada, passando o foco não apenas para os custos, mas incluindo considerações a respeito dos benefícios. Isso passaria pelo reconhecimento que a regulação não seria ruim por si só, e que precisa ser avaliada caso a caso, de modo a verificar em que termos esta contribui para os objetivos da política pública.

Para Delia Rodrigo (2005, p. 2 e 3), AIR seria útil para analisar e medir prováveis benefícios, custos e efeitos, através de dados empíricos que auxiliariam na avaliação de opções e de consequências das decisões, ajudando a identificar e definir problemas, de modo que as ações governamentais sejam justificadas e apropriadas.

A AIR é, portanto, um processo ou procedimento que ao final deve ser concluído com a produção de um relatório. Nesse sentido, a AIR possui um caráter duplamente instrumental, que poderíamos distinguir aqui como intrínseco e extrínseco.

O caráter intrínseco da instrumentalidade da AIR se daria em função de que o seu procedimento tem como finalidade a elaboração de um relatório, e nessa medida, as fases ou etapas desse processo estão intimamente ligadas a esta produção.

Já o caráter extrínseco da instrumentalidade da AIR se daria pelo fato de que esta não se destina necessariamente a produzir uma determinada regulação. Em outras palavras, a regulação que se formula em função da elaboração de um relatório de AIR é posterior e incidental.

Por exemplo, uma determinada análise de impacto pode avaliar que os custos de se elaborar e implementar alternativas regulatórias para a solução de um determinado problema são maiores que os benefícios esperados desta solução. Nesse caso, a recomendação da análise pode ser de não fazer nada, e desta forma, esta AIR não resultaria numa regulação.

Outra hipótese que também é possível de ocorrer, seria a de uma determinada análise verificar que a existência, ou ao menos o agravamento de um determinado problema decorre de uma regulação já em vigor. Nesse caso, uma solução possível seria a revogação desta regulação, ou melhor, desregular a questão. Aqui também poderíamos entender que a AIR não se prestou à produção de regulação, ao menos em seu sentido positivo.

Esta dupla dimensão da instrumentalidade da AIR tem enorme importância no potencial uso da ferramenta. Caso a autoridade reguladora já tenha se decidido em regular para solucionar determinado problema, é possível que a produção de uma AIR não seja capaz de 
dissuadi-la desta decisão, ainda que desta análise se verifique que regular não seria a melhor alternativa para a questão.

Nesse sentido, tendo a autoridade reguladora já decidido por regular, muito provavelmente a forma de regular também já deve estar, no mínimo, pré-concebida (se também já não se encontra na esfera da decisão). Nesta situação, é razoável imaginar que a análise de impacto poderia ter a missão implícita de fundamentar a decisão que já foi anteriormente tomada.

Assim, mesmo que se proceda a uma análise com algum grau de imparcialidade da escolha prévia, também é possível que esta AIR não seja capaz de alterar a decisão do regulador (DIAS, 2015, p. 83). Em sendo este o caso, provavelmente seria melhor que, no lugar da elaboração de uma AIR, se procedesse a uma exposição de motivos, e que se elabore a regulação, conforme já se havia decidido (SALGADO; BORGES, 2010, pp 22 e 23).

Em sentido oposto, pode-se também argumentar que, promovendo a possibilidade de escolhas racionais, a AIR também poderia ser capaz de alterar a decisão prévia do regulador. Poderíamos inclusive usar como exemplo o caso da utilização de chumbo na gasolina, durante o governo Reagan, onde a autoridade pretendia desregular, mas após a análise de custos e riscos, terminou por ampliar a regulação e restringir ainda mais o uso (VALENTE, p. 38 e 39).

Entretanto, presumir que essa capacidade de fazer com que a autoridade reguladora “mude de ideia” é absoluta, parece uma posição no mínimo ingênua 5 .

É exatamente por isso que o procedimento da AIR tem como finalidade a elaboração de um relatório de análise de impacto, e não de uma ou algumas alternativas de regulação. E as fases ou etapas desse processo estão ligadas intimamente à produção deste relatório. A elaboração de eventual regulação é posterior e incidental e espera-se (é claro) que reflita a opção de escolha sugerida no referido relatório de AIR. Nesse sentido é importante que alternativas não regulatórias, manutenção do status quo bem como a hipótese de desregulação figurem, tanto quanto possível, entre as opções analisadas.

Assim como nos ciclos de políticas públicas, não encontraremos consenso na quantidade ou descrição das etapas. A variação da quantidade de etapas também resulta da facilidade de integração e de subdivisão entre as etapas, que são racionalmente encadeadas. A falta de uma regra geral e uniforme sobre AIR contribui para esta falta de consenso, mas não é a única questão. A regulação ocorre em setores econômicos diversos e distintos, e tenta solucionar problemas de variados graus de complexidade. Por isso ocorrem soluções e

\footnotetext{
${ }^{5}$ Podemos observar que, no exemplo utilizado, a vontade política inicial era de desregular e que fundamentar a regulação parece uma atividade muito mais "natural” para um regulador, que agir de modo contrário.
} 
alternativas regulatórias distintas e a análise deste amplo espectro de problemas e respostas demanda uma certa flexibilidade na escolha das metodologias aplicáveis (RODRIGO, 2014). O grau de complexidade dos problemas e alternativas pode, inclusive, resultar na utilização de modelos de AIR mais simples ou mais elaborados.

\section{Identificação do Problema}

Assim como nos ciclos de política pública, ou modelo conceitual de processos, a identificação do problema é a primeira etapa na elaboração da AIR, sendo também uma das etapas mais relevantes. Definir o problema de maneira adequada estará intimamente ligado à possibilidade de se atuar, buscando sua solução. A definição do problema também influenciará na opção de uma metodologia que seja capaz de proceder à sua análise (SILVA, 2015, p.14).

Apesar destas afirmações iniciais, colocadas em termos abstratos, parecerem relativamente simples, quando postas em termos práticos em casos concretos, não devem ser subestimadas.

Quando observamos um fato, ou um fenômeno, o que se destaca, em regra, são suas consequências e seus efeitos. Uma identificação correta de um problema deve se preocupar com a(s) causa(s), além das consequências.

Tomemos, portanto, a seguinte situação hipotética: ao retornar para nossa casa após o trabalho, deparamo-nos com o chão da cozinha encharcado de água. Uma verificação precipitada pode estabelecer que "água no chão da cozinha" é a descrição do nosso problema hipotético. Entretanto, a água no chão não surgiria de forma espontânea (por não estar sob céu aberto, não iria chover no chão da cozinha). O aparecimento da água é um efeito, e será necessário, por tanto, uma maior investigação de sua causa.

Digamos que a torneira da pia da nossa cozinha esteja quebrada, e a água que escorre pela torneira transbordou pela pia e acumulou-se no chão. Nesse caso, o nosso problema poderia ser descrito como "torneira da pia quebrada".

Suponhamos, no entanto, que a torneira esteja funcionando perfeitamente. Ao observar a parede da cozinha, verificamos que a água vem da parede. Em função desta observação iremos inferir que há algum vazamento na tubulação e que a água dali infiltrada, acumulou-se no chão. Nesta hipótese, o problema poderia ser descrito como "infiltração de água na parede", ou "tubulação de água defeituosa". Vale notar que nessa hipótese, só seríamos capazes de estabelecer se a tubulação defeituosa é da nossa própria cozinha, ou da tubulação do vizinho que divide a parede entre nossos apartamentos, ou ainda de alguma tubulação comum, 
do condomínio, depois de quebrada a parede (ou seja, dependendo de análises posteriores).

Vamos imaginar, contudo, que não há torneira quebrada, ou qualquer vazamento ou infiltração de água, seja das paredes ou do teto. Digamos que, nesse caso, nossa esposa chega em casa logo em seguida, e nos explica que deixou uma garrafa se enchendo de água na cozinha, mas atrasada que estava para o trabalho, esqueceu-se desta, apenas vendo-a transbordar quando já estava prestes a sair de casa. Desta forma, fechou a torneira e guardou a garrafa, mas deixou como estava, a água acumulada no chão da cozinha. Nessa hipótese, podemos dizer que não há um problema que mereça ser descrito (ocorreu um fato isolado, ainda que a atitude da esposa hipotética pudesse ser questionada).

O exemplo proposto, ainda que prosaico, serve para ilustrar que uma descrição equivocada do problema pode resultar na elaboração de alternativas de solução que tenderiam a não serem efetivas, não alcançando os benefícios a que se propõem. Nos casos de problemas no âmbito da regulação, algumas questões adicionais ainda se impõem nesta fase, tais como: se este decorre de uma falha de mercado, de uma falha institucional, ou ainda de uma falha

regulatória (ANS, Agência Nacional de Saúde Suplementar, 2014, pp. 10 e 11). É também interessante que a competência do regulador para agir também esteja verificada, desde o princípio.

\section{Identificação dos grupos afetados}

Uma vez que o problema se encontra adequadamente identificado, é também importante verificar de forma apropriada todos aqueles que são afetados pelo problema. Nesta etapa é importante que essa identificação seja feita individualizando os grupos, tão especificamente quanto possível.

Em termos amplos, Estado e sociedade sempre seriam afetados por qualquer problema, mas um mesmo problema pode afetar, de forma bastante distinta, diferentes grupos de interesse.

Num dado segmento de mercado, uma mesma questão pode ser extremamente impactante para determinados agentes econômicos de um elo da cadeia de valor e pouco relevante para outros. Um problema para a produção pode pouco afetar a distribuição, e viceversa. E mesmo dentro da cadeia de valor produtivo, uma questão pode afetar um determinado grupo de forma distinta que afetará outros. Uma barreira à entrada, por exemplo, pode ser extremamente negativa para o surgimento de novos agentes econômicos, bem como para agentes econômicos que atuem há pouco tempo no mercado, mas poderia também ser vista positivamente por agentes econômicos já estabelecidos. 
Uma correta e detalhada identificação dos grupos afetados ajudará a identificar potenciais participantes de grupos de discussão (ANS, p. 11), de consultas e audiências públicas, além de colaborar também para uma melhor seleção de dados para auferir custos, benefícios, riscos, potencial de efetividade, etc.

\section{Objetivos Pretendidos}

Já descrito o problema e identificados os grupos afetados, é necessário identificar os objetivos que se pretende alcançar. O estabelecimento de metas é uma etapa de relevância significativa, já que a intervenção estatal em um determinado problema sempre será permeada de forma ampla do alcance de solução. Arbitrar metas inatingíveis pode resultar no insucesso de uma política pública. Do outro lado, subestimar objetivos fatalmente resultará em políticas públicas pouco efetivas.

Desta forma, o estabelecimento de metas deve ser procedido de maneira criteriosa. Uma das metodologias possíveis de se utilizar com esta finalidade é o critério, ou indicador S.M.A.R.T. (acrônimo da palavra smart - esperto, inteligente). Essa metodologia especifica cinco elementos que devem ser verificados para uma melhor fixação de objetivos: 1- Specific (específico); 2- Measurable (mensurável); 3-Achievable (alcançável); 4- Realistic (realista); e 5- Time-bound (Ligado ao tempo, com prazo determinado). (RODRIGO, e SILVA, p. 15.)

Nesse sentido, os objetivos devem ser concretos e bem definidos, a evolução da aplicação da política pública deve ser capaz de medir os resultados alcançados, devem haver recursos suficientes destinados à implementação da política pública, que não deve ser desenvolvida de forma nem subestimada nem superestimada, e devem haver prazos previamente estabelecidos para que se possa verificar o quão acertado foi o estabelecimento dos objetivo, possibilitando assim os ajustes e aprimoramentos que se façam necessários.

Um objetivo estabelecido de forma clara e específica, de forma realística e alcançável no tempo, com sua persecução mensurável será fundamental para que se possa formular alternativas de solução que possuam efetividade auferível, sendo por isso, proporcionalmente impactante na etapa seguinte da AIR.

Outra questão importante de se observar é quando do estabelecimento de múltiplos objetivos. Nas hipóteses em que, identificado um determinado problema, existam múltiplos objetivos a serem alcançados, duas questões imediatamente se asseveram: a potencial existência de objetivos conflitantes e a imperiosa necessidade de hierarquização de objetivos pretendidos.

Digamos que num determinado segmento de mercado extremamente concentrado, o 
preço do serviço ao consumidor tenha sido identificado com um problema a ser solucionado pela autoridade reguladora. O objetivo que naturalmente emerge desta situação é a redução do preço do serviço ao consumidor. Mas outros objetivos podem ser também estabelecidos, como, por exemplo, aumentar a concorrência, diminuindo a concentração do mercado. Assim, temos que, para este segundo objetivo, reduzir barreiras para facilitar a entrada de novos agentes neste segmento de mercado seria uma das primeiras opções formuláveis.

Ocorre, entretanto, que novos entrantes possuem altos custos de implantação, que somados a ganhos de escala potencialmente menores do que aqueles incorridos por agentes econômicos já estabelecidos, tornam improvável a potencial capacidade destes novos entrantes de competirem por preço. Isso significa que é bem possível que, com a redução de barreiras à entrada e ingresso de novos agentes no mercado, o preço do serviço num momento inicial tenda a subir, e não a ser reduzido. Ou seja, num primeiro momento, atingir o segundo objetivo pode em nada influenciar no primeiro objetivo, ou até influenciar de forma negativa.

Ainda quanto ao exemplo proposto, poder-se-ia argumentar que, inobstante num primeiro momento os novos entrantes terem pouca capacidade potencial de competirem por preço, à medida em que os custos de implantação vão sendo recuperados, esta capacidade aumenta, e o aumento da concorrência, no médio prazo, tenderia à redução de preços.

Isto posto, temos então a imperiosa necessidade de hierarquização de objetivos pretendidos. Digamos que, para um dado problema, tenham sido fixados os objetivos "um" e “dois". Para a solução desse problema e atingimento dos objetivos, foram então sugeridas as opções "A", "B" e "C". Ao se analisar as opções, verificou-se que:

As projeções e estimativas resultantes de se adotar a opção "A” resultavam numa ótima relação de custo-benefício em relação ao objetivo "um”, mas apresentava pouca relevância nas projeções de resultados relativos ao objetivo "dois".

As projeções e estimativas resultantes de se adotar a opção "B” resultavam numa ótima relação de custo-benefício em relação ao objetivo "dois", mas apresentava pouca relevância nas projeções de resultados relativos ao objetivo "um".

Já as projeções e estimativas resultantes de se adotar a opção "C" resultavam numa relação de custo-benefício mediana, mas que se apresentava para ambos os objetivos "um" e “dois" com equivalente significância de resultados esperados.

A escolha da melhor opção para o exemplo proposto está diretamente relacionada à hierarquia estabelecida entre os objetivos propostos: caso o primeiro objetivo seja mais relevante, a opção mais adequada será "A"; caso o segundo objetivo seja mais relevante, a opção mais adequada será "B”; e se ambos possuírem o mesmo grau de importância, será mais 
adequada a opção "C".

Entre os critérios mais utilizados para hierarquizar objetivos, estariam os de importância e de prazo, mas a fixação desses critérios não ocorre de maneira necessariamente proporcional.

\section{Formulação de Opções}

Entre os objetivos que se espera atingir, quando se propõe a elaboração de uma AIR, destaca-se a sua potencial contribuição para a melhoria da qualidade da decisão regulatória. Nesse sentido, a formulação de opções e elaboração de alternativas desempenha um papel de acentuada importância.

Na fase de formulação de opções é importante que se tente identificar o maior número possível de alternativas, sejam elas de regulação prescritiva, não prescritiva, campanhas educativas, incentivos aos regulados, ou ainda uma combinação de alternativas complementares (ANS, p. 14).

Em termos práticos, minimamente sempre existirão ao menos duas opções de alternativas: manter-se o status quo, sem que se proceda a nenhuma alteração das coisas como estão, ou propor ao menos uma ação de intervenção na situação que se apresenta.

É pouco provável que para alterar a situação que se apresenta exista apenas uma alternativa de ação, mas sendo esse o caso, é recomendável que esta limitação de alternativas esteja devidamente fundamentada.

Caso já exista intervenção do Estado na questão analisada, por exemplo, haveria ao menos uma terceira alternativa (além da manutenção do status quo ou de uma alternativa de intervenção) que seria a desregulação.

É relevante sublinhar que a formulação de opções tem por fundamento elencar e descrever alternativas viáveis na consecução dos objetivos esperados. Não se espera que uma AIR se preste a analisar todas as alternativas possíveis, mas o descarte de alternativas inviáveis deve ocorrer de maneira racional e fundamentada (RODRIGO, e SILVA, p. 16).

Tomemos, por exemplo, uma regulação que decorre de uma obrigação legal estabelecida por determinado marco regulatório. Neste caso, a desregulação poderia ser tomada por inviável, a priori. Entretanto, caso após a análise de dados e cenários, a desregulação fosse a opção mais recomendável, seu descarte prematuro faria com que se perdesse a oportunidade de se fundamentar uma revisão benéfica do marco regulatório em questão. 
Desta forma, nesta etapa, é importante buscar formular a maior quantidade de alternativas possíveis, e não apenas as opções regulatórias em sentido estrito, já que a etapa posterior é que irá se prestar à análise dessas opções, bem como dos cenários em que elas se apresentam.

\title{
7. Análise de Cenários e Opções
}

Uma vez estabelecidas todas as opções possíveis, chega o momento de colocá-las à prova. Nesta etapa, uma das questões mais relevantes é a escolha da metodologia de análise. A AIR, como já foi apontado anteriormente, deve prestar-se para uma verificação empírica que permita uma melhor escolha entres as possíveis opções formuladas. Diferentes impactos poderão ser avaliados, tais como impactos econômicos, sociais, ambientais (RODRIGO).

Desta forma, sua análise não pode se constituir de mera argumentação retórica sobre cenários e alternativas. As considerações devem ser feitas com base em dados (já disponíveis ou especialmente apurados) e a escolha da metodologia deve fundamentar-se na relação entre o problema a ser enfrentado, os atores envolvidos e as possíveis alternativas elencadas, face aos objetivos estabelecidos.

Existem várias metodologias disponíveis para a elaboração das análises numa AIR, tais como, por exemplo, análise de conformidade, análise de custo-benefício, análise de custoefetividade, análise de risco e análises multicritério, que serão abordadas mais detalhadamente no item 2.5. A relevância das metodologias para os resultados das análises forma apontadas pelo PRO-REG nos seguintes termos:

\begin{abstract}
A AIR mede os potenciais custos e benefícios, diretos e indiretos, a serem gerados por uma nova regulação. A depender do grau de detalhamento da análise, essa medição poderá consistir da identificação dos custos e benefícios, da quantificação, chegando até a monetização de custos e benefícios. A AIR pode também medir os custos e benefícios relativos a cada opção de política pública apresentada na análise. O risco também pode ser um item a ser medido na AIR, principalmente nos itens de difícil mensuração, como saúde pública, segurança e meio-ambiente. Também é pertinente a AIR avaliar as consequências não pretendidas de uma regulação. (PRO-REG, 2010, p. 11.)
\end{abstract}

A utilização sistemática de uma determinada metodologia deve influenciar positivamente na utilidade de ferramenta, já que a familiaridade dos envolvidos (dos técnicos que elaboram, das autoridades que decidem e dos atores impactados pela regulação), facilitaria sua melhor compreensão. 
Entretanto, a regulação atua num espetro significativamente variado de problemas, e restringir a utilização das metodologias em princípio poderia limitar as perspectivas de análise da AIR. A escolha da metodologia também depende da capacidade dos técnicos em sua utilização, face a existência de dados disponíveis (ou a possibilidade de sua apuração), bem como da capacidade de compreensão das autoridades reguladoras. Por isso, parece-nos que o mais importante é que a metodologia seja identificada e descrita (ainda que sucintamente) em cada AIR, que seja capaz de valorar das alternativas apresentadas nas avaliações para fundamentar a decisão e que se priorize a utilização de uma mesma metodologia sempre que possível.

Independente da metodologia que seja utilizada, a etapa de análise é o momento em que se pretende testar as opções propostas, de forma que o fundamento de escolha da opção se baseie no melhor resultado esperado, comparando-se as alternativas de ação a partir das avaliações.

O processo de análise sempre será projetado e estimativo, e por isso mesmo, já sujeito a erros. Para minimizar a margem de erros, o ideal é que as projeções sejam feitas sob a perspectiva de cenários, que podem ser mais otimistas ou mais pessimistas. Aponta-se na doutrina para uma dificuldade de se realizar análises estimativas, e que os reguladores teriam uma tendência de superestimar tanto custos (RADAELLI; DE FRANCESCO, 2008, pp. 14 e 15), quanto benefícios (JACOBS, p. 8).

Entre as opções propostas, como já dito anteriormente, a primeira a se destacar é a inerte, ou absenteísta. Nesse sentido, é importante que sejam constatados todos os elementos relevantes e se apure a situação atual do problema. É importante que, destacados os fatores relevantes, se faça uma apuração da evolução do problema no tempo, verificando-se seu comportamento no passado, para que se possa estimar sua evolução no futuro. Todas as alternativas devem ser avaliadas para que os resultados possam ser considerados na tomada de decisão.

\section{Participação social}

A participação social é extremamente relevante em processos de AIR. Entre as finalidades esperadas de uma AIR, estão o aumento da transparência e da legitimidade que envolvem a atividade regulatória, e nesse sentido, a qualidade da participação social é uma etapa significativa nesta consecução. 
Mas transparência e legitimidade não são as únicas razões para que se permita e que se busque de forma efetiva, a participação social nos procedimentos de AIR. A assimetria de informação é um fator significativo na atividade regulatória e a oportunidade de se obter informações junto aos grupos afetados é uma das medidas que buscam reduzir essa assimetria ${ }^{6}$.

Existem diversas maneiras de se assegurar a participação social, tais como a criação de comissões e grupos de trabalho, a realização de pesquisas, consultas e audiências públicas (presenciais ou através da internet). Mesmo a realização de consultas internas (envolvendo o corpo técnico do órgão regulador) podem ser produtivas para o processo de elaboração da AIR (ANS, p. 17.).

Apesar de estarmos inserindo esta etapa como posterior à etapa de análise, esse não é o único momento em que a participação social deve ser realizada. Aponta-se também que, além de útil nesta já avançada etapa do procedimento de AIR, a participação social também seria recomendável em seus momentos iniciais, quando ainda estão se definindo a descrição do problema e a elaboração de opções (VALENTE, p. 58 e SILVA, p. 21). Nesse sentido, pode ser conveniente que se utilize distintas formas de participação social para as diferentes etapas da AIR.

Independentemente do momento ou da metodologia que se utilize para permitir a participação social, o mais importante nessa etapa é que se garanta a amplitude de seu alcance, isso é, que todos os grupos afetados tenham igual oportunidade de participação, e que a participação seja efetiva, isto é, que todas as contribuições sejam efetivamente levadas em consideração.

Obviamente que não se espera que todas as contribuições sejam efetivamente acatadas, até por que, grupos de interesse diversos podem contribuir de forma diametralmente oposta. $\mathrm{O}$ que se espera, entretanto, é que todas as contribuições sejam apreciadas, e nesse sentido, o retorno (ou feedback) das apreciações para a sociedade como um todo (não apenas para o agente que formulou a contribuição) é fundamental.

Já apontamos que todas as agências reguladoras, independentemente da previsão ou ausência de previsão legal, preocupam-se de alguma forma com a participação popular em seus processos decisórios, fazendo uso de consultas públicas, audiências públicas ou alguma outra forma de oitiva social (STUCKERT, 2015, pp. 128 e 129.). Mas também já foi apontado que a utilização das consultas públicas como ferramenta de participação social, bem como a participação social efetiva nas consultas realizadas ainda é muito baixa, e amplamente

\footnotetext{
${ }^{6}$ Não se deve esperar, entretanto que a obtenção de dados ocorra apenas a partir da intervenção dos interessados, o que poderia aumentar o risco de "captura dos dados", como apontado pela OCDE 2008, apud SAMPAIO, p. 12.
} 
concentrada nos agentes dos mercados (PEIXOTO, 2014, pp. 117 a 121). Por isso, a divulgação das consultas e os prazos estabelecidos para contribuições são questões que merecem especial atenção. No relatório de AIR deve estar devidamente apontado como se deu a participação social, quem foram os participantes, quando foram consultados e quais foram os teores das contribuições (RODRIGO).

\section{Conclusão e Recomendações}

Após as análises das opções, com a classificação de quais delas melhor se adequam para a solução do problema, espera-se que a AIR seja capaz de indicar de forma clara e objetiva a melhor opção preferida, bem como os fundamentos que amparam essa escolha (RODRIGO; SILVA, p. 21 e 22).

Para tanto, é razoável que se realize um resumo das opções sugeridas, justificando a rejeição das opções que não devem ser levadas adiante e demonstrando como se espera que essa opção seja capaz de alcançar os objetivos que foram definidos. As conclusões não devem ser uma mera repetição daquilo que foi exposto nas análises, mas sim, uma síntese que visa deixar claro aquilo que se verificou na etapa de análise, levando também em consideração as sugestões que foram realizadas pela participação social.

Nesta etapa também deve ser descrito como se espera que a opção seja posta em prática e monitorada, alertando-se no caso da existência de riscos ou outros fatores que, não tendo sido plenamente verificados (tais como fatores exógenos, ou possíveis custos adicionais de monitoramento).

Há quem entenda que a implementação e o monitoramento constituem uma outra etapa da AIR (VALENTE, p. 58; RODRIGO; SILVA, p. 22 e 23), mas não vemos desta forma. Em primeiro lugar, quem assim inclui, coloca as etapas de implementação e monitoramento posteriores à etapa de conclusão, o que de per si já colocaria em dúvida o uso de termo "conclusão" ou indicaria que essas etapas são de fato posteriores à AIR. Entendemos ser esse o caso. Em segundo lugar, incluir uma etapa de "implementação" seria impossível nas hipóteses em que, verificadas as opções possíveis, fosse constatado que a melhor seria a opção de absenteísmo, de não fazer nada. Ou então já se estaria por princípio admitindo que esta jamais seria a opção escolhida, o que não faz sentido, já que há grande consenso de que que essa seria a primeira hipótese a ser efetivamente testada.

Por fim, teríamos o fato de que implementar e monitorar são atividades típicas da regulação, independentemente da utilização de AIR. Espera-se que os órgãos reguladores 
estejam constantemente monitorando as atividades por eles regulados, e implementando as regulações que se mostrem necessárias. Inobstante essas atividades serem úteis para a AIR, delas independem e não decorrem necessariamente. Entender de forma distinta corresponderia a dizer que uma AIR não teria um termo propriamente dito, já que seu monitoramento permanente impingiria na indeterminação de seu prazo. Nada impede, entretanto, que uma nova AIR seja realizada posteriormente, para que se verifique a validade das opções que foram feitas, ou a alteração das condições relevantes para o problema. Não temos dúvidas, entretanto, que o monitoramento auxilia no aprimoramento do uso da ferramenta, pois é através dele que se pode identificar o quanto as análises das opções se afastaram dos resultados efetivamente decorridos quando da implementação.

\section{Conclusão:}

Na sociedade contemporânea, em que a regulação é uma forma do Estado implementar políticas públicas em setores da economia, a qualidade da regulação está intimamente ligada ao êxito do objetivo definido na política pública ${ }^{7}$. Da mesma forma, a qualidade da AIR também poderá estar intimamente ligada à qualidade da regulação, ainda que seja efetivamente complicado se demonstrar ganhos econômicos substanciais ligados à adoção de análises de impacto (RADAELLI; DE FRANCESCO, pp. 16).

Enquanto instrumento de boas práticas recomendado pela Organização para a Cooperação de Desenvolvimento Econômico (OCDE), a AIR seria uma ferramenta no processo decisório das instituições que as adotam, especialmente as ARs, aumentando o equilíbrio e a permeabilidade democrática através do aumento do controle social.

Almeja-se principalmente, que a AIR seja capaz de melhorar a qualidade da decisão regulatória, assim como aprimorar também a qualidade das regulações. Aumento da transparência, participação social, responsabilização, legitimidade e controle social seriam aspectos em que também se espera incrementos pela utilização da ferramenta.

Para tanto, a AIR não deve ser apenas mais um procedimento meramente justificador de decisões já postas em processos administrativos, incapaz de produzir qualquer alteração na tomada de decisões. Desta forma, esta ferramenta deve se diferenciar daquilo que poderia ser tomado por uma exposição de motivos ou mesmo de uma análise técnica. Para tanto, o uso e a compreensão das etapas que constituem esta ferramenta são fundamentais para que dela se

\footnotetext{
${ }^{7}$ Nesse sentido posiciona-se Colin Jacobs: "Needless to say a poorly formulated policy which is unclear about its objectives at the outset, will adversely affect the quality of the overall RIA" (2005).
} 
possam extrair os resultados esperados.

Podemos aqui observar que as etapas que constituem uma AIR são encadeadas de maneira estruturada a partir de uma dupla presunção de racionalidade: de sua elaboração e de sua apreciação.

Esperamos ter contribuído com os debates e estudos dos temas aqui abordados, sem ter a pretensão de ter exaurido as possíveis questões que se referem à utilização das análises de impacto regulatório, mas colaborando para a compreensão, tanto do uso da ferramenta quanto de sua esperada contribuição para a melhoria da qualidade da decisão regulatória.

\section{Referências bibliográficas}

ANS, Agência Nacional de Saúde Suplementar, Guia técnico de boas práticas regulatórias: orientações técnicas para o aprimoramento do processo regulatório, 2014, disponível em: http://www.ans.gov.br/images/stories/Materiais_para_pesquisa/Materiais_por_assunto/guia_te cnico_boas_praticas.pdf, acesso em: 16/02/2016.

BLACK, Julia, Managing Discretion, 2001, disponível em: http://www.lse.ac.uk/collections /law/staff\%20publications\%20full\%20text/black/alrc\%20managing\%20discretion.pdf, acesso em: 22/09/2015.

DIAS, Bruno Fernandes, Análise de Impacto Regulatório: notas sobre a OCDE e sobre o Brasil, em Revista Digital de Direito Administrativo, v. 2, n. 1, São Paulo, 2015, disponível em: http://www.egov.ufsc.br/portal/sites/default/files/85316-166536-1-pb.pdf, acesso em: $15 / 11 / 2015$.

JACOBS, Colin, Improving the Quality of Regulatory Impact Assessments in the UK, Working Paper 102, 2005, disponível em: http://ageconsearch.umn.edu/bitstream /30611/1/cr050102.pdf, acesso em: 17/10/2013.

JACOBS, Scott H., Current Trends in Regulatory Impact Analysys: The challenges of mainstreaming RIA into policy making, 2006, disponível em: https://www.wbginvestmen tclimate.org/uploads/6.CurrentTrends.pdf, acesso em: 28/02/2016. 
KIRKPATRICK, Colin, Zhang Yin-Fang, Regulatory Impact Assessment in Developing and Transition Economies: a survey of current practice, 2004, disponível em: http://ageconsearch .umn.edu/bitstream/30673/1/cr040083.pdf, acesso em: 16/09/2015.

, PARKER, David, Regulatory Impact Assessment: An Overview, disponível em:

http://www.som.cranfield.ac.uk/som/dinamiccontent/media/knowledgeinterchange/booksumm $\operatorname{aries/207/summary.pdf,~acesso~em:~16/09/2015.~}$

OCDE, Better Regulation in Europe: United Kingdom, Paris, 2010.

\section{, Recommendation of the Council of the OECD on Regulatory Policy and}

Governance, 2012, disponível em: http://www.oecd.org/gov/regulatory-policy/49990817.pdf, acesso em: 17/10/2013.

PECI, Alketa, Desenho de uma estratégia de implantação e institucionalização da AIR, em: PROENÇA, Jadir Dias (org.), Contribuições para melhoria da qualidade da regulação no Brasil - Vol. 1, Brasília: Casa Civil da Presidência da República - PRO-REG - Semear Editora gráfica, 2010.

PEIXOTO, Flavio Luna, Participação social na Regulação através do mecanismo de consulta pública - o caso da ANCINE, em STUCKERT, Gabriel Fliege de Lucena e SCHNEIDER, Lorelei Simil (Org), Regulação e Fomento do Mercado Audiovisual Vol. II, Rio de Janeiro: $1^{\text {a }}$ Edição - ASPAC - 2014.

PRO-REG, ANÁLISE DO IMPACTO REGULATÓRIO A importância da melhoria da qualidade da regulação, 2010, disponível em: http://www.regulacao.gov.br/centrais-deconteudos/artigos/analise-de-impacto-regulatorio-a-importancia-da-melhoria-da-qualidadeda-regulacao/view, acesso em: 15/02/2016.

RADAELLI, Claudio and DE FRANCESCO, Fabrizio (2008), Regulatory Impact Assessment. Literature Review, University of Exeter, Chapter 15, disponível em: The Oxford Handbook of Regulation. http://centres.exeter.ac.uk/ceg/research/riacp/documents /Regulatory_impact_assessment_v1.2.pdf, acesso em: 17/10/2013. 
RODRIGO, Delia, Curso de Formação de Análise de Impacto Regulatório - AIR (material didático), Rio de Janeiro, ANCINE, 2014.

, Regulatory Impact Analysis in OECD Countries. Challenges for Developing

Countries, OECD, Paris, 2005, disponível em: www.oecd.org/dataoecd/21/52/35258511.pdf, acesso em: 17/10/2013.

SALGADO, Lucia Helena; BORGES, Eduardo Bizzo de Pinho. Análise de Impacto Regulatório: Uma Abordagem Exploratória, disponível em: http://www.ipea.gov.br/portal/ images/stories/PDFs/TDs/td_1463.pdf, acesso em: 17/11/2015.

SAMPAIO, Patrícia Regina Pinheiro, Questões Relevantes ao Desenho do Marco Normativo Adequado à Implantação da Análise de Impacto Regulatório em Âmbito Federal, 2010, disponível em: http://www.regulacao.gov.br/acompanhe-o-pro-reg/trabalhos-de consultoria/proposta-de-atos-normativos-para-implantacao-da-analise-de-impacto-regulatorio, acesso em: 01/07/2015. , Regulação e Concorrência, São Paulo: Saraiva, 2013

SILVA, Carolina Brasil Romão e, A Análise de Impacto Regulatório - AIR como instrumento de política pública, 2015, disponível em:

http://www.conpedi.org.br/publicacoes/c178h0tg/619jk46k/BG1KhemQBWle6dwm.pdf, acesso em: 15/02/2016.

STUCKERT, Gabriel Fliege de Lucena, As Políticas Públicas e o papel das Agências Reguladoras, em LIMA, Eduardo Martins de; SCHNEIDER, Yuri; FÉLIX, Ynes da Silva (Org.), Direitos Sociais e Políticas Públicas II: XXIV Congresso Nacional do CONPEDI, disponível em:http:/www.conpedi.org.br/publicacoes/66fs1345/g5znv4pn/X4M8ses2Y5ooT9TK.pdf, acesso em: 25/02/2016.

VALENTE, Patricia Pessôa, Análise de Impacto Regulatório - Uma ferramenta à disposição do Estado, Belo Horizonte: Editora Fórum, 2013. 


\title{
APLICATIVOS DE ECONOMIA COLABORATIVA: O CASO DO UBER E AIRBND NO BRASIL
}

\author{
Handerson Gleber de Lima Cavalcanti \\ Universidade Federal da Paraíba \\ Arnaldo Sobrinho de Morais Neto \\ Universidade Federal da Paraíba
}

\begin{abstract}
Resumo
A economia de compartilhamento é formada por um sistema socioeconômico construído em torno do compartilhamento de recursos humanos, físicos e intelectuais, através de novos instrumentos tecnológicos. Por meio dos novos modelos de compartilhamentos, o acesso a bens e serviços tradicionais passam a ser compartilhados ao invés de adquiridos, o que vem gerando em alguns países diversos conflitos entre usuários e os prestadores de serviço tradicionais. Diante dessa celeuma, trazemos no presente artigo a situação atual no Estado brasileiro sobre dois grandes aplicativos de compartilhamento que vem impactando setores fundamentais da sociedade: o Uber e o Airbnb.
\end{abstract}

Palavras-chave: economia de compartilhamento, uber, airbnb, aplicativos, Brasil.

\section{Abstract/Resumen/Résumé}

The sharing economy is formed by a socioeconomic system built around the sharing of human, physical and intellectual resources, through new technological tools. Through the new models of sharing, access to traditional goods and services are shared rather than acquired, which has generated in some countries several conflicts between users and traditional service providers. Considering this excitement, we bring in the present article the current situation in the Brazilian State about two large sharing applications that have impacted and impacted fundamental sectors of society: Uber and Airbnb.

Keywords/Palabras-claves/Mots-clés: sharing economy, uber, airbnb, apps, Brazil. 


\section{Introdução}

Nos últimos anos, muito temos ouvido falar sobre a economia de compartilhamento ou sharing economy, apresentada como um conceito "inovador" que agrega valor ao consumo colaborativo. A economia de compartilhamento é formada por um sistema socioeconômico construído em torno do compartilhamento de recursos humanos, físicos e intelectuais, através de novos instrumentos tecnológicos.

Os primeiros indícios da economia de compartilhamento remota o fim do séc. XX. Esse novo modo de compartilhar, fruto da Era informacional, da Web 2.0, ocasionou mudanças relevantes nas relações sociais e econômicas.

Não se pode afirmar que a economia de compartilhamento veio para substituir definitivamente o mercado tradicional e as relações clássicas de consumo, todavia, é notório que esse fenômeno trouxe impactos que merecem atenção. Com tantos avanços tecnológicos, diariamente novas modalidades de relações e interações pessoais vão surgindo, e o Estado não consegue acompanhar o desenvolvimento de tantos fenômenos, ainda mais com auxílio dessa ferramenta democrática e descentralizada, que é a internet.

Diante desse cenário percebemos a expansão das plataformas de compartilhamento, disseminando o compartilhamento de produtos e serviços, promovendo novas relações socioeconômicas. Em razão dessa expansão da economia de compartilhamento, destacamos, portanto, no presente artigo dois casos de plataformas de compartilhamento que vêm gerando polêmicas em alguns países devido aos seus impactos em setores essenciais da sociedade: o Uber, no serviço de transporte individual de passageiros, e o Airbnb, com o setor de hotelaria.

Para tanto, tomamos como base de análise as medidas regulatórias que vem sendo discutidas e tomadas no Estado brasileiro, de maneira a observar o caminho da regulação dessas atividades tão importantes.

\section{Uber: novo setor de transporte urbano individual de pessoas}

O modelo de negócio oferecido pelo Uber enquadra-se no transporte individual de pessoas, no qual a plataforma que age como intermediária promove a interação entre usuários que desejam se descolar de um lugar para outro e os potenciais motoristas disponíveis para realizar essa corrida.

\footnotetext{
${ }^{1}$ A ideia de se compartilhar, realizar trocas, como será demonstrado ao longo do estudo, sempre existiu na história, por isso, o termo "inovador" já que a prática não é novidade, porém, no contexto que vivenciamos hoje, essa prática encontra uma nova roupagem que acarretam impactos diversos e em escalas jamais imaginadas.
} 
A plataforma, originária dos Estados Unidos, inicialmente surgiu como uma proposta de ser um serviço de táxi de luxo. No entanto, a acessibilidade do serviço fez com que seus fundadores expandissem o negócio, transformando-a em um serviço de transporte individual de passageiros disponível não só para carros de luxo, mas para todo tipo de público.

Comparando-se com os serviços tradicionais de transporte individual (os táxis) geralmente serviços monopolizados por uma empresa permissionária pelo Poder Público, o Uber oferece mais agilidade, conforto e segurança, além de ter um custo bem menor que o serviço tradicional. A partir do momento que a plataforma oferece ao usuário a disponibilidade em tempo real de um veículo na área da solicitação do pedido, ele permite que o usuário saiba exatamente quanto tempo levará para a chegada de seu veículo e o tempo estimado da corrida, não sendo necessário passar longos minutos ao telefone solicitando um táxi, ou ter de deslocar até um ponto de táxi para conseguir solicitar um.

Além da agilidade na prestação do serviço, a segurança é outro fator apontado como grande diferencial da plataforma. Quando um usuário solicita seu veículo, o aplicativo localiza o motorista disponível que se encontra mais próximo da localização do usuário, sendo aceita a corrida, os dados do motorista são transmitidos para o cliente, permitindo que o mesmo acompanhe o trajeto do veículo e saiba exatamente em quanto tempo chegará, quem é seu motorista, quais as características do veículo e o preço estimado do deslocamento.

Caso algum incidente ou imprevisto ocorra, a plataforma permite o contato entre as partes, de forma que a corrida seja realizada da melhor forma possível. O usuário pode aguardar com segurança em qualquer local que o motorista chegará até ele. Além da segurança de não precisar ficar na rua à procura de um táxi disponível, o aplicativo oferece segurança também na prestação do serviço, uma vez que antes do usuário solicitar a corrida, a plataforma dá uma estimativa de preço, de maneira que o consumidor tem a garantia de que não será enganado nem estará arcando com um valor muito além do que imaginava, o que muito ocorre com os serviços tradicionais, pois nestes o passageiro desconhece o percurso que será feito pelo motorista.

Outro ponto de destaque em relação ao serviço do Uber é o seu sistema baseado na reputação. Tanto os motoristas quanto os usuários são avaliados e seus comportamentos aferem sua conduta dentro do aplicativo, de modo que é possível relatar a plataforma motoristas que desrespeitem as leis de trânsito, que não tratam bem os passageiros ou não oportunizou uma corrida agradável, enquanto o motorista também pode avaliar o passageiro de acordo com seu comportamento. 
Esse sistema baseado na reputação permite que se crie uma rede de confiança com a plataforma, pois quando um dos usuários do aplicativo, seja motorista ou passageiro, não recebe avaliações positivas suficientes ele é excluído do aplicativo. Essa ferramenta confere um poder de decisão muito maior ao consumidor, que passa a exigir mais dos motoristas uma boa prestação do serviço, o que não acontece com os serviços tradicionais de táxi: quando a reclamação de um consumidor não possui força suficiente para acarretar qualquer sanção ao motorista, que será mantido pela empresa ao qual pertence enquanto for de sua vontade.

Além desses pontos favoráveis aos usuários, a plataforma também oportuniza a inserção no mercado de trabalho de pessoas desempregadas, geração de renda e consequentemente aquecimento da economia, como afirma a empresa em seu website:

\footnotetext{
Para as mulheres e homens que dirigem com a Uber, nosso aplicativo representa uma forma flexível de ganhar dinheiro. Para as cidades, ajudamos a fortalecer as economias locais, melhorar o acesso ao transporte e tornar as ruas mais seguras. Quando você torna o transporte tão confiável como água corrente, todos se beneficiam. Especialmente, quando está nevando lá fora. (UBER, s.d.).
}

Todos esses fatores contribuem massivamente para a propagação e difusão do serviço por todo o mundo. No entanto, muitas críticas têm sofrido a plataforma, sendo considerada uma "usurpadora" do mercado tradicional. Muitos afirmam se tratar de uma mera plataforma de tecnologia, que não assume nenhuma responsabilidade sobre os possíveis incidentes. Eles podem ocorrer durante a prestação desse serviço, e nesse quesito gera muitas discussões acerca da sua responsabilidade solidária.

A questão da responsabilidade gira tanto em torno dos motoristas quanto dos passageiros, quando se questiona os direitos indenizatórios ou trabalhistas por parte dos primeiros, e a responsabilidade pela prestação do serviço na seara consumerista no que tange o cliente.

Outro fator que promove a grande polêmica envolvendo a plataforma é o fato da empresa não precisar arcar com nenhum custo de aquisição ou manutenção dos veículos postos à disposição pelo aplicativo, sendo responsável apenas pelo pagamento de seus funcionários administrativos. Ademais, sua rede e provedores isentam-se dos muitos encargos tributários que os serviços tradicionais estão obrigados a arcar.

Em Londres, no Reino Unido, a empresa enfrentou duras críticas de sindicatos, legisladores e motoristas dos famosos "black cabs" (táxis pretos), que são tradicionais na cidade em relação às condições de trabalho.

De acordo com o jornal “The sun”, em 22 de setembro de 2017, a TfL (Transporte for London), reguladora dos transportes na capital, anunciou que não renovaria a licença de 
operação da Uber. Isso significa que a partir de 30 de setembro daquele ano ele não será mais licenciado, entretanto, pode continuar a operar até que todos os recursos sejam esgotados. (THE SUN, 2017).

Segundo a TfL, a regulamentação sobre os comércios de táxis e contratações de Londres é projetada para garantir a segurança dos passageiros. Sendo assim, os operadores de contratações privadas, a fim de possuírem uma licença, devem cumprir os regulamentos e prestar conta das suas ações à Tf, convencendo o órgão de que se encontra apto e adequado para trabalhar.

Nesse sentido, através da decisão emitida em setembro do ano passado, a empresa concluiu que a Uber London não está adequada para possuir uma licença de operador privado de transporte, uma vez que segundo a instituição, a abordagem e a conduta de Uber demonstram ausência de responsabilidade corporativa em relação a uma série de assuntos que potencializam implicações tanto de segurança particular quanto de segurança pública (TFL, 2017).

Em Nova York, EUA, berço da economia de compartilhamento, três agências do estado emitiram regulamentos de "emergência", em junho de 2017, para tratar dos serviços de compartilhamento de corridas realizados pelas plataformas Uber, Lyft e outras empresas semelhantes.

Os novos regulamentos passam a exigir que a tarifa ou a tarifa estimada sejam fornecidas no aplicativo de compartilhamento de viagem ao consumidor, antes do início da viagem, exibindo: uma fotografia do motorista, marca, modelo, cor do veículo e o número da matrícula do automóvel. Acerca dos veículos de compartilhamento de passeio, a estes passa a ser obrigatório o uso de um emblema proeminente no para-brisa dianteiro do veículo, ao lado do passageiro, identificando a empresa para a qual trabalham (DEMASI, 2017).

Ademais, o Departamento de Veículos Motorizados do Estado de New York (DMV) passa a ser obrigado a estabelecer procedimentos de reclamação para violações de licença de empresas de compartilhamento de viagens, bem como impõe essas empresas de viagens o estabelecimento de um processo para queixas dos consumidores.

Conforme a regulamentação, para se tornar uma empresa de compartilhamento de viagem aprovada, um aplicativo deve ser preenchido e enviado ao DMV e as empresas devem ter um aplicativo para se conectar com os motoristas. Cobra-se uma taxa de inscrição no valor de US \$ 100.000,00 (cem mil dólares) dos quais \$ 90.000,00 (noventa mil dólares) são reembolsados caso a empresa não for aprovada. Há também uma taxa anual de renovação de US \$ 60.000,00 (sessenta mil dólares). 
Para as empresas passa a ser exigido um seguro de responsabilidade civil para veículos, a adoção de políticas antidiscriminatórias para todos os passageiros, incluindo aqueles com deficiência. Os motoristas devem enviar uma verificação de antecedentes criminais antes de poderem transportar passageiros, o que inclui uma revisão de seu registro de condução, e as empresas devem inscrever os motoristas no Sistema de Notificação de Eventos de Licença do DMV, que rastreia e denuncia suspensões, revogações, reinvindicações e outros eventos. (DEMASI, 2017).

Segundo o DMV, qualquer pessoa que deseja se tornar empregada nesta indústria, deve entrar em contato com as empresas de compartilhamento de viagens, sendo requisito legal para ser motorista portar uma licença emitida e válida pelo DMV e ter pelo menos 19 anos de idade.

No Brasil, conforme informações da própria plataforma, a Uber chegou em São Paulo, em junho de 2014, "buscando oferecer a todos mais uma opção de mobilidade, fosse nos centros ou nas periferias.” (UBER, s.d.). Desde seu ingresso no país, a Uber é alvo de diversas críticas por parte do mercado tradicional, através dos sindicatos e associações dos taxistas. Inclusive, vem sendo objeto de discussão legislativa desde então.

Em São Paulo, uma nova regulamentação para os aplicativos de mobilidade urbana deve passar a valer a partir de janeiro de 2018. Desse modo, por meio da Resolução $\mathrm{n}^{\mathrm{o}} 16$, publicada em 12 de junho de 2017, o Comitê Municipal de Uso do Viário (CMUV) do Município de São Paulo regulamenta as normas que passam a ser exigidas de motoristas e das empresas de transporte individual de passageiros por aplicativo e dos condutores cadastrados para operar nelas (SÃO PAULO, 2017).

Segundo a nova regulamentação, os veículos utilizados pelos condutores credenciados nos aplicativos cadastrados na Prefeitura, só poderão ter placas licenciadas da cidade de São Paulo. Contrapondo essa medida, a Uber (2017) relata em nota em seu website que "basicamente cria uma série de burocracias que servem apenas para trazer ineficiência a um sistema que hoje funciona de forma eficiente". Para tanto, a empresa apresenta um gráfico demonstrando o fluxo para se tornar parceiro da plataforma nos dias de hoje e qual a perspectiva a partir de janeiro de 2018, quando a Resolução 16 entrar em vigor: 

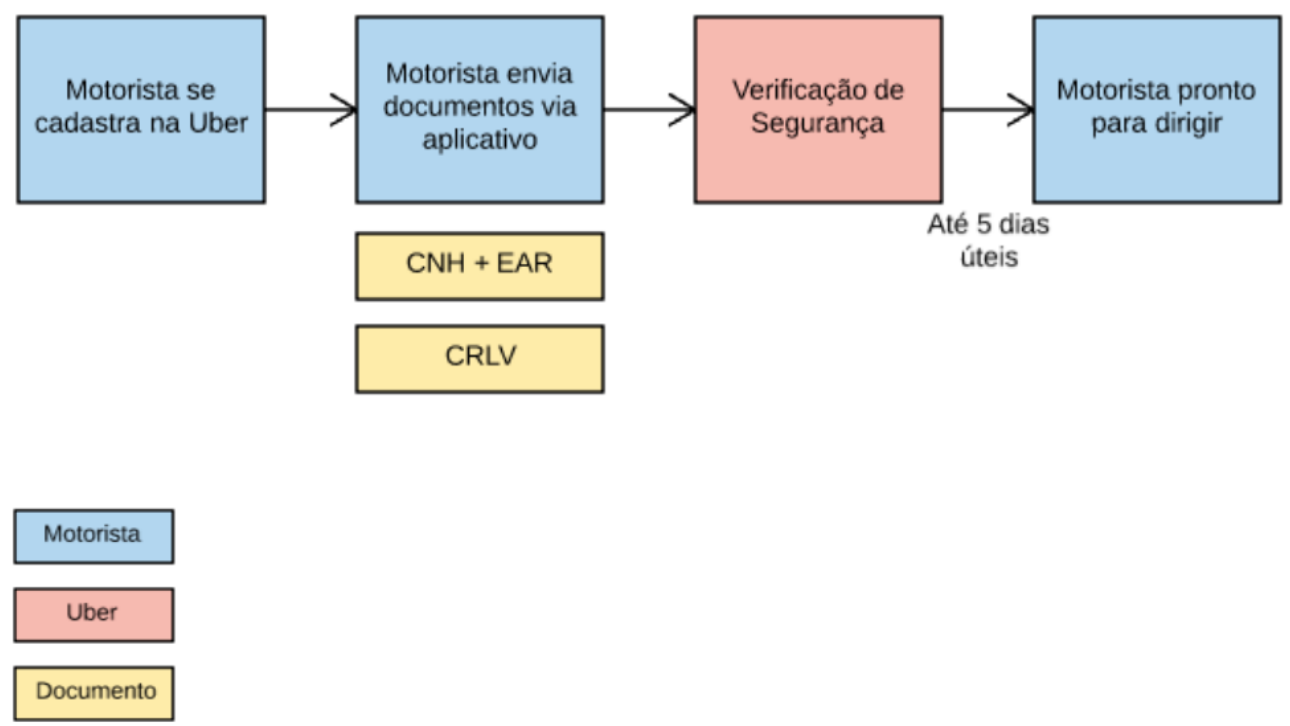

Figura 3: Fluxo atual de cadastramento de motoristas

Fonte: Uber, 2017.

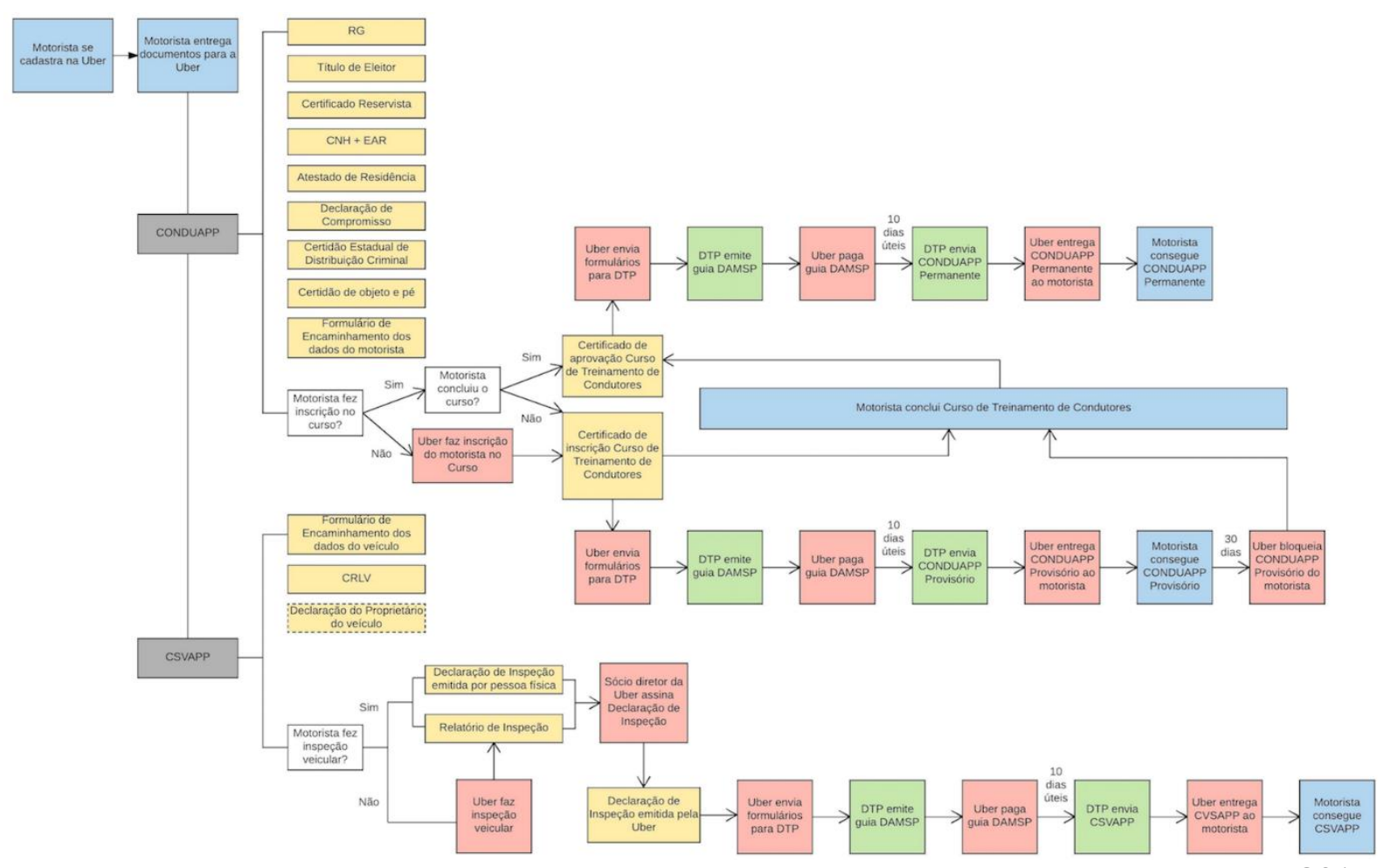

Figura 4: Fluxo previsto após regulamentação

Fonte: UBER, 2017.

Pela análise dos gráficos é possível perceber a burocratização imposta pela Regulamentação, que na visão da Uber apenas será um fato de desaceleração da economia, obstaculizando a prestação do serviço.

Em âmbito federal, no dia 26 de setembro de 2017, o senador Pedro Chaves (PSC-MS) apresentou à Comissão de Ciências e Tecnologia (CCT) um relatório alternativo a três Projetos de Lei (PL), regulamentando o transporte remunerado individual por aplicativos. As propostas 
que discutem o tema são o PLS 530/2015, PLS 726/2015 e PLC 28/2017, apresentadas respectivamente pelos parlamentares: senador Ricardo Ferraço (PSDB-ES), senador Lasier Martins (PDT-RS) e deputado Carlos Zarattini (PT - SP).

O PLS no 530 de 2015 apresenta como proposta a regulamentação e organização do sistema de transporte privado individual a partir de provedores de rede de compartilhamento, inserindo o inciso XIV ao art. 4 da Lei $\mathrm{n}^{\circ}$ 12.587/2012, de maneira a definir essa modalidade.

Já a PLS n 726 de 2015 propõe a alterarão da Lei de Mobilidade Urbana (Lei ${ }^{\circ}$ 12.587/2012) e do Código de Trânsito Brasileiro (9.503/1997) para disciplinar o serviço de transporte privado individual de passageiros, destinado à realização de viagens individualizadas, por intermédio de veículos particulares cadastrados junto às autoridades competentes, cuja contratação se dá de maneira prévia, desenvolvido em caráter de livre concorrência. Assim, passam a ser de competência do poder público municipal a sua disciplina e fiscalização.

Por fim, o PLC $n^{\circ} 28$, de 2017, propõe a alteração do inciso X, no art. $4^{\circ}$ da Lei $n^{\circ}$ $12.587 / 2012$ para incluir o conceito de transporte remunerado privado individual de passageiros, atribuindo a responsabilidade quanto a fiscalização e regulamentação da atividade aos Municípios e ao Distrito Federal.

Conforme relatório, existe um consenso no Parlamento acerca da necessidade de regulamentação da atividade de transporte individual realizada através de aplicativos, devido os grandes embates envolvendo o aplicativo de compartilhamento de corridas Uber. Nesse sentido, o Senador relator adverte que necessitam ser criadas regras tanto para que o mercado possa se desenvolver livremente, como para incrementar a segurança dos usuários dessas plataformas. Diante disso, o voto do relatório foi pela rejeição do PLS n 726/2015 do PLC n ${ }^{\circ}$ 28 /2017, e apela aprovação do PLS nº 530/2015.

Seguindo para as votações no Plenário do Senado, em 31 de outubro de 2017 o PLC 28/2017, foi aprovado por 46 votos, sendo acatada três das vinte emendas apresentadas. Dentre as mudanças aprovadas pelo Senado, tem-se a retirada da obrigatoriedade do uso de placas vermelhas e a exigência de que o condutor seja proprietário do veículo. Além dessas emendas excludentes, também foi aprovada a atribuição ao Município para fiscalizar o serviço de aplicativos, não se tratando de autorização para exercício da atividade, porém, de mera fiscalização.

Conforme o texto aprovado, que segue para a Câmara dos Deputados, o aplicativo será obrigado a mandar para a prefeitura a sua base de dados, para que o município tenha acesso aos cadastros dos motoristas. Prevê ainda que os motoristas devem: possuir carteira nacional de habilitação na categoria B ou superior; ter inscrição como contribuinte individual do INSS; 
contratar o seguro de acidentes pessoas a passageiros (APP); ter o obrigatório de danos pessoais causados por veículos automotores de vias terrestres (DPVAT).

Indo em contrapartida aos Projetos de Lei no Congresso Nacional, a Câmara Municipal de João Pessoa revogou uma Lei municipal aprovada em 2015 que inviabilizava o transporte individual remunerado realizado através de aplicativos de compartilhamento de corridas.

Comemorando a revogação da lei, o Vereador Lucas Brito (PSL/Livres) destaca a importância de não privar o direito de empreendedorismo das pessoas, haja vista que "pode haver uma melhoria significativa nos serviços aos cidadãos, além da movimentação na economia num período de crise como o que estamos vivendo", e acrescenta que acerca das propostas de lei em tramitação no Congresso Nacional de "um grande retrocesso ao querer transformar a atividade em concessão pública”. (PARAÍBA(JP), 2017).

A visão do parlamentar coaduna com os valores expostos por Meyer (2016), em sua obra "Uber-positive: Why Americans Love the Sharing Economy", ao ressaltar a importância da livre concorrência, da livre iniciativa e do poder de escolha do consumidor, de modo que a burocratização desses sistemas se torna uma barreira ao desenvolvimento econômico e social.

Um dos grandes pontos positivos apontados pelos apoiadores da economia de compartilhamento é a oportunidade que o compartilhamento de corridas proporciona àquelas pessoas que por algum impedimento não podem trabalhar em tempo integral, como é exigência de maioria dos empregos. Desta forma, um pai/mãe que não dispõe de tempo integral para trabalhar, pode escolher seus horários para realizar corridas e garantir uma renda.

Além disso, a livre concorrência, a oportunidade de escolha do consumidor, e a acessibilidade que os aplicativos de compartilhamento de corridas proporcionam, são pontos de destaque para o consumidor. No mais, por se tratar de um serviço de transporte prestado em natureza privada, é muito provável que o fornecer do serviço tenda a propiciar ao usuário uma experiência agradável, uma vez que sua intenção é além de fidelizar o consumidor, expandir sua atividade por meio da sua boa reputação.

Meyer (2016) aduz que ao invés de competir e adaptar-se às mudanças da economia, alguns empresários de ramos tradicionais tentam sufocar as empresas de compartilhamento através de processos políticos, buscando engessar essa modalidade econômica que vem causando impactos em seus serviços.

Portanto, segundo Meyer, "Liberar os 'compartilhadores de corridas' de tais regulamentos não só expandirá as oportunidades de emprego, também reduzirá os custos para 
os motoristas"

A economia americana está mudando, e as atitudes dos milênios em relação ao trabalho e suas carreiras estão mudando com ele. O rápido crescimento da economia compartilhada incorpora o novo ideal econômico dos jovens americanos - um impulsionado pela tecnologia, conveniência e flexibilidade. ${ }^{3}$ (MEYER, 2016, p.27).

Corroborando com tais ideias, Moura e Sales (2017) concluem:

Trata-se, portanto, de um serviço com relevo social, desprovido, contudo, de essencialidade. Caso ocorra sua paralisação, o impacto nos sistemas de transporte é mínimo e não traz transtornos para a sociedade. Tem uma natureza suplementar dentre os serviços de transporte direcionado ao público e sua prestação não constitui dever imprescindível do Estado. (MOURA, SALES, 2017).

O tema ainda enfrenta debates no Poder Judiciário brasileiro. O Partido Social Liberal (PSL) ajuizou Arguição de Descumprimento de Preceito Fundamental (ADPF 449) no Supremo Tribunal Federal (STF) contra a Lei Municipal 10.553/2016, de Fortaleza (CE). Essa lei proíbe o uso de carros particulares, cadastrados ou não em aplicativos, para o transporte remunerado individual de pessoas, prevendo multa de $\mathrm{R} \$ 1.400$ (um mil e quatrocentos reais) ao condutor do veículo, que pode ser aplicada até o limite de quatro vezes esse valor, em caso de reincidência no período de 12 meses.

Segundo o partido PSL, a norma foi “encomendada" pelas associações dos taxistas para conter o avanço do aplicativo Uber na capital cearense e acabou estabelecendo uma reserva de mercado para a categoria, em afronta aos princípios constitucionais do valor social do trabalho e da livre iniciativa (artigo $1^{\circ}$, inciso IV), da livre concorrência (artigo 170, inciso IV), da defesa do consumidor (artigo 170, inciso V) e da busca do pleno emprego (artigo 170, inciso VIII) (STF, 2017).

O PSL afirma que, embora a lei municipal não tenha feito distinção entre transporte público individual (táxi) e transporte privado individual (Uber e similares) sem a devida permissão legal, seu artigo $1^{\circ}$ limita sua aplicação especificamente ao transporte público individual, como seria o caso de exploração do serviço de táxi sem a devida licença.

Nesse sentido, conforme Partido (SÃO PAULO, 2017) “A Prefeitura de Fortaleza, no entanto, concede interpretação totalmente inconstitucional a este dispositivo, e diariamente o aplica para proibir, fiscalizar, apreender e multar o transporte privado individual, que sequer

\footnotetext{
2 "Freeing ride-share drivers from theses regulations would not only expand employment opportunities but also lower costs for riders. "

${ }^{3}$ Tradução livre para: "The American economy is changing, and millennials' attitudes about work and their careers are changing with it. The sharing economy's rapid rise embodies many young American's new economic ideal - one driven by technology, convenience, and flexibility.",
} 
está previsto na hipótese de incidência da norma".

Manifestando-se acerca do caso, a Procuradoria-Geral da República, em seu parecer ministerial, posicionou-se pela realização de audiência pública, haja vista entender que:

o caráter inovador da forma de contratação de serviço de transporte individual por programas (aplicativos), a natureza disruptiva do serviço e os múltiplos e conflitantes interesses envolvidos justificam que entidades e especialistas habilitados tragam subsídios para melhor julgamento da lide por parte do Supremo Tribunal Federal (BRASIL, 2017).

Nesse mesmo sentido, o Tribunal de Justiça do Estado de São Paulo em recente julgado entendeu se tratar o tema de questão relevante, que passa por grandes debates jurídicos acerca da sua natureza e adequação perante a legislação vigente, de modo que não reconheceu a aplicação integral da Lei Municipal que regulamenta o serviço de táxi à atividade do motorista do Uber:

\begin{abstract}
APELAÇÃO. MANDADO DE SEGURANÇA. MOTORISTA DO UBER. Serviço UBER ainda não regulado no Município de Jundiaí. Lei Municipal n ${ }^{\circ}$ 8.267/2014 menciona que a "prestação do Serviço de Táxi no Município de Jundiaí não autorizada pela PMJ será considerada clandestina", o que não se aplica aos veículos que trabalham por meio do UBER. O conceito genérico da livre iniciativa não pode servir para impedir qualquer fiscalização da Municipalidade, tendo em vista que o poder de polícia pode ser exercido em relação a qualquer veículo de transporte. Impossibilidade de se conceder um "salvo conduto" ao impetrante. RECURSO PROVIDO EM PARTE somente para que eventuais apreensões ou autuações não ocorram com base na Lei Municipal $n^{\circ} 8.267 / 2014$. (TJSP, 2017, online).
\end{abstract}

Em extrato do inteiro teor da decisão acima mencionada, o órgão reconhece a lacuna legislativa acerca do tema, a importância e necessidade de sua regulação, contudo, diante da ausência de regulamentação sobre o serviço o tribunal entendeu pela liberação da atividade: Não se desconhece que o tema no qual se funda o pedido é controvertido a ponto de
suscitar pareceres jurídicos subscritos por renomados juristas que chegaram a
conclusões opostas. Além disso, a discussão se dá em torno de questões relevantes,
entre as quais se destaca a natureza do serviço prestado, os limites da livre iniciativa,
a reserva de mercado à uma determinada categoria, bem assim a necessidade de
interpretação das Leis mencionadas. No caso em tela, é fato incontroverso que o
serviço UBER ainda não se encontra regulado no Município de Jundiaí, sendo certo
também que não pode haver lei municipal que simplesmente proíba a atividade.
(TJSP, 2017).

Em outros julgados, o TJSP ratifica seu posicionamento perante o embate:

APELAÇÃO. MANDADO DE SEGURANÇA. UBER. MUNICÍPIO DE OSASCO Lei Municipal no 3.455/1999 inaplicável na espécie - Abstenção, pelos órgãos públicos municipais, da prática de atos que restrinjam ou impossibilitem o livre exercício pelo impetrante da atividade profissional de transporte privado de passageiros, como parceiro do UBER - Lei Federal $\mathrm{n}^{\mathrm{o}}$ 12.587/2012 prevê a modalidade de prestação de serviços de transporte urbano de natureza privada, sem 
qualquer restrição - Existência de direito líquido e certo. Precedentes desta C. Câmara - Sentença de concessão da ordem mantida. Recurso não provido.

REEXAME NECESSÁRIO. Mandado de Segurança. "UBER". 1. Lei Municipal no 13.775/2010. Inaplicabilidade à plataforma UBER. Legislação que rege a atividade de transporte público, submetido aos princípios da Administração Pública. Hipótese dos autos que abrange o exercício de natureza privada de transporte individual de passageiros, não podendo ser cominada as sanções previstas na mencionada lei municipal. 2. Órgão Especial desta Corte que reconheceu a inconstitucionalidade de norma municipal de São Paulo que fixava as mesmas sanções previstas na lei municipal de Campinas. Sentença concessiva da segurança mantida. Negado provimento ao reexame necessário. (TJSP, 2017, online).

Nesse ínterim, percebemos que o Judiciário brasileiro diante da discussão regulamentária sobre a atividade do Uber entende que as leis atuais não se adequam perfeitamente ao novo cenário de transportes individuais. É perceptível a preocupação dos magistrados em preservar a continuidade do serviço oferecido pela plataforma e ao mesmo tempo reconhecer a necessária fiscalização pelo ente público do exercício dessa atividade.

De acordo com texto até então aprovado pelo Senado Federal acerca do tema, vislumbramos um primeiro passo em prol da regulamentação referente a um dos modelos de economia de compartilhamento, promovendo a intervenção necessária do Estado para se proteger as relações pessoais envoltas no uso do aplicativo. Também visa preservar ao poder público a possibilidade de fiscalização para que se possa tomar medidas de responsabilização cabíveis e baseadas nas legislações em vigor relacionadas ao caso.

\section{Airbnb e o mercado de hotelaria}

Possuidora de um sucesso e renome internacional, a Airbnb, plataforma de compartilhamento de hospedagem, é fruto da ideia do aproveitamento da capacidade excessiva de um simples quarto de um apartamento nos Estados Unidos. Assim, tanto o Uber quanto ela são alvos de grandes embates envolvendo setores tradicionais na área de hospedagem.

Da mesma forma que o aplicativo do Uber, o Airbnb apresenta-se como intermediador entre os usuários interessados em reservar um espaço para se abrigar, e os detentores dos espaços ociosos, disponíveis para serem ocupados. Seguindo a mesma lógica do aplicativo de transportes individual, o Airbnb não despende gastos como o setor de serviços de hotelaria, nem estão sujeitos as inúmeras regulamentações, autorizações e requisitos para exercício da atividade, o que gera grandes debates com as redes hoteleiras.

Na visão de Brian Chesky, CEO e cofundador do Airbnb, a plataforma traz um conceito de inovação no setor de hospedagem, baseado na ideia de comunidade e no oferecimento de um serviço personalizado ao usuário. Dessa feita, é fundamentado na confiança e promove a 
interação e interconectividade de culturas entre o anfitrião e o hóspede. Para o CEO da plataforma, o maior desafio da empresa é a discriminação em relação a sua atividade:

\begin{abstract}
Nossa missão fundamenta-se na ideia de que as pessoas são essencialmente boas e que uma comunidade é um lugar onde você possa se sentir em casa. Não dizemos isso para parecermos bonzinhos. Eu acredito sinceramente que [a discriminação] é o maior desafio que enfrentamos como empresa. Ela dilacera o âmago do que somos e os valores que defendemos. (AIRBNB, 2017, online).
\end{abstract}

De um lado, a plataforma afirma que contribui com o oferecimento de uma ampla oferta de unidades habitacionais, promovendo um grande impacto na movimentação econômica do país, de outro, nos deparamos com a Associação Brasileira da Indústria de Hotéis (ABIH), afirmando que sem a devida regulamentação e contribuição com impostos pelo serviço, tratase de uma atuação ilegal e abusiva economicamente:

A concorrência é desleal, pois são diversos impostos que recaem sobre a atividade de hospedagem que não são pagos pelas plataformas: municipais (ISS, IPTU, Taxas de limpeza e iluminação pública, alvará de funcionamento, taxas de divulgação e licença do corpo de bombeiros); estadual (ICMS) e federais (Imposto de renda, PIS, COFINS, INSS e FGTS), além de outros custos relacionados a procedimentos contábeis e fiscais, como comissão de corretagem, taxas do sistema " $\mathrm{S}$ ", diferença do valor unitário da conta de energia elétrica e da conta de água e esgoto, custo Brasil referente à Justiça do Trabalho e ao código de defesa do consumidor.(ABIH, 2017, online).

Outro problema relatado é o fato de que os aluguéis a curto prazo se tornaram tão lucrativos que os proprietários e inquilinos mais gananciosos desviam ilegalmente o estoque precioso da habitação para a promover a sua prática, sacrificando muitas vezes as relações domésticas e o convívio familiar em busca da rentabilização dos espaços, além de burlar contratos de locação de imóveis para atingir seu intento. (SAID, 2015).

Nesse sentido, deparando-se com litígios envolvendo o uso do aplicativo, o Tribunal de Justiça do Estado de São Paulo ao ser questionado sobre o uso de propriedade em condomínio residencial para hospedarem a curto prazo através do aplicativo, entendeu pela sua impossibilidade, fundamentando sua decisão no argumento de que a utilização dada para a propriedade não se monstra compatível com a destinação da edificação.

Agravo de instrumento. Ação visando a anulação de deliberação condominial. Utilização do apartamento como hospedagem, por meio da plataforma eletrônica “Airbnb". Impossibilidade. Edifício de caráter residencial. Liminar revogada. Recurso provido. (TJSP, 2017, online). 
Na fundamentação da referida decisão, o tribunal junta ao teor do acórdão posicionamento anterior proferido pela corte, no sentido de considerar incompatível a destinação intentada pelos proprietários de apartamentos em condomínios residenciais para fins comerciais:

\begin{abstract}
Neste sentido o entendimento já manifestado nesta Corte: "Agravo de Instrumento. Interposição contra decisão que deferiu a tutela de urgência com determinação à ré a abstenção de locar ou ceder o imóvel com finalidade característica de hotelaria ou hospedaria, sob pena de multa diária de $\mathrm{R} \$ 1.000,00$. Possibilidade de se determinar a antecipação dos efeitos da tutela determinada, diante da presença de elementos que evidenciam a probabilidade do direito e o perigo de dano ou risco ao resultado útil do processo, nos termos do artigo 294 e 300 do Código de Processo Civil de 2015. Observação com relação ao teto da incidência da multa (astreintes) em caso de eventual descumprimento da decisão. Decisão mantida, com observação." (Agravo de Instrumento $\mathrm{n}^{\circ}$ 2047686-61.2017, relator Desembargador Mário A. Silveira) (TJSP, 2017, online).
\end{abstract}

Segundo a revista Fortune (2017), várias cidades e regiões de Berlim - Alemanha a São Francisco - EUA implementaram restrições ao Airbnb, alegando que a empresa está violando os regulamentos instituídos para o setor de hotelaria.

Nos Estados Unidos da América, o tema vem sido debatido há tempos, e várias regulamentações já foram impostas para o setor. Nos estados de San Francisco e Nova York permitiu-se o serviço, no entanto, adota-se a política que permite os aluguéis apenas se os anfitriões forem residentes em tempo integral do imóvel. Ademais, segundo a regulamentação, a hospedagem é limitada a 90 dias e todos os anfitriões devem se registrar na cidade. (TUN, 2015).

Acerca da atividade do Airbnb no Brasil, foi protocolado em novembro de 2015 no Senado o PLS 748/2015, propõe a alteração da Lei no 8.245, de 18 de outubro de 1991 para atualizar o regime da locação para temporada, disciplinando a atividade de compartilhamento de imóveis residenciais por meio de sítios eletrônicos ou aplicativos.

Dando uma interpretação de que a atividade da plataforma não se enquadra na Lei geral de turismo (Lei no 11.771/2008), todavia, é pertinente na Lei do Inquilinato 8.245/1991. Diante disso, o projeto estabelece que a locação de imóveis residenciais para a temporada deve seguir sendo regulada pela Lei 8.245/1991, independentemente do auxílio de novas ferramentas tecnológicas.

Na visão do relator do projeto, Senador Ricardo Ferraço:

Não obstante, é mister que o expresso reconhecimento legal das novas manifestações culturais não se traduza em brecha para oportunismos, tal como a proliferação de "hotéis ilegais". Daí o motivo de se esclarecer, no texto da proposição, que não se pode tomar por simples "locação para temporada" a disponibilização de unidades indissociavelmente acompanhadas de serviços regulares, característicos de hotelaria, 
sobretudo quando tal prestação se dá em ambiente tipicamente ligado a este tipo de estabelecimento. (BRASIL, 2015).

Tratando ainda sobre os debates legislativos acerca da regulamentação de plataformas de reservas online, o Estado do Ceará apresenta-se como pioneiro dentre os entes da federação ao aprovar uma indicação (Indicação $n^{\circ}$ 0304/2017), que visa estabelecer normas para o funcionamento de plataformas internacionais de reservas online, como o Airbnb.

Segundo a justificativa do Vereador, em razão da popularização da internet e expansão do alcance dos aplicativos de prestação e intermediação de serviços, os moradores do Município de Fortaleza passaram a aderir ao sistema de compartilhamento de hospedagem, dispondo de suas residências. No entanto, tais operações, segundo o parlamentar, ocorrem de maneira precária, sem a devida regulação do poder público, o que pode ocasionar diversos prejuízos aos usuários, além da questão da sonegação de impostos suscitada.

Percebemos que os grandes embates no legislativo acerca do serviço do Airbnb giram em torno da tributação da atividade. As discussões são cercadas de interesses políticos e mercadológicos, e as propostas legislativas basicamente suscitam a implementação das regras adotadas para o mercado tradicional, não atendo às peculiaridades desse novo modelo de compartilhamento.

Nesse rumo, temos que os debates encerrados no Brasil até o momento resumem-se a estender a aplicação dos encargos dos mercados tradicionais aos mercados de compartilhamento, sendo insuficiente no quesito referente, especificamente, da proteção do consumidor. $\mathrm{O}$ que esperamos que venha a ocorrer com o marco regulatório proposto pelo Congresso Nacional.

\section{Conclusão}

Muitos acreditam que a economia de compartilhamento não passa de um capital de risco, ou seja, no momento econômico que vivenciamos, a iniciativa do capital de investimento proporcionou o crescimento desse fenômeno da economia compartilhada. Para outros, a economia colaborativa apresenta-se como um presente econômico, fruto da evolução social e tecnológica.

O que podemos perceber é que a medida que o tempo passa, os avanços tecnológicos, as plataformas digitais crescem em escala exponencial. emblemática análise de casos práticos envolvendo atividades de consumo colaborativo: os quais foram objeto de discussões e regulamentações no estrangeiro e continuam encerrando grandes debates no legislativo 
brasileiro.

É fato que a internet e os avanços tecnológicos ocasionaram grandes impactos para a sociedade, mudando nossos modos, estilos de vida, relacionamentos, nossos hábitos, valores e principalmente a economia. Diante desse cenário, devemos nos atentar à maneira como o Estado vem se comportando diante deste novo panorama.

Nesse caminho, por mais que existam muitos aspectos ainda desconhecidos em relação à internet, e seu uso, apesar da incipiente regulamentação nesse sentido, a existência de novos fenômenos decorrentes das constantes inovações, não pode servir de escusa para a não aplicação das normas existentes de proteção das partes envolvidas, uma vez que o jurista deve procurar sempre maneiras de inibir práticas abusivas, lesivas aos direitos básicos do individuo, ainda que tenha que adaptar diante do contexto de infindáveis mudanças sociais que vivenciamos.

Destarte, aguardamos o posicionamento final do nosso legislativo acerca das atividades envolvendo setores específicos da economia de compartilhamento e esperamos que nosso ordenamento jurídico possa progredir em relação dessas novas relações socioeconômicas.

A necessidade de atualização dos sistemas normativos diante das transformações socioeconômicas é latente, entretanto, não podemos nos apartar das proteções de direitos fundamentais existentes, pois, devemos reconhecer e adaptar as medidas protetivas positivas perante a economia de compartilhamento.

\section{Referências bibliográficas}

BOCKMANN, Marco. The The Shared Economy: it is time to start caring about sharing; value creating factors in the shared economy. The Netherlands, 2014. Disponível em: $<$ http://thelovettcenter.com/wp-content/uploads/2014/11/bockmann-shared-economy.pdf $>$. Acesso em: 11 mar. 2016.

BOTSMAN, Rachel; ROGERS, Roo. O Que é meu é seu: como o consumo colaborativo vai mudar o nosso mundo. Porto Alegre: Bookman, 2011.

BRASIL, LEI n 12.965 de 23 de abril de 2014. Disponível em: <http://www.planalto.gov.br/ ccivil_03/_ato2011-2014/2014/lei/112965.htm>. Acesso em: 10 out. 2017. 
BRASIL. PARECER No 286.344/2017. Ministério Público Federal, Brasília, DF, 2017.

Disponível em: <file://D:/Downloads/texto_313198291.pdf>. Acesso em: 15 set. 2017.

BRASIL, PROJETO DE LEI n 748 de 2015. Disponível em: < http://www.planalto.gov.br/ ccivil_03/_ato2011-2014/2014/lei/112965.htm>. Acesso em: 10 out. 2017.

CHASE, Robin. Economia compartilhada: como as pessoas e as plataformas estão inventando a economia colaborativa e reinventando o capitalismo. Tradução de Cristina Yamagami - São Paulo: HSM do Brasil, 2015.

DEMASI, Michael. Just in time: New regulations govern Uber, Lyft in upstate New York. Albany Business Review, 7 Jun 2017. Disponível em: <https://www.bizjornals.com/albany/ne ws/2017/06/07/just-in-time-new-regulations-govern-uber-lyft-in.html>. Acesso em: 05 jan. 2018.

DE MOURA, Cid Capobiango Soares; DE SALES, Ana Carolina. Serviço de transporte da Uber tem respaldo na liberdade de profissão. Conjur, janeiro de 2017. Disponível em: $<$ http://www.conjur.com.br/2017-jan-08/servico-transporte-uber-base-liberdade-profissao $>$. Acesso em: 15 set. 2017.

FASTINO, Rafael. Após críticas, Sebrae suspende convênio com Airbnb. Panrotas, 03 ago. 2017. Disponível em: <http://www.parontas.com.br/noticia-turismo/hotelaria/2017/08/ aposcriticas-sebrae-suspende-convenio-com-airbnb148460.html?leiaTambem>. Acesso em: 10 dez. 2017.

FREITAS, Ana. A economia do compartilhamento. Revista Galileu, Rio de Janeiro, Ed. Globo S/A, 2013. Disponível em: <http://revistagalileu.globo.com/Revista/ Common/0,EMI33 9483-17770,00-A+ECONOMIA+DO+COMPARTILHAMENTO.html>. Acesso em: 11 mar. 2016.

JOAO PESSOA, Câmara Municipal de João Pessoa - PB. Disponível em: $<$ https://antigo.cmjp.pb.gov.br/licitacoes.php>. Acesso em: 17 set. 2017. 
KERR, Ronny. Uber, Airbnb, and Lyft valuations immune to market deflation. Londres, 22 jan. 2016. Disponível em: <http://vator.tv/n/42d6>. Acesso em: 22 mar. 2016.

LONDON, Transport for London (TfL). Disponível em $<$ https://tfl.gov.uk/infofor/media/press-releases/2017/september/licensing-decision-on-uberlondon-limited> Acesso em 08 de fev 2018.

LOTT, Thiago da Costa e Silva. UBER - A polemica sobre a natureza jurídica do aplicativo e sua legalidade. Disponível em: <http://www.lottbraga.com.br/artigos/uber-polemicasobrenatureza-juridica-do-aplicativo-e-sua-legalidade/>. Acesso em:15 set. 2017.

MATIAS, Eduardo Felipe P. A Humanidade e suas Fronteiras: Do Estado Soberano à Sociedade Global. São Paulo: Paz e Terra, 2005.

MAGRI, Rodrigo. Economia do Compartilhamento. Disponível em: $<$ http://economiadocom partilhamento.com.br/>. Acesso em: 10 mar. 2016.

MEELEN, Toon; FRENKEN, Koen. Stop Saying Uber is Part of the Sharing Economy. Londres, 14 jan. 2015. Disponível em: <http://www.fastcoexist.com/3040863/stop-sayinguberis-part-of-the-sharing-economy>. Acesso em: 01 jun. 2016.

MEYER, Jared. Uber-positive: why Americans love the sharing economy. New YorkEncounter Books, 2016.

NEW YORK. Departament of moto vehicles. Disponível em: $<$ https://dmv.ny.gov/moreinfo/faq-tnc-drivers.>. Acesso em: 5 fev. 2018.

OLIVEIRA, Patrick L. S. O Uber e o Mito da Panaceia Tecnológica. 21 jul 2015. Disponível em: < http://www.cartacapital.com.br/sociedade/uber-taxistas-4216.html>. Acesso em: 22 mar. 2016.

PIRONTI, Rodrigo. A polêmica do UBER: uma resumida análise jurídica e econômica da atividade. Direito do Estado, setembro 2016. Disponível em: 
$<$ http://www.direitodoestado.com .br/colunistas/rodrigo-pironti/a-polemica-do-uber-umaresumida-analise-juridica-e-economica -da-atividade>. Acesso em: 15 set. 2017.

RAUCH, Daniel E.; SCHLEICHER, David. Like Uber, But for Local Government Policy: The Future of Local Regulation of the 'Sharing Economy'. George Mason Law \& Economics Research Paper, no 15-01. Arlington, 14 jan. 2015. Disponível em: $<$ htpp://ssrn.com/abstract= 2549919>. Acesso em: 12 mai. 2016.

SAID, Carolyn. The Airbnb effect. San Francisco Chronicle, 12 jul. 2015. Disponível em: $<$ http://www.sfchronicle.com/airbnb-impact-san-francisco-2015/\#1>. Acesso em: 6 fev. 2018.

SÃO PAULO (SP). Comitê Municipal de Uso do Viário regulamenta normas obrigatórias para setor de transporte individual de passageiros por aplicativo. Disponível em: $<$ http://www.prefeitura.sp.gov.br/cidade/secretarias/transportes/noticias/?p=237438>. Acesso em: 15 set. 2017. 


\title{
FUNDAMENTO EXISTENCIAL E CONTRATUAL DA PROTEÇÃO CONTRA O SUPERENDIVIDAMENTO NA SOCIEDADE DA INFORMAÇÃO
}

\author{
Maíra Matsue Shimizu de Sousa \\ Centro Universitário das Faculdades Metropolitanas Unidas \\ Roberto Senise Lisboa \\ Centro Universitário das Faculdades Metropolitanas Unidas
}

\begin{abstract}
Resumo
O presente artigo estabelece a noção introdutória ao estudo do superendividamento e traça breves comparações entre o modelo francês e o brasileiro, prestando-se a tratar do fundamento existencial e contratual da proteção do consumidor contra o superendividamento na sociedade da informação.
\end{abstract}

Palavras-chaves: Sociedade da informação, negócio jurídico, boa-fé e confiança, dignidade da pessoa humana, vulnerabilidade do consumidor.

\begin{abstract}
Resumen/Résumé
The present article establishes the introductory notion to the study of super indebtedness and draws brief comparisons between the French and Brazilian models, dealing with the existential and contractual basis of consumer protection against over-indebtedness in the information society.
\end{abstract}

Keywords/Palabras-claves/Mots-clés: Information society, contract, good-faith and trust, consumer vulnerability, dignity of the human person. 


\section{Introdução}

A sociedade atual, também denominada sociedade da informação, encontra-se baseada no consumo, neste novo modo de desenvolvimento informacional, a fonte de produtividade baseia-se na tecnologia de geração de conhecimento, de processamento de informação e geração de símbolos (CASTELLS, 1999. p. 53).

Somos testemunhas, desde o último quarto do século $\mathrm{XX}$, de uma reestruturação do sistema capitalista, marcada, de um lado, pela revolução de técnicas informacionais, de outro, pela globalização dos mercados e desregulamentação financeira, como enfatiza Gilles Lipovetsky (LIPOVETSKY, 2007. p. 53).

Diante desse contexto, o superendividamento do consumidor torna-se uma consequência previsível, que segmenta as pessoas em classes ao considerar mais o que consomem do que o que são efetivamente.

O consumo tornou-se mais emocional do que necessário. Viver melhor, aproveitar a vida, gozar do conforto e das novidades mercantis são como direitos indisponíveis. Exalta-se uma cultura que valoriza os prazeres momentâneos, gozar a felicidade aqui e agora, viver para si mesmo, adquirir bens materiais como símbolos de status.

Em um ambiente caracterizado pelas novas tecnologias da informação e da comunicação, a hipervelocidade, a acessibilidade direta, o imediatismo impõe-se como novas exigências temporais.

Assim, o direito de construir nosso modo de existência como "bem nos parece" já não encontra outro obstáculo além do nível do poder de compra. No presente, é o dinheiro de que se dispõe, mais do que a classe de origem, que faz a diferença nos âmbitos de vida.

Enquanto as desigualdades econômicas se aprofundam, as aspirações consumistas se aproximam; as práticas sociais divergem, mas o sistema referencial é idêntico, a globalização padroniza as necessidades.

Mesmo excluída do universo do trabalho, a população dos subúrbios desqualificados compartilha valores individualistas e consumistas das classes médias, a preocupação com a personalidade individual e a auto realização. Os jovens, em particular, valorizam a dimensão pessoal de seu consumo (roupas, música, lazeres), os signos capazes de distingui-los de seus grupos de pares. 
Para Bauman:

Tudo que o homem faz em seu mundo simbólico é uma tentativa de negar e sobrepujar seu destino grotesco. Ele literalmente se lança em um esquecimento cego por meio de jogos sociais, truques psicológicos, preocupações pessoais tão afastadas da realidade de sua situação que são formas de loucura: loucura aceita, compartilhada, disfarçada e dignificada, mas mesmo assim loucura (BAUMAN, 2008. p. 7).

A insuficiência financeira, não é somente a falta de dinheiro, é também o que degrada a relação com a vida em geral, favorecendo a ansiedade, a depressão, a falta de autoestima. A pobreza material é vivida como falta de autonomia e de projeto, obsessão com a sobrevivência, sentimento de fracasso e de queda social.

\section{Crédito na sociedade da informação}

O crédito vem sendo utilizado desde tempos remotos, é anterior a própria cunhagem de moedas. A palavra tem sua origem etimológica em credere, que significa crer, caracterizando uma relação de confiança na qual se concede uma disposição imediata de valor para que seja paga em uma contraprestação futura, geralmente acrescida de juros.

O crédito é elemento essencial para o desenvolvimento da economia, através dele pode-se adquirir bens, desenvolver negócios, realizar viagens e tantas outras coisas que o pagamento à vista dos valores não permitiria. Torna-se penoso quando há um abuso ao crédito ou quando a pessoa se vê em uma situação imprevista na qual não pode arcar com suas dívidas, ocasionando a inadimplência.

O aumento do crédito acompanhou o aumento do consumo, como bem explica Gilles Lipovetsky:

\footnotetext{
A sociedade de consumo criou em grande escala a vontade crônica dos bens mercantis, o vírus da compra, a paixão pelo novo, um modo de vida centrado nos valores materiais. Shopping compulsivo, frente dos objetos, escalada das necessidades, profusão e esbanjamento espetacular (LIPOVETSKY, 2007. p. 22).
}

Toda esta euforia pelo consumo, veio acompanhada da facilidade em conseguir crédito e de uma grande margem de lucro das instituições financeiras e operadoras de cartão de crédito.

Com a sociedade da informação o acesso ao crédito facilitou-se, não sendo necessário dirigir-se a uma agência bancária, por meio de caixas eletrônicos ou mesmo pelo celular podese conseguir um empréstimo pessoal ou solicitar um cartão de crédito. 
No Brasil, após a estabilização econômica, o aumento do consumo possibilitou o acesso as instituições bancárias das classes C e D. Com a nova perspectiva de adquirir produtos antes impensáveis como carros, eletrodomésticos e até imóveis, grande parte da população aderiu a diversas formas de financiamentos como empréstimos pessoais, cartões de crédito, leasing, financiamentos de veículos e outras modalidades de contratação para pagamento futuro.

Na sociedade denominada pós-moderna, também denominada da informação, houve uma inversão de valores, se antes o hábito era poupar para depois comprar, tornou-se hábito comprar para depois pagar.

O advento da Internet deu início a uma nova perspectiva no sistema de comunicação do planeta, a sociedade da informação ampliou a interatividade que passou a ocorrer de forma globalizada.

Esse imediatismo dos dias atuais facilitou a aquisição de contratos de crédito e o endividamento tornou-se inevitável.

Contudo, faz-se necessário esclarecer que o endividamento por si só funciona como um importante motor para economia, todo investimento exige uma contraprestação e quando bem planejado resulta em um aumento de patrimônio.

O problema surge quando há um abuso como explica Clarissa Costa de Lima:

Apesar das evidências de que a expansão do crédito ao consumo traz inúmeros benefícios para os consumidores e para o desenvolvimento da economia, há custos e riscos que precisam ser enfrentados, a exemplo da redução da poupança familiar, da inflação e da perpetuação do endividamento (LIMA, 2014, p. 26).

O governo brasileiro com base no desenvolvimento e na economia de massa sempre incentivou a concessão de crédito, as instituições financeiras passaram a oferecer linhas de crédito para financiamento de imóveis, construção, compra de móveis, veículos, estudos, etc. Ampliou-se a oferta de crédito consignado, modalidade que é descontada diretamente da folha de pagamento, para funcionários públicos, aposentados e pensionistas, sempre com a ideia da necessidade de inclusão social.

$\mathrm{Na}$ atual realidade brasileira, após anos de incentivo ao crédito o cenário é desolador: O país começou 2017 com quase 60 milhões de pessoas inadimplentes. Esse é o maior número de brasileiros no vermelho desde 2012. As dívidas atrasadas desses consumidores chegam a R\$ 270 bilhões ${ }^{1}$.

1 http:/g1.globo.com/jornal-hoje/noticia/2017/03/quase-60-milhoes-de-brasileiros-nao-pagam-dividas-em-dia- 
A insolvência civil caracteriza-se quando as dívidas comprometem o adimplemento de gastos básicos, considerados mínimo existencial, como alimentação, transporte, educação; ocasionando não só a exclusão social como problemas de ordem psicológica e na pior das hipóteses suicídios, por não encontrar saídas viáveis.

Nesse cenário líquido como o caracterizado pela sociedade da informação, o que parecia ser a realização de um sonho, fez o consumidor despertar para a amarga realidade da inadimplência.

Sobredita colocação pode ser confirmada em Bauman, que ensina:

\begin{abstract}
A instabilidade dos desejos e a insaciabilidade das necessidades, assim como a resultante tendência ao consumo instantâneo e a remoção, também instantânea, de seus objetos, harmonizam-se bem com a nova liquidez do ambiente em que as atividades existenciais foram inscritas e tendem a ser conduzidas no futuro previsível. Um ambiente líquido moderno é inóspito ao planejamento, investimento e armazenamento de longo prazo (BAUMAN, 2007. p.45).
\end{abstract}

A sociedade de consumo acentuou diferenças sociais, pois apesar da oferta estar para todos, nem todos conseguem utilizá-la de maneira controlada, ao serem estimulados constantemente ao consumo acabam endividando-se e apartando-se da vida social. Bauman elucida muito bem esta dicotomia em sua obra Globalização: as consequências humanas. Sobre a qual também se manifesta Senise Lisboa:

Ele acredita que a sociedade de consumo aprofundou as desigualdades sociais, e que a capacidade de consumir ou não será o modo de avaliar se somos consumidores experientes e aptos a ser integrados na sociedade ou consumidores falhos ou fracassados, aqueles sem condições de fazer parte da roda da economia. Para estes, a exclusão social acontece de fato (SENISE LISBOA, 2012, p. 94).

Além da exclusão social está atrelado ao consumo a falsa ideia de felicidade. A aparente ideia de satisfação se desfaz ao ver que foi lançado outro produto mais moderno. Jean Baudrillard (BAUDRILLARD, 2010), em sua obra explica que os objetos têm um valor de signo e possuí-los confere uma qualidade de status, possibilita o enquadramento do indivíduo em determinado grupo social, fazendo com que se sinta aceito. Acumular dívidas se torna uma consequência deste estilo moderno de vida. Por meio de seus ensinamentos vemos que: "a imagem, o signo, a mensagem, tudo o que 'consumimos', é a própria tranquilidade selada pela distância em relação ao mundo, o que ilude, mais do que compromete, a alusão violenta ao real”. 
Nesse cenário, tendo em vista a facilidade da oferta de crédito, o consumidor entra em um processo de insolvência civil denominado de superendividamento.

\section{Superendividamento e suas modalidades}

O superendividamente ocorre quando o devedor não consegue pagar suas dívidas, entrando em um ciclo de inadimplência. O Projeto de Lei 3515/2015 define como superendividamento o "comprometimento de mais de $30 \%$ da renda líquida mensal do consumidor com o pagamento do conjunto das dívidas pessoais, excluído o financiamento para a aquisição de casa para a moradia".

A respeito do tema, Cláudia Lima Marques assim leciona: "superendividamento é a impossibilidade global do devedor-pessoa física, consumidor, leigo e de boa-fé, de pagar todas suas dívidas atuais e futuras de consumo".

O que se vê atualmente, é que a função social do crédito no sistema financeiro nacional, que seria promover o desenvolvimento econômico equilibrado do país e servir aos interesses da coletividade, como preconizado pela Constituição Federal em seu art. 192, não está sendo cumprida. Tornando-se imprescindível a regulamentação sobre esse tema.

A doutrina distingue o superendividamento em passivo e ativo. A primeira categoria é levada ao estado de insolvência por razões externas a sua vontade, já na segunda o devedor concorre diretamente para que isso aconteça.

São consideradas razões externas, as circunstâncias imprevistas como: o desemprego, divórcio ou doença. Os superendividados ativos são subdivididos em conscientes e inconscientes, ou seja, os inconscientes são aqueles que não souberam calcular o impacto da dívida sobre o seu orçamento, enquanto que os conscientes ativos contratam de má-fé, com a intenção de não honrar o seu compromisso.

Na prática, tanto os denominados acidentes da vida como o abuso do crédito podem gerar o endividamento crônico, levando o devedor à impossibilidade global de arcar com suas dívidas atuais e futuras. Desse modo, tanto o superendividado passivo como o ativo são merecedores da tutela protetiva do consumidor, exigindo-se, em ambos os casos, a boa-fé objetiva, afinal ambos estão expostos às práticas comerciais agressivas dos fornecedores de crédito e aos riscos decorrentes da aquisição de crédito fácil. 


\section{Fundamento existencial da proteção do consumidor contra o superendividamento}

Há dois fundamentos existenciais que justificam a proteção do consumidor contra o superendividamento, que devem ser realçados: a proteção da dignidade da pessoa humana e a vulnerabilidade perante as práticas comerciais e as cláusulas contratuais ofertadas e colocadas no mercado pelos fornecedores.

\subsection{Dignidade da pessoa humana}

A dignidade da pessoa é princípio fundamental da República Federativa do Brasil. É denominado princípio estruturante, constitutivo e indicativo das ideias diretivas básicas de toda a ordem constitucional. Aplica-se como leme a todo o ordenamento jurídico nacional.

A Constituição da República de 1988, pôs o indivíduo no centro do ordenamento jurídico ao estabelecer em seu artigo $1^{\circ}$, inciso III, que a dignidade da pessoa humana constitui fundamento da República, assegurando, desta forma, absoluta prioridade às situações existenciais ou extrapatrimoniais da pessoa.

Como ressalta Maria Celina Bodin de Moraes (MORAES, 2003), este princípio constitucional não garante o respeito e a proteção da dignidade humana apenas no sentido de assegurar um tratamento humano e não degradante, nem tampouco traduz somente o oferecimento de garantia à integridade física, psíquica e moral do ser humano. O imperativo categórico, de ordem moral, tornou-se um comando jurídico. A Constituição Federal considera esta dignidade fundamento da República.

A dignidade da pessoa humana concede unidade aos direitos e garantias fundamentais, sendo inerente à personalidade humana. É um valor espiritual e moral, que se manifesta singularmente na autodeterminação consciente e responsável da própria vida e que traz consigo a pretensão ao respeito por parte das demais pessoas, constituindo-se um mínimo invulnerável que todo estatuto jurídico deve assegurar, de modo que, somente excepcionalmente, possam ser feitas limitações ao exercício dos direitos fundamentais, mas sempre sem menosprezar a necessária estima que merecem todas as pessoas enquanto seres humanos.

\subsection{Vulnerabilidade do consumidor}

Trata-se de princípio norteador do direito do consumidor, previsto no artigo $4^{\circ}$, I do 
CDC, que reconhece a existência de uma parte vulnerável nas relações abrangidas por este diploma legal.

$$
\text { Art. } 4^{\circ} .(\ldots)
$$

I - reconhecimento da vulnerabilidade do consumidor no mercado de consumo;

Pode-se identificar quatro tipos de vulnerabilidade do consumidor: a técnica, quando o consumidor não possui conhecimentos específicos sobre o produto ou serviço, o fornecedor sim; a jurídica ou científica, pois o consumidor não possui conhecimentos jurídicos, de contabilidade, de economia, matemática financeira e outros, para analisar, por exemplo, sobre os juros cobrados e distinguir se são viáveis ou não; socioeconômica, o fornecedor é o detentor do poderio econômico, encontrando-se em posição de supremacia, e por fim, a informacional, que decorre da vulnerabilidade técnica, mas que deve ser tratada de forma autônoma, por força da dinâmica que as relações de consumo têm diante da era digital, onde o acesso à informação foi ampliado de forma a ser determinante para a decisão de compra do consumidor, assim, a proteção à vulnerabilidade informacional do consumidor pressupõe o controle da qualidade e da clareza da informação transmitida pelos fornecedores.

Deve haver uma equiparação de forças para que o sistema funcione perfeitamente. É isso que o Código de Defesa do Consumidor estabelece.

Diante disso, a Constituição Federal, expressa o seu dever de defesa ao consumidor em seu Artigo 170, V.

Em decorrência da previsão constitucional o Código de Defesa do Consumidor possibilita ainda: relativizar a forma obrigatória dos contratos, a fim de não permitir que a plena vontade do fornecedor se sobreponha sobre o consumidor; considera como regra a responsabilidade objetiva do fornecedor e a inversão do ônus da prova e busca a efetivação da igualdade substancial entre o fornecedor e o consumido.

A proteção do vulnerável significa concretizar o princípio constitucional da igualdade ou isonomia, pelo qual serão tratados igualmente os iguais, e desigualmente os desiguais, na medida em que se desigualam. Inegável a coerência da proteção do consumidor em relação ao princípio constitucional supracitado.

É importante destacar que vulnerabilidade e hipossuficiência são dois conceitos diferentes. O consumidor pode ser vulnerável, mas nem sempre hipossuficiente. A hipossuficiência trata-se de conceito fático e não jurídico, fundado em uma disparidade ou discrepância notada no caso concreto. A hipossuficiência é auferida casuisticamente, quando a pessoa não possui recursos financeiros. Já a vulnerabilidade pode ser presumida no caso de pessoa física, devendo ser analisada em cada caso concreto, quando tratar-se de pessoa jurídica. 
Vulnerabilidade e hipossuficiência são institutos jurídicos diferentes que geram consequências distintas, a vulnerabilidade traz a aplicabilidade de normas protetivas do Código de Defesa do Consumidor, enquanto que a hipossuficiência traz consequências exclusivamente processuais, como a justiça gratuita.

\section{Fundamento contratual de proteção do consumidor contra o superendividamento: confiança e boa-fé objetiva.}

Dentre os princípios informativos dos contratos de consumo, devem ser destacados, indiscutivelmente, para a análise do superendividamento contraído pelo consumidor: a boa-fé e a confiança.

A boa-fé traduz-se em uma conduta pautada nos princípios da lealdade, da confiança e da ética. Constitui-se, um regramento comportamental, em outras palavras, uma espécie de pré-condição abstrata de uma relação ideal (GIANCOLI, 2008. p. 91).

No direito romano, o vocábulo fides apresentava três significados, o primeiro deles estava presente nas XII tábuas, a chamada fides-sacra, que era ligada à boa-fé de conotação religiosa e moral; a segunda, a fides-fato, ligada à noção de garantia; e a terceira a fides-ética, que era vista como um dever. Esta última, certamente, foi primordial para o desenvolvimento dos estudos sobre a boa-fé objetiva, vista nos tempos atuais como um dever ético-moral.

$\mathrm{O}$ aspecto jurídico da boa-fé só veio se consolidar com o chamado jus gentium, que eram normas jurídicas aplicadas aos romanos e aos estrangeiros. Deve-se também destacar que a boa-fé, vista como instituto jurídico, é fruto do desenvolvimento do comércio, que permitia inúmeras relações contratuais, sendo necessário que houvesse entre os contraentes uma conduta ética.

No entanto, foi no direito alemão que o princípio da boa-fé ganhou importância. A noção de boa-fé saiu do plano psicológico e alcançou sentido de conduta, de dever, de norma a ser seguida pelas partes até a conclusão do negócio jurídico.

No direito alemão a regra Treu und Glauben (lealdade e confiança) resume bem como os doutrinadores alemães deram contornos objetivos a esse princípio. Para eles essa regra deveria ser observada por todos.

Como explica Senise Lisboa:

Boa-fé e confiança não se confundem, se complementam. Boa-fé não se tutela, boafé se espera. Boa-fé se revela na conduta pessoal. O que se tutela é a pessoa. O Direito tem por finalidade proteger pessoas (SENISE LISBOA, 2012. p. 151). 
Com relação ao superendividamento, a boa-fé implica que seja analisada a intenção do devedor e a sua vontade de solucionar a situação. Nos ordenamentos jurídicos que tratam a respeito do superendividamento a boa-fé não é vista somente como um princípio, mas como um requisito comportamental essencial as partes (GIANCOLI, 2008. p. 102).

\title{
6. Aspectos do superendividamento na França
}

$\mathrm{Na}$ França a proteção ao consumidor de crédito é mais abrangente, segundo o art. L.311 do Code de la Consommation, credor é considerado toda pessoa que concede crédito, independente de ser bancos ou instituições financeiras, vendedores ou lojistas que vendam a crédito também são considerados credores e inseridas nas regras do Código do Consumidor Francês.

Em relação aos tomadores de crédito a distinção é feita entre os que adquirem ou utilizam crédito com um fim profissional ou não profissional. Os que utilizam para fim profissional ficam excluídos dessa lei.

Geraldo de Faria Martins da Costa, ilustra tais casos:

\begin{abstract}
Foram excluídos do campo de aplicação da lei empréstimos contratados por um comerciante de eletrodomésticos para comprar cartões de visita destinados a diversificar a sua atividade. Por outro lado, outros acórdãos as aplicam, como no caso em que um comerciante que, visitado por um vendedor em domicílio, havia comprado a crédito um sistema de alarme para sua loja. Nesta última decisão, a Corte de Cassação entendeu que a compra a crédito de um sistema de alarme não está em relação direta - rapport direct - com a atividade profissional do tomador (COSTA, 2002. p. 41).
\end{abstract}

No entanto, é possível que as partes se submetam voluntariamente às regras do crédito ao consumo, mesmo se tratando de um empréstimo para financiar uma atividade profissional.

A Lei é clara ao dizer "toda operação de crédito", não importando a natureza jurídica dos contratos: venda a crédito, prestação de serviços a crédito, empréstimos acessórios, cartões de crédito, locação com opção de compra (COSTA, 2002. p. 43).

Os contratos de crédito são realizados de acordo com modelo pré-determinado pelo Comitê de Regulamentação Bancária, mencionando o que regulamenta o art. L.311-10 do Code de la Consommation, identidade das partes, montante do crédito, custo total do crédito, taxa de juros, despesas extras, seguro e suas condições. 
A falta de tal formalismo é sancionada na esfera penal, com multa e na esfera civil, com a perda dos juros decorrentes do contrato e o ressarcimento da soma dos juros já pagos, uma punição exemplar que causa um grande desconforto para os credores.

Comenta Geraldo de Faria Martins da Costa que: "os magistrados têm aplicado esta sanção com uma severidade exemplar, pouco importando a existência de prejuízo do tomador, pois as disposições da lei são de ordem pública, logo, irrenunciáveis" (COSTA, 2002. p. 60).

Depois que o devedor já se encontra em uma situação de descontrole de suas dívidas pode recorrer voluntariamente as commissions de surendettement, que dão início a um processo administrativo, no qual estas comissões conciliam as partes a fim de elaborar um plano de reescalonamento das dívidas.

Os devedores devem declarar os elementos passivos e os ativos de seu patrimônio. As parcelas serão fixadas considerando um reste à vivre, ou seja, respeitando o equivalente ao mínimo existencial aqui no Brasil. Somente as pessoas físicas e de boa-fé podem iniciar o procedimento.

A falta de liquidez passageira não é motivo para caracterizar o superendividamento, pois pode ser pleiteado o délai de grâce, ou seja, um prazo de suspensão do contrato.

Os dispositivos visam não só regularizar as dificuldades inerentes ao superendividamento, como também as prevenir, por isso, as dívidas vencidas e as vincendas são consideradas na análise da situação do requerente.

Uma vez aprovado o plano, deve ser cumprido à risca pelas partes, se houver inadimplemento por parte do devedor, o plano de reestruturação caduca e os credores podem cobrar individualmente os seus créditos (GIANCOLI, 2008. p. 143).

Contudo, o devedor insolvente pode solicitar à Comissão a abertura de um novo processo, se esta aceitar o pedido, pode requerer ao juiz a suspensão das execuções do primeiro acordo.

O art. L. 333-2 do Code de la Consommation cita três causas de perda do procedimento de superendividamento: as declarações falsas ou remessas de documentos inexatos; a tentativa de desvios de bens; e por último, o agravamento do endividamento. Essas causas são analisadas na abertura ou durante o procedimento e não se confundem com a má-fé, pois essa se aprecia no momento em que surge o superendividamento (COSTA, 2002. p. 121).

Para casos extremos são adotadas as recomendations extraordinaires, que se justificam pela ausência de rendas ou bens penhoráveis do devedor. Nestes casos pode ser adotado um prazo de até dez anos para a quitação da dívida, a suspensão do crédito por até três anos, ou mais extremamente, a supressão parcial ou total dos créditos. 
Parte da doutrina francesa considera que tais medidas atentam contra o princípio essencial da força obrigatória dos contratos.

As recomendações podem ser contestadas, e o juiz será o responsável por solucionar as questões, cabendo ainda, apelação de sua decisão.

As recomendações das comissões necessitam de homologação pelo juiz competente, não têm força obrigatória por si mesmas.

\section{Aspectos jurídicos do superendividamento no Brasil}

A legislação brasileira ainda é carente em tutelar o consumidor endividado. $\mathrm{O}$ Código de Defesa do Consumidor trata do tema em alguns artigos como: art.6 $6^{\circ}$ IV; art. 43; art. 46; art.49; art.52 e art.54.

$\mathrm{O}$ artigo $6^{\circ} \mathrm{IV}$, visa proteger o consumidor de práticas desleais e maliciosas dos fornecedores de crédito, como por exemplo, propor um novo empréstimo para quitar o anterior ou cláusulas contratuais consideradas abusivas, como taxa de juros abusivas.

Já o artigo 43, trata dos bancos de dados e cadastros de consumidores. Dispõe que o consumidor sempre terá acesso aos cadastros. Ressalta-se que qualquer registro feito há mais de cinco anos deverá ser retirado do banco de dados.

$\mathrm{O}$ artigo 46 do CDC trata da proteção contratual, desobrigando o consumidor quando ele não for informado de todos os requisitos do contrato de forma prévia e se esse contrato for escrito de maneira que o consumidor não o compreenda. Sendo assim, uma forma de obrigar o fornecedor de crédito a agir com imparcialidade e clareza na elaboração do contrato de crédito.

Aproveitando o enfoque, ressalta-se que os $\S 3^{\circ}$ e $\S 4^{\circ}$ do artigo 54 do CDC, trata sobre os contratos de adesão, ou seja, contratos pré-estabelecidos pelo fornecedor o qual deve informar claramente seu conteúdo ao consumidor.

E, finalmente, o artigo 52 do $\mathrm{CDC}$, trata das cláusulas abusivas, informa que o fornecedor de bens ou serviços, havendo a concessão de crédito, deverá informar ao consumidor, dentre vários requisitos: o valor do produto; o total dos juros dessa transação; os acréscimos previstos; o número de prestações; o valor em caso de multa ou atraso do pagamento das parcelas; e, por último, é assegurado ao consumidor poder extinguir a dívida, a qualquer momento, em seu montante total e real, retirando os juros e demais acréscimos. Portanto, impõe ao fornecedor a obrigação de prestar informações claras e objetivas ao consumidor de maneira que não restem dúvidas sobre o contrato. 
Como se pode ver, apenas indiretamente há legislação para proteger o consumidor do superendividamento. No Brasil, o Código de Defesa do Consumidor, o Código Civil e também princípios da Constituição Federal de 1988 possuem normas que devem ser aplicadas em favor dos consumidores enquanto não se obtém um regramento especializado por parte dos legisladores.

O Projeto de lei 283/2012, no qual o senador Ricardo Ferraço (PSDB-ES) foi relator, após conciliar o diálogo com diversos setores da sociedade, conseguiu a aprovação do texto final do projeto no fim de 2015.

Em 2016 o projeto seguiu para a Câmara dos Deputados, sob o número PL 3515/2015 estando atualmente na Comissão de Defesa do Consumidor dessa Casa, com a relatoria do deputado Eli Corrêa Filho (DEM-SP).

Esse projeto de lei vem justamente propor uma complementação ao Código de Defesa do Consumidor com a finalidade de tutelar especificamente os consumidores superendividados.

Apresenta-se divido em duas partes, tratando da prevenção ao superendividamento no Capítulo VI, Seção IV e da chamada conciliação no Capítulo V.

Na seção que trata sobre a prevenção ao superendividamento têm como princípios norteadores a boa-fé, a função social do crédito, assim como a dignidade da pessoa humana, trata-se também, do acesso responsável ao crédito e da educação financeira do consumidor, artigo 54-A.

O artigo 54-B dispõe sobre medidas que devem ser adotadas pelos contratantes, especificando que a informação deve ser prestada "prévia e adequadamente". Estabelece prazo mínimo de dois dias para que o tomador do crédito possa refletir

$\mathrm{O}$ artigo 54-C, veda a publicidade abusiva vedando expressamente palavras referentes a crédito como: gratuito, sem juros, taxa zero, sem acréscimo.

Já o artigo 54-D, fixa em no máximo $30 \%$ do valor do salário para créditos consignados, estabelecendo um prazo de até 7 dias para desistência.

O Capítulo V dispõe sobre a conciliação das dívidas, estabelece o prazo máximo de cinco anos para escalonamento da dívida, preservando o mínimo existencial. Caso não haja a conciliação poderá haver um plano judicial compulsório, em que o magistrado fixará os termos e condições do pagamento das dívidas, permitindo que o consumidor volte a ter dignidade na sociedade de consumo (Art.104-A).

Também modifica o Art.96 da Lei 10.741 (Estatuto do Idoso), não constituindo crime a negativa de crédito por superendividamento. 


\section{Conclusão}

A sociedade da informação encontra-se baseada no consumo, novas tecnologias facilitaram tanto a aquisição de bens e serviços como a aquisição de crédito, essa facilidade fez surgir o descontrole que ocasiona o superendividamento dos consumidores.

$\mathrm{Na}$ atualidade, o crédito tornou-se mercadoria de fácil acesso trazendo consigo todas as consequências tanto positivas como negativas.

O desenvolvimento da informação e da autonomia de vontade é essencial para assegurar a integridade do consentimento do consumidor e a prevenção do superendividamento.

Trata-se o crédito como um elemento de inclusão social, essencial para o desenvolvimento da vida em sociedade. O problema surge quando há um descontrole na sua aquisição causando a inadimplência.

Esse problema repercute tanto na microeconomia familiar, como na macroeconomia social.

O superendividamento pode ser dividido em passivo e ativo. A primeira categoria é levada ao estado de insolvência por razões externas a sua vontade, já na segunda o devedor concorre diretamente para que isso aconteça.

Essa insolvência caracteriza-se quando as dívidas comprometem o denominado mínimo existencial que inclui alimentação, transporte, educação.

$\mathrm{Na}$ França, a legislação em vigor já oferece robusta proteção para os casos de superendividamento dos consumidores.

No Brasil, apesar dos esforços na aprovação de uma legislação específica que trate especificamente do assunto, ainda não pode ser concretizada.

A reformulação do código de defesa do consumidor corresponde aos anseios da sociedade, visando maior proteção para os endividados.

Nessa visão socioeconômica do superendividamento nota-se que a manutenção do mercado com a contínua produção de bens, serviços e informações depende da "boa saúde financeira" do consumidor e de sua reinserção no ciclo de produção, o que só é possível por meio da tutela jurídica específica destinada a prevenir e a solucionar as situações de endividamento.

Diante da análise percebe-se que o superendividamento é um problema recorrente, atingindo a parcela mais humilde da população, sendo imprescindível a tutela estatal para regulamentar e impedir o aumento das diferenças sociais já existentes. 


\section{Referências bibliográficas}

BAUDRILLARD, Jean. A sociedade de consumo, Ed.70, 2010.

BAUMAN, Zigmunt. Vida para consumo. São Paulo: Zahar, 2007.

BAUMAN, Zygmunt. A sociedade individualizada: vidas contadas e histórias vividas. Trad. José Gradei. Rio de Janeiro: Ed. Zahar, 2008.

CASTELLS, Manuel. A Sociedade em Rede. São Paulo: Paz e Terra. 1999.

COSTA, Geraldo de Faria Martins da. Superendividamento: a proteção do consumidor de crédito em direito comparado brasileiro e francês. São Paulo: Revista dos Tribunais, 2002.

GIANCOLI, Brunno Pandori. O superendividamento do consumidor como hipótese de revisão dos contratos de crédito. Porto Alegre: Verbo Jurídico, 2008.

LIMA, Clarissa Costa de Lima. O tratamento do superendividamento e o direito de recomeçar dos consumidores. São Paulo: Ed.Revista dos Tribunais, 2014.

LIPOVETSKY, Gilles. A Felicidade Paradoxal: ensaio sobre a sociedade de hiperconsumo. São Paulo: Cia das Letras, 2007.

MARQUES, Cláudia Lima. Direitos do consumidor endividado: superendividamento e crédito. São Paulo: Revista dos Tribunais, 2006. v. 29.

MORAES, Maria Celina de Bodin. Danos à pessoa humana: uma leitura civil-constitucional dos danos morais. Rio de Janeiro, 2003.

SENISE LISBOA, Roberto Senise. Confiança Contratual. São Paulo, Atlas. 2012.

SENISE LISBOA, Roberto. Solidarismo Internacional e Constitucional: Em defesa do Estatuto de Erradicação da Pobreza. In: Direito Constitucional Contemporâneo: Homenagem ao Professor Michel Temer. São Paulo: Quartier Latin, 2012. 


\title{
HERMETISMO NO PROCESSO DE RECALL DE MEDICAMENTOS NO BRASIL: AFRONTA AO DIREITO À INFORMAÇÃO E CONSEQUENTE AMEAÇA À SAÚDE E SEGURANÇA DO CONSUMIDOR
}

\author{
Juliana Barbalho Brasileiro \\ Centro Universitário de João Pessoa - UNIPE \\ Carolina Valença Ferraz \\ Centro Universitário de João Pessoa - UNIPE
}

\section{Resumo}

Esta pesquisa busca desvelar e compreender o processo de recall de medicamentos no Brasil, bem como verificar até que ponto este instituto vêm efetivamente cumprindo o seu papel em proteger a saúde e segurança dos consumidores. Para isto, analisou-se o Código do Consumidor, a Portaria $n^{\circ}$ 487/2012 do Ministério da Justiça e a RDC n 55/2012 da Anvisa. Também foram analisados dados abertos de recalls de medicamentos extraídos da Anvisa e da Senacon, bem como de procedimentos instaurados na $1^{\mathrm{a}}$ Promotoria do Consumidor de João Pessoa, buscando fundamentar a discussão empiricamente.

Palavras-chave: direito à informação, saúde do consumidor, recall de medicamentos.

\begin{abstract}
Resumen/Résumé
This research seeks to unveil and understand the drug recall process in Brazil, as well as to verify the extent to which this mechanism has been effectively fulfilling its role in protecting consummer's health and safety. To achieve this goal, we analyzed the Consumer Code, Ordinance $n^{\circ} 487 / 2012$ of the Ministry of Justice and Anvisa's RDC $n^{\circ}$ 55/2012. We also analyzed open data on drug recalls extracted from Anvisa and Senacon, as well as from procedures instituted in the $1^{\text {st }}$ Consumer Prosecutor's Office of João Pessoa, seeking to empirically substantiate the analysis.
\end{abstract}

Keywords/Palabras-claves/Mots-clés: right to information, consumer health, drug recall. 


\section{Introdução}

O advento da sociedade de massa e a intensificação da globalização comercial possibilitou que uma única falha na produção pudesse ocasionar danos a milhares - ou mesmo milhões - de pessoas. À vista disso, percebe-se uma crescente preocupação quanto à segurança de produtos e serviços ofertados no mercado de consumo. Entretanto, casos de desvio de qualidade ocorrem constantemente, e uma das principais medidas a ser tomada é a realização de recall ou chamamento, que consiste em comunicar o risco às autoridades $\mathrm{e}$ aos consumidores, bem como o recolhimento dos produtos com desvio de qualidade.

No Brasil, foi o Código de Defesa do Consumidor - CDC de 1990 que previu o instituto. $\mathrm{O}$ art. $10, \S \S 1^{\circ}$ e $2^{\circ}$, e a Portaria ${ }^{\circ} 487 / 2012$ do Ministério da Justiça que o disciplina, estabelecem as normas gerais de recall para qualquer produto ou serviço que apresente desvio de qualidade. Ocorre que alguns produtos, devido à necessidade de maior cuidado em sua fabricação, comercialização e uso, são fiscalizados e regulamentados por agências reguladoras, que no caso de medicamentos, o ente responsável é a Agência Nacional de Vigilância Sanitária - ANVISA. Diante dessa realidade, existe a RDC n 55/2005, da ANVISA, que regulamenta especificamente os casos de recall de medicamentos.

O problema central da pesquisa é: até que ponto os recalls de medicamentos realizados no Brasil vêm efetivamente cumprindo o seu papel em proteger a saúde e segurança dos consumidores? A hipótese levantada é a de que o processo de recall de medicamentos no Brasil fica adstrito à agência reguladora, a Anvisa, e aos fornecedores, ocasionando, assim, um alheamento dos órgãos de proteção do consumidor e dos próprios consumidores, ferindo frontalmente o princípio à informação e atentando contra à saúde e segurança dos consumidores.

No desenvolvimento do estudo, mostrar-se-á a indissociabilidade da proteção da saúde e segurança do consumidor e seu o direito à informação, visto que apenas o cidadão bem informado possui real liberdade para fazer suas escolhas e se resguardar de acidentes de consumo. Em sequência, foram estudados os principais pontos das normas da Anvisa e do MJ que se aplicam aos casos de recalls de medicamentos. Para mais, buscou-se compreender o instituto empiricamente através da análise de dados.

O objetivo geral do artigo é analisar a efetividade dos recalls de medicamentos no Brasil na proteção da saúde e segurança do consumidor. Elegeu-se como objetivos específicos: compreender a importância do direito à informação na prevenção de acidentes de consumo; evidenciar a ocorrência de inúmeros procedimentos de recalls de medicamentos que ocorrem 
no Brasil mas que não chegam ao conhecimento dos órgãos de proteção e defesa do consumidor e dos próprios consumidores; problematizar o cumprimento das normas que regem o recall de medicamentos pelos fornecedores; coletar e analisar dados de recalls de medicamentos para produção de conhecimento prático do instituto.

Metodologicamente, examinou-se o processo de recall no Brasil através da dimensão jurídico-normativa, pela análise do Código do Consumidor, da Portaria $n^{\circ} 487$ do Ministério da Justiça e da Resolução n 55/2012 da ANVISA, bem como o embasamento doutrinário e jurisprudencial, e da dimensão empírica, através da análise de dados abertos de recall extraídos da Anvisa e da SENACON, bem como de procedimentos instaurados na $1^{\text {a }}$ Promotoria do Consumidor de João Pessoa, para fundamentar as proposições do estudo. Utilizou-se o método de abordagem indutivo, onde se busca extrair uma proposição geral a partir da análise da amostragem selecionada de recalls de medicamentos. A pesquisa será preponderantemente exploratória, considerando ser um campo novo de estudo, visto que não foi encontrado nenhum estudo com o mesmo objeto desta pesquisa.

\section{Proteção à saúde e segurança do consumidor e a indissociabilidade com o direito à informação}

Os movimentos em prol da proteção e defesa do consumidor surgiram como resposta às transformações sociais e aos riscos advindos da sociedade de massa que fragilizou excessivamente uma das partes contratuais, reduzindo - ou quase anulando - o seu poder de barganha e a colocando em situação de vulnerabilidade frente ao fornecedor. Assim, nos ensinamentos de Sodré (2009, p. 12), “o direito do consumidor é uma resposta aos novos problemas que a sociedade de consumo trouxe, ou seja, os problemas na demanda que nasceram do desenvolvimento da sociedade industrial”.

No ordenamento jurídico brasileiro, para suprir essa demanda social e promover a igualdade material nas relações contratuais de consumo, foi criado o Código de Defesa do Consumidor - $\mathrm{CDC}^{1}$, que traz em seu corpo normas de caráter de ordem pública e de interesse social $^{2}$.

\footnotetext{
${ }^{1}$ Importante ressaltar que o Direito do Consumidor não se resume ao CDC. Este possui este caráter de norma principiológica o que lhe confere status supralegal, devendo, assim, guiar todo o ordenamento. Mas qualquer norma que tenha por objetivo proteger o consumidor, obviamente, faz parte do objeto de estudo deste ramo do direito. Pode-se dizer que já havia normas que direta ou indiretamente promoviam a proteção do consumidor antes mesmo do CDC, como, por exemplo, a lei $\mathrm{N}^{\circ}$ 5991, de 17 de dezembro de 1973, que dispõe sobre o controle sanitário do comércio de drogas, medicamentos, insumos farmacêuticos e correlatos.

${ }^{2} \mathrm{CDC}$, art. $1^{\circ} \mathrm{O}$ presente código estabelece normas de proteção e defesa do consumidor, de ordem pública e
} 
Nesse contexto, é uma preocupação basilar do CDC proteger um dos bens mais caros do consumidor, qual seja, a saúde, pois ao tempo em que a industrialização e o progresso tecnológico, impulsionados pelo nosso modelo econômico, promoveram a multiplicação e estimularam o acesso a uma infinidade de produtos e serviços a toda a população, os riscos e perigos inerentes a estes também foram multiplicados, com consequente ampliação dos danos colaterais. Como exemplo, tem-se o caso da talidomida, substância amplamente comercializada como inócua e segura no final da década de 50 em mais de 45 países, isenta de prescrição médica. Posteriormente, descobriu-se que a utilização deste medicamento provocava uma anomalia congênita que impediria a formação de braços e pernas no feto; estima-se que de 10.000 a 15.000 de pessoas nasceram com má formação devido ao seu uso por grávidas.

O exemplo da talidomida é apenas um dentre tantos outros casos de danos causados pelo consumo. Obviamente nem todos os incidentes devido a desvio de qualidade de produtos e serviços possuem a mesma gravidade do que foi exposto, mas o que se pretende ressaltar é a vulnerabilidade do consumidor frente à eventualidade de acidentes de consumo.

Em sua incumbência de zelar pela integridade física e psicológica do consumidor, resta evidente a função protetiva do direito à saúde no $\mathrm{CDC}$, onde vários dispositivos abordam a prevenção; empenha-se vigorosamente em evitar a ocorrência de quaisquer danos, uma vez que o acontecimento destes pode resultar em grandes catástrofes em nossa sociedade massificada. O ponto fulcral da norma é resguardar a saúde do consumidor, garantindo-lhe um máximo de segurança frente a qualquer produto ou serviço, e reconhecer a responsabilidade do fornecedor na ocorrência de eventuais danos.

Um dos principais instrumentos utilizados pelo código para atuar preventivamente é a garantia do direito fundamental à informação ${ }^{3}$ em toda a sua amplitude; este deverá ser respeitado nas fases do pré-consumo, do consumo e do pós-consumo. "É através da informação que o Estado aguarda ofertar meios de o próprio cidadão consumidor proteger sua saúde contra produtos ou serviços impróprios para uso ou consumo" (VASCONCELOS e MAIA, 2012, p. 182).

A prevenção através da garantia do direito à informação é proveniente da vulnerabilidade do consumidor, onde o respeito a esse direito fundamental reduzirá a posição

\footnotetext{
interesse social, nos termos dos arts. $5^{\circ}$, inciso XXXII, 170, inciso V, da Constituição Federal e art. 48 de suas Disposições Transitórias.

${ }^{3}$ Jean Calais-Auloy (2010, p. 55) traz uma importante ressalva ao afirmar que publicidade não pode ser confundida com informação: "No entanto, não devemos confundir informações com publicidade. Isto não se destina a informar; sua missão é atrair consumidores. (...) Mas uma propaganda, mesmo que não seja enganosa, é necessariamente tendenciosa. Portanto, é necessário que os profissionais também forneçam aos consumidores informações genuínas, informações objetivas." (tradução da autora)
} 
de fragilidade em que este se encontra nas relações contratuais. Para Corchero y Murillo (p. 93, 2007, apud Vaz, p. 67, 2015):

O desequilíbrio nas relações entre profissionais e consumidores se explica em boa medida pela desigualdade de informação: os profissionais conhecem os bens e serviços postos no mercado, enquanto os consumidores são incapazes de julgar antecipadamente.

Por isso, a essencialidade da veracidade do que é veiculado em ofertas, publicidades e apresentação de produtos e serviços. O respeito ao princípio da informação é fundamental para resguardar os direitos dos consumidores, pois inexistirá a plena liberdade de escolha do consumidor se houver omissões ou dados incorretos acerca do produto ou serviço.

A informação é imprescindível para a concreção de outros princípios essenciais que balizam as relações de consumo, como a boa-fé, a transparência e a confiança. Nos dizeres de Antônio Herman Benjamin, em seu voto no Recurso Especial n 586.316 - MG, "No âmbito da proteção à vida e saúde do consumidor, o direito à informação é manifestação autônoma da obrigação.". Continua o jurista na decisão supracitada:

Só o consumidor bem informado consegue de fato usufruir integralmente os benefícios econômicos que o produto ou serviço lhe proporciona, bem como protegerse de maneira adequada dos riscos que apresentam. Por esse último aspecto (proteção contra riscos), a obrigação de informar deriva da obrigação de segurança, que modernamente, por força da lei ou da razão, se põe como pressuposto para o exercício de qualquer atividade no mercado de consumo.

Importante ressaltar que o direito à informação abrange duas perspectivas: o direito a ser informado e o dever de informar. Quanto ao direito a ser informado, temos o consumidor como titular desse direito, como já exposto anteriormente; isso fica claro ao elencar a informação como direito básico do consumidor e em outros dispositivos do código, como o art, 43, que garante ao consumidor acesso às informações existentes em cadastros, fichas, registros e dados pessoais e de consumo arquivados sobre ele.

Já em relação ao dever de informar, é uma obrigação que cabe principalmente aos fornecedores, como informar a respeito dos produtos e serviços: eventuais riscos (art. $\left.8^{\circ}, \mathrm{CDC}\right)$, garantir informações claras, corretas e precisas quanto à qualidade, quantidade, características (art. 31, CDC), prestar as informações técnicas e científicas (art. 36, CDC), dentre outras. Contudo, essa obrigação também se desdobra para o Estado, que tem o poder-dever de fiscalizar e controlar toda a cadeia de produção garantindo e promovendo a veracidade e a promoção das informações tendo por escopo garantir a dignidade dos consumidores. 
Assim, apenas com o empoderamento do consumidor através da informação é que se pode assegurar a liberdade de escolha nas relações de consumo e advertir os consumidores sobre eventuais riscos e perigos advindos da utilização de bens, evitando, assim, acidentes de consumo. O dever de observância ao direito à informação é não apenas do fornecedor, mas também do Poder Público, tendo em vista que cabe a este o dever de promoção da saúde, o que no caso no Direito do Consumidor está intrinsecamente ligado ao direito à informação, tanto garantindo a veracidade das informações quanto proporcionando a difusão destas.

\section{Recall de medicamentos no Brasil}

As relações jurídicas são regidas pelo princípio da confiança, e no caso das relações de consumo, o consumidor adquire um bem ou serviço na busca da satisfação de uma necessidade; acredita que este não causará nenhum dano à sua saúde e à sua segurança. Aposta na credibilidade do fornecedor. Outrossim, não podemos olvidar a confiança depositada no Estado pelo cidadão; se há instituições estatais especializadas responsáveis por avaliar quais bens ou serviços podem circular em nosso país, é esperado que os produtos ou serviços autorizados por essas instituições gerem confiabilidade nos cidadãos que os adquirirem ${ }^{4}$.

Em que pese os esforços do ordenamento jurídico e do aparato estatal, e mesmo o empenho dos fornecedores, para coibir a circulação de produtos e serviços inseguros, estes acabam chegando ao mercado por diversos motivos como: falha na produção, desconhecimento da nocividade de alguma substância ou ausência de fiscalização eficiente.

Até a publicação do CDC, não havia no direito brasileiro norma que expressamente impusesse a suspenção da venda ou fabricação de produtos potencialmente perigosos. Apesar de não utilizar a palavra recall, foi o art. $10, \S 1^{\circ}$, do $\mathrm{CDC}$, que deu início à previsão do instituto no Brasil:

$\S 1^{\circ} \mathrm{O}$ fornecedor de produtos e serviços que, posteriormente à sua introdução no mercado de consumo, tiver conhecimento da periculosidade que apresentem, deverá comunicar o fato imediatamente às autoridades competentes e aos consumidores, mediante anúncios publicitários.

A Secretaria Nacional do Consumidor - SENACON 5 define recall como "a forma pela qual um fornecedor vem a público informar que seu produto ou serviço apresenta riscos aos

\footnotetext{
${ }^{4}$ Para Shuenquener de Araújo (2009, p. 5), essa confiança nos atos estatais é um fator relevante para o sucesso de um país, pois ela se mostra indispensável para viabilizar a eficiência da atividade comercial através de estruturas e operações mais complexas.

5 Conceito retirado do site do Ministério da Justiça. Disponível em: http://www.justica.gov.br/seus-
} 
consumidores. Ao mesmo tempo, recolhe produtos, esclarece fatos e apresenta soluções”. Em consonância com esse entendimento, Nelson Nery Júnior e Rosa Maria Nery (NERY e NERY, 2010, p. 189) conceituam o instituto como:

\begin{abstract}
$\mathrm{O}$ ato pelo qual o fornecedor informa o consumidor a respeito do defeito do produto que tem potencialidade para causar danos ou prejuízo à sua saúde ou à sua segurança. Pelo recall o fornecedor chama de volta o produto (nocivo ou perigoso) para a correção do risco que apresenta. Esta correção pode se dar pela substituição total ou parcial do produto (peças, acessórios, etc.).
\end{abstract}

Desta maneira, extrai-se que recall é um procedimento, previsto em lei, que deve ${ }^{6}$ ser adotado pelos fornecedores como forma de alertar os consumidores, indicando para a necessidade de chamar de volta o consumidor, tendo em vista problemas verificados em produtos ou serviços colocados no mercado de consumo, evitando, assim, a ocorrência de um acidente de consumo ${ }^{7}$, atuando, assim, precipuamente na prevenção.

$\mathrm{O}$ art. 10 do CDC, ao prever o instituto do recall, foi um avanço legislativo no sentido de proteção da saúde e segurança do consumidor. Contudo, as normas ali previstas, claramente relacionadas aos princípios da vulnerabilidade do consumidor, da boa-fé, da transparência e da informação não foram suficientes para nortear as primeiras campanhas de recall. Não havia padronização, muitas vezes informações básicas eram suprimidas ou eram muito técnicas, o que inviabilizava o entendimento pelos consumidores.

A primeira regulamentação específica sobre recall no Brasil ocorreu somente em 2001, por meio da Publicação da Portaria $n^{\circ} 789$ do Ministério da Justiça. Atualmente, a norma que rege o processo de chamamento é a Portaria 487/2012, do Ministério da Justiça, que buscou aprimorar a Portaria 789/2001 e promover campanhas de recall mais efetivas.

Devido à maior potencialidade de risco, alguns produtos têm a sua cadeia produtiva intensamente regulamentada e controlada pelo Estado. É o caso dos medicamentos. No Brasil, cabe à ANVISA a regulação, monitoramento e fisscalização de produtos de saúde. Assim, para regulamentar os procedimentos de recolhimento de medicamentos, bem como promover o acompanhamento pelos órgãos do Sistema Nacional de Vigilância Sanitária, a agência nacional publicou em 2005 a Resolução ${ }^{\circ}$ 55, que estabelece os requisitos mínimos a serem observados

\footnotetext{
direitos/consumidor/saude-e-seguranca/recall>. Acesso em: 25/01/2018

${ }^{6}$ Cláudia Lima Marques (MARQUES, BENJAMIN, MIRAGEM, 2016, p. 490) afirma que o recall decorre de um dever pós-contratual do fornecedor baseado nos princípios da boa-fé, da transparência e da proteção do consumidor.

${ }^{7}$ Acidente de consumo é quando um produto ou serviço causa um dano ao consumidor, além do dano material, mesmo quando da sua utilização regular.
} 
pelas empresas detentoras de registros (fabricantes ou importadores) em caso de desvio de qualidade de seus produtos ${ }^{8}$.

\section{Análise da RDC $n^{\circ} 55 / 2005$ da Anvisa em face da Portaria $n^{\circ}$ 487/2012 do Ministério da Justiça}

A RDC $n^{\circ} 55 / 2005$ da ANVISA e a Portaria $n^{\circ}$ 487/2012 do MJ foram publicadas com o intuito de padronizar os processos de recall e proporcionar um maior controle dessas ações pelos órgãos de fiscalização. Enquanto a norma do $\mathrm{MJ}$ veio para regulamentar o art, $10, \S \S 1^{\circ}$ e $2^{\circ}$, do $\mathrm{CDC}$, descrevendo o procedimento geral do recall de qualquer produto ou serviço defeituoso, a norma da ANVISA, aborda especificamente o procedimento de recall de medicamentos com desvio de qualidade. Interessam para este artigo os seguintes pontos de ambas as normas: comunicado às autoridades, recolhimento e alerta aos consumidores.

Quanto ao comunicado às autoridades, a Portaria $\mathrm{n}^{\circ} 487$, do $\mathrm{MJ}$, prevê que o fornecedor, ao iniciar uma campanha de recall, deverá comunicá-la formalmente ao Departamento de Proteção e Defesa do Consumidor - DPDC, da Secretaria Nacional do Consumidor - SENACON, aos demais órgãos de proteção do consumidor e ao órgão normativo ou regulador competente ${ }^{9}$. Este informe deverá conter todos os dados relevantes que possibilitem a identificação clara do fornecedor e do produto ou serviço do chamamento, bem como a descrição pormenorizada do vício ou defeito.

Já a RDC n55, da ANVISA, dispõe que em caso de desvio de qualidade ou cancelamento de registro, caberá ao detentor do registro apresentá-lo à ANVISA, bem como a toda a cadeia de produção, informando todas as informações pertinentes, como o nome do

\footnotetext{
${ }^{8}$ Impende ressaltar que não é de hoje a preocupação em se retirar do mercado medicamentos inócuos ou que apresentem grau de periculosidade maior do que benefícios para aqueles que o consomem. A Lei n ${ }^{\circ} 6360$, de 1976, já previa a retirada do mercado e a proibição de fabricação e comercialização de medicamentos que apresentassem efeitos nocivos à saúde humana. Vejamos: Art. $6^{\circ}$ - A comprovação de que determinado produto, até então considerado útil, é nocivo à saúde ou não preenche requisitos estabelecidos em lei implica na sua imediata retirada do comércio e na exigência da modificação da fórmula de sua composição e nos dizeres dos rótulos, das bulas e embalagens, sob pena de cancelamento do registro e da apreensão do produto, em todo o território nacional. Parágrafo único. É atribuição exclusiva do Ministério da Saúde o registro e a permissão do uso dos medicamentos, bem como a aprovação ou exigência de modificação dos seus componentes. Art. $7^{\circ}$ - Como medida de segurança sanitária e a vista de razões fundamentadas do órgão competente, poderá o Ministério da Saúde, a qualquer momento, suspender a fabricação e venda de qualquer dos produtos de que trata esta Lei, que, embora registrado, se torne suspeito de ter efeitos nocivos à saúde humana.

${ }^{9}$ Portaria $\mathrm{n}^{\circ} 487 / 2012$, do $\mathrm{MJ}$, art $2^{\circ} \mathrm{O}$ fornecedor de produtos e serviços que, posteriormente à sua introdução no mercado de consumo, tiver conhecimento da nocividade ou periculosidade que apresentem, deverá comunicar o fato imediatamente: I - ao Departamento de Proteção de Defesa do Consumidor - DPDC; II - aos órgãos estaduais, do Distrito Federal e municípios do consumidor - PROCON; e III - ao órgão normativo ou regulador competente.
} 
produto e seu registro, o motivo do desvio, a classificação de risco e a consequência à saúde. A comunicação deverá ser feita em até 48 horas a partir da ciência de indícios suficientes ou da comprovação do desvio.

Por se tratar de um produto regulado, a produção e comercialização de medicamentos devem observar às normas da Agência Reguladora, ou seja, a ANVISA. Entretanto, isso não implica em inobservância das normas que regem os produtos em geral. Muito pelo contrário: as normas da agência reguladora deveriam reforçar as normas já existentes e aumentar o rigor quanto aos produtos regulados, vez que esses são regulados exatamente por haver necessidade de maior atenção para estarem disponíveis no mercado de consumo.

Diante disso, em casos de recall, o fornecedor deverá obedecer tanto a norma geral, que é a Portaria $n^{\circ}$ 487/2012 do MJ, quanto a Resolução $n^{\circ} 55$ da ANVISA. A questão da complementaridade normativa é essencial para que o objetivo do recall seja cumprido: os fornecedores devem ter ciência de que os procedimentos em âmbito federal, embora complementares, não são excludentes. Isso significa dizer que, mesmo completando todos os trâmites impostos por uma agência reguladora, a empresa não se exime do dever de cumprir os requisitos previstos na legislação consumerista. Tal distinção é de suma importância, tendo em vista, principalmente, que o conceito de risco não é unânime, mesmo entre os órgãos governamentais (GONÇALVES e MELO, 2015, p. 5).

Entretanto, o que vem acontecendo no Brasil é que os casos de recall acabam ocorrendo apenas entre os fornecedores e a ANVISA, gerando um alheamento dos órgãos de defesa e proteção do consumidor nos casos de recall de medicamentos no Brasil.

As duas normas preveem que os fornecedores devem elaborar uma estratégia para que a informação do desvio de qualidade de produtos chegue até os consumidores. A Portaria $\mathrm{n}^{\circ}$ 487/2012, do MJ, determina a elaboração de um plano de mídia de anúncio da campanha do recall ${ }^{10}$. Já a RDC n ${ }^{\circ}$ 55/2012 prevê que caberá ao detentor do registro veicular mensagem de alerta aos consumidores, informando de maneira clara e direta o tipo do desvio e os riscos inerentes a ele, bem como os meios de comunicação a serem utilizados, o que em essência, trata-se de um plano de mídia; esse comunicado será submetido aos critérios da ANVISA.

\footnotetext{
${ }^{10}$ Portaria 487/2012, do MJ , Art. $3^{\circ}$ O plano de mídia de que trata o art. 2o, § 1o, inciso VII, deverá conter as seguintes informações: I - data de início e fim da veiculação publicitária; II - meios de comunicação a serem utilizados, horários e frequência de veiculação, considerando a necessidade de atingir a maior parte da população, observado o disposto art. 10, $\S 2$ o, da Lei no 8.078, de 1990; III - modelo do aviso de risco de acidente ao consumidor, a ser veiculado na imprensa, rádio e televisão, incluindo a imagem do produto, sem prejuízo de inserção na Internet e mídia eletrônica; e IV - custos da veiculação, respeitado o sigilo quanto às respectivas informações.
} 
Conforme as normas supramencionadas, a responsabilidade do fornecedor não se exaure com o comunicado às autoridades e aos consumidores a respeito da inadequação do produto. Há também o dever de recolhimento do produto. A RDC n 55/2005 define recolhimento como:

\begin{abstract}
Ação que visa a imediata e eficaz retirada do mercado, de determinado(s) lote(s) de medicamento, com indícios suficientes ou comprovação de desvio de qualidade, que possa representar risco à saúde, ou por ocasião de cancelamento de registro, relacionado com a segurança e eficácia do produto, a ser implementada pelo detentor do registro e seus distribuidores. ${ }^{11}$
\end{abstract}

O recolhimento poderá ser voluntário ou determinado pela ANVISA, e implicará na imediata suspensão da comercialização dos respectivos lotes do medicamento e segregação do estoque de todos que compões a cadeia de produção e comercialização. Ademais, o distribuidor deverá apresentar à agência nacional o plano de recolhimento, e, posteriormente, caberá ao detentor do registro encaminhar relatórios de monitoração do processo.

Por se tratar de uma norma geral e abarcar as peculiaridades de todos os tipos de produtos e serviços, a Portaria $n^{\circ}$ 487/2012 fala na obrigatoriedade dos fornecedores em elaborar um plano de atendimento ${ }^{12}$ aos consumidores, delineando a forma, os locais e os horários de atendimento, bem como um plano de contingência e a estimativa de prazo para adequação completa de todos os produtos ou serviços afetados. O plano de atendimento engloba o recolhimento de produtos, se for o caso ${ }^{13}$. Esta norma também prevê para os fornecedores a obrigação de emitir relatórios periódicos informando o progresso do chamamento ${ }^{14}$.

Feitas essas considerações, chega-se a um dos pontos nevrálgicos desta análise: o grau de periculosidade do desvio de qualidade do produto. O CDC não faz distinção de grau de periculosidade para que as normas do recall sejam observadas. Seguindo este direcionamento, a Portaria $n^{\circ} 487$, do MJ, também não limita o recall ao nível de nocividade ou periculosidade, devendo ocorrer a comunicação aos órgãos elencados na norma e aos consumidores em todos os casos de desvio de qualidade de produtos e serviços. Ademais, por haver um desvio, o

\footnotetext{
${ }^{11}$ Art. $2^{\circ}$, I, Resolução n 55/2005, Anvisa.

${ }_{12}$ Portaria $n^{\circ} 487 / 2012$, do MJ, Art. 4o O plano de atendimento ao consumidor de que trata o art. 2o, $\S 1$, inciso VIII, deverá conter as seguintes informações: I - formas de atendimento disponíveis ao consumidor; II - locais e horários de atendimento; III - duração média do atendimento; e IV - plano de contingência e estimativa de prazo para adequação completa de todos os produtos ou serviços afetados.

${ }^{13} \mathrm{Nem}$ todo plano de atendimento envolve o recolhimento de produtos. Pode haver o conserto, exemplificando com os recalls de automóveis.

${ }^{14}$ Portaria $n^{\circ} 487 / 2012$, do MJ, Art. $7^{\circ}$ O fornecedor deverá apresentar ao DPDC, aos PROCONS e ao órgão normativo ou regulador competente: I - relatórios periódicos de atendimento ao chamamento, com intervalo máximo de 60 (sessenta) dias, informando a quantidade de produtos ou serviços efetivamente recolhidos ou reparados, inclusive os em estoque, e sua distribuição pelas respectivas unidades federativas;
} 
recolhimento é desdobramento do próprio recall, não havendo brechas para que em alguns casos de desvio de qualidade ocorram o recolhimento e em outros não.

Entretanto, a RDC da ANVISA classifica os riscos dos desvios de qualidade dos medicamentos conforme a periculosidade à saúde. Vejamos:

Art. $2^{\circ}$ Para os efeitos deste regulamento, são adotadas as seguintes definições:

(...)

IV - Classificação de Risco à saúde: determinação de classes (I, II e III) de qualificação de risco relativo à saúde, a que uma população está exposta pelo uso do medicamento com indícios suficientes ou comprovação de desvio de qualidade, ou uso de medicamentos cujo registro tenha sido cancelado em virtude de ausência de segurança e eficácia nos seguintes termos:

a) Classe I: situação na qual existe alta probabilidade de que o uso ou exposição a um medicamento possa causar risco à saúde acarretando morte, ameaça à vida ou danos permanentes.

b) Classe II: situação na qual existe alta probabilidade de que o uso ou exposição a um medicamento possa causar agravo temporário à saúde ou reversível por tratamento medicamentoso.

c) Classe III: situação na qual existe baixa probabilidade de que o uso ou exposição a um medicamento possa causar consequências adversas à saúde.

A grande relevância desta categorização da periculosidade é que, apesar de a RDC $n^{\circ}$ 55/2005 prever a comunicação à ANVISA e demais órgãos da vigilância sanitária e aos consumidores e determinar o recolhimento de medicamentos com desvio de qualidade, condiciona essas obrigações do procedimento de recall apenas às classificações de risco I e II. Conforme a norma sanitária:

Art. $3^{\circ} \mathrm{O}$ recolhimento previsto neste regulamento, será obrigatoriamente implementado pela empresa detentora do registro, nas situações enquadradas nas classes I e II da classificação de risco à saúde, previstas no inciso IV do art. $2^{\circ}$ do presente regulamento, e implicará também na imediata suspensão da comercialização do(s) respectivo(s) lote(s) do medicamento e segregação do estoque na empresa detentora do registro, distribuidores e estabelecimentos receptores. (grifo nosso)

(...)

Art. $^{\circ} \mathrm{O}$ detentor do registro, deverá veicular mensagem de alerta aos consumidores, informando sobre a periculosidade ou nocividade do(s) lote(s) do medicamento por ele colocado no mercado, nos casos definidos nas classes I e II da classificação de risco à saúde previstas no inciso IV do art. $2^{\circ}$ do presente regulamento. (grifo nosso)

Assim, não há obrigatoriedade de recolhimento e de comunicação aos consumidores se os desvios de qualidade forem classificados como risco III, abrindo uma brecha no cumprimento dos direitos consumeristas relativos a recall de produtos. Percebe-se a afronta ao direito à informação, tanto pelo fornecedor, quanto pelo Estado, e, consequentemente, à saúde e segurança do consumidor. A Resolução n 55, da ANVISA, que deveria robustecer as normas já existentes sobre recall, proporcionando um maior rigor em casos de desvios de qualidade de 
medicamentos, propiciou exatamente o inverso, afrouxando as regras e anuindo com a não observância do CDC e da Portaria n 487/2012, MJ.

\section{Confrontação dos dados da Senacon face os dados da $1^{\text {a }}$ Promotoria do Consumidor de João Pessoa quanto a recall de medicamentos no Brasil}

A $1{ }^{\text {a }}$ Promotoria do Consumidor de João Pessoa do Ministério Público da Paraíba vem desenvolvendo o Programa de Prevenção de Acidentes de Consumo. Dentro deste programa, foram formulados projetos com foco nos principais segmentos do mercado consumidor. Estrategicamente, pelo crescente consumo de medicamentos no Brasil e por este ser um produto regulado, exigindo, assim, maior controle e rigor desde a sua produção até o seu consumo, o monitoramento da qualidade deste produto passou a figurar como prioridade desta Promotoria.

A Promotoria já realizava o acompanhamento de recall de automóveis, outro segmento importantíssimo, onde defeitos nos produtos podem custar vidas. O monitoramento é realizado principalmente pelas informações abertas de recalls transmitidas pela Secretaria Nacional do Consumidor - SENACON. Também já investigava laboratórios farmacêuticos, mas foi em 2015 que o foco em recall de medicamentos ganhou maior expressão e sistematização no órgão.

O que mais chamou a atenção ao iniciar a pesquisa, foi que o número de recalls de medicamentos apontado pela SENACON era bem pequeno, o que sugeriria que ou a qualidade dos produtos estava dentro do padrão esperado. Contudo, em pesquisa no site da ANVISA, no setor de farmacovigilância, há diversas resoluções determinando a suspensão da fabricação, do uso e do recolhimento de medicamentos por desvio de qualidade, o que são casos evidentes de recalls. Diante deste fato, a Promotoria buscou coletar os dados perante às indústrias farmacêuticas, baseando-se nas resoluções emitidas pela ANVISA quanto ao recolhimento e compará-los com os dados da SENACON para poder dimensionar o hiato existente nas informações emitidas pela Anvisa e pela SENACON.

Exercendo o seu poder de polícia quanto ao controle de medicamentos comercializados no mercado de consumo brasileiro, a ANVISA regularmente emite Resoluções determinando a suspensão cautelar, no caso de indícios de desvio de qualidade, ou a suspensão da fabricação, da comercialização e do uso de produtos farmacêuticos, no caso de desvio de qualidade comprovado.

Fundamentando-se nessas Resoluções, a $1^{\text {a }}$ Promotoria do Consumidor instaurou Inquéritos Civis - IC para apurar possíveis responsabilidades dos laboratórios farmacêuticos quanto ao desvio de qualidade de seus produtos. Contabilizando todos os Inquéritos Civis 
envolvendo recall de medicamentos, nos anos de 2015 e 2016, foram instaurados 84 procedimentos.

Deste universo de 84 procedimentos, foi definida uma amostra de 32 procedimentos. Os critérios da amostragem foram selecionar apenas os procedimentos ativos fundamentados em Resoluções da Anvisa que determinavam a suspensão da fabricação, da comercialização e do uso de medicamentos, bem como o recolhimento desses, e que não houvesse controvérsia quanto ao desvio de qualidade. Excluiu-se, assim, procedimentos arquivados, fundamentados em Resoluções que determinavam a suspensão cautelar ou que houvesse liminar judicial suspendendo a determinação da Anvisa. Feitas essas considerações, os 32 procedimentos objetos desta pesquisa abarcaram 37 medicamentos com desvio de qualidade.

No que diz respeito aos processos de recall no Brasil, no ano de 2015 a Secretaria Nacional de Defesa do Consumidor publicou o "Boletim Saúde e Segurança do Consumidor - 2015" contendo informações referentes aos processos de Recall nos anos de 2013 e 2014, bem como o Boletim Recall $2015^{15}$ e o Boletim Recall $2016^{16}$. Diante das investigações iniciadas para a verificação do recall de medicamentos na $1^{\mathrm{a}}$ Promotoria do Consumidor da Capital, em decorrência no expressivo número de inquéritos instaurados, buscou-se através dos boletins acima a criação de um panorama específico dos recolhimentos de medicamentos no período compreendido entre os anos de 2013 e 2016. A tabela abaixo detalha o número de empresas que comunicaram o início do processo de recolhimento à SENACON, bem como o número de unidades afetadas.

15 Disponível em:: <http://www.justica.gov.br/noticias/mj-divulga-balanco-de-recalls-2015/boletim-recall2015.pdf $>$. Acesso: 14/10/2017.

16 Disponível em: < http://www.justica.gov.br/news/ministerio-da-justica-lanca-balanco-de-recalls-em2016/boletim-recall-2016.pdf> . Acesso em: 06/01/2018. 
Tabela 1: Unidades de medicamentos afetadas entre 2013 e 2016 - Dados da Senacon UNIDADES AFETADAS

\begin{tabular}{cccc}
\hline $\mathbf{2 0 1 3}$ & 2014 & 2015 & 2016 \\
$\mathbf{3 . 4 6 9 . 8 1 3}$ & 160.041 & 45.665 & 0
\end{tabular}

Fonte: elaboração própria a partir do Boletim Saúde e Segurança do Consumidor 2015 e dos Boletins Recall 2015 e 2016 divulgados pela Senacon

Tabela 2: Quantidade de recalls de medicamentos realizados - Dados da Senacon No DE LABORATÓRIOS

\begin{tabular}{cccc}
\hline $\mathbf{2 0 1 3}$ & 2014 & 2015 & 2016 \\
$\mathbf{3}$ & 6 & 1 & 0
\end{tabular}

Fonte: elaboração própria a partir do Boletim Saúde e Segurança do Consumidor 2015 e dos Boletins Recall 2015 e 2016 divulgados pela Senacon.

Dos valores acima, percebe-se uma redução brusca de mais de três milhões de unidades, entre 2013 e 2016, chegando até a zerar em 2016, ocorrendo, consequente, neste mesmo ano, a ausência de empresas que realizaram recall de medicamentos. Essa diferença fica mais nítida quando expressa graficamente, vide abaixo o gráfico 1:

\section{Gráfico 1: Unidades afetadas - 2013 a 2016}

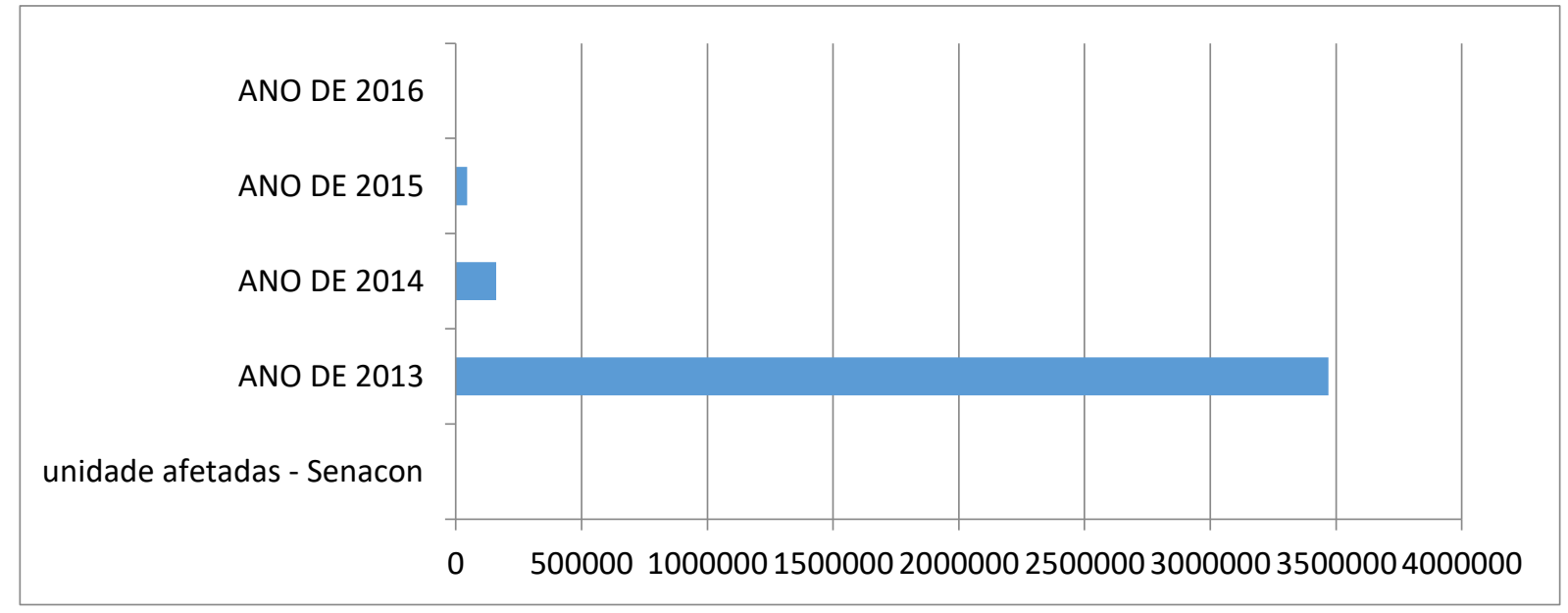

Fonte: elaboração própria a partir do Boletim Saúde e Segurança do Consumidor 2015 e do Boletim Recall 2015 e 2016 divulgados pela Senacon.

Ao avaliar tais dados, presume-se que houve uma melhora no controle de qualidade o que ocasionou uma redução significativa da abertura de processos de recalls e 
consequentemente uma maior segurança para os consumidores quanto à qualidade dos medicamentos.

Ocorre que ao realizar o somatório das unidades afetadas de medicamentos por desvio de qualidade da amostragem e compara-lo com os dados oficiais publicados pela SENACON do mesmo período, percebeu-se uma enorme diferença numérica. Conforme Tabela 3, têm-se os seguintes valores:

Tabela 3: Comparativo entre dados da $1^{\text {a }}$ Promotoria do Consumidor - MPPB e BoletimRecall da SENACON dos anos de 2015 e 2016 quanto à unidades afetadas UNIDADES AFETADAS

$1^{\text {a }}$ PROMOTORIA DO CONSUMIDOR -

MPPB (Inquéritos Civis - 2015 e 2016)

\section{SENACON}

(Boletim Recall 2015 e 2016)

45.000

15.842 .334

Fonte: elaboração própria a partir do Boletim Recall 2015 e 2016 da Senacon.e dos dados da $1^{\text {a }}$ Promotoria

Assim, fica evidente a discrepância entre os dados apurados pela Promotoria do Consumidor, em um universo de apenas 37 casos de recalls e os dados emitidos pela SENACON no Boletim de recall de 2015 e 2016. Para mais, essas informações quanto ao recolhimento de medicamentos não estão chegando aos Órgãos de Defesa do Consumidor, e muito menos aos consumidores.

\section{Desvios de qualidade motivadores dos recalls e classificação de risco dos desvios}

Segundo a ANVISA, produtos com desvios de qualidade são aqueles em que durante o processo de fabricação, transporte ou armazenamento se afastaram dos parâmetros de qualidade pré-estabelecidos, representando riscos à saúde.

Analisando a amostragem dos procedimentos, verifica-se que os desvios de qualidade mais recorrentes estão relacionados a embalagens, como embalagens primária ${ }^{17}$ e secundária ${ }^{18}$ não correspondentes ou impressão de data de validade incorreta; e resultados insatisfatórios nos ensaios de aspecto e descrição da amostra. Ainda se observam vários outros desvios de

\footnotetext{
${ }^{17}$ Embalagem que mantém contato direto com o medicamento.

18 Embalagem externa do produto, que está em contato com a embalagem primária ou envoltório intermediário, podendo conter uma ou mais embalagens primárias.
} 
qualidade, como presença de corpo estranho, alteração no processo produtivo ou da fórmula sem autorização do ente regulador.

Para o presente trabalho, os desvios de qualidade apresentados pelos 37 medicamentos constantes nos procedimentos foram categorizados em 6 grupos: resultado insatisfatório nos ensaios de aspecto e descrição da mostra; contaminação cruzada; alteração nos processos de produção sem avaliação da ANVISA, alteração de fórmula sem autorização da Anvisa; embalagens; e presença de corpo estranho. A seguir o Gráfico demonstra em termos percentuais as causas motivadoras dos recalls dos processos que serviram como amostragem:

\section{Gráfico 2: Causas motivadoras de recall de medicamentos}

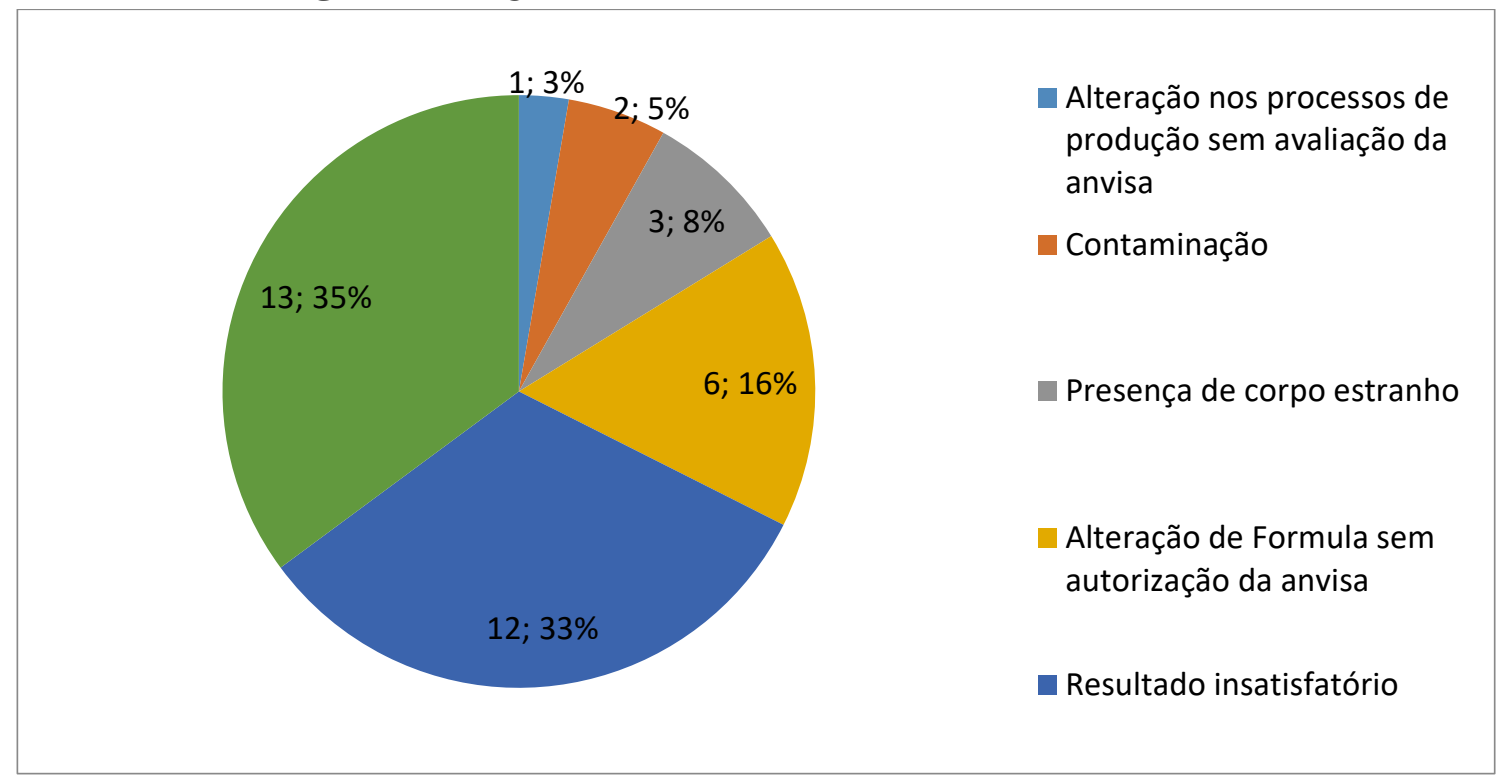

Fonte: elaboração própria a partir dos Inquéritos Civis Instaurados na $1^{\mathrm{a}}$ Promotoria do Consumidor de João Pessoa em 2015 a 2016.

Para melhor ilustrar, exemplificar-se-á alguns desvios de qualidade. Quanto à contaminação cruzada, tem-se o caso do produto Peritosteril Andy Disc, que envolveu 33 lotes do produto. O recall foi motivado por reclamações de ocorrência de peritonite asséptica associada ao uso deste. Peritonite asséptica é uma inflamação no abdômen provocada por algum agente físico ou químico. É uma situação grave que, se não for tratada precoce e adequadamente, na maioria das vezes é fatal. Segundo a empresa, foi identificada a contaminação por endotoxina bacteriana nos lotes que geraram as reclamações. O produto é utilizado na realização do tratamento de Diálise Peritoneal. Esta é uma das opções de tratamento disponíveis para Insuficiência Renal Crônica Terminal. É uma técnica ${ }^{19}$ fisiológica que utiliza

\footnotetext{
${ }^{19}$ Técnica também conhecida por "auto diálise", uma vez que é realizado em ambiente domiciliar pelo próprio paciente ou com auxílio de outrem.
} 
a membrana peritoneal (membrana que envolve os órgãos abdominais), atua como um filtro do sangue removendo excesso de água e toxinas do corpo.

Quanto a erros nas embalagens, verifica-se o Alprazolam 1mg na embalagem secundária do Alprazolam $2 \mathrm{mg}$. O Alprazolam, é um ansiolítico indicado para estados de ansiedade e para o transtorno do pânico. É um medicamento controlado justamente por seus efeitos serem mais perigosos que os demais, assim, precisam ser tomados seguindo rigorosamente a indicação do médico. Essa troca de embalagem faria com que o paciente tomasse o medicamento pela metade da dose indicada para o seu tratamento. Ainda quanto a embalagem, em alguns casos percebese a impressão incorreta do prazo de validade, como o Keltra, que o prazo de validade era de 24 meses, mas foi impresso 36 meses.

Esses foram alguns exemplos de desvios de qualidade observados, mas tantos outros ocorrem, como soluções injetáveis que têm suas ampolas estilhaçadas ao serem abertas, inserção de princípio ativo sem autorização; ausência do princípio ativo secundário que prolonga o efeito anestésico etc. E o grande problema é que todos esses desvios são considerados como baixo potencial ofensivo, tanto pela empresa, quanto pela agência reguladora. Será abordada a classificação de risco no próximo tópico.

Quanto à classificação de risco, dos 37 procedimentos analisados, 32 foram classificados como risco III, apenas 5 como risco II, e nenhum classificado como risco I. Importante ressaltar que o risco I é o mais severo, sendo o risco III o mais brando. Graficamente, tem-se o seguinte:

\section{Gráfico 3 - Classificação de risco nos processos analisados}

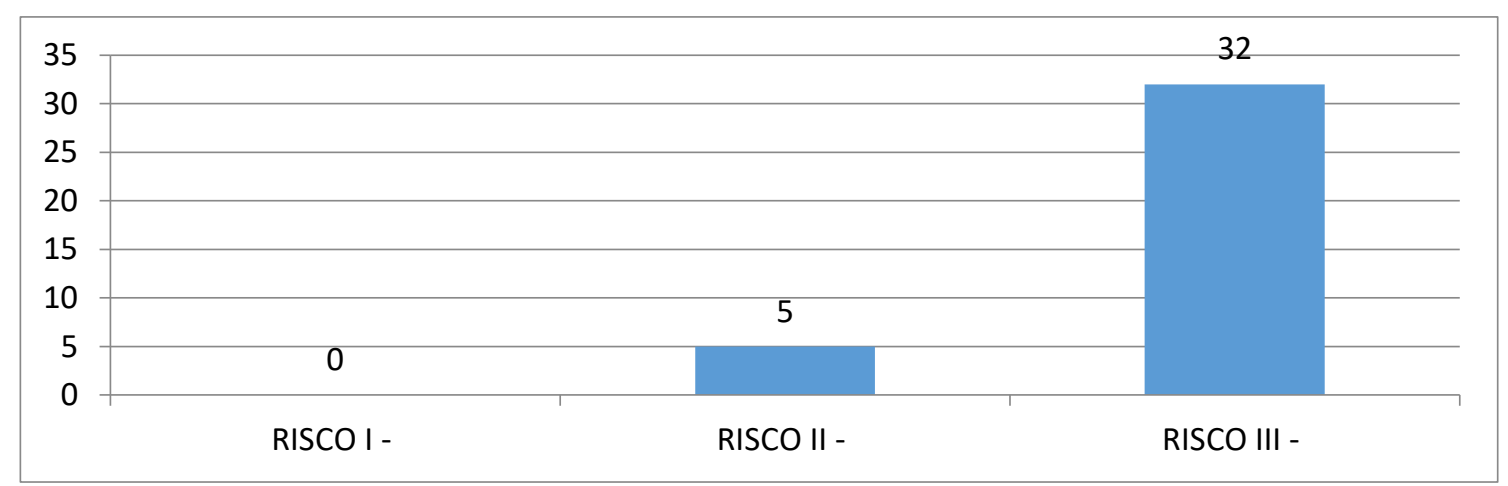

Fonte: elaboração própria a partir dos Inquéritos Civis Instaurados na $1^{\mathrm{a}}$ Promotoria do Consumidor de João Pessoa em 2015 a 2016.

Assim, da amostragem, aproximadamente $86,5 \%$ dos medicamentos são classificados como risco III, o implica dizer que em todos esses casos de desvio de qualidade de medicamentos não houve obrigatoriedade em realizar comunicado aos consumidores do desvio 
nem de realizar o recolhimento. Cabe destacar que apesar da não obrigatoriedade de recolhimento em caso de risco III, em todos os recalls da amostragem houve o recolhimento dos produtos, ou voluntariamente ou por determinação da ANVISA.

Outro ponto relevante a se considerar quanto à classificação de risco é que quem faz o laudo de risco é quem toma a iniciativa do recall. E como a política da ANVISA é estimular o recall voluntário, neste caso será a própria empresa quem fará o laudo de risco do desvio de qualidade do medicamento.

Dos casos analisados, a maioria foi de recall com iniciativa voluntária, como pode ser observado no gráfico abaixo:

\section{Gráfico 4: Iniciativa do recall de medicamentos}

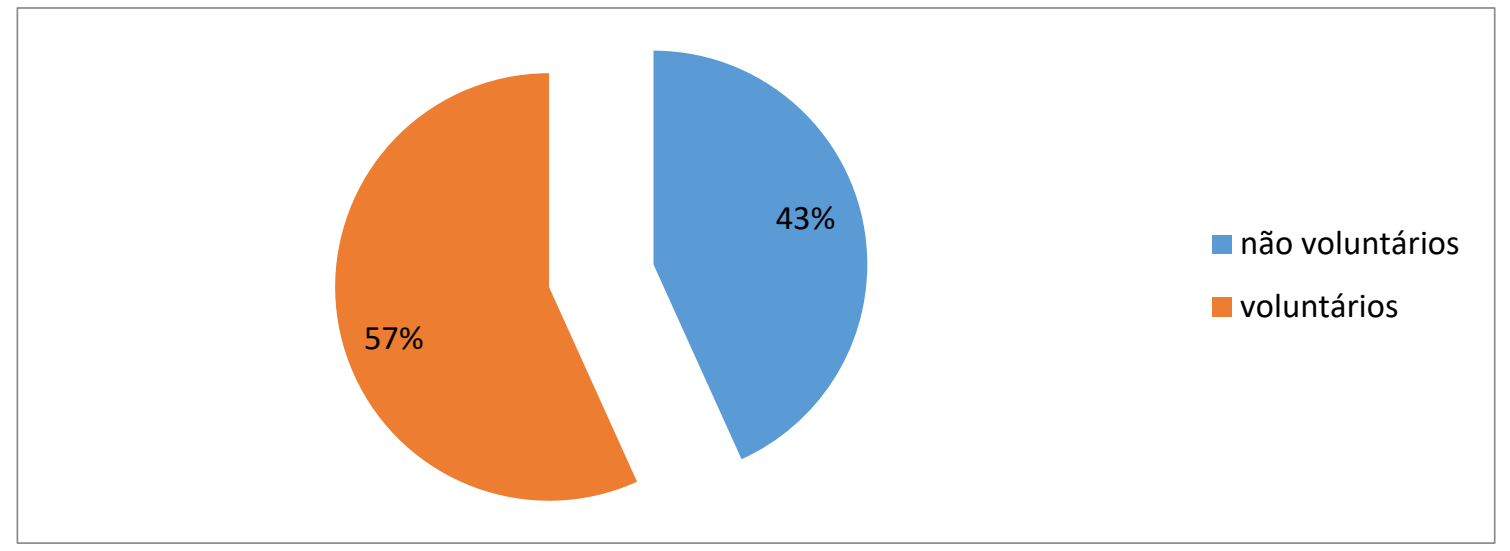

Fonte: elaboração própria a partir dos Inquéritos Civis Instaurados na $1^{\mathrm{a}}$ Promotoria do Consumidor de João Pessoa em 2015 a 2016.

Dos 37 casos analisados de recall de medicamentos, a ANVISA entendeu que 21 foram voluntários, ao passo que 16 não foram voluntários.

Cabe ressaltar que dos procedimentos analisados, muitos dos casos em que a houve o recolhimento voluntário de medicamentos, a identificação do desvio de qualidade foi de algum órgão sanitário, e não da própria empresa, constituindo, assim, um instituto híbrido entre recall voluntário e não voluntário, visto que a detecção do desvio não foi proveniente de controle de qualidade interna.

\section{Considerações finais}

Através de embasamento doutrinário, análise das normas que regem o processo de recall de medicamentos e exame de dados, buscou-se no presente estudo verificar até que ponto este 
instituto no Brasil vem cumprindo o seu papel em proteger a saúde e segurança dos consumidores.

Devido aos medicamentos serem produtos regulados, além das normas gerais de recall, previstas no CDC e na Portaria $n^{\circ} 487 / 2012$, em caso de desvio de qualidade de medicamentos também devem ser observadas as normas específicas do ente regulador, que se encontram na $\mathrm{RDC}^{\circ} 55 / 2005$. Contudo, constatou-se que os fornecedores observam apenas a norma do ente regulador.

É fato que ambas as normas possuem muitos pontos de congruência e a mesma finalidade em padronizar e facilitar a fiscalização pelos entes estatais dos processos de recall, entretanto, apontaremos a seguir consequências negativas advindas desta preterição da norma geral:

1) O processo de recall fica adstrito apenas ao ente regulador e ao laboratório farmacêutico, excluindo-se, assim, todos os órgãos de defesa e proteção do consumidor, inclusive a Secretaria Nacional do Consumidor - SENACON, que é o órgão responsável por gerir todo e qualquer processo de chamamento no Brasil;

2) Anualmente, a ANVISA emite mais de uma centena de resoluções abordando o desvio de qualidade de medicamentos e o consequente recolhimento. Contudo, esses casos de recalls de medicamentos não são contabilizados nos dados oficiais da SENACON. Isso fica evidente na publicação da SENACON BoletimRecall 2016, onde esta afirma compilar todas as campanhas de recalls ocorridas no ano de 2016 no Brasil, entretanto não há um único caso de recall de medicamentos. Qualquer cidadão que tiver acesso a este boletim, incorrerá em erro acreditando que não há casos de recall de medicamentos;

3) Evidencia-se a falta de harmonização entre instituições que deveriam atuar em parceria em suas atuações. As duas normas em questão são complementares; uma não exclui a outra. Elas deveriam fortalecer o instituto do recall de medicamentos, aumentando a sua transparência e efetividade, mas o que acontece na prática é exatamente o contrário: uma norma acaba anulando a outra. Exemplo disso, é que a Portaria $n^{\circ} 487$ prevê a obrigatoriedade de comunicação tanto para o Departamento de Proteção e Defesa do Consumidor, departamento da SENACON, quanto ao órgão regulador. Entretanto, esse mandamento é totalmente ignorado pelos fornecedores e pela própria Anvisa.

Ao analisar a norma da ANVISA e os dados extraídos da amostragem dos processos de recall, denota-se como principais conclusões:

1) A RDC $\mathrm{n}^{\circ} 55 / 2005$ impõe a obrigatoriedade para os fornecedores de comunicação aos consumidores e o recolhimento dos medicamentos em caso de desvio de 
qualidade apenas para os desvios classificados como mais severos. Essa brecha fere frontalmente o direito à informação, visto que mesmo detectado pelo fornecedor e por um órgão estatal um desvio de qualidade - ainda que considerado mais brando -, este não chega ao conhecimento do consumidor. Além disso, existe uma grande dificuldade em se conseguir classificar adequadamente o que consistiria em menor potencial ofensivo quando o produto é medicamento; problemas envolvendo apenas embalagens normalmente são considerados como risco III, que é o mais leve, contudo, é inconcebível que trocas de datas de validade para menor ou embalagens primária e secundária que não correspondem quanto à informação da quantidade do princípio ativo sejam considerados desvios que não atentem contra à saúde do consumidor;

2) É política da ANVISA estimular o recall voluntário do laboratório farmacêutico, assim, é o próprio laboratório quem emite o laudo de risco. Da amostragem que abarcou o recall de 37 medicamentos, 32 foram considerados risco III, 5 foram considerados risco II e nenhum foi considerado risco I. A quase totalidade da amostragem dos recalls de medicamentos terem sido classificados com o risco mais brando possivelmente é um indicativo de benevolência em casos de auto avaliação, o que torna questionável a confiabilidade da avaliação do risco nos casos de desvios de qualidade. Desse modo, 86,5\% dos recalls da amostra, por serem classificados como risco III, não chegaram ao conhecimento dos consumidores;

3) Quanto ao número de unidades afetadas, apesar do valor final ser extraído apenas de uma amostragem de 37 recalls de medicamentos ocorridos entre 2016 e 2017, o número é bastante expressivo: 15.842.334 de unidades de com desvio de qualidade. Os dados oficiais da SENACON informam que neste mesmo período houve apenas uma totalidade de 45.665 de unidades afetadas por desvio de qualidade.

4) A resolução da ANVISA é bem mais complacente quanto aos riscos suportados pelo consumidor.

Conclui-se que a maneira como o recall de medicamentos vem sendo realizado no Brasil ainda é incipiente e contradiz o seu próprio fundamento, o direito à informação do consumidor, ao criar uma exceção na responsabilidade dos fornecedores de realizar o recall de medicamentos. Além disso, desconsidera a posição vulnerável do consumidor; em verdade, o consumidor de medicamentos faz parte do grupo classificado como hipervulnerável, tendo em vista a condição de fragilidade da saúde decorrente de alguma doença, o que implica em normas ainda mais rígidas na proteção desses consumidores. Percebe-se também a atuação pouco expressiva da agência reguladora no controle de qualidade de medicamentos expostos no mercado de consumo, onde este setor mercadológico é praticamente autorregulado. 
Ademais, sugere-se a articulação entre e ANVISA e a SENACON em suas atuações quanto ao controle de qualidade de medicamentos, e uma atualização da RDC n55/2012 que observe os direitos básicos do consumidor à informação e proteção da saúde e segurança dos cidadãos e que esteja em consonância com as normas gerais de recall.

\section{Referências bibliográficas}

ANVISA. AGENCIA NACIONAL DE VIGILÂNCIA SANITÁRIA. Resolução da diretoria colegiada- $R D C \mathrm{n}^{\circ}$ 55, de 17 de março de 2005. Disponível em:

http://portal.anvisa.gov.br/documents/33880/2568070/RDC_55_2005.pdf/958b1146-2e2c498f-8f15-32c8a76f3a8b>. Acesso em 08/02/2018;

ARAÚJO, Valter Shuenquener de. O princípio da proteção da confiança. $2^{\mathrm{a}} \mathrm{ed}$. Rio de Janeiro. Impetus, 2016;

BRASIL. Lei N ${ }^{\circ}$ 6.360/76, de 23 de setembro de 1976. Dispõe sobre a Vigilância Sanitária a que ficam sujeitos os Medicamentos, as Drogas, os Insumos Farmacêuticos e Correlatos, Cosméticos, Saneantes e Outros Produtos, e dá outras Providências.Disponível em: $<$ http://www.planalto.gov.br/ccivil_03/leis/16360.htm> . Acesso em: 22/03/18;

Lei ${ }^{0}$. 8.078, de 11 de setembro de 1990. Código de Defesa do. Consumidor. Dispõe sobre a proteção do consumidor e dá outras providências.Disponível em: $<$ http://www.planalto.gov.br/ccivil_03/leis/18078.htm>. Acesso em: 22/03/18;

CALAIS-AULOY. Droit de la Consomation. $8^{\text {a }}$ ed. Paris: Dalloz, 2010;

CORCHERO, Miguel; MURILLO, Ana Grande. La proteción de los consumidores. Navarra: Thomson Aranzadi, 2007;

MARQUES, Cláudia Lima; BENJAMIN, Antônio Herman V,; MIRAGEM, Bruno. Comentários ao Código de Defesa do Consumidor. $3^{\text {a }}$ ed. São Paulo: Revista dos Tribunais, 2010 
MINISTÉRIO DA JUSTIÇA. Portaria n 487, de 15 de março de 2012. Disponível em:

<file://C:/Users/promotor/Downloads/Portaria\%20n\%C2\%BA\%20487-2012\%20(1).pdf>. Acesso em: 08/02/2018;

NERY JÚNIOR, Nelson; NERY, Rosa Maria de Andrade. Leis Civis Comentadas, $2^{\mathrm{a}}$ ed. Ver., atual. E ampl. São Paulo: RT, 2010;

SODRÉ, Marcelo Gomes. A construção do direito do consumidor: um estudo sonbe as origens das leis principiológicas de defesa do consumidor. São Paulo: Atlas, 2009;

VASCONCELOS, Fernando A. de; MAIA, Maurílio Casas. O direito à saúde na

Constituição e no Código de Defesa do Consumidor. Cadernos da Escola de Direito de Relações Internacionais, Curitiba: 2012. p. 181-196;

VAZ, Carolina. Direito do consumidor à segurança alimentar e responsabilidade civil. Porto Alegre: Livraria do Advogado, 2015. 


\title{
O DIREITO AO DESENVOLVIMENTO SUSTENTÁVEL DA ZONA COSTEIRA
}

\author{
Lair da Silva Loureiro Filho \\ Universidade de São Paulo
}

\begin{abstract}
Resumo
$\mathrm{Na}$ zona costeira brasileira encontra-se grande parte da atividade econômica, significativas referências de nossa identidade nacional, bem como áreas de interesse turístico, de recreação e de lazer, atividades que proporcionaram uma segunda fase na sua ocupação, agora às voltas com as descobertas de expressivas jazidas de petróleo e gás, que por certo darão nova moldura à região. Não obstante a sua inserção no art. 225 da Carta de 1988, como área de patrimônio nacional, até o momento, o Estado Brasileiro foi incapaz de promover o desenvolvimento sustentável da região costeira e de atender à demanda por serviços públicos básicos.
\end{abstract}

Palavras-chave: Zona costeira, Desenvolvimento sustentável, Litoral, meio ambiente.

\section{Abstract/Resumen/Résumé}

In the Brazilian coastal zone is much of the economic activity, significant references of our national identity, as well as areas of tourist interest, recreation and leisure activities that provided a second phase in their occupation, now grappling with the findings of significant oil and gas fields, which certainly will frame new to the region.Despite their inclusion in art. 225 of the 1988 Constitution as a national heritage area, to date, the Brazilian State was unable to promote the sustainable development of the coastal region and meet the demand for basic public services.

Keywords/Palabras-claves/Mots-clés: Coastal zone; Sustainable development; Coast; Environment. 


\section{Introdução}

$\mathrm{Na}$ zona costeira brasileira encontra-se grande parte da atividade econômica, significativas referências de nossa identidade nacional, bem como áreas de interesse turístico, de recreação e de lazer, atividades que proporcionaram uma segunda fase na sua ocupação, agora às voltas com as descobertas de expressivas jazidas de petróleo e gás, que por certo darão nova moldura à região.

Essa diversidade de atividades desenvolvidas na região, sem adequado planejamento ambiental e urbanístico, somada a um regramento jurídico confuso, obsoleto e em descompasso com as demandas econômicas e sociais que ora se apresentam, constituem entraves ao desenvolvimento sustentável da zona costeira.

Não obstante a sua inserção no art. 225 da Carta de 1988, como área de patrimônio nacional, até o momento, o Estado Brasileiro foi incapaz de promover o desenvolvimento sustentável da região costeira e de atender à demanda por serviços públicos básicos, gerando um quadro de carências estruturais e consequente exclusão social, refletidas na ocupação irregular de áreas, na favelização e no aumento da criminalidade.

\section{Conceito e delimitação da zona costeira}

Pela definição do parágrafo único do art. $2^{\circ}$ da LF n ${ }^{\circ} 7.661$, de 16.05.1988 ${ }^{1}$, considerase zona costeira o espaço geográfico de interação do ar, do mar e da terra, incluindo seus recursos renováveis ou não, abrangendo uma faixa marítima e outra terrestre, que serão definidas pelo Plano.

A região abriga um conjunto complexo de ecossistemas de alta relevância ambiental, cuja diversidade é marcada pela transição de ambientes terrestres e marinhos, com interações que lhe conferem um caráter de fragilidade e que requerem, por isso, atenção especial de todos em geral, e do poder público em especial, o que justifica a sua inserção no art. 225 da Constituição Federal como área de patrimônio nacional. ${ }^{2}$

\footnotetext{
${ }^{1}$ Projeto 216-A/87, portanto antes mesmo da promulgação da Carta de 88 que a define como patrimônio nacional no art. $225, \S 4^{\circ}$.

${ }^{2}$ Art. 225, § $4^{\circ}$ A Floresta Amazônica brasileira, a Mata Atlântica, a Serra do Mar, o Pantanal Mato Grossense e a Zona Costeira são patrimônio Nacional, e a sua utilização far-se-á na forma da lei, dentro de condições que assegurem a preservação do meio ambiente, inclusive quanto ao uso dos recursos naturais.
} 
A zona costeira brasileira, com $7.400 \mathrm{~km}$ de extensão (sem considerar baías e reentrâncias, o que totaliza $8.500 \mathrm{~km}$ ), compreende três grandes sistemas: o oceânico, o atmosférico e o continental, variando, na largura, de 70 a $480 \mathrm{~km}$. Nela vive um quarto da população, aproximadamente 36,5 milhões de pessoas, residentes em cerca de 500 municípios, com densidade populacional de $87 \mathrm{~h} / \mathrm{km}^{2}$, cinco vezes a média nacional. ${ }^{3}$

Com o predomínio de uma estreita franja de litoral, a costa brasileira apresentagrandes estoques de manguezais e estuários, formando extensa planície lodosa ao Norte; dunas, rios e

\footnotetext{
${ }^{3}$ Relação dos municípios abrangidos pela faixa terrestre da zona costeira: Amapá (Oiapoque, Calçoene, Amapá, Itaubal, Macapá, Santana e Cutias), Pará (Afiuá, Chaves, Soure, Salvaterra, Cachoeira do Arari, Barcarena, Belém, Ananindeuá, Santo Antonio do Tauá, Colares, Benevides, Vigia, São Caetano de Odivelas, Curuça, Marapanim, Magalhães Barata, Maracanã, Salinópolis, São João de Pirabás, Primavera, Bragança, Augusto Corrêa, Vizeu, Santa Bárbara do Pará e Quatipuru), Maranhão (Carutapera, Luís Domingues, Godofredo Viana, Cândido Mendes, Tiriaçu, Bacuri, Cururupu, Cedral, Guimarães, Bequimão, Alcântara, Cajapió, São João Batista, Anajatuba, Santa Rita, Rosário, São Luís, Raposa, Paço do Lumiar, São José de Ribamar, Axixá, Icatu, Humberto de Campos, Primeira Cruz, Barreirinhas, Tutóia e Araioses), Piauí Cajueiro da Praia, Ilha Grande, Parnaíba e Luiz Correia), Ceará (Chaval, Barroquinha, Camocim, Cruz, Jiboca de Jericoacoara, Acaraú, Itarema, Amontada, Itapipoca, Trairi, Paraipaba, Paracuru, São Gonçalo de Amarante, Caucáia, Fortaleza, Maracanaú, Maranguape, Horizonte, Pacajus, Itaitinga, Guaiúba, Pacatuba, Eusébio, Aquiraz, Pindoretena, Cascavel, Beberibe, Aracati e Icapuí), Rio Grande do Norte (Grossos, Tibau, Areia Branca, Mossoró, Carnaubais, Macau, Guamaré, Galinhos, São Bento do Norte, Pedra Grande, Touros, Maxaranguape, Rio do Fogo, Ceará-Mirim, Extremoz, Natal, Parnamirim, Nísia, Floresta, Senador Georgino Avelino, Goianinha, Arês, Tibau do Sul, Vila Flôr, Canguaretama, Baia e Formosa), Paraíba (Mataracá, Baía da Traição, Rio Tinto, Lucena, Cabedelo, João Pessoa, Bayeux, Santa Rita, Condé, Pitimbu, Caaporã e Alhandra), Pernambuco (Goiana, Itapissuma, Itamaracá, Igarassu, Abreu e Lima, Paulista, Olinda, Recife, Camaragibe, São Lourenço da Mata, Jaboatão dos Guararapes, Moreno, Cabo, Ipojuca, Sirinhaém, Rio Formoso, Tamandaré, Barreiros e São José da Coroa Grande), Alagoas (Maragogi, Japaratinga, Porto de Pedras, São Miguel dos Milagres, Passo de Camaragibe, Barrade Santo Antônio, Maceió, Pilar Satuba, Paripueira, Santa Luzia do Norte, Coqueiro Seco, Marechal Deodoro, Barra de São Miguel, Roteiro, São Miguel dos Campos, Coruripe, Piaçabuçu, Felix Deserto e Penteado, Sergipe (Brejo Grande, Pacatuba, Indiaroba, Pirambu, Santa Luzia do Itanhy, Barra dos Coqueiros, Laranjeira, Santo Amaro das Brotas, Riachuelo, Aracaju, Maruim, Nossa Senhora do Socorro, Rosário do Caeté, São Cristóvão, Itaporanga D’Ajuda, Estância, Ilhas das Flores e Neópolis), Bahia (Jandaíra, Conde, Esplanada, Cardeal da Silva, São Félix, Mata de São João, Itanagra, Camaçari, Dias D’Ávila, Lauro de Freitas, Salvador, Simões Filho, Aratuipe, Candeias, Taperoá, São Francisco do Conde, Madre de Deus, Santo Amaro, Cachoeira, Saubara, Maragigipe, Salinas da Margarida, Itaparica, Vera Cruz, Jaguaripe, Valença, Cairú, Nilo Peçanha, Ituberá, Igrapiúna, Camamu, Maraú, Itacaré, Uruçuca, Ilhéus, Una, Canavieira, Belmonte, Santa Cruz de Cabrália, Porto Seguro, Prado, Alcobaça, Caravelas, Nova Viçosa e Mucuri), Espírito Santo (Conceição da Barra, São Mateus, Jaguaré, Linhares, Sooretama, Aracruz, Fundão, Serra, Vitória, Cariacica, Vila Velha, Viana, Guarapari, Anchieta, Piúma, Presidente Kennedy, Itapemirim e Marataizes), Rio de Janeiro (São João da Barra, São Francisco de Itabapoana, Campos dos Goytacazes, Quissamã, Carapebus, Macaé, Casimiro de Abreu, Rio das Ostras, Armação de Búzios, Cabo Frio, São Pedro d'Aldeia, Arraial do Cabo, Araruama, Saquarema, Maricá, Itaboraí, Niterói, São Gonçalo, Magé, Guapimirim, Duque de Caxias, Rio de Janeiro, São João do Meriti, Nilópolis, Nova Iguaçu, Queimados, Japeri, Belford Roxo, Itaguaí, Seropédica, Mangaratiba, Angra dos Reis e Parati), São Paulo (Ubatuba, Caraguatatuba, São Sebastião, Ilha Bela, Bertioga, Guarujá, Cubatão, São Vicente, Santos, Praia Grande, Mongaguá, Itanhaém, Peruíbe, Iguape, Cananéia e Ilha Comprida), Paraná (Quaraqueçaba, Antonina, Morretes, Paranaguá, Pontal do Paraná, Matinhos e Guaratuba), Santa Catarina (Itapoá, São Francisco do Sul, Joinville, Araquari, Balneário Barra do Sol, Barra Velha, Imaruí, Piçarras, Capivari de Baixo, Penha, Navegantes, Itajaí, Balneário Camboriú, Camboriú, Itapema, Porto Belo, Tijucas, Governador Celso Ramos, Biguaçu, Florianópolis, São José, Palhoça, Paulo Lopes, Garopaba, Imbituba, Laguna, Jaguaruna, Içara, Araranguá, Sombrio, São João do Sul, Bombinhas, Guaruva, Passo de Torres, Tubarão, Criciúma, Sangão e Santa Rosa do Sul), Rio Grande do Sul (Torres, Arroio do Sal, Três Cachoeiras, Três Forquilhas, Maquiné, Capão da Canoa, Terra da Areia, Xangrilá, Osório, Imbé, Tramandaí, Cidreira, Palmares do Sul, Viamão, Mostardas, Barra do Ribeiro, Tapes, Tavares, Camaquã, Atambé, São José do Norte, São Lourenço do Sul, Rio Grande, Pelotas, Arroio Grande, Jaguarão e Santa Vitória do Palmar).
} 
recifes de franja ao Nordeste; recifes de franja, parceis e deltas ao Leste; baías e lagunas no Sudeste e lagunas ao Sul.

Cabe, aqui, a indagação sobre a exata abrangência dazona costeira, para que se delineie a eficácia espacial (dominial) e material (atividade) das normas que lhe são próprias, ressaltando desde logo não se tratar de uma área estanque e homogênea.

Mariana Almeida Passos de Freiras (2005, p. 27) salienta a peculiaridade do sistema litorâneo: "O ecossistema litorâneo é todo especial. Nele se encontra uma variedade de habitats e ecossistemas, como restingas, costões, manguezais, ilhas, dunas, praias arenosas, dentre outros, nos quais estão abrigadas inúmeras espécies da flora e da fauna brasileiras”.

A área de abrangência do Plano Nacional de Gerenciamento Costeiro compreende as faixas marítima e terrestre. Pela primeira, entende-se a faixa que se estende mar afora distando 12 milhas marítimas das linhas de base estabelecidas de acordo com a Convenção das Nações Unidas sobre o Direito do Mar de 1982, realizada em MontegoBay na Jamaica, compreendendo a totalidade do Mar Territorial. A segunda aponta a faixa do continente formada pelos municípios que sofrem influência direta dos fenômenos ocorrentes na zona costeira:a) os municípios defrontantes com o mar, assim considerados em listagem dessa classe, estabelecida pelo Instituto Brasileiro de Geografia e Estatística - IBGE; b) os municípios não defrontantes com o mar que se localizem nas regiões metropolitanas litorâneas; c) os municípios contíguos às grandes cidades e às capitais estaduais litorâneas, que apresentem processo de conurbação; d) os municípios próximos ao litoral, até $50 \mathrm{~km}$ da linha de costa, que aloquem, em seu território, atividades ou infraestruturas de grande impacto ambiental sobre a zona costeira e ecossistemas costeiros de alta relevância; e) os municípios estuarinos-lagunares, mesmo que não diretamente defrontantes com o mar, dada a relevância desses ambientes para a dinâmica marítimo-litorânea; f) os municípios que, mesmo não defrontantes com o mar, tenham todos seus limites estabelecidos com os municípios referidos nas alíneas anteriores. ${ }^{4}$

No direito francês não há definição jurídica de litoral e a relação dos municípios litorâneos é fixada por decreto em Conselho de Estado, ou seja, um decreto submetido pelo Governo à apreciação do Conselho de Estado, considerando três categorias: aqueles localizados à beira mar, os situados em estuários e deltas e, por fim, os municípios próximos desses que sofrem efeitos econômicos e ecológicos do litoral (MORAND-DEVILLER, 1996, p. 29).

\footnotetext{
${ }^{4}$ PNGC II, item 3 da Resolução no 05, de 03.12.1997.
} 
De todo modo, as atividades desenvolvidas no território costeiro têm reflexos diretos no mar territorial, não sendo possível gerir o mar sem considerar as atividades desenvolvidas nas áreas próximas.

$\mathrm{O}$ fato de ser considerado patrimônio nacional, contudo, não justifica atribuirtitularidade exclusiva à União.

O Plano Nacional de Gerenciamento Costeiro, aprovado pela Resolução n. 01, de 21.11.1990, optou por delegar aos Planos Estaduais a definição dos limites físicos do que venha a ser o ecossistema denominado de zona costeira ${ }^{5}$.

A heterogeneidade da costa brasileira, seja no tocante às paisagens e aspectos naturais, seja em relação à forma de sua ocupação, bem como sua extensão permite, ou melhor, exige a integração dos níveis locais e regionais com o nacional para que o Plano conheça razoável eficácia.

Dessa forma, uma gama de critérios deve ser adotada na definição dos limites da zona costeira, abandonado aquele pautado apenas nas distâncias fixas. É o que dispõe o item 3.2 da Resolução no 01, de 21.11.1990, que aprovou o Plano Nacional de Gerenciamento Costeiro: a) não fragmentação da unidade natural dos ecossistemas costeiros; b) para a linha externa da faixa terrestre, a linha de cristas da configuração topográfica do litoral ou, no caso de planícies costeiras muito extensas, o ponto até onde se faz sentir a influência do mar; c) para o limite externo da faixa marítima, o espaço submerso até onde ocorram movimentos (ondas, correntes e marés), que possam ocasionar processos naturais (sedimentação ou erosão) capazes de afetar a natureza constitutiva da costa; d) considerar áreas marcadas por intensa atividade econômica e sua área de influência.

Diante da impossibilidade técnica ou ausência de manifestação legislativa estadual para a definição de tais parâmetros, deverão ser adotados os seguintes critérios gerais: a) para a faixa marítima: 5 milhas marítimas $(11,1 \mathrm{~km})$ sobre uma perpendicular, contadas a partir da Linha da Costa; b) para a faixa terrestre: $20 \mathrm{~km}$ sobre uma perpendicular, contados a partir da Linha da Costa.

Há que se considerar, portanto, que nas políticas de ordenamento territorial, não se deve mais conceber a costa como uma rigorosa linha de separação, mas como um elemento da

\footnotetext{
${ }^{5}$ As Constituições estaduais apresentam farta exemplificação. A Constituição Paulista (art. 196) menciona a proteção ao Complexo Estuarino Lagunar entre Iguape e Cananéia, bem como aos manguezais e áreas estuarinas (art. 197, I e IV); a Baiana (art. 215, III), a Maranhense (art. 241, IV, d), e a Paraibana (art. 227, p.u.) os recifes; a Pernambucana (art. 205) dos "arrecifes"; a Paraibana (art. 227, p.u., IX) e a Fluminense (art. 265, II) as praias, incluindo esta última os costões rochosos; entre outras. Em São Paulo, a Lei n ${ }^{\circ} 10.019$, de 03.07.1998, estabelece as bases do zoneamento costeiro no Estado.
} 
terra, em que o interesse humano é determinado pela proximidade do mar; nem o mar deve ser concebido como um mundo diferente e ilimitado, mas como uma realidade próxima que se presta, pelo seu fundo e pelo seu subsolo, a uma variada utilização mais diferenciada que no passado. $^{6}$

Chama atenção a contraposição de competências federativas na disciplina do uso e ocupação do solo e das atividades desenvolvidas na região, cuja delimitação deve resultar da conjugação do critério territorial com aspectos relevantes da vida social e econômica.

\section{Ocupação da zona costeira}

No Brasil, a zona costeira é a faixa de urbanização mais antiga do país, pois, dos dezoito primeiros núcleos fundados pelos portugueses, apenas São Paulo não se encontrava à beira-mar.

Nessa faixa estão significativas referências de nossa identidade nacional, bem como as áreas de interesse turístico, de recreação e lazer, atividades que proporcionaram uma segunda fase na sua ocupação, agora às voltas com as descobertas de expressivas jazidas de petróleo e gás, que delinearão nova moldura à região.

A ocupação do interior do território brasileiro deu-se pelo deslocamento de contingentes populacionais para o sertão, seja pela busca de riquezas minerais, pelos ciclos econômicos da borracha e do gado, ou por estratégias geopolíticas para o planalto central, com a construção das cidades de Brasília e Goiânia.

A colonização do Brasil começou pelo mar, com os primeiros assentamentos localizados na costa. A partir daí iniciaram-se os fluxos de colonização do interior, através de um padrão denominado bacia de drenagem, reproduzindo o padrão um desenho na estruturação da rede de circulação, no qual todos os caminhos demandavam um eixo principal, e este finalizava seu curso num porto marítimo. Após esse período seguiu-se a industrialização e a consolidação urbano-industrial concentrada em áreas portuárias, ocasionando ao final a ocupação dos vazios existentes com a indústria do turismocom o fenômeno das segundas residências (MORAES, 2007, p. 31).

As atividades econômicas costeiras são responsáveis pela parcela majoritária do PIB nacional, principalmente devido à existência de portos nos quais é realizada grande parte da

\footnotetext{
${ }^{6}$ Carta de Torremolinos (Espanha, 1983).
} 
atividade econômica exportadora brasileira, decorrendo dessa conjuntura natural, econômica e social, três grupos de impactos ambientais: o extrativismo animal e vegetal; a infraestrutura urbana, portuária, de turismo, transporte e lazer; e a agricultura, pastagens e silvicultura localizadas.

O bem-estar e, em alguns casos, a própria sobrevivência das populações litorâneas dependem da saúde e das condições dos sistemas costeiros, o que exige a definição de instrumentos de efetivo combate à poluição, coleta de esgotos e de lixo, bem como normas relativas ao gabarito das construções e atividades desenvolvidas na região. ${ }^{7}$

Todavia, até o momento o Estado brasileiro foi incapaz de promover o desenvolvimento sustentável da região costeira e de atender à demanda por serviços públicos básicos, gerando um quadro de carências estruturais e consequente exclusão social, refletido na ocupação irregular de áreas, na favelização e no aumento da criminalidade.

Um dos fatores mais relevantes, causador de uma aceleração da degradação dos ecossistemas costeiros está ligado à aglomeração de uma população mundial em crescimento nas zonas costeiras, cuja superfície é bem menor do que as áreas continentais interiores ${ }^{8}$ : Em 1990 tínhamos 1.96 bilhões de pessoas vivendo a menos de $100 \mathrm{~km}$ da linha de costa, enquanto que em 1995 esse número já tinha ascendido a 2.14 bilhões de pessoas. Ou seja, em 1995, 39\% da população mundial ocupava uma zona que representa apenas $20 \%$ da superfície terrestre, tendência de crescimento mantida (BELCHIOR, 2008, p. 13-14)

Um dos problemas mais relevantes do litoral português, a excessiva concentração populacional e a erosão. Um dos problemas mais relevantes do litoral é a excessiva concentração populacional que exerce uma forte pressão sobre a zona costeira e gera problemas sobre os recursos naturais, nomeadamente a degradação da paisagem, a sobre-exploração dos recursos, a poluição do ambiente (ar, água e sedimentos), a alteração do uso do solo trazendo

\footnotetext{
${ }^{7}$ Sobre os efeitos da atividade industrial na zona costeira, conferir Claudio A. Gonçalves Egler, Os impactos da política industrial sobre a zona costeira. Brasília: Ministério do Meio Ambiente, 1997.

${ }^{8}$ De acordo com a Agenda 21, documento que coroou a ECO/92 - Conferência das Nações Unidas sobre Meio Ambiente e Desenvolvimento, integrado por um complexo de compromissos jurídico-político destinado a definir uma transformação nos padrões de desenvolvimento da humanidade, a maior parte da população mundial está concentrada em zonas costeiras, havendo uma tendência permanente ao aumento da concentração demográfica nessas regiões: Cap. 17, item 3. A área costeira contém habitats diversos e produtivos, importantes para os estabelecimentos humanos, para o desenvolvimento e para a subsistência das populações locais. Mais de metade da população mundial vive num raio de 60 quilômetros do litoral e esse total pode elevar-se a 75 por cento até o ano 2000. Muitos dentre os pobres do mundo vivem aglomerados nas zonas costeiras. Os recursos costeiros são vitais para muitas comunidades locais e populações indígenas. A zona econômica exclusiva também é uma importante área marinha, onde os Estados gerenciam o desenvolvimento e a conservação dos recursos naturais em benefício de suas populações. Em se tratando de pequenos Estados ou países insulares, essas são as regiões que melhor se prestam às atividades ligadas ao desenvolvimento.
} 
como resultadoa impermeabilização para a construção de infraestruturas, com implicações em nível das escorrências e drenagens naturais (MARTINS; ALBUQUERQUE, 1998, p. 336)

Outro grande problema sentido na zona costeira é a erosão, verificando-se nos últimos anos um acentuado recuo da linha da costa em vários troços costeiros portugueses. Esta erosão deve-se à excessiva concentração de construções no litoral, às pressões das atividades dos visitantes, nomeadamente na época alta, e ainda à excessiva exploração de interesses econômicos nos rios, estuários e litoral e dragagens portuárias, que diminuem as areias que deveriam alimentar o litoral".

Desta forma, o aumento da concentração populacional da zona costeira provoca efeitos de toda ordem na região, como a degradação ambiental, o crescimento urbano desordenado e a alteração de sua geografia física.

\section{Desenvolvimento sustentável da zona costeira}

A região possui características naturais e recursos ambientais, fundamentais para a manutenção do equilíbrio ecológico necessário à sadia qualidade de vida e ao desenvolvimento econômico e social do Brasil, que deverá se dar de forma sustentável.

Para Nusdeo (2005, p. 144), o termo desenvolvimento sustentável representa, em nosso contexto, "a exploração adequada do meio ambiente, a menos agressiva, a que é feita de forma que nãocomprometa a manutenção da existência da espécie natural, tanto no plano presente quanto para o futuro”. Essa ideia surgiu em 1987 com o relatório da Comissão Mundial sobre Meio Ambiente da ONU (Relatório Brundtland ${ }^{9}$, publicado em 1987 sob o título Nosso futuro comum), ganhando fortalecimento com a ECO/92.

Prossegue a autora, em outro estudo, asseverando que o modelo de sustentabilidade gira em torno de um consumidor socialmente sustentável (consome com moderação, selecionando empresas comprometidas com o meio ambiente natural), "é a verdadeira harmonização dos interesses dos consumidores com a necessidade de aumento do bem estar geral da sociedade, através do aumento da produtividade e da inovação, balizada pela alocação eficiente dos recursos" (NUSDEO, 2006, p. 357).

Destarte, o desenvolvimento é sustentável quando satisfaz as necessidades presentes sem comprometer a habilidade das futuras gerações em satisfazer as suas próprias, compatibilizando a expansão e a eficiência da atividade econômica com a sustentabilidade

\footnotetext{
${ }^{9}$ GroHarlemBrundtland era primeira-ministra da Noruega por ocasião da elaboração do relatório, texto preparatório à ECO 92.
} 
econômica e ecológica.

Derani (2008, p. 110-112) alude às dificuldades de se compatibilizar a limitação dos recursos naturais com o ilimitado crescimento econômico, pois o crescimento constante da economia é necessário para expandir-se o bem estar pelo mundo, ajustando uma correlação de valores em que o máximo econômico reflita igualmente um máximo ecológico. Desta forma, a tentativa de conciliar a limitação dos recursos naturais com o ilimitado crescimento econômico, écondicionada à consecução do desenvolvimento sustentável e a mudanças no estado da técnica e na organização social.

A noção de desenvolvimento sustentável se apresenta em cinco dimensões: a) social: devido à disrupção social que paira de forma ameaçadora sobre muitos lugares problemáticos de nosso planeta; b) ambiental: que leva em conta o meio ambiente como sistema de sustentação da vida, provedor de recursos e recipiente para a disposição de resíduos; c) territorial: relacionado à distribuição espacial dos recursos das populações e atividades; d) econômico: sendo a viabilidade econômica a conditio sinequa non para que as coisas aconteçam; e) político: a governança democrática é um valor fundador e um instrumento necessário para fazer as coisas acontecerem. ${ }^{10}$

Para assegurar o desenvolvimento sustentável da zona costeira, estabelecendo uma série de limitações ao seu uso, uma exploração racional dos recursos costeiros e o uso equilibrado do espaço litorâneo exigem que as decisões tomadas sobre o litoral levem em conta as condicionantes ambientais, sopesados os direitos e interesses dos usuários e proprietários com predomínio do interesse geral, especialmente em longo prazo, assegurada a transparência e a publicidade, a fim de se evitar privilégios de determinados grupos ou pessoas (TRAPERO, 1990, p. 55).

Clark (1996, p. 436-437) também chama atenção ao uso sustentável dos recursos da zona costeira, como forma de preservar a qualidade de vida das futuras gerações, ponderando que os objetivos do desenvolvimento econômico devem ser formulados de modo a satisfazer as necessidades básicas e assegurar a qualidade de vida da população costeira sem comprometer a capacidade produtiva e a utilização eficiente dos recursos naturais a longo prazo.

Em outro plano, Morand-Deviller (2010, p. 70) assevera em interessante estudo, que a felicidade do indivíduo está inseparável de seu bem estar e do direito de todos a um meio ambiente sadio: "a busca dos valores-penas poderia juntar-se aos da avaliação do risco. Admitindo-se que o risco zero não exista, a maximização da felicidade repousaria na

\footnotetext{
${ }^{10}$ Conferir o trabalho de Ignacy Sachs, Desenvolvimento: includente, sustentável, sustentado, Rio de Janeiro, Garamond, 2004, p. 15 e ss.
} 
determinação do risco aceitável, pois todo risco não aceitável levaria à 'pena' e à dor, diante das quais os indivíduos não são iguais. O 'bomgoverno do risco' exige prudência, a também chamada precaução, a fim de levar em consideração as situações, mesmo aleatórias, e fazer as escolhas políticas suscetíveis de conduzir ao máximo de bem estar, através da redução da gravidade do mal estar".

Nessa linha, o conceito de desenvolvimento passa de uma visão tradicional, centrada na percepção das variáveis econômicas, para uma visão holística, mais abrangente, considerando diversos aspectos relativos à qualidade de vida e impactos regionais.

Entretanto, ao cotejo dos avanços econômicos e tecnológicos obtidos pela humanidade com a deterioração das condições de vida no planeta, alguns autores prenunciam panorama demasiadamente sombrio.

É a posição de Drobenko (2005, p. 59), para que a humanidade tornou-se desrespeitosa de si mesma, "revelando o homem na plenitude de sua mediocridade". Ao mesmo tempo em que s evoluções ocorridas levaram a uma situação intolerável, indigna da inteligência humana, se produz abundante riqueza e, pela primeira vez na breve História da Humanidade, os seres humanos são capazes de destruir de maneira irreversível certos ecossistemas, certas espécies ou espaços, mas também as condições globais de vida sobre o planeta.

A vista desse paradoxo, a Constituição elevou à condição de princípio de alta relevância a proteção ambiental, como interesse de titularidade de toda a humanidade, a despeito da nacionalidade ou da condição de estar vivo, portanto transnacional, transindividual e intergeracional.

Dessa forma, o direito de acesso e fruição de bem público, ao colidir com o direito ao ambiente ecologicamente equilibrado, traz a ideia de resolução dos conflitos entre princípios pelo critério do peso.

A respeito da colidência entre princípios e regras, vale a lição segundo a qual princípios se diferenciam de regras, pois não exigem a realização total, permitindo conformação (SILVA, 2011, p. 45-46). No caso dos princípios não se pode falar em realização sempre total daquilo que a norma exige. Ao contrário: em geral essa realização é apenas parcial. Isso, porque no caso dos princípios há uma diferença entre aquilo que é garantido (ou imposto) prima facie e aquilo que é garantido (ou imposto) definitivamente'.

De acordo com Alexy (2011, p. 90-91), o ponto decisivo da distinção entre regras e princípios é que 'princípios' são normas que ordenam que algo seja realizado na maior medida possível dentro das possibilidades jurídicas e fáticas existentes. "Princípios são, por 
conseguinte, 'mandamentos de otimização', que são caracterizados por poderem ser satisfeitos em graus variados e pelo fato de que a medida devida de sua satisfação não depende somente das possibilidades fáticas, mas também das possibilidades jurídicas". Mesmo depois de determinado qual princípio deve prevalecer, das medidas capazes de realizá-lo, deverá ser escolhida aquela que cause menor prejuízo aos demais princípios não escolhidos.

Por outro lado,regras são normas que são sempre ou satisfeitas ou não satisfeitas, deve se fazer exatamente aquilo que ela exige: nem mais, nem menos, "regras contêm, portanto, 'determinações' no âmbito daquilo que é fática e juridicamente possível. Isso significa que a distinção entre regras e princípios é uma distinção qualitativa, e não uma distinção de grau. Toda norma é ou uma regra ou um princípio” (ALEXY, 2011, p. 90-91).

Quando um princípio entra em colisão com uma regra, deve haver um sopesamento, mas esse sopesamento não ocorre entre o princípio e a regra, já que regras não são sopesáveis, Ele deve ocorrer entre o princípio em colisão e o principio no qual a regra se baseia (SILVA, 2011, p. 58-59) .

Ao aludir à tormentosa questão da colidência entre regras e princípios, no caso específico do acesso à praia, Marques Neto (1995, p. 40-45) lembra, também com esteio na lição de Alexy,que a densidade que faz um princípio jurídico prevalecer em relação a outro não pode ser tomada como definitiva, restando eminentemente conjuntural: "O peso diferencial da proteção ambiental é infinitamente mais denso que o uso irrestrito de bem público travestido na impossibilidade de limitar o acesso dos eventuais banhistas às áreas praianas”.

No mesmo estudo, prossegue o autor salientando a preponderância da preservação ambiental, vislumbrando mecanismos que viabilizam tal harmonização: a) restrição ao tráfego e ao acesso imposta pelo poder público no exercício do seu poder de polícia; b) a outorga de uso privativo de bem público mediante condição de preservação ambiental.

Assim, o princípio da função social da propriedade, previsto no rol dos direitos e garantias fundamentais e na ordem econômica, longe de constituir antinomia ao direito de propriedade, integra a sua estrutura ao lhe fornecer os instrumentos necessários para assegurar o direito ao desenvolvimento sustentável como direito fundamental. ${ }^{11}$

\footnotetext{
${ }^{11}$ Conferir nessa linha Antonio Herman Benjamin (Org.) Direitos humanos e meio ambiente. São Paulo: Imprensa Oficial do Estado, 2006; Antonio Augusto Cançado Trindade. Direitos humanos e meio ambiente: paralelo dos sistemas de proteção ambiental. Porto Alegre: Fabris, 1993; Meio ambiente e desenvolvimento: formulação e implementação do direito ao desenvolvimento como um direito humano. Boletim da Sociedade Brasileira de Direito Internacional, ano XLV, $\mathrm{n}^{\circ}$ 81/83, jul.-nov. 1992, p. 49-76; Tiago Fensterseifer. Direitos fundamentais e proteção do ambiente. A dimensão ecológica da dignidade humana no marco jurídico-constitucional do estado socioambiental do direito. Porto Alegre: Livraria do Advogado, 2008.
} 
Trata-se de síntese da dialética estabelecida entre os princípios do desenvolvimento econômico e o direito ao meio ambiente equilibrado.

Nesse sentido, o princípio da função social da propriedade define os contornos da propriedade (pública e privada) e direciona as políticas públicas. É o que aponta o escólio deFigueiredo (2008, p. 129), para quem referido princípio constitui a via para a implementação dos valores arrolados no caput do art. 225 da CF e, sem ele, tais valores tornar-se-iam uma abstração: "Por esse princípio, pretende-se a adequação do exercício do direto de propriedade no sentido da proteção do meio ambiente, o que não reduz o conteúdo econômico da propriedade nem causa qualquer dano patrimonial".

Na verdade, o pano de fundo de toda problemática consiste em desenvolver uma ética da sobrevivência, um sistema de controle social sobre o fato humano, revertendo a lógica da privatização dos benefícios com a socialização dos prejuízos, projetando seus efeitos paratodo o planeta alcançando as gerações futuras. A questão dos direitos (meio ambiente, direitos humanos) não mais aparece como questão secundária, mas como uma questão fundamental, que assegura a perpetuação de toda forma de vida sobre o planeta.

\section{Perspectivas e atuação do poder local}

\subsection{Extinção dos terrenos de marinha}

Malgrado a necessidade de tratamento da zona costeira como uma totalidade geográfica, social e econômica e consequente disciplina jurídica unitária, o direito brasileiro persiste na manutenção do vetusto instituto do terreno de marinha, previsto no art. 20, da Constituição Federal e no art. $2^{\circ}$ do Decreto $n^{\circ}$ 9.760, de 05.09.1946, proporcionando uma sobreposição de competências (dominial da União com atividades dos Municípios) que constitui entrave ao desenvolvimento sustentável do ambiente costeiro urbano.

A extinção do referido instituto, construído com base em critérios dotados de pouca cientificidade e estribado nos fundamentos de defesa nacional, constitui providência destinada a eliminar gargalo que dificulta o desenvolvimento das regiões costeiras, seja pela imposição de ônus despido de contrapartida, seja pelos entraves burocráticos causados pela referida sobreposição de competências.

Referidos argumentos não subsistem diante da atual tecnologia de defesa, da superveniência da política urbana delineada no art. 182 da Constituição Federal, efetivada pela Lei n $\mathrm{n}^{\mathrm{O}}$ 10.257, de 10.07.2001, e da previsão da participação do Município no Plano Nacional de Gerenciamento Costeiro. 
Em abono a essa tese, os Projetos de Emenda Constitucional no 53/07 e 56/09 preveem sua extinção, consolidando o domínio dos terrenos de marinha na esfera particular sem implicar na transferência das receitas hauridas pela União ao Município e tampouco na criação de novos tributos. No plano infraconstitucional, a Lei $\mathrm{n}^{\mathrm{o}}$ 13.240, de 30.12.2015, dispõe sobre a transferência de gestão de imóveis da União e seu uso para constituição de fundos, incluindo os terrenos de marinha.

\subsection{Atuação do município e o Projeto Orla}

O Projeto ORLA ${ }^{12}$ foi criado para responder às demandas de ordenamento do uso e ocupação das bordas litorâneas, que se tornaram evidentes na prática da gestão ambiental e patrimonial, como reflexo da fragilidade dos ecossistemas, da falta de planejamento, do crescimento desordenado das cidades, do aumento dos processos erosivos e das fontes contaminantes de orla. No âmbito deste Projeto, as atribuições reservadas aos entes federativos superiores possuem natureza de supervisão e coordenação, ao passo que aos Municípios compete execução do projeto, com o levantamento da documentação necessária, elaboração do plano, entabulamento de convênios edefinição da agenda.

A Agenda 21 destaca que a atuação da autoridade local, enquanto nível decisório de governo mais próximo do povo, portanto mais apto à obtenção de soluções consensuais e menos intrusivas, desempenha um papel essencial na educação, mobilização e resposta ao público, em favor de um desenvolvimento sustentável, pois a participação do cidadão munícipe nas decisões que afetam a comunidade ocorre com maior eficácia no nível decisório local do que no plano regional ou na distante esfera nacional.

Nesse sentido, um dos objetivos do Projeto Orla é precisamente acelerar a implantação de cessão patrimonial para os Municípios, especialmente para aqueles de pequeno porte, desprovidos de recursos e quadros, para que possam enfrentar as atribuições decorrentes da consolidação da área na esfera municipal, no caso de extinção do terreno de marinha, sem que a eliminação do referido instituto resulte na instituição de novo tributo, com a contrapartida de que a gestão da Orla Marítima seja feita de forma compatível com o conceito de patrimônio coletivo.

\footnotetext{
${ }^{12}$ O Projeto foi inserido em 1999 no âmbito do Grupo Interministerial de Gerenciamento Costeiro (GI-GERCO) como parte das ações prioritárias do Plano de Ação Federal para a Zona Costeira (PAFZC), aprovado pela Resolução CIRM $\mathrm{n}^{\circ} 5 / 1998$.
} 
Enfim, caberá ao Poder Público Municipal elaborar e executar o Plano de Intervenção da Orla Marítima de modo participativo com o colegiado municipal, órgãos, instituições e organizações da sociedade interessados, lançando mão dos inúmeros instrumentos postos à sua disposição no Decreto n 5.300 , de 07.12.2004 e na Lei $n^{\circ}$ 10.257, de 10.07.2001.

A questão, portanto, reside em conjugar os dois instrumentos de ordenamento do uso do solo à disposição das autoridades locais,o zoneamento costeiro e o zoneamento urbano decorrente do plano diretor do Município.

\subsection{Impactos da extração de petróleo e gás}

As recentes descobertas de jazidas de gás e petróleo na camada do pré sal ${ }^{13}$, situada na Bacia de Santos, a par das atividades petrolíferas já desenvolvidas na Bacia de Campos (RJ), intensificarão as atividades industrial e de serviços e acentuarão o processo de urbanização, bem como agravarão os riscos ambientais diante da possibilidade de eventuais vazamentos, seja nos poços em atividade ou no transporte do produto. ${ }^{14}$

Não obstante previsão constitucional assegurando à União a propriedade dos recursos minerais, petróleo e gás natural, os impactos da atividade de exploração, transporte, refino e distribuição no meio urbano/ambiental local exigirão providências que irão onerar os Municípios, seja pelo atendimento de demandas sociais por moradia, emprego, transporte, saneamento e urbanização, ou pelo exercício do poder de polícia fiscalizador, visando assegurar a manutenção ou mesmo preponderância do interesse local, inclusive pelo manejo de receitas provenientes da mencionada atividade.

Vale lembrar que esse tipo de exploração requer adequada infraestrutura de operações e instalações de apoio logístico ${ }^{15}$, tanto no mar como em terra (plataformas, redes de dutos,

\footnotetext{
${ }^{13}$ A Bacia de Santos está localizada numa área de $352 \mathrm{mil} \mathrm{km}{ }^{2}$, se estende pelo litoral sul do Estado do Rio de Janeiro, passando por toda a costa de São Paulo e do Paraná e pelo norte do litoral de Santa Catarina.

${ }^{14}$ Sobre os riscos ambientais da exploração da atividade na região e as medida atinentes à sua mitigação, ver Mitigação dos riscos na exploração e produção de petróleo e gás na Bacia de Santos, LuisAntonio de Mello Awazuet alii,. Conferir também Governança ambiental e gerenciamento social dos riscos, Ícaro A. da Cunha e Luciano A. Prates Junqueira, in Alcindo Gonçalves e Gilberto M. A. Rodrigues, Direito do petróleo e gás, Santos, Leopoldianum, 2007,p. 141-149 e 151-163.

${ }^{15}$ As operações na Bacia de Santos serão atendidas por bases de apoio aéreas localizadas nas cidades de Itanhaém (SP), Navegantes (SC) e Rio de Janeiro (RJ); o apoio portuário a partir do Rio de Janeiro (RJ) e Itajaí (SC). Outras duas bases logísticas, que contemplam áreas de porto, aeroporto, armazenagem, laboratórios e Centro de Defesa Ambiental estão em fase de estudos, sendo uma em Itaguaí (RJ) e outra em Guarujá (SP). As instalações para a Unidade de Operações de Exploração e Produção da Bacia de Santos - UO-BS está instalada em sete endereços na cidade de Santos. A Unidade de Tratamento de Gás Monteiro Lobato - UTGCA, em Caraguatatuba (SP), completa o grupo de instalações terrestres da unidade. Uma sede definitiva para a Unidade da Bacia de Santos está em construção no bairro do Valongo, em Santos, com três torres com capacidade para cerca de duas mil pessoas cada uma. Não há qualquer trecho do litoral brasileiro, de Santa Catarina ao Espírito Santos que ficará imune ao impacto causado pela
} 
bases de apoio, tanques de armazenamento, emissário para o descarte de águas tratadas, instalações destinadas ao abastecimento e manutenção de navios e aeronaves), com reflexos na atividade econômica e de serviços privados e públicos da região, bem como a necessidade de aumento da malha urbana para acomodar o crescimento populacional. ${ }^{16}$

Granziera (2011, p. 576) lembra que pelo litoral escoam-se as riquezas brasileiras através de estradas e portos. As atividades de extração de petróleo e gás se intensificam na costa brasileira, muitas vezes próximo ao litoral. Da mesma forma, muitos polos petroquímicos e cloroquímicos situam-se próximos do mar, além das usinas nucleares de Angra 1 e Angra 2. A apropriação desse território tem sido realizada, desde o período colonial, de forma comprometedora para a biodiversidade e a economia do país.

Cunha (2004, p. 151) também chama a atenção para o problema, salientando o despreparo dos municípios para enfrentar as complexas transformações territoriais determinadas pelo exercício de atividades de alto risco ambiental: As áreas portuárias da costa de São Paulo (Santos e São Sebastião) têm nas operações de petróleo e gás uma atividade importante na constituição de uma rede técnica que as integre entre si e com outros parques produtivos do Estado e das regiões Sudeste/Centro-Oeste, por meio de dutovias. Tais operações estão em fase de expansão, com novos aproveitamentos dos recursos da Bacia de Santos, por meio de estruturas que passam pelo licenciamento ambiental para conexões na Baixada Santista e no Litoral Norte, e da infraestrutura existente, além do desenvolvimento de novas, complementares.. É um cenário em que interagem órgãos federais, estaduais e prefeituras, estas últimas, via de regra, mais despreparadas para governar as transformações territoriais complexas determinadas por atividades de risco ambiental. Completa-se este quadro com grupos das comunidades afetadas de alguma forma por tais intervenções, um público que emerge como ator relevante diante da tendência a reconhecer a importância de esquemas participativos de gestão.

exploração do Pré-Sal, considerando incremento do sistema viário (duplicação de rodovias Tamoios, Rio-Santos), ferroviário, bases de apoio marítimo (supplyhouses), estaleiros, instalações para armazenagem e manutenção, expansão do setor de serviços, comércio, hotelaria e expansão imobiliária, especialmente nas cidades-dormitórios que surgirão a partir da farta oferta de estoque de terreno, como Praia Grande, Ubatuba e a Costa Sul de São Sebastião neste Município a costa Norte e o Centro vivem em função do porto (Diagnóstico Urbano Socioambiental - Município de Santos - Bases das Informações até 2012 - Revisão Março de 2013 - Convênio Petrobrás Instituto Polis - Relatório $\mathrm{n}^{\mathrm{a}}$ 6, p. 107-109).

${ }^{16}$ Fenômeno ocorrido na Bacia de Campos, em especial no município de Macaé, e agora em franca instalação no litoral paulista, especialmente nos municípios de Santos, Caraguatatuba (centro de beneficiamento de gás) e São Sebastião, cuja expansão do porto já está em andamento, aumento a capacidade de atracação simultânea de 4 para 18 navios, na maioria petroleiros, além de terminal de contêineres com capacidade para receber 240 mil contêineres por mês, com a duplicação da rodovia dos Tamoios que passará a receber cerca de 4.000 caminhões por dia. 
A questão apresenta contornos ainda mais dramáticos, porquanto decorrente da exploração extrativista, cujas características demandam atenta análise, podendo resultar em maldição ou ddiva. ${ }^{17}$

É que a mineração ${ }^{18}$ é insustentável e locacional, já que os minerais são recursos inevitavelmente exauríveis. Todavia, pode ser um vetor de desenvolvimento econômico, desde que observadas duas condições: a primeira é promover investimentos que gerem riqueza alternativa, para substituir o patrimônio mineral consumido; a segunda é a minimização dos danos ambientais provocados pela atividade de mineração e de beneficiamento.

Um polo de extração não se torna, necessariamente, um polo de desenvolvimento, pois a lógica do enclave não gera nem os encadeamentos anteriores (abastecimento de insumos das atividades não primárias), nem os encadeamentos posteriores (como insumo em atividades novas) necessários para que ocorra efetivo desenvolvimento.

Assim, os conceitos de sustentabilidade fraca ou sensata podem ser usados a partir de duas perspectivas: a da atual geração (intrageracional), que pressupõe a minimização dos danos ambientais e o aumento do bem estar social; e a da geração futura (intergeração), pela qual a atividade deve ser capaz de gerar um fluxo permanente de rendimentos para garantir o nível de bem estar.

O ideal é que as decisões de políticas públicas em torno da matéria tenham por objetivo básico proporcionar às gerações futuras uma compensação pela exploração presente de um recurso exaurível, o que pode ser feito sob diversas formas de poupança e investimento (AFONSO; GOBETTI, 2008, p. 233).

Os autores sugerem ainda que a alocação de recursos deveria seguir a lógica de um Fundo Soberano, a exemplo de experiências de alguns países árabes, da Noruega ou mesmo de Estados como o Alaska e a província canadense Alberta,para formação de poupança e sua aplicação, especialmente em investimentos em infraestrutura econômica e social.

\section{Referências bibliográficas}

AFONSO, J.R.R.; GOBETTI, S.W. Rendas do petróleo no Brasil: Alguns aspectos fiscais e federativos. Revista do Banco Nacional de Desenvolvimento Econômico e Social, Rio de Janeiro, n. 30, p. 231-269, dez. 2008.

\footnotetext{
${ }^{17}$ Conferir obra de Maria Amélia Enriquez, Mineração: maldição ou dádiva. Os dilemas do desenvolvimento sustentável a partir de uma base mineira, São Paulo, Signus, 2008, p. 95.

${ }^{18}$ Importante ressaltar que petróleo não é mineral, mas hidrocarboneto.
} 
ALEXY, R.Teoria dos direitos fundamentais. 2 ed. 2 tiragem. Trad.Virgílio Afonso da Silva, São Paulo: Malheiros, 2011.

BELCHIOR, C.C.Gestão costeira integrada - Estudo de caso do Projeto ECOMANAGE na Região Estuarina de Santos-São Vicente. Dissertação de Mestrado - Ciência Ambiental, Instituto Oceanográfico da Universidade de São Paulo, 2008.

BENJAMIN, H.B. (Org.) Direitos humanos e meio ambiente. São Paulo: Imprensa Oficial do Estado, 2006;

CANÇADO TRINDADE, A.A.Direitos humanos e meio ambiente: paralelo dos sistemas de proteção ambiental. Porto Alegre: Fabris, 1993;

. Meio ambiente e desenvolvimento: formulação e implementação do direito ao desenvolvimento como um direito humano. Boletim da Sociedade Brasileira de Direito Internacional, ano XLV, $\mathrm{n}^{\circ}$ 81/83, jul.-nov. 1992, p. 49-76;

CLARK, J. R. Coastal zone management handbook.New York: Lewis Publishers, 1996.

CUNHA, Í. Portos no ambiente costeiro.Santos: Universitária Leopoldianum, 2004.

; NEVES, M.F.B. (Org.). Gestão ambiental na costa. Portos e sustentabilidade. 2ed. Santos: Leopoldianum, 2009.

DERANI, C.Direito ambiental econômico. 3. ed. São Paulo: Saraiva, 2008.

DROBENKO, B.Droit de l'urbanisme. 2 ed. Paris: Gualino, 2005.

EGLER, C.A.G. Os impactos da politica industrial sobre a zona costeira. Brasília: Ministério do Meio Ambiente, 1997.

ENRÍQUEZ, M.A. Mineração: maldição ou dádiva. Os dilemas do desenvolvimento sustentável a partir de uma base mineira. São Paulo: Signus, 2008. 
FENSTERSEIFER, T. Direitos fundamentais e proteção do ambiente. A dimensão ecológica da dignidade humana no marco jurídico-constitucional do estado socioambiental do direito. Porto Alegre: Livraria do Advogado, 2008.

FIGUEIREDO, G.J.P. A propriedade no direito ambiental. 3. ed. São Paulo: Revista dos Tribunais, 2008.

GONÇALVES, A.; RODRIGUES, G.M.A. Direitodo Petróleo e Gás: aspectos ambientais e internacionais. Santos: Universitária Leopoldianum, 2007.

GRANZIERA, M.L.M. Direito ambiental. 2 ed. São Paulo: Atlas, 2011.

MARQUES NETO, F.A. O conflito entre princípios constitucionais: breves pautas para sua solução. Cadernos de Direito Constitucional e Ciência Política. Vol. 10. São Paulo, Revista dos Tribunais/Instituto Brasileiro de Direito Constitucional,jan.-mar. 1995, p. 40-45.

MARTINS, F.M.; ALBUQUERQUE, H.M. Politicas de planeamento, ordenamento e gestão Costero. Contributo para uma discussão metodológica. Tese de Doutorado, Universidade de Aveiro - CESAM, Departamento de Ambiente e Ordenamento, 1998.

MEDAUAR, O.; SILVA, S.T.; MARQUES, C.L. O novo direito administrativo, ambiental e urbanístico - Estudos em homenagem a Jacqueline Morand-Deviller. São Paulo: Revista dos Tribunais, 2010.

MORAES, A.C.R. Contribuições para a gestão da zona costeira do Brasil-Elementos para uma geografia do litoral brasileiro. São Paulo: Annablume - HUCITEC EDUSP, 2007.

MORAND-DEVILLER, J. Droit de l'urbanisme. 3. ed.Paris: Dalloz, 1996.

NUSDEO, A.M.O. Defesa da concorrência e globalização econômica: o controle da concentração de empresas. São Paulo: Malheiros, 2002. 
Ambiental, n. 37, São Paulo, Revista dos Tribunais,p. 144-159, jan.-mar. 2005.

PASSOS DE FREITAS, M.A. Zona costeira e meio ambiente. Curitiba: Juruá, 2005.

SACHS, I. Desenvolvimento includente, sustentável, sustentado. Rio de Janeiro: Garamond, 2004.

SILVA, V.A.Direitos fundamentais. Conteúdo essencial, restrição e eficácia. 2 ed. 2 tiragem. São Paulo; Malheiros, 2011.

TRAPERO, J.J. Aspectos urbanísticos de la proteción del territorio litoral. Revista de Derecho Urbanístico, n. 117,Madrid,Montecorvo, p. 53-64, mar.-abr. 1990. Año XXIV; 


\title{
O FENÔMENO DA ECONOMIA DE COMPARTILHAMENTO: NOVOS PARADIGMAS SOCIAIS, ECONÔMICOS E TECNOLÓGICOS
}

\section{Kerolinne Barboza da Silva}

$U F P B$

Fernando Antônio de Vasconcelos

UFPB e Unipê

\section{Resumo}

Os ideais do mundo globalizado trazem consigo novas modalidades de relações interpessoais e comerciais, dentre esse mundo de inovações destacamos o fenômeno da economia de compartilhamento ou economia colaborativa. Este fenômeno pode ser entendido como um sistema socioeconômico construído em torno do compartilhamento de recursos, tornando acessível bens e serviços sem a necessidade de sua aquisição. Tratando-se de um sistema crescente e inovador, diante da era informacional e da tecnologia que vivenciamos, faz-se necessário o estudo conceitual sobre esse fato, em razão de seus impactos socioeconômicos, tendo em vista suas interferências nas relações pessoais.

Palavras-chave: Economia de compartilhamento, relações de consumo, sistema de compartilhamento, consumo colaborativo, relações pessoais.

\begin{abstract}
Resumen/Résumé
The ideals of the globalized world bring with it new modalities of interpersonal and commercial relations, among this world of innovations we highlight the phenomenon of the sharing economy or collaborative economy. The sharing economy is a socioeconomic system built around the sharing of resources, making goods and services accessible without the need of their acquisition. Being a growing and innovative system, in view of the information age and the technology we are experiencing, it is necessary to study this fact, due to its socioeconomic impacts, in view of its interference in personal relations.
\end{abstract}

Keywords/Palabras-claves/Mots-clés: Sharing economy, consumer relations, sharing system, collaborative consumption, personal relationships. 


\section{Introdução}

A sociedade contemporânea tem refletido, na sua estrutura social, os grandes avanços tecnológicos. Os impactos da globalização têm se demonstrado maiores e, cada vez mais, enraizados na dinâmica da pós-modernidade ${ }^{1}$. O avanço da era digital suscita hoje novos paradigmas e debates relativos à organização social, à tecnologia e aos impactos que esse novo cenário tecnológico tem gerado não só no âmbito das relações pessoais, mas na economia global.

$\mathrm{Na}$ era digital e da Informação, deparamo-nos com uma nova forma de viver, baseada na tendência à facilitação da transmissão da informação e da comunicação. Com os novos ideais do mundo globalizado, a relação do Estado com a economia tem se modificado, posto que atualmente visualizamos um mundo sem fronteiras, culminando na expansão e inovação das relações pessoais. As relações privadas, sejam comerciais ou interpessoais, ultrapassam hoje os limites territoriais, e a participação do Estado nessas novas modalidades de relações demonstrase insuficiente, haja vista a rápida modificação e atualização dos conceitos tecnológicos.

Com a ampliação dos conceitos de "desterritorialização" e "descentralização" a difusão de novos padrões sociais torna-se um fenômeno crescente. É certo que, muitas vezes, torna-se imprescindível a atuação estatal com vistas a minimizar possíveis prejuízos aos direitos fundamentais e os riscos que a ausência de regulação dessas novas relações pessoais possa ocasionar como, por exemplo, no que tange a questão da responsabilidade por reparação de danos.

A economia de compartilhamento ou sharing economy, como é conhecida externamente, apresenta-se como um conceito "inovador" ${ }^{2}$ que agrega valor ao consumo colaborativo, ou seja, um sistema socioeconômico construído em torno do compartilhamento de recursos humanos, físicos e intelectuais, através de novos instrumentos tecnológicos. $\mathrm{O}$ acesso a bens e serviços, tais como carros, alimentos, hospedagem, informação, tecnologia, entre outros, podem ser simplesmente compartilhados, sem necessidade de aquisição dos mesmos, consubstanciando uma nova forma sustentável de consumo.

\footnotetext{
${ }^{1}$ A pós-modernidade é um conceito atual e complexo que se liga ao surgimento de uma sociedade pós-industrial, na qual o conhecimento torna-se a principal força econômica de produção, cujas características podem ser citadas: a explosão tecnológica da eletrônica moderna e seu papel como principal fonte de lucro e inovação, predomínio de empresas e corporações multinacionais, crescimento da especulação internacional e ascensão da comunicação que ultrapassa fronteiras. (SANFELICE, 2003, p.5-6).

${ }^{2}$ A ideia de se compartilhar, realizar trocas, como será demonstrado ao longo do estudo, sempre existiu na história, por isso, o termo "inovador" já que a prática não é novidade, porém, no contexto que vivenciamos hoje, essa prática encontra uma nova roupagem que acarretam impactos diversos e em escalas jamais imaginadas.
} 
Muitos benefícios são evidenciados com a economia de compartilhamento, dentre eles, o imperioso destaque se firma sobre os aspectos social, financeiro e ambiental, provando-se um avanço no conceito de sustentabilidade, na aproximação das relações pessoais, promovendo uma abordagem altruísta e dando preferência ao acesso (compartilhamento) ao invés de aquisição (centralização).

É certo que a carência de conhecimento acerca da temática e a consequente ausência específica de regulamentação dessas práticas, claramente lacunas legislativas, podem trazer efeitos danosos à sociedade. Também, inúmeros questionamentos acerca da sua natureza jurídica, impactos e a concorrência com o mercado tradicional, bem como a responsabilidade dos fornecedores/cedentes dos serviços e produtos vêm à tona.

Neste ponto, o presente artigo visa apresentar a temática da economia de compartilhamento, seu conceito e suas nuances, destacando a relevância do tema, seus impactos socioeconômicos e culturais na sociedade global, e como podemos enxergar esse fenômeno em seus diversos sistemas de compartilhamento.

\section{Novas formas de pensar}

Após discutir tanto sobre globalização, seus inúmeros efeitos, impactos sociais e culturais, temos presentemente que é um aspecto econômico chamativo para nossa sociedade, e como o mundo contemporâneo se transformou após a Webeconomia ${ }^{3}$, modalidade de economia do século XXI, a qual traz novas formas de relações comerciais, imersa no universo virtual.

Passamos por um período em que o consumo está mais do que nunca atrelado a ideia de consumismo, ao invés da simples aquisição de bens e serviços. Botsman e Rogers (2016) chamam de "hiperconsumo", as quatro forças que desempenham um papel fundamental para manipulação e estímulo ao consumo: o poder de persuasão; a cultura de comprar agora e pagar depois; a lei dos ciclos de vida; e, por fim, o fator do "apenas mais um", e ressaltam como consequência desse fenômeno:

De maneira semelhante, quanto mais espaço e quanto mais tempo nós gastarmos dedicados a acumular coisas em nas nossas vidas, menos espaço teremos para outras pessoas. Nosso ímpeto por riqueza material causou a exclusão das nossas necessidades sociais mais básicas, como os vínculos de família e de comunidade, paixões pessoais e responsabilidade social. Achamos que poderíamos suprir estas necessidades por meio de compras e do acúmulo de cada vez mais coisas. (BOTSMAN; ROGERS, 2016, p. 33).

\footnotetext{
${ }^{3}$ Referência aos novos modelos econômicos decorrentes da era digital.
} 
Esse sistema de consumo deposita um valor extremo na propriedade: "você é aquilo que você tem". Os bens apresentam-se como um portfólio, não importa o que você faz ou seus interesses, o status social estava enraizado na propriedade.

Apesar da grande propagação dessas ideias, e de termos e ainda estarmos vivenciando uma cultura do "hiperconsumismo", essa mentalidade, entretanto, não pode ser interpretada como um fato intrínseco e imutável da sociedade:

O sistema de consumismo parece um fato fixo da vida moderna. Mas não é. O fato de o sistema ter sido produzido sugere que é possível remodelar essas forças a fim de criar um sistema mais saudável e sustentável com uma meta mais gratificante do que "mais coisas". (BOTSMAN; ROGERS, 2016, p. 33).

Rompendo com esse paradigma, começamos a nos desvincular desse sistema de "hiperconsumismo" e de maneira gradual, percebemos a mudança de valores na sociedade. Através do acesso à informação (da informatização) o consumidor apresenta-se cada vez mais consciente, e conceitos como sustentabilidade passaram a fazer parte dos elementos decisivos para tomada de suas decisões. A preocupação com o uso irracional de recursos e o consumo frenético vai ganhando força. Além do mais, o cenário econômico contribui para que o consumidor pense duas vezes antes de consumir e tenda mais a procurar alternativas para economizar. Vejamos:

Essa tendência de digitalização está atualmente caminhando para a maior transparência, significando mais dados da cadeia de fornecimento, mais dados na ponta dos dedos dos consumidores e, portanto, mais comparações ponto a ponto (peerto-peer) sobre o desempenho dos produtos que transferem poder aos consumidores. Por exemplo, os sites de comparação de preços facilitam a comparação deles, da qualidade dos serviços e do desempenho do produto. Com o clique de um mouse ou toque do dedo, os consumidores instantaneamente passam de uma marca, serviço ou agência digital para a seguinte. (SCHWAB, 2016, p.59).

Sob o aspecto social, o que Schwab chama de "Quarta Revolução Industrial” é justamente esta fase que vivenciamos, ocorrendo a fusão dessas tecnologias e interação entre os domínios físicos, digitais e biológicos:

As tecnologias digitais, fundamentadas no computador, software e redes, não são novas, mas estão causando rupturas à terceira revolução industrial; estão se tornando mais sofisticadas e integradas e, consequentemente, transformando a sociedade e a economia global. (SCHWAB, 2016, p.16).

Para Rabin:

A sociedade contemporânea vive um período de transição feroz dos cânones da economia de produção de bens físicos (e da vinculação ao espaço geográfico) para uma era dos serviços, da informação, da comunicação e da geração de experiências, que desconhece fronteiras e desagrega o sentido ancestral das raízes "territoriais". (RABIN, 2004, p.171). 
Nesse sentido, a necessidade econômica vem tornando as pessoas mais abertas a novas formas de ter acesso e de como podem obter as coisas de que elas precisam. Essa transformação do modo de pensar, começa então a ocorrer a partir dos próprios consumidores.Segundo Botsman e Rogers (2016), no século XXI do consumo colaborativo, não somos mais definidos pelo que possuímos, mas sim pela nossa reputação, por aquilo que podemos acessar, pela comunidade ao qual pertencemos e pelo modo como compartilhamos, rompendo o paradigma da propriedade.

Nesse sistema nada é forçado, o compartilhamento surge de forma natural e coloca em vigor um sistema no qual as pessoas podem partilhar recursos sem, no entanto, perder sua individualidade e liberdades pessoais. Diante disso, a internet tem sido o grande fator do crescimento dessa nova modalidade de economia, haja vista que proporciona o acesso e incentiva o custo marginal de oferecimento de bens e serviços, além de agregar valores sociais e de sustentabilidade.

Outro fator é apontado como propulsor desse "novo modo de pensar", que caracteriza o consumo colaborativo: são os chamados millennials, também conhecidos como "geração Y" ou "geração da internet". Essa geração é caracterizada por ser ambiciosa e competitiva, um grupo que foi criado em meio ao universo digital e que cresce e envelhece com os avanços tecnológicos, fator este que contribui para o crescimento do compartilhamento (ANDRADE e PINTO, 2014).

O novo paradigma econômico, portanto, é o consumo colaborativo:

\begin{abstract}
Estas novas tecnologias vêm sendo "festejadas" nos círculos de marketing e negócios, onde são denominadas de tecnologias " $\mathrm{R}$ " (de Relacionamento), pois viabilizam a "aglutinação" de pessoas que compartilham de interesses ou ideias comuns em torno de uma atividade ou projeto. A cada dia mais, aumenta a consciência de que estabelecer "comunidades virtuais" ou "de interesses" por assim chamá-las, pode ser a maneira mais efetiva de captar e reter a atenção dos "clientes" e estabelecer e consolidar relações duradouras. (RABIN, p. 172).
\end{abstract}

A economia de compartilhamento oferece oportunidade de crescimento econômico, aumenta o poder de escolha do consumidor e proporciona oportunidades de trabalho. Desse modo, corroborando com os pensamentos de Botsman e Rogers (2016), estamos percebendo uma transição gradual do pensamento individual egocêntrico para um pensamento de interesse próprio e coletivo ao mesmo tempo, transcendendo o simples significado de consumo.

Adiante veremos de que maneira ocorreu essa transição e quais foram os fatores que corroboraram para o crescimento e difusão dos sistemas de compartilhamento, culminando para que a economia de compartilhamento cada vez mais ganhe força e se torne um elemento inerente no nosso dia-a-dia. 


\title{
3. Quando o compartilhamento substitui a propriedade: surgimento da ideia de economia compartilhada e fatores de difusão
}

As tecnologias de hoje parecem estar nos levando de volta para o comportamento colaborativo familiar, para o emprego por conta própria, e formas de comunidade baseadas na troca. Um fenômeno já vivenciado no passado, mas revestido de uma nova roupagem, cada dia que passa adere novos adeptos e que vem se expandido.

O uso eficiente de produtos e serviços é o ponto central da economia compartilhada. Aqui se verifica a posse dando vez ao acesso compartilhado. A ideia de compartilhar um bem e um serviço congrega valores econômicos, sociais e ambientais.

Chegamos a um momento em que possuímos coisas demais, e nos tornamos para além de proprietários, acumuladores. Muitas vezes os bens que possuímos não são mais utilizados, quando os são não é com frequência, ou ainda a sua manutenção não apresenta uma relação custo-benefício muito favorável.

Seguindo o sistema do "hiperconsumismo" narrado por Botsman e Rogers (2016), nos deparamos com inúmeros bens e serviços aglomerados, amontoados em torno de um único indivíduo. Diante disso, gera-se uma imensa massa de ociosidade, uma vez que ninguém será capaz de sozinho, aproveitar com máxima eficiência desses produtos e serviços.

Estamos cada vez mais envoltos do que Chase (2015, p. 33) chama de capacidade excedente: "A capacidade excedente, por si só, não passa de um valor latente. O valor real resulta de sua utilização". Chase nos apresenta a capacidade excedente como o primeiro passo para a composição da economia colaborativa, visto que a ociosidade de um bem ou serviço pode ser aproveitado se for pensado de maneira coletiva e com organização. Assim, promoverá a utilização daquele bem de maneira mais eficiente, aproveitando-se do valor real da coisa:

\begin{abstract}
A capacidade excedente se revela um insumo importantíssimo para compor um produto ou serviço da Peers $\operatorname{Inc}{ }^{4}$. O custo da experimentação é reduzido à medida que o novo é extraído de algo que já existe e já foi consideravelmente (ou inteiramente) pago. [...] Em todos os casos, sai muito mais barato alavancar a capacidade excedente do que comprar uma nova matéria-prima. E a execução pode ser realizada em apenas uma fração do tempo, já que não precisamos encontrar, comprar, construir ou financiar os insumos. (CHASE, 2015, p. 34).
\end{abstract}

\footnotetext{
${ }^{4}$ Peers refere-se ao que Chase chama de pontos fortes individuais da colaboração, que são as pessoas e pequenas empresas que se envolvem em atividades regionais, em pequena escala, customizadas e especializadas para criar produtos e serviços específicos e especiais. Por outo lado, temos a Inc que constitui os pontos fortes industriais. Elas são as empresas, governos e instituições que alocam recursos, talentos e dinheiro consideráveis para simplificar o complexo. (CHASE, 2015, p. 15).
} 
Outro fator que contribuiu para mudança de pensamento em favor da nova economia foi a crise financeira e a atual situação de restrição orçamentária vivenciada por muitas famílias. Algumas pessoas passam a buscar alternativas ao consumo, formas de economizar e de ganhar uma renda extra. Nesse sentido, visualiza-se uma tendência de maior procura por mecanismos colaborativos, haja vista que os mesmos dispensam a necessidade de aquisição de produtos de alto custo e viabiliza a utilização de serviços mais baratos do que serviços tradicionais. Em tempos de crise, compartilhar traduz-se em economizar.

\begin{abstract}
Primeiro, a crise econômica criou uma profunda desconfiança das marcas e modelos mais antigos. Historicamente, tais épocas favorecem o surgimento de novas empresas e remodelação das antigas. E existe de fato uma considerável evidência de que as atitudes dos consumidores estão mudando em resposta à crise, incluindo uma disposição de experimentar novas marcas. Segundo, na esteira da crise os consumidores estão repensando o que consideram valioso em suas vidas. Isso é uma abertura para novos modelos para a entrega de produtos e serviços que ofereçam mais valor com menos custo. (GANSKY, 2011, p. 28).
\end{abstract}

Segundo Bockman (2014) são condutores sociais da economia compartilhada o aumento da densidade populacional que permite o compartilhamento e o acesso a áreas com esse grande contingente populacional, que significa o aumento da oferta e da procura, tornando mais simples a criação de uma correspondência na economia compartilhada. Coadunando com tal fato, o consequente aumento do número de empresas que surgem e o seu crescimento explosivo que têm contribuído.

A chamada "vontade de comunicação" também é apontada por Bockman como um fator social, os indivíduos têm o desejo de se comunicar e socializar com os outros em seu entorno. Novas formas de tendências econômicas também exigem novas formas de comunicação.

O pensamento sustentável é outro fator apontado por Bockman como um fator social que contribui para a economia compartilhada: "Uma norma social ensinada pela economia compartilhada é a colaboração da comunidade em conjunto para garantir o desenvolvimento sustentável ${ }^{5}$ ".

Já do ponto de vista econômico, dos fatores apontados por Bockman fazem parte: a) a rentabilização do excesso de estoque ou de espera, e nesse sentido os recursos ociosos, agora podem ser compartilhados e muitas vezes rentabilizado; b) o aumento da flexibilidade financeira - a crescente globalização e comunicação em todo o mundo permite que as pessoas descubram o benefício de obter renda com a propriedade ou a concessão de independência por

\footnotetext{
${ }^{5}$ Tradução livre: One social norm taught by the shared economy is to have the community collaborate together to ensure sustainable development.
} 
não-propriedade; c) a possibilidade de proprietários encontrar possibilidades de ganhar renda e conquistar a independência financeira; d) o acesso pela posse - produtos mais caros e de luxo de repente se tornar acessível na economia compartilhada para novos grupos de clientes que não eram capazes de pagar por eles antes.

Por fim, as conduções tecnológicas são apresentadas pelas redes sociais, que ajudam a facilitar as transações pessoa para pessoa ( $\mathrm{P} 2 \mathrm{P}$ - peer to peer). A disponibilidade de dispositivos móveis e plataformas também representa um aspecto de condução à economia de compartilhamento - a ascensão dos smartphones ajudou a iniciar a difusão das plataformas e a facilitação de sistemas de pagamento também contribuem, posto que os sistemas de comércio eletrônico inteligente e faturação necessários para transações rápidas ajudam os clientes para ganhar a confiança e garantir o pagamento.

A economia compartilhada e o consumo colaborativo, portanto, difundiram-se e, de tamanha forma, que hoje já faz parte da vida cotidiana nos grandes centros urbanos. $\mathrm{O}$ crescimento da interação entre as pessoas através da internet e a percepção de que o consumo por meio da posse de bens acarreta em ociosidade, desperdício e mais consumo, permite que o compartilhamento vá assumindo como um estilo de vida socioeconômico da sociedade contemporânea.

Nesse sentido:

O consumo colaborativo permite que as pessoas percebam o benefício do acesso aos produtos ao invés da sua posse. Com isso, elas economizam dinheiro, tempo, espaço, além de terem a chance de fazer novos amigos e se legitimar como cidadãos conscientes e ativos. Com essa dinâmica, o consumo colaborativo possui uma configuração que permite que ele cresça cada vez mais. (ANDRADE; PITO, 2014 apud BOSTMAN e ROGERS, 2011; p.6).

Atualmente, a economia compartilhada tem se tornado um estilo de vida, e sua prática tem aderido inúmeros seguidores a cada dia.

\footnotetext{
Hoje, existe um grau sem precedentes de interconectividade, assim como uma infraestrutura para participação. Nossa imersão em plataformas de informações inovadoras, comunicação e tecnologia (ICT), especificamente redes sociais online e dispositivos móveis portáteis, é o segundo fenômeno que nos leva a uma mentalidade de "nós". (BOTSMAN; ROGERS, 2016, p. 43).
}

Com essa ferramenta democrática e descentralizada, que é a internet, o desenvolvimento cultural se tornou cada vez mais célere e a formação de redes sociais potencializou essa capacidade. É certo que a ideia de se compartilhar sempre dependeu de uma rede de interações, no entanto, a rede atual do compartilhamento está redefinindo seu âmbito, seu significado e sua possibilidade, essa rede é a internet (BOTSMAN; ROGERS, 2016). 
Muitos acreditam que a economia de compartilhamento não passa de um capital de risco, ou seja, no momento econômico que vivenciamos, a iniciativa do capital de investimento proporcionou o crescimento desse fenômeno da economia compartilhada.

Para outros, a economia colaborativa apresenta-se como um presente econômico, fruto da evolução social e tecnológica. O que se pode afirmar é que este fenômeno agrega um pouco de cada visão.

Autores como Botsman e Rogers (2016) afirmam que a colaboração se tornou palavra de ordem de economistas, filósofos, comerciantes, empresários, analistas de negócios:

Quanto mais examinamos essas tendências, mais convencidos ficamos de que todos estes comportamentos, estas histórias pessoais, teorias sociais e exemplos de negócios apontam para uma onda socioeconômica emergente; os velhos C's estigmatizados, associados com o ato de juntar e "compartilhar" - cooperativas, bens coletivos e comunas - estão sendo renovados e transformados em formas atraentes e valiosas de colaboração e comunidade. Chamamos esta onda de consumo colaborativo. (BOTSMAN; ROGERS, 2016, p. 14).

Para Sundararajan (2016), não é de se estranhar que não achemos surpreendente a ideia de compartilhamento, haja vista que o fato de compartilhar a casa para uma hospedagem "be a

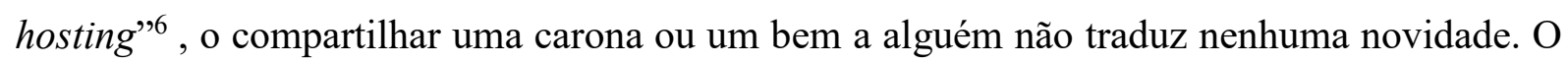
que de fato é novo e se demonstra ser o ponto chave da economia de compartilhamento é a sua questão econômica. As pessoas não deixaram de compartilhar, apenas agregaram um valor econômico a essa prática, o que corroborou no fenômeno que hoje chamamos de consumo colaborativo.

Se todas as atividades aparentemente "novas" fossem amplamente prevalentes no passado, por que há tanta empolgação? Bem, primeiro, essas novas formas de fazer coisas familiares estão sendo alimentadas por tecnologias que estendem sua "comunidade" econômica muito além da família ou amigos que vivem em seu bairro, a um subconjunto digital da população em geral: permitindo que nos envolvamos no que a socióloga Juliet Schor chama de "compartilhamento estranho" 7 . (SUNDARARAJAN, 2016, p.5).

Conceituar este fenômeno não tem sido uma tarefa fácil, segundo Schor (2014):

Chegar com uma definição sólida da economia de compartilhamento que reflete o uso comum é quase impossível. Existe uma grande diversidade entre as atividades, bem como os limites desconcertantes elaborado pelos participantes. ${ }^{8}$

$[\ldots]$

O termo "economia partilhada" é um termo relativamente novo não muito usado na literatura científica atual. A “economia comum" descreve um tipo de modelo de

\footnotetext{
6 Tradução livre: ser hospedeiro.

${ }^{7}$ Tradução livre: "If all of theses seemingly "new" activies were widely prevalent in the past, the why there so much excitement? Well, first, theses new ways of doing familiar things are being powered by technologies that extend your economic "community" far beyond family or friends who live in your neighborhood, to a digitally vetted subset of the population at large: allowing us to engage in what the sociologist Juliet Schor calls "stranger sharing".

${ }^{8}$. Tradução livre: "Coming up with a solid definition of the sharing economy that reflects common usage is nearly impossible. There is great diversity among activities as well as baffling boundaries drawn by participants."
} 
negócio que se baseia na partilha de recursos entre os indivíduos através de serviços de pessoa para pessoa - permitindo aos clientes acesso aos bens quando necessário. Enquanto o compartilhamento de bens sempre foi uma repetição mútua entre as pessoas que estão próximos uns dos outros (vizinhos, familiares e amigos), nos últimos anos o conceito de partilha progrediu de uma prática de comunidade em um modelo de negócio rentável. Esta crescente legitimidade reflete os fenômenos de redes pessoa para pessoa, o consumo colaborativo e economia de acesso. ${ }^{9}$ (SCHOR, 2014, p.2).

Da mesma forma, afirma Orsi (2013) que a economia compartilhada é difícil de se definir, em sua opinião, o fenômeno engloba uma ampla gama de atividades, incluindo cooperativas de trabalho, programas de partilha de carros de moradores, cooperativas habitacionais, hortas comunitárias, cooperativas de alimentos, e as cooperativas de energia renováveis, entre outras.

Na visão de Marco Bockman (2014):

O termo abrange uma gama extensa de plataformas digitais e atividades off-line, de empresas financeiramente bem-sucedidos como Airbnb, um serviço de acomodação pessoa por pessoa, a iniciativas menores, como coletivos de reparação e bibliotecas de ferramentas. Muitas organizações estão ansiosas para posicionar-se no âmbito da "grande tenda" da economia compartilhada por causa do significado simbólico positivo de partilha, o magnetismo das tecnologias digitais inovadoras, e o volume crescente de atividade de compartilhamento representa um fenômeno mais recente. Ela decorre da proliferação, como uma resposta funcional à evolução das necessidades da comunidade mundial, de sistemas regulatórios globais por sectores, por vezes, fornecidos com poderes de regulamentação e chamadas a adoptar medidas individuais, bem como dos organismos responsáveis pela resolução das controvérsias que possa surgir entre os reguladores globais e os destinatários da sua ação ${ }^{10}$

\section{Para Meyer:}

[...]A ideia de economia de compartilhamento não é novidade. O que distingue essas empresas inovadoras do passado é a sua capacidade de usar a Internet e os smartphones para conectar facilmente aqueles que querem algo com aqueles que têm algo a oferecer ${ }^{11}$. (MEYER, 2016, p.1).

\footnotetext{
9.Tradução livre: "The term "shared economy" is a relatively new term not used much in the current scientific literature. The "shared economy" describes a type of business model that builds on the sharing of resources between individuals through peer-2-peer services - allowing customers to access goods when needed. While sharing goods has always been a mutual repetition between people that are close to each other (neighbours, family and friends), in recent years the concept of sharing has progressed from a community practise into a profitable business model. This growing legitimacy reflects the phenomena of peer-2-peer networks, collaborative consumption and the access economy."

${ }^{10}$ Tradução livre: "The term covers a sprawling range of digital platforms and offline activities, from financially successful companies like Airbnb, a peer-to-peer lodging service, to smaller initiatives such as repair collectives and tool libraries. Many organizations have been eager to position themselves under the "big tent" of the sharing economy because of the positive symbolic meaning of sharing, the magnetism of innovative digital technologies, and the rapidly growing volume of sharing activity represents a more recent phenomenon. It stems from the proliferation, as a functional response to the changing needs of the world community, of global regulatory systems by sectors, sometimes provided with rulemaking powers and called to adopt individual measures, as well as of bodies responsible for the resolution of the controversies that may arise between the global regulators and the addressees of their action, or between the latter."

${ }^{11}$ Tradução livre: "The ideia of sharing economy is nothing new. What sets theses innovative companies apart from those of the past is their ability to use the Internet and smart phones to easily connect those who want something with those who have something to often."
} 
Botsman e Rogers (2011) afirmam que o consumo colaborativo não é mais uma tendência, mas, sim, uma realidade, apontando como fator de sua consolidação a crise econômica de 2008, de modo que colocar em uso aquilo que os economistas chamam de "capital morto" se tornou o ponto central da economia de compartilhamento.

A questão que diverge o "novo compartilhar" daquele praticado desde tempos remotos é o fato de que antes o problema era encontrar pessoas que oferecessem tais produtos e serviços. No entanto, essa barreira foi ultrapassada com a $W e b 2.0^{12}$ e a disseminação das redes sociais. Com a propagação da rede mundial de computadores, como se sabe, os conceitos de espaço e tempo foram modificados, a possibilidade de se localizar um bem ou serviço desejado se tornou uma questão de segundos no universo digital.

A formação e o desenvolvimento das redes sociais, apontada por Botsman e Rogers como o fato "mais inclusivo e perturbador em termos culturais do nosso tempo" foi o grande responsável, portanto, pela difusão da economia colaborativa.

[...] a Internet criava uma infraestrutura aberta automatizada sem limites para compartilhar, mas também um sistema de valores de querer fazer parte de algo maior do que os seres de consumo individuais. Projetos abertos e de colaboração apelavam para a necessidade de individualidade e autonomia de um participante e, ao mesmo tempo, forneciam um senso de pertencimento, de uma comunidade. (BOTSMAN; ROGERS, 2016, p.49).

Segundo os autores, o poder da coletividade e a constatação de sua eficiência, através de indivíduos mesmo dispersos fisicamente, mas conectados virtualmente, teve seu ponto decisivo na década de 2000, com casos de sucesso como o crowsourcing.

O crowdsourcing foi um conceito cunhado por Jeff Howe como "o ato de pegar uma tarefa tradicionalmente desempenhada por um agente designado (usualmente um funcionário) e terceirizá-la para um grupo indefinido, geralmente grande, de pessoas na forma de uma convocação aberta", tornou-se uma importante ideia de negócios. (BOTSMAN; ROGERS, 2016).

Trata-se, portanto, de uma colaboração massiva de indivíduos que não pertencem a uma entidade ou instituição, todavia, que em conjunto investem recursos em trabalho comum, ensejando uma modalidade aberta de trabalho conjunto.

Desse modo, partindo do princípio da colaboração, as pessoas juntas, realizam o que antes não poderiam fazer sozinhas.

\footnotetext{
${ }^{12}$ Web2.0 consubstancia-se num termo popularizado a partir dos anos 2000 para designar uma segunda geração de comunidades e serviços, tendo como conceito a "Web enquanto plataforma", envolvendo wikis, aplicativos baseados, redes sociais, blogs e Tecnologia da Informação.
} 
O que o sucesso do crowdsourcing mostrou foi que à medida que as pessoas deixam os comportamentos de consumo hiperindividualistas, que passam de uma "mentalidade eu" para uma "mentalidade nós", surge que passam de uma dinâmica de empoderamento. Especificamente, redes online reaproximam as pessoas, tornando-as mais dispostas a alavancar a velha regra empírica: os números têm poder. E os impactos do compartilhamento e da colaboração online não estão restritos ao mundo virtual. Eles estão vazando para o mundo off-line, criando mudança dentro dos nossos mundos culturais, econômicos, políticos e de consumo. (BOTSMAN; ROGERS, 2016, p.50).

A ideia de compartilhamento ganhou forças diante do cenário socioeconômico que passamos a vivenciar, e fatos como o surgimento de novas modalidades de negócio como o crowdsourcing representa essa mudança de visão econômica de um paradigma individual para um capital aberto, compartilhado.

Nesse cenário de transformações, a economia de compartilhamento se apresenta em diversas formas e novos modelos de negócios, formado por sistemas de colaboração, que merecem uma análise cuidadosa a fim de que possamos compreendê-lo dentro do nosso sistema normativo. É o que faremos no próximo item.

\section{Sistemas da economia de compartilhamento: mercados e estilos de vida colaborativos}

A colaboração no cerne do consumo colaborativo pode ser local e pessoal, ou usar-se a Internet para conectar, combinar, formar grupos e encontrar algo ou alguém a fim de criar interações entre partes do tipo "muitos para muitos".

Para Botsman e Rogers (2016), de maneira simples as pessoas estão novamente compartilhando com a comunidade, porém este fenômeno está acontecendo de uma forma e em uma escala que nunca se tinha visto ou imaginado anteriormente, culminando o que os autores chamam de "cultura do o que é meu é seu".

Ornellas (2012) apresenta o consumo colaborativo em três sistemas: 1) Sistema de produtos e serviços, 2) sistema de redistribuição de mercados, e 3) estilos de vida colaborativos: o sistema de produtos e serviços compreende um sistema de múltiplos produtos de uma companhia ou privados, que podem ser compartilhados ou alugados; já o sistema de redistribuição de mercados propicia a reutilização de itens antigos e que não mais estão em uso; e, por fim, o terceiro sistema consiste na interação de pessoas com interesses semelhantes e que desejam compartilhar seus conhecimentos, recursos, espaços, etc.

Botsman e Rogers (2016), também dividem a economia de compartilhamento em sistemas de consumo, classificados de maneira semelhante: Sistema de serviços de produtos (SSP), Mercados de distribuição, e Estilos de vida colaborativos. 
Com base no sistema de serviços de produtos, o usuário paga pela utilização de um produto sem a necessidade de adquiri-lo, trata-se, portanto, de um serviço que permite o acesso de vários tipos de produtos de propriedade de uma empresa, bem como abrange a disponibilização de produtos de propriedade privada que também são postos para compartilhamento entre pares, pessoas físicas. A essa relação atribui-se o nome peer to peer ${ }^{13}$ (P2P).

Um exemplo de SSP é a plataforma Netflix, que propicia o compartilhamento de filmes, sendo proprietária dos direitos sobre os títulos apresentados em catálogo para o usuário, que paga um valor mensal para ter acesso a uma infinidade de conteúdo cinematográfico e de mídias de entretenimento. Outro exemplo é o caso da Zipcar, plataforma de compartilhamento de automóveis. Esta é uma empresa que fornece o serviço de locação de carros por hora, sendo proprietária de uma frota variada de estilos e modelos, permitindo que o consumidor através de sua plataforma online escolha por quantas horas irá utilizar o veículo desejado.

Além desses, há um sistema de serviços de produtos que tem por finalidade o compartilhamento de brinquedos infantis. A plataforma DimDom, de origem francesa, propicia o aluguel de brinquedos através de assinaturas que permitem a troca constante do produto, pois são bens que perdem rapidamente seu uso em razão do célere e constante desinteresse da criança pelo brinquedo, assim, os pais podem realizar a troca deste sempre que não estiver sendo mais utilizado (BOTSMAN E ROGERS, 2016).

Percebe-se que no sistema de serviço de produtos, enxergamos na verdade uma transformação de um mercado de venda de produtos para um mercado de serviços. Ao invés de simplesmente vender o produto e a partir dali romper a ligação com o consumidor, as empresas estão mudando seus estilos de negócio para manter uma relação duradoura e constante com o cliente, oferecendo o mesmo produto, porém, assumindo os encargos de sua manutenção e propriedade, enquanto o consumidor desfruta eficientemente do bem.

Dentro desse sistema, Botsman e Rogers (2016) destacam ainda o chamado SSP de longa vida, um sistema que promove um "ciclo fechado" em torno do produto, ou seja, um sistema que compreende todo o processo de criação, produção, comercialização e descarte de um produto. Em um SSP de longa duração a empresa que fabrica e comercializa o produto se torna responsável além da manutenção do mesmo, pelo seu descarte. Após o esgotamento da utilização do produto, a empresa faz o recolhimento dele e oferece a devida destinação, aproveitando muitas vezes os materiais para reciclagem, reutilizando os insumos e promovendo

\footnotetext{
${ }^{13} \mathrm{O}$ termo peer que na língua inglesa significa "par" atribui uma ideia da relação peer-to-peer como uma relação entre pares, entre pessoas físicas, entre os próprios usuários do produto.
} 
um sistema mais limpo e verde, ecologicamente correto.

No modelo de hiperconsumo, a propriedade de um produto e a responsabilidade por ele são transferidas para o consumidor e para o ponto de venda, criando uma cultura de "uso e descarte" e bastante lixo. Com um SSP de longa vida, a responsabilidade da empresa não termina quando o produto é fabricado ou vendido - ela é responsável pelo ciclo de vida completo. (BOTSMAN E ROGERS, 2016, p. 99).

No que diz respeito ao sistema de mercados de redistribuição, esse é caracterizado pela redistribuição de mercadorias, podendo ser usadas ou não, cujos proprietários desejam passar a diante. Nesse caso, as mercadorias usadas serão redistribuídas deixando o local onde não mais serão úteis para servir a alguém. Esse sistema remove os encargos da propriedade, como manutenção, conserto e seguro, e permite o usuário aproveitar ao máximo o ativo adquirido.

São classificados como mercados de distribuição o craiglist, que funciona como uma lista de classificados online que coloca à disposição pessoas que tem algo a oferecer e ao mesmo tempo aquelas que buscam algo específico, propiciando a interação entre os interessados em realizar a troca. Outros exemplos conhecidos de mercado de redistribuição são o E-bay e Freecycle.

O E-bay, que inicialmente tinha como proposta promover a troca de produtos e serviços, hoje se apresenta como um mercado diversificado de espaços, assumindo a característica de mercado eletrônico (e-commerce). Por outro lado, o Freecycle é uma rede de troca de bens a nível local, que funciona via grupos de discussão, onde um potencial interessado subscreve em um grupo para a sua cidade, e depois envia e-mails com pedidos de objetos de seu interesse, ou ofertas de bens que não necessite mais. A entrega é combinada entre o doador e o receptor. Segundo o site do grupo, que se denomina como uma organização sem fins lucrativos: "Ser membro é grátis, e tudo o que é anunciado tem que ser grátis, legal e apropriado para todas as idades".

Na visão de Botsman e Rogers (2016), mesmo diversas vezes se tratando de propostas distintas, os modelos de mercado de distribuição trazem inúmeros benefícios para a sociedade, pois ao tornar acessível a troca de bens, promovendo a reutilização destes, o mercado propicia a extensão da vida útil dos bens, além de reduzir a acumulação e produção de lixo. Ademais, com facilitação da comercialização entre particulares e pequenos comerciantes, esses mercados favorecem a economia local, fazendo girar o capital, auxiliando os pequenos negócios a crescerem e se expandirem.

Independentemente das especificidades da troca, um mercado de redistribuição estimula a reutilização e a revenda de itens antigos, em vez de jogá-los fora, e também reduz significativamente o desperdício e os recursos que acompanham uma nova produção. (BOTSMAN; ROGERS, 2016, p. 62). 
Por fim, temos o sistema do estilo de vida. Nesse quesito, o compartilhamento ultrapassa os bens físicos compartidos. Aqui as pessoas com interesses comuns buscam dividir bens intangíveis, como o tempo, espaço, habilidades, dinheiro etc. Dentro desse sistema, encontramos o Zopa, grande site inglês que promove o compartilhamento de empréstimos pessoais. Sobre ele, Botsman e Rogers (2016) explicam se tratar de uma rede de credores e tomadores de empréstimo, onde as pessoas com dinheiro sobrando o emprestam a pessoas que queiram tomar emprestado, ao invés de investi-lo, eliminando a função de intermediário do banco.

Existe o Kickstarter, que promove o compartilhamento de recursos para promoção de ideias inovadoras: a proposta aqui é lançar a ideia de projeto e outras pessoas interessadas investirem nela, falando-se, portanto, em um financiamento coletivo de ideias.

O famoso Airbnb, compartilhador de hospedagens, promove uma experiência diferenciada ao inserir o hóspede em contato direto com a vida cotidiana dos residentes, proporcionando uma maior interação e imersão social, e ao mesmo tempo garante uma maior economia para o usuário em relação aos altos custos de uma hospedagem tradicional.

Nesse último sistema, se faz necessário haver um elevado grau de confiança, haja vista que o foco é a troca de interação entre as partes.

Ao longo dos sistemas de serviços de produtos, dos mercados de redistribuição e dos estilos de vida colaborativos, a motivação poderá variar da economia de dinheiro ao ato de ganhar dinheiro, da conveniência a conhecer amigos, de economizar espaço a economizar tempo, de se sentir parte de uma comunidade a "fazer a coisa certa". A sustentabilidade, em geral, é uma consequência não intencional do consumo colaborativo. (BOTSMAN; ROGERS, 2016, p. 62).

Ainda, na visão dos autores, o consumo colaborativo se baseia em quatro princípios: a) massa crítica, b) capacidade ociosa, c) crença no bem comum e d) confiança no entre desconhecidos.

A massa crítica para os autores configura-se em um impulso satisfatório para tornarse um sistema sustentável, logo, faz-se necessário a existência de mercadorias suficientes para atender os demasiados gostos de todos que participam de um sistema colaborativo, assim, atendendo a demanda o sistema consegue se consolidar atraindo ainda mais consumidores.

No que diz respeito à capacidade ociosa, os autores apresentam a importância do saber se o objeto que se irá colocar em disposição pode ser utilizado, haja vista que o elemento central do sistema colaborativo é a troca, o oferecimento de um bem ou serviço que teoricamente encontra-se ocioso. Para tanto, é imprescindível que aquele bem que será colocado à disposição detenha também um tempo de vida útil aproveitável. 
Já o princípio do bem comum refere-se a mudança do pensamento romano da res publica para a ideia da propriedade privada, o que segundo os autores, com o advento da tecnologia e mídias digitais, vem tomando novos significados, o que reforça valores da comunidade e promovem o encontro de pessoas com interesses em comum.

O princípio da confiança, um dos mais latentes, é apresentado por Andrade e Pinto (2014) como um dos elementos centrais do consumo colaborativo, destaca-se, pois, a relação formada através dessa interação é uma relação baseada no grau de confiança entre duas pessoas.

Nessa relação é possível se inserir em dois polos distintos:

Também existem duas maneiras de participar do consumo colaborativo, sendo que cada uma delas tem um apelo diferente para pessoas diferentes. Você pode desempenhar o papel de "par provedor", ao fornecer bens para alugar, compartilhar ou tomar emprestado; ou desempenhar o papel de "par usuário", ao consumir os produtos e serviços disponíveis. Alguns participantes escolherão fazer as duas coisas, mas outros talvez se sentirão confortáveis em uma única ponta do espectro. (BOTSMAN; ROGERS, 2016, p. 60).

Girando em torno de todos esses sistemas de compartilhamento, deparamo-nos com as plataformas, que, para Chase (2015) são responsáveis pela disponibilização da capacidade excedente por meio de três maneiras: decompondo, agregando e abrindo a capacidade excedente.

Com a ideia de decomposição e agregação, temos a possibilidade de utilização do bem de maneira mais eficiente. Ao decompor a capacidade excedente, a plataforma abarca um grande e volumoso ativo e o transforma em pequenas fatias e incrementos, disponibilizando o seu uso pormenorizado de forma a torná-lo mais aproveitável. Um exemplo de plataforma de decomposição é a Zipcar, uma vez que ao possuir um carro, que passa muitas horas do dia ocioso, ela quebra essa ociosidade oferecendo a sua utilização por frações de tempo, de maneira a se tornar aproveitável o tempo suficiente para cada cliente utilizando-se do mesmo produto reiteradas vezes.

Diferente da decomposição, que traz uma ideia de divisão da ociosidade do produto por meio de uma plataforma, as plataformas de agregação reúnem a ociosidade de vários bens, de maneira que a capacidade excedente de vários ativos que individualmente era pequena demais transforma-se em algo grande, confiável e uniforme (CHASE, 2015).

O Airbnb é um caso de plataforma de agregação, quando ao permitir que pessoas aluguem uma propriedade ou parte dela (quartos ociosos), ela promove a reunião de várias "capacidades excedentes” em um único espaço. Dessa forma, simplifica e torna mais fácil o acesso a esses bens, agregando um valor de confiança ao usuário. 
Ambos os casos de plataformas de decomposição e agregação possibilitam o usuário obter mais valor de um ativo utilizando-o de forma mais prática e barata do que seria possível anteriormente.

Quando Chase (2015) fala sobre a plataforma de abertura, refere-se as plataformas que favorecem a criação de novos valores, abrindo a capacidade excedente à criatividade e inovação. Para exemplificar esse sistema, a autora faz alusão ao uso de dados pagos e coletados pelo poder público, que sendo postos à disposição da sociedade, são capazes de promover a criação de novas plataformas voltadas para o benefício da própria comunidade. Destarte, foi o caso do GPS (sistema de posicionamento por satélite), financiado pelo governo norte-americano que hoje é utilizado por diversas plataformas para facilitar seus negócios e transações, bem como para auxiliar diversas pessoas em deslocamento diário, transmitindo informações sobre tráfico local, como o caso do aplicativo $\mathrm{Waze}^{14}$.

No fim das contas, o propósito de uma plataforma é liberar o valor escondido na capacidade excedente mobilizando os ativos, o tempo, o conhecimento e a criatividade dos outros. Utilizar-se da capacidade excedente é um ato fundamentalmente colaborativo. É compartilhar. (CHASE, 2015, p. 48).

Diante de tamanha grandeza de possibilidades, modelos e interações que a economia de compartilhamento proporciona, encontramos inúmeros novos fatores que juridicamente não descobrem uma solução concreta para eventuais problemas decorrentes dessas novas relações. Temos acompanhando a constante inovação de conceitos e valores atribuídos as novas relações jurídicas, e precisamos analisá-las sobre seu aspecto e enquadramento no ordenamento legal.

Os primeiros indícios da economia de compartilhamento remota o fim do séc. XX. Conforme descrito nos capítulos anteriores, esse novo modo de compartilhar, fruto da Era informacional, da Web 2.0, ocasionou mudanças relevantes nas relações sociais e econômicas.

Não se pode afirmar que a economia de compartilhamento veio para substituir definitivamente o mercado tradicional e as relações clássicas de consumo, todavia, é notório que esse fenômeno trouxe impactos que merecem atenção.

Com tantos avanços tecnológicos e diariamente novas modalidades de relações e interações pessoais vão surgindo, o Estado não consegue acompanhar o desenvolvimento de tantos fenômenos.

Nesse sentido, Schwab bem expressa esse descompasso entre legislação e fenômenos sociais:

\footnotetext{
${ }^{14}$ Aplicação para smartphones ou dispositivos móveis baseados na navegação por satélite, contém informações de usuários e detalhes sobre rotas, dependendo da localização do dispositivo portátil na rede mundial de computadores.
} 
Primeiro, acredito que os níveis exigidos de liderança e compreensão sobre as mudanças em curso, em todos os setores, são baixos, quando contrastados com a necessidade, em resposta à quarta revolução industrial, de repensar nossos sistemas econômicos, sociais e políticos. O resultado disso é que, nacional e globalmente, o quadro institucional necessário para governar a difusão das inovações e atenuar as rupturas é, na melhor das hipóteses, inadequado, e na pior, totalmente ausente. (SCHWAB, 2016, p.17).

À medida que o tempo passa, os avanços tecnológicos, as plataformas e o Peers Inc crescem em escala exponencial. Percebemos como um dos resultados desse rápido crescimento e expansão um efeito de concentração, como bem explana Roxane Googin citada por Robin Chase:

\begin{abstract}
O efeito de concentração é extremo. Não é fácil criar e desenvolver o mecanismo de processamento centralizado [o que a Peers Inc chama de plataforma], mas, uma vez que estiver funcionando, a próxima transação sai efetivamente de graça. Com isso, o mecanismo sai devorando todas as operações menores e menos eficientes por ser ao mesmo tempo mais barato e mais eficaz. Os lucros de todas as empresas falidas, bem como a diferença de eficiência entre o negócio manual e o automatizado, revertem para o centro. (GOOGIN apud CHASE, 2015, p. 210).
\end{abstract}

Nesse sentido notamos que a tendência é que as Peers Inc que primeiro se lançaram no mercado, com o sucesso de sua implementação, tenderão a monopolizar o serviço, pois segundo Chase (2015, p. 211): "todo mundo quer usar o serviço de locação de quartos para estadias curtas com a mais ampla gama possível de quartos anunciados ou participar de uma rede social na qual a maioria dos nossos amigos está. Os vencedores continuam vencendo e tendem a deter o poder monopolista.”.

Além de gerar um tipo de poder monopolista, que tende a expandir-se cada vez mais e absorver os mercados tradicionais, e causar impactos na concorrência, esse fenômeno acarreta inúmeras outras reflexões, que a curto e longo prazo geram consequências sociais importantes, destacando-se claramente a questão da relação de emprego, direitos e benefícios trabalhistas. Surgem questionamentos acerca dessa nova relação Peers Inc, a qual não há um vínculo trabalhista, mas, sim, um indivíduo que voluntariamente dispõe da sua capacidade ociosa em prol de uma atividade que para ele conjuga benefícios tanto econômicos quanto pessoais.

Cada vez mais pessoas estão migrando da relação de emprego estável para o mundo inovador e eficiente da economia de compartilhamento, devido a múltiplos fatores, dentre eles, destaca Chase (2015): a flexibilidade de horários, a autonomia em relação ao tempo dedicado ao trabalho, localização, quantidade e tipo de trabalho. Portanto, são fatores que culminam no benefício da qualidade de vida do trabalhador.

Além desse fator da relação de trabalho, destacamos também o posicionamento dos usuários desses sistemas de compartilhamento, que tipo de relação é configurada? Quais garantias existem para ambos os polos dessas relações? 
Em razão destas novas relações consequentes da economia de compartilhamento, diante de tantos novos modelos de negócios que vem crescendo no cenário global, importante se faz a análise da natureza jurídica dessas relações, questionando-se o papel do Estado na regulação dessas atividades para fins de garantir a segurança e proteção dos usuários nesse cenário multifacetado da economia colaborativa. Questionamento esse merecedor de futuros debates, estudos e pesquisas aprofundadas.

\section{Conclusão}

A nossa sociedade já passou por diversas transformações ao longo da história e inúmeros elementos foram responsáveis pelo rompimento de paradigmas. Após a difusão da rede mundial de computadores e sua rápida e ainda crescente popularização, as pessoas desenvolveram dessa ferramenta tecnológica novos valores e estilos de vidas.

O surgimento das redes sociais é hoje um forte exemplo de como a internet foi uma ferramenta que revolucionou a sociedade. Encontramos nas redes sociais uma nova forma de socializar, compartilhar histórias, vivências e experiências. Esse instrumento se tornou tão popular e importante na vida das pessoas que elas passaram a agregar um amplo valor, transcendendo o mero caráter social, a fim de acrescentar também um poderoso valor econômico.

Nesse sentido, seguindo a tendência da virtualização, do compartilhamento, proporcionado e facilitado pelas redes sociais através da internet, acrescido de outros fatores econômicos, desenvolveu-se o que chamamos de economia de compartilhamento, que sobre os efeitos da globalização, trouxe inúmeros impactos sociais, econômicos e culturais, ocasionando uma série de mudanças nas relações interpessoais e comerciais.

Ficou claro que o surgimento e desenvolvimento da economia de compartilhamento foi ocasionado pela reunião de vários fatores, dentre eles pudemos destacar uma base tríplice de condutores da economia colaborativa, tratando-se dos fatores sociais, econômicos e tecnológicos. Dentre os fatores sociais condutores da economia compartilhada, evidenciamos o aumento da densidade populacional, que ocasionalmente gerou um aumento da oferta e da procura, tornando mais simples a criação de uma correspondência na ideia de troca e compartilhamento, agregada ao fator da crescente expansão da comunicação e interação através das redes sociais.

Do ponto de vista econômico, percebemos como principais fatores: a constatação da rentabilização da chamada capacidade excedente, gerando um aproveitamento dos recursos 
ociosos; o aumento da flexibilidade financeira decorrente da crescente globalização econômica; e a possibilidade do acesso pela posse, aproveitando-se os mercados para oportunizar novos modelos baseados no compartilhamento como alternativas mais viáveis e econômicas para o consumo.

Nesse aspecto, por fim, analisamos as conduções tecnológicas representadas pelas redes sociais, que ajudaram a facilitar as transações e por meio da ascensão dos smartphones promoveu-se a difusão das plataformas e a acessibilidade a sistemas de comércio eletrônico.

Foi possível destacar, dentro do estudo acerca da economia colaborativa que este fenômeno, apesar de não se apresentar como algo essencialmente novo, visto que a sociedade já conhecia a muito tempo a ideia de compartilhamento de recursos, acarretou em novos mercados, formas de negócio e estilos de vida. Diante de suas consequências, chegamos à conclusão que o fenômeno merece maiores estudos haja vista que o fato de nos depararmos com novos modelos econômicos impõe ao Estado a responsabilidade perante a sociedade, posto que sua função reguladora comina como ferramenta essencial na proteção do cidadão.

\section{Referências bibliográficas}

ANDRADE, H. G. C.; PINTO, M. de R.? O que é meu é seu?!?? Pode-se aproximar os debates entre consumo colaborativo e inovação social?. Perspectivas Contemporâneas, v. 12, p. 191-210, 2017.

BOCKMANN, Marco. The Shared Economy: it is time to start caring about sharing; value creating factors in the shared economy. The Netherlands, 2014. Disponível em: $<$ http://thelovettcenter.com/wp-content/uploads/2014/11/bockmann-shared-economy.pdf $>$. Acesso em: 11 mar. 2016.

BOTSMAN, Rachel; ROGERS, Roo. O Que é meu é seu: como o consumo colaborativo vai mudar o nosso mundo. Porto Alegre: Bookman, 2011.

CHASEN, Robin. Economia compartilhada: como as pessoas e as plataformas estão inventando a economia colaborativa e reinventando o capitalismo. Tradução de Cristina Yamagami - São Paulo: HSM do Brasil, 2015.

FREITAS, Ana. A economia do compartilhamento. Revista Galileu, Rio de Janeiro, Ed. 
Globo S/A, 2013. Disponível em: <http://revistagalileu.globo.com/

Revista/Common/0,EMI33948317770,00A+ECONOMIA+DO+COMPARTILHAMENTO.ht ml>. Acesso em: 11 mar. 2016.

MEYER, Jared. Uber-positive: why Americans love the sharing economy. New YorkEncounter Books, 2016.

\section{MILLER, Stephen R. First Principles for Regulating the Sharing Economy. SSRN}

Eletronic Journal, fev. 2015. Disponível em: <http://papers.ssrn.com/abstract=2568016>. Acesso em: 10 jun. 2016.

ORNELLAS, R.S.O Consumo Colaborativo de Transporte Individual Car Sharing e o Processo Decisório do Consumidor na Cidade de São Paulo. São Paulo, 2012, 151 f. Dissertação (Mestrado em Ciências) - Universidade de São Paulo; São Paulo.

ORSI, Janelle. The Sharing Economy Just Got Real. Shareable. Setembro 2013. Disponível em $<$ http://www.shareable.net/blog/the-sharing-economy-just-got-real $>$. Acesso em: 15 set. 2017.

RABIN, Alberto. A era do acesso: comunidades virtuais, tudo isto é "ser humano". PPGCOM - Programa de Pós-Graduação em Comunicação. Universidade Federal de Pernambuco (UFPE). Revista Contemporânea, 2004. Disponível em:

$<$ http://www.contemporanea.uerj.br/pdf/ed_03/contemporanea_n03_16_rabin.pdf $>$. Acesso em: 10 out. 2017.

RIFKIN, Jeremy. The rise of the sharing economy. Los Angeles Time, abr. 2014. Disponível em: <htpp://www.latimes.com/opinion/op-ed/la-oe-rifkin-airbnb-20140406story.html>. Acesso: 15 set. 2017.

ROOSE, Kevin. The Sharing Economy Isn't About Trust, It's About Desperation. Nova Iorque, 24 abr. 2014. Disponível em: <http://nymag.com/daily/intelligencer/2014/04/sharingeconomy-is-about-desperation.html>. Acesso em: 22 mar. 2016. 
SCHOR, Juliet. Debating the Sharing Economy. Great Transition Initiative, October, 2014.

Disponível em: <http://www.greattransition.org/publication/debating-the-sharing-economy.\#s thash.z6dBv0VY.dpuf>. Acesso em: 13 mar. 2016.

SCHWAB, Klaus. A quarta revolução industrial. Tradução Daniel Moreira Miranda - São Paulo: Edipro, 2016.

SUNDARARAJAN, Arun. Peer-to-Peer Businesses and the Sharing (Collaborative)

Economy: Overview, Economic Effects and Regulatory Issues. Jan 2014. Disponível em:

$<$ http://smallbusiness.house.gov/uploadedfiles/1-15-2014_revised_sundararajan_testimony.pd f>. Acesso em: 13 mar. 2016.

The sharing economy: the end of employment and the rise os crowd-based capitalism. Cambridge, MA - The MIT Press, 2016. 


\title{
O PAPEL DA EMPRESA NO DESENVOLVIMENTO SUSTENTÁVEL: DA FUNÇÃO SOCIAL DA EMPRESA AOS VALORES SOCIAIS PARA O MERCADO E A SOCIEDADE
}

\author{
Emília Paranhos Santos Marcelino \\ Universidade Federal de Campina Grande
}

Hertha Urquiza Baracho

Universidade Federal da Paraíba

\begin{abstract}
Resumo
O presente artigo tem como objetivo analisar a relação entre o papel da empresa e o desenvolvimento sustentável. A necessidade de estudo deste trabalho surgiu com o estabelecimento da função social das empresas e o advento de uma nova ordem econômica mais voltada para as questões sociais. Diante da importância do segmento empresarial, analisamos a função social e os valores da empresa para o desenvolvimento sustentável. A metodologia a ser utilizada será a pesquisa bibliográfica, através da conceituação de elementos relevantes para a análise da pesquisa realizada no contexto do ordenamento jurídico brasileiro.
\end{abstract}

Palavras-chave: Função Social, Responsabilidade Social, Desenvolvimento Sustentável.

\begin{abstract}
Resumen/Résumé
This article aims to analyze the relationship between the role of business and sustainable development. The need to study this work came with the establishment of the social function of companies and the advent of a new economic order more geared to social issues. Given the importance of the business segment, we analyze the social function and the company values for sustainable development. The methodology to be used will be the literature through the concept of evidence relevant to the analysis of the survey in the context of the Brazilian legal system .
\end{abstract}

Keywords/Palabras-claves/Mots-clés: Social Function, Social Responsibility, Sustainable Development. 


\section{Introdução}

Em meio ao desenvolvimento das ciências jurídicas, nasce para o direito a oportunidade de voltar-se cada vez mais para as questões sociais e econômicas, abandonando a esfera do estritamente legal. Neste cenário de transformações do pensar jurídico, onde há uma valorização pela humanização das relações privadas, é notório no campo do direito econômico, no que se refere à empresa, o seu novo papel na sociedade e no mundo jurídico, com a adoção da função social.

Assim, a função social das empresas, seria o desempenho das atividades empresarias de forma que proporcionassem benefícios à sociedade. Assim uma empresa estaria cumprindo a sua função social quando ela estivesse alinhando os seus interesses com os da sociedade. Os principais benefícios e contribuições para o mercado nacional, que podemos apontar em relação ao cumprimento da função social das empresas são; a geração de empregos, a geração de renda, a geração de tecnologia, o fornecimento de produtos e serviços, o pagamento de impostos, entre outros.

O não cumprimento da sua função social por parte da empresa acarreta prejuízos para a sociedade e para a economia do país. Pois o desenvolvimento da atividade econômica se dá com a geração de empregos, o fomento da sociedade e garante existência digna às pessoas. Configurando-se assim, o papel da empresa na sociedade e no mercado.

A Constituição Federal de 1988, em seu art.170, traz a função social da propriedade privada, como um dos princípios a serem adotados, quando observada à questão da ordem econômica nacional. Tal diretriz deve ser estendida, sem ressalvas a questão da atividade empresarial. Até mesmo por motivos de manutenção da ordem econômica, a função social das empresas é, hoje, motivo de muitos aplausos no ambiente jurídico pela adoção deste princípio, para esta esfera, pois outrora estava voltada unicamente à obtenção de lucros e às atividades puramente econômicas, tendo hoje como obrigação rever suas consequências sociais.

Atualmente, a função social da empresa aparece como um princípio norteador das relações de mercado, que busca não apenas exaltar valores objetivos da empresa em sua atuação no mercado, mas também a sua valorização enquanto organismo de grande impacto social e econômico. Inserida na carta maior, ou seja, na Constituição Federal de 1988, no art.170, a função social da propriedade privada é um princípio que refletiu fortemente na área empresarial, econômica e social.

Diante disto, questiona-se: qual o papel que a empresa desempenha no desenvolvimento sustentável? 
Assim, a abordagem ao tema escolhido é de grande importância para a sociedade e para a economia, em geral, pois iremos tratar da atuação das empresas no ambiente econômico e social em razão do cumprimento da função social das empresas, no desenvolvimento sustentável.

Trata-se de pesquisa bibliográfica, uma vez que se deseja estudar o papel da empresa no desenvolvimento sustentável, com foco nas relações sociais e econômicas, e no cumprimento da função social por parte das empresas. Tudo sob a égide da melhor literatura teórica disponível e pesquisa documental, em livros, artigos e periódicos.

\section{O Conceito de Empresa}

O conceito de empresa está relacionado ao de empresário e à utilização da propriedade dos bens de produção. O Código Civil de 2002, em seu art.966, conceitua empresário como aquele que exerce profissionalmente atividade econômica organizada para a produção ou circulação de bens ou de serviços. Entretanto, a dinâmica desta atividade é muito mais complexa nas suas práticas diárias, envolvendo outros elementos que serão explicados mais adiante, para conceituar a empresa.

Partindo do entendimento de que o empresário ${ }^{1}$ é o proprietário dos bens de produção, entende-se que a empresa é uma atividade econômica organizada e tem como objetivo produzir bens ou serviços para a sociedade. Neste sentido a empresa passa a existir quando existe o empresário e a execução da atividade por meio da organização de bens e pessoas.

A organização dos fatores de produção pelo empresário é a empresa. A empresa é considerada um dos principais elementos para o desenvolvimento da economia de um País. Caracteriza-se pelo exercício de atividade econômica gerando empregos, renda e produzindo bens e serviços que serão inseridos no mercado, e consumidos pela sociedade.

O tripé empresarial é formado por: bens, pessoas e atividade. Explicando cada um desses elementos verifica-se que as pessoas exercem a atividade econômica, por meio da utilização de sua mão de obra, ou seja, com seu trabalho; a atividade são os atos exercidos com

\footnotetext{
${ }^{1} \mathrm{O}$ conceito de empresário adotado por Rubens Requião relaciona o empresário com a organização das atividades de produção (2009, p. 59) "O empresário, assim, organiza a sua atividade, coordenando os seus bens (capital) com o trabalho aliciado de outrem. Eis a organização. Essa organização, em si, o que é? Constitui apenas um complexo de bens e um conjunto de pessoal inativo. Esses elementos - bens e pessoal - não se juntam por si; é necessário que sobre eles, devidamente organizados, atue o empresário, dinamizando a organização, imprimindo-lhe atividade que levará a produção. Tanto o capital do empresário como o pessoal que irá trabalhar nada mais são isoladamente do que bens e pessoas. A empresa somente nasce quando se inicia a atividade sob orientação do empresário."
} 
a finalidade de produzir e comercializar bens ou serviços; e os bens ou serviços referem-se ao exercício da atividade empresarial.

A empresa necessita da organização dos fatores de produção - terra, trabalho e capital. A terra é um fator representado pela matéria prima de que toda empresa necessita para produzir bens ou serviços, o trabalho é a utilização da mão de obra dos trabalhadores e o capital o valor monetário de que a empresa precisa para se estabelecer e desenvolver as suas atividades.

Neste sentido podemos dizer que a empresa é o conjunto composto por trabalhadores (mão de obra), matéria prima, maquinário, espaço físico, processo de produção ou escala de serviço, circulação de bens ou serviços. ${ }^{2}$ A empresa é fonte geradora de emprego, renda, produtos ou serviços e tributos. A empresa é a atividade caracterizada pela busca do lucro através do fornecimento ao mercado de bens e serviços, provenientes da organização dos fatores de produção.

A figura do empresário encontra-se diretamente relacionada à empresa. Distingue-se então o empresário daquele que exerce ocasionalmente atos negociais. O empresário é aquele que exerce profissionalmente atividades comerciais, com o intuito de lucro. Dessa forma a empresa $^{3}$ se caracteriza como sendo um local onde o empresário exerce atos negociais de forma ordenada e habitual com fins lucrativos.

Quando uma organização estruturada produz bens ou presta serviços estamos diante de uma organização empresarial, ou seja, uma empresa. O desenvolvimento de atividades econômicas, a existência de uma estrutura humana e de bens necessários à produção e o objetivo de gerar lucro, o intuito empresarial, caracterizam a empresa. A empresa é uma estrutura organizada com o objetivo de produzir e fazer circular no mercado bens e serviços de interesse da população ${ }^{4}$.

A empresa pode ser conceituada de diversas formas e visões diferentes. Adotando uma visão de mercado, a empresa pode ser vista como uma organização puramente econômica, que

\footnotetext{
${ }^{2}$ Os elementos listados representam os fatores de produção, que podem ser também relacionados como força de trabalho, matéria prima, capital e tecnologia empregada para a produção, que são organizados pelo empresário.

${ }^{3}$ Associa-se ao conceito de empresa a noção de investimento de capital e obtenção de lucros, configura-se assim "A empresa é a organização de meios materiais e imateriais, incluindo pessoas e procedimentos, para a consecução de determinado objeto (o objeto social), com a finalidade genérica de produzir vantagens econômicas que sejam apropriáveis por seus titulares, ou seja, lucro que remunere aqueles que investiram na formação do seu capital empresarial (que será chamado de capital social, sempre que à empresa corresponda uma sociedade empresária)." (MAMEDE, 2007, p.32)

${ }^{4}$ Ao falar em interesse da população remete-se aos bens econômicos, que são aqueles que se apresentam como "o bem econômico é aquele útil e escasso" para a população. O bem produzido pela empresa deverá ter utilidade para o consumidor, assim, deverá ter a capacidade de suprir ou atender a necessidade. Fábio Nusdeo (2015, p. 29-33) relaciona alguns exemplos para explicar e conceituar os termos; necessidade, satisfação, escassez, entre outros relacionados ao mercado.
} 
gera bens ou serviços, lucro, renda e contribui para o desenvolvimento do mercado. Já abordando uma visão social, a empresa pode ser vista também como uma organização que gera empregos, ocupação da mão de obra ativa do País, que interage com a sociedade, buscando suprir as necessidades desta além de se relacionar com o ambiente interno e externo (funcionários, fornecedores, consumidores e sociedade em geral).

A partir dos elementos conceituais acima listados, a empresa é a proprietária dos bens de produção, responsável pela produção e circulação dos bens e serviços e pela geração de emprego e renda na sociedade, ${ }^{5}$ tendo como objetivo central a busca do lucro. Logo, surge uma nova preocupação: a de explorar a propriedade dos bens de produção com uma destinação social, buscando preservar e beneficiar a sociedade.

\section{A Função Social da Empresa}

Como visto anteriormente no conceito de empresa, um dos elementos que compõem a empresa é a propriedade dos bens de produção, necessários ao desenvolvimento das atividades empresariais. Neste sentido, a propriedade dos bens de produção é a propriedade privada assegurada pelo princípio da ordem econômica. Relaciona-se assim o princípio da função social da propriedade com a função social dos bens de produção e da empresa como a detentora desses bens.

Os bens de produção, pois, ${ }^{6}$ são aqueles bens adquiridos pelas empresas e destinados à produção de mercadorias ou serviços que são colocados à disposição da sociedade no mercado. Estes são utilizados pela empresa e devem cumprir a função social da propriedade. Não podemos esquecer os trabalhadores, fornecedores e o mercado consumidor que assim como os bens de produção compõem a empresa e são necessários para o cumprimento da função social.

\footnotetext{
${ }^{5}$ Questiona-se como a empresa irá atuar para que possa promover também o desenvolvimento social, e não apenas o econômico. "Sabe-se que a empresa não tem por finalidade única e exclusivamente a geração de lucros para seus sócios. Ela é uma expressão social, econômica e financeira, que gera renda capaz de influenciar a comunidade na qual se encontra inserida. Isso porque o Estado Democrático de Direito abriu espaços para a livre iniciativa de participar de maneira direta na circulação e produção de bens e serviços, objetivando um maior desenvolvimento social.” (BARACHO e JATOBÁ, 2015, p. 52)

${ }^{6}$ Fabio Konder Comparato (1995, p. 29) realiza a distinção dos bens de produção e dos bens de consumo; "Os bens de produção são móveis ou imóveis, indiferentemente. Não somente a terra, mas também o dinheiro, sob a forma de moeda ou de crédito, podem ser empregados como capital produtivo. De igual modo os bens destinados ao mercado, isto é, as mercadorias, pois a atividade produtiva é reconhecida, na análise econômica, não pela criação de coisas materiais, mas pela criação de valor. Mas as mercadorias somente se consideram bens de produção enquanto englobadas na universidade do fundo de comércio; uma vez destacadas dele, ao final do ciclo distributivo, ou elas se incorporam a uma atividade industrial, tornando-se insumos de produção, ou passam à categoria de bens de consumo."
} 
A função social da propriedade dos bens de produção é de grande importância, pois tem como objetivo conscientizar as empresas de como e quanto produzir, para que não ocorra falta ou excesso de produtos ${ }^{7}$ no mercado. As empresas precisam atender à função social dos bens de produção, dando a destinação que atenda os interesses da sociedade, das empresas e da economia. ${ }^{8}$ A função social dos bens de produção dá origem à função social da empresa.

O desenvolvimento econômico e a livre iniciativa empresarial devem estar de acordo com os princípios norteadores da ordem econômica. A empresa deverá atender à destinação social, estabelecida na Constituição Federal de 1988. Cria-se um novo papel para as empresas no mercado, ou seja, a função social da empresa, que está relacionada à geração de emprego, ao desenvolvimento social e econômico, à preservação do meio ambiente e à geração de tecnologia.

Para que a empresa desenvolva sua função social, precisará cumprir os princípios constitucionais da ordem econômica ${ }^{9}$, observando os fundamentos da valorização do trabalho humano e da livre iniciativa, assegurando a justiça social e a existência digna. A propriedade empresarial assume uma nova postura diante da sociedade, adotando a função social. Desta forma as empresas deverão condicionar a utilização dos bens de produção não apenas aos fins econômicos individuais, mas também a fins sociais e econômicos, por meio da distribuição com aqueles que contribuem através do trabalho.

Antes da Constituição Federal de 1988 a Lei das Sociedades Anônimas (Lei n ${ }^{\circ}$ 6.404/76) já trazia as primeiras ideias sobre a função social da empresa. O texto da lei em seu art.116, parágrafo único, estabelece os deveres do acionista controlador da as que: “deve usar o poder com o fim de fazer a companhia realizar o seu objeto e cumprir sua função social, e tem

\footnotetext{
${ }^{7}$ A oferta de produtos no mercado pode ocorrer de duas formas: a falta de produtos ou o excesso. A falta de produtos no mercado, a escassez, gera prejuízos à sociedade que passa a pagar um preço mais alto para adquirir aquele produto tendo em vista o elevado preço praticado pelas empresas produtoras. $\mathrm{O}$ excesso de produtos ocasiona prejuízos para as empresas, que muitas vezes não conseguem vender seus produtos e ficam no prejuízo dos gastos que tiveram com sua produção, bem como para a sociedade que passa a consumir mais com a queda dos preços, muitas vezes produtos de qualidade inferior, e para a economia que sofre os abalos do grande número de ofertas, que muitas vezes não possui procura suficiente e acaba acarretando a falência de muitas empresas, que deixam de gerar emprego, renda e pagamento de impostos.

${ }^{8}$ Relacionando o interesse coletivo com a função social da propriedade dos bens de produção, Fabio Konder Comparato (1995, p. 24) estabelece que; “(...) a função social da propriedade não se confunde com as restrições legais ao uso e gozo dos bens próprios; em se tratando de bens de produção, o poder-dever do proprietário de dar à coisa uma destinação compatível com o interesse da coletividade transmuda-se, quando tais bens são incorporados a uma exploração empresarial, em poder-dever do titular do controle de dirigir a empresa para a realização dos interesses coletivos."

${ }^{9}$ O conceito de Função Social da Empresa relacionado com a Ordem Econômica é apresentado por Eduardo Tomasevicius Filho (2003, p. 42) "A Ordem Econômica brasileira está assentada sob dois pilares: o trabalho e o capital. Através deste é possível o exercício da livre iniciativa, que consiste na liberdade de exercício de atividade econômica. Essa liberdade de empresa não é absoluta. Sua razão de ser é assegurar a todos os indivíduos uma existência digna, conforme os ditames da justiça social e o exercício desta liberdade deve necessariamente atender a uma função social."
} 
deveres e responsabilidades para com os demais acionistas da empresa, os que nela trabalham e para com a comunidade em que atua, cujos direitos e interesses deve lealmente respeitar e atender.” (BRASIL, 1976, grifo nosso)

O conceito de função social trazido pelo texto da Lei das sociedades anônimas (Lei ${ }^{\circ}$ 6.404/76) refere-se ao cumprimento dos deveres e responsabilidades que a empresa possui perante a comunidade e os seus funcionários, buscando sempre atender o interesse de toda a sociedade. Neste sentido, as empresas deverão adotar boas práticas empresariais ${ }^{10}$ nas suas relações com o ambiente interno e externo, buscando agregar valor sem causar prejuízos a sociedade.

A empresa deverá equilibrar ${ }^{11}$ a busca pelo lucro com o desenvolvimento de suas atividades. O objetivo da função social da empresa não é proibir o lucro empresarial, mas sim fazer com que as empresas que se encontram no mercado trabalhem em benefício da sociedade. Estes benefícios são percebidos através da geração de emprego ${ }^{12}$, renda, distribuição de produtos e serviços para a sociedade e crescimento do desenvolvimento social e econômico.

O cumprimento da função social pelas empresas está relacionado ao exercício da sua atividade empresarial. Podemos afirmar que a função social da empresa ocorre através das práticas positivas dentro e fora do seu espaço físico. Todas as empresas para sobreviverem no mercado necessitam gerar lucro, mas dentro da ótica da função social, ele deve ser perseguido de forma consciente, que não cause prejuízos à sociedade. Assim as empresas deverão buscar o lucro através da produção e circulação de bens ou serviços, exercendo suas atividades essenciais de forma responsável sem causar prejuízo à coletividade.

\footnotetext{
${ }^{10}$ Em referência ao que seria a adoção de boas práticas empresariais, pode-se dizer que as organizações devem se preocupar em preservar o meio ambiente, respeitar a relação de consumo, proporcionar um ambiente de trabalho saudável para o desempenho das atividades laborais entre outras coisas. As empresas que desenvolvem os cuidados necessários e observam as exigências da coletividade que as cerca, desempenham sua função social.

${ }^{11}$ A atuação de uma empresa no cumprimento da sua função social se dá através de um conjunto de ações exercidas com o objetivo de organizar as suas atividades para a produção de bens e serviços com valor social agregado. A empresa precisa gerar lucro para sobreviver no mercado, as suas ações para o cumprimento da função social não devem resultar em prejuízos para ela.

12 “A missão precípua de uma empresa é propiciar o crescimento de todos, sócios e sociedade, através da criação de empregos, geração de renda, produção e distribuição de bens. A função lucro é um plus que será alcançado como consequência, uma vez que o princípio da função social demonstrado no interesse pela coletividade através da possibilidade de vida digna a seus funcionários, respeito ao meio-ambiente, circulação de riquezas, gera uma posição de reconhecimento de toda a sociedade, acarretando maior lucro para a empresa. Assim, a empresa, ao realizar a sua função social, otimiza seus lucros, aumenta sua rentabilidade.”(TELES, 2009, p. 04).
} 


\section{A Diferença entre a Função Social e a Responsabilidade Social da Empresa}

A função social da empresa torna-se um elemento importante para a sociedade, na medida em que limita as ações empresariais, ao enquadrá-la de forma a atender os interesses da coletividade, por isso fala-se em poder-dever das empresas. Assim não deve ser confundida com a responsabilidade social da empresa, que nada tem a ver com as limitações e o dever, presente no conceito de função social.

A responsabilidade social, também conhecida como cidadania empresarial ${ }^{13}$, refletese nas ações empresariais de forma livre. O trecho acima explica que o cumprimento da função social é uma obrigação legal das empresas, mas a responsabilidade social é uma liberalidade, diante da qual as empresas podem ou não atuar de forma socialmente responsável. A responsabilidade social não é preestabelecida por lei, as empresas são livres para atuar na área que lhes interessar. As ações de responsabilidade social são muitas vezes utilizadas como marketing social pelas empresas, gerando benefícios não apenas para a área favorecida pelas ações sociais, mas principalmente para a empresa.

Os conceitos de função social da empresa e de responsabilidade social podem ser confundidos por muitas empresas que exercem uma atividade de responsabilidade social e passam a imagem de uma empresa que cumpre sua função social. Em muitos casos as empresas divulgam responsabilidade social, mas não cumprem sua função social, de gerar empregos dignos, respeitar o meio ambiente e as relações de consumo, entre outras práticas já explicadas.

A responsabilidade social ${ }^{14}$ implica liberalidade, por ser uma prática voluntária; as empresas não possuem a obrigação de exercer a responsabilidade social. Isso se dá apenas quando esta prática pode gerar benefícios diretos à organização empresarial.

\footnotetext{
${ }^{13}$ Sobre a distinção entre os conceitos de função social e responsabilidade social das empresas, Luiz Fernando de Camargo Prudente do Amaral (2008, p. 117) afirma que: "A previsão legal de institutos que impõem a função social à propriedade e the delimitam a incidência é de suma importância, inclusive, para que se diferencie a função social da empresa da responsabilidade social desta última, a qual é por vezes denominada cidadania empresarial. Aquela, por encontrar previsão legal, é dotada de certo grau de coercitividade emanada da própria norma que a prevê. Esta, no entanto, encontra-se no plano da liberdade do empresário, no que tange ao auxílio a terceiros que não estejam envolvidos diretamente em sua atividade empresarial, ficando muito mais no plano da fraternidade e da beneficência do que da legalidade."

${ }^{14}$ A Responsabilidade Social da Empresa apresenta-se de duas formas, a responsabilidade interna e a externa, abrangendo suas relações com funcionários e com consumidores e sociedade em geral, neste sentido Eduardo Tomasevicius Filho (2003, p. 47) classifica; "A responsabilidade social das empresas costuma ser dividida em dois tipos: responsabilidade social interna, que consiste na preocupação com as condições de trabalho, qualidade de emprego, remuneração, higiene e saúde de seus funcionários; e responsabilidade social externa, que consiste na preocupação da empresa com a comunidade em que está inserida, bem como seus clientes, fornecedores e entidades públicas.”
} 
Muitas vezes a responsabilidade social empresarial é utilizada como uma ferramenta de estratégia e marketing. Através desta prática as empresas justificam aos seus consumidores os seus lucros, disponibilizando serviços que em sua grande maioria são de competência do Estado, como por exemplo, criam instituições de ensino para pessoas carentes das comunidades onde atuam, promovem ações sociais de cuidados com a saúde, entre outras ações. Utilizada como ferramenta, as empresas fazem dela uma oportunidade de mostrar seu produto, diferenciando-o dos outros existentes no mercado e agregando valor $^{15}$ a este. Com isso conquistam novos clientes, recebem benefícios do Estado por estarem atuando em uma atividade que é de responsabilidade deste, entre outros benefícios.

Assim o desenvolvimento da atividade empresarial deverá ser pautado em boas práticas empresariais, que a empresa adotará no cumprimento da sua função social visando aos interesses internos e externos a ela. Ao relacionar a ocorrência da responsabilidade social da empresa, tem-se um conceito pautado no que se espera das organizações, ações éticas e responsáveis que promovam benefícios não apenas para o consumidor, mas também para a sociedade em geral ${ }^{16}$. Neste sentido é importante que as empresas cumpram sua função social, para que possam projetar ações de responsabilidade social.

A diferença entre os conceitos reside na obrigatoriedade do cumprimento da função social, já a responsabilidade social empresarial ${ }^{17}$ representa uma postura que poderá ser adotada pelas organizações. O que se espera das empresas, é a observância de alguns aspectos que são elencados de acordo com os princípios constitucionais da ordem econômica, que tratam da valorização do trabalho humano, da existência digna, da preservação do meio ambiente, o respeito às relações de consumo e a redução das desigualdades sociais e regionais, entre outros.

\footnotetext{
${ }^{15} \mathrm{O}$ valor agregado a organização representa a adoção de "ações sociais das empresas são uma oportunidade de diferenciar o seu produto à medida em que se constrói a imagem da corporação. Os consumidores passam a identificar as empresas que apoiam causas sociais e ambientais como sérias e comprometidas e a preferir os seus produtos a outros de mesma qualidade e preço." (TEIXEIRA, 2004, p. 04)

${ }^{16} \mathrm{Na}$ Responsabilidade Social as empresas devem construir uma relação pauta em valores éticos com os chamados stake-holders (que são o público interno, fornecedores, clientes, acionistas, comunidade, governo e sociedade, meio ambiente).

${ }^{17}$ A Associação Brasileira de Normas Técnicas (ABNT) no dia 8 de Dezembro de 2010, lançou a versão em português da norma ABNT NBR ISSO 26000, que trata das diretrizes para a responsabilidade social empresarial, que "se expressa pelo desejo e pelo propósito das organizações em incorporarem considerações socioambientais em seus processos decisórios e a responsabilizar-se pelos impactos de suas decisões e atividades na sociedade e no meio ambiente. Isso implica um comportamento ético e transparente que contribua para o desenvolvimento sustentável, que esteja em conformidade com as leis aplicáveis e seja consistente com as normas internacionais de comportamento. Também implica que a responsabilidade social esteja integrada em toda a organização, seja praticada em suas relações e leve em conta os interesses das partes interessadas." (a norma encontra-se disponível no site $<$ http://www.inmetro.gov.br/qualidade/responsabilidade_social/iso26000.asp >)
} 
Com o objetivo de tornar a vida em sociedade mais justa e digna, na responsabilidade social empresarial as ações são adotadas de forma voluntária pelo empresário. As atividades não costumam estar ligadas ao objeto social da empresa, mas são atividades desempenhadas por ela, que envolvem toda a comunidade, esteja ela ligada diretamente a organização ou não, por meio do trabalho. Como exemplo de ações de responsabilidade social, podem ser citados, os investimentos em educação e patrocínio de eventos culturais e cursos, entre outras práticas, como as de preservação ambiental.

Neste sentido, quando uma empresa observa e segue os princípios constitucionais da Ordem Econômica esta cumprindo a sua função social, e poderá também adotar ações de responsabilidade social.

\section{Os Valores Sociais da Empresa para o Mercado e a Sociedade}

A empresa é uma organização que gera emprego, renda, produz e circula bens ou serviços para a sociedade e colabora no desenvolvimento econômico do País. Em meio a este conceito podemos apontar os aspectos sociais que compõem as atividades essenciais da empresa e colaboram para o cumprimento dos princípios da Ordem Econômica.

Um aspecto social importantíssimo que a empresa representa é a geração de emprego, que contribui para a ocupação da mão de obra ativa do País. A produção e circulação de bens ou serviços para suprir a necessidade da sociedade, como por exemplo, a produção de alimentos e vestuário. A geração de renda é de fundamental importância, pois é através dela que o trabalhador poderá prover a sua subsistência e de seus dependentes, contribuindo ainda para a movimentação do mercado.

Como pode ser observado no parágrafo anterior, as atividades essenciais da empresa possuem aspectos sociais, que são inerentes à própria atividade empresarial. Para que a empresa cumpra sua função social, deverá promover o melhoramento no desempenho dessas atividades. Isso ocorre através das boas práticas empresarias, não basta o exercício da atividade, apenas é necessário que as empresas promovam a preocupação social, possuam bons relacionamentos internamente com seus funcionários e externamente com consumidores, fornecedores e sociedade em geral.

A empresa passa a ser um elemento componente da sociedade, que tem como um de seus objetivos atender os interesses da própria sociedade. Desta forma a empresa que atende às necessidades da coletividade na qual está inserida e gera benefícios para ela, apresenta assim, um valor social. Atender aos interesses da sociedade por meio da atuação da empresa nas 
questões econômicas e sociais utilizando-se de ações de forma responsável junto aos seus funcionários, fornecedores e consumidores, agrega valor à organização, que a torna um elemento importante dentro do cenário do mercado e da sociedade.

Os valores sociais que a empresa representa devem ser preservados, é através deles que pode ser garantida a dignidade da pessoa humana. Amartya Sen (2010, p. 26) relata que as oportunidades de participação no mercado de trabalho ajudam o indivíduo a gerar abundância, fazendo a distinção entre aquele que participa da sociedade como "paciente" e como "agente"18. Neste sentido o autor trabalha com a ideia de que, as oportunidades sociais adequadas podem mudar o destino do desenvolvimento de uma Nação.

Os valores sociais ${ }^{19}$ que estão vinculados à empresa, refletem no mercado e na sociedade, bem como promovem a inclusão social, e asseguram a dignidade da pessoa humana. O suporte normativo desses valores encontra-se previsto na Constituição Federal de 1988 nos princípios da ordem econômica ${ }^{20}$, e que são fundamentados na valorização do trabalho humano, na livre iniciativa e na existência digna.

Desta forma as empresas devem buscar pautar suas ações sociais de acordo com o que estabelece a Constituição Federal de 1988, visando à proteção e preservação do meio ambiente, ao respeito às relações de consumo e às relações trabalhistas, promover o desenvolvimento social e econômico da região em que está situada ou exerce suas atividades, entre outras práticas empresariais necessárias ao cumprimento dos princípios constitucionais.

O principal valor social agregado à sociedade e ao mercado, é o desenvolvimento econômico e social, que se encontra relacionado com a melhoria das condições sociais e econômicas dos indivíduos, e consequentemente uma melhora na qualidade de vida. Assim o valor social do desenvolvimento, apoia-se na geração de riquezas e na distribuição da mesma

\footnotetext{
18 "Pela antiquada distinção entre "paciente" e "agente", essa concepção da economia e do processo de desenvolvimento centrada na liberdade é em grande medida uma visão orientada para o agente. Com oportunidades sociais adequadas, os indivíduos podem efetivamente moldar seu próprio destino e ajudar uns aos outros. Não precisam ser vistos sobretudo como beneficiários passivos de engenhosos programas de desenvolvimento." (SEN, 2010, p.26)

${ }^{19}$ Ao falar nos valores sociais, busca-se a representação do papel social que a empresa desempenha para o mercado e para a sociedade, assim pode-se dizer que "o papel social da empresa, por exemplo, é ser um centro produtor de riquezas, através do capital e do trabalho. Essa ideia leva em conta as coisas como elas são e não como elas deveriam ser." (THOMASEVICIUS FILHO, 2003, p. 35)

${ }^{20}$ Ver o artigo 170 da Constituição Federal de 1988 "Art. 170. A ordem econômica, fundada na valorização do trabalho humano e na livre iniciativa, tem por fim assegurar a todos existência digna, conforme os ditames da justiça social, observados os seguintes princípios: I - soberania nacional; II - propriedade privada; III - função social da propriedade; IV - livre concorrência; V - defesa do consumidor; VI - defesa do meio ambiente, inclusive mediante tratamento diferenciado conforme o impacto ambiental dos produtos e serviços e de seus processos de elaboração e prestação; VII - redução das desigualdades regionais e sociais; VIII - busca do pleno emprego; IX tratamento favorecido para as empresas de pequeno porte constituídas sob as leis brasileiras e que tenham sua sede e administração no País. Parágrafo único. E assegurado a todos o livre exercício de qualquer atividade econômica, independentemente de autorização de órgãos públicos, salvo nos casos previstos em lei.” (BRASIL, 1988)
} 
de forma que seja observado o princípio da redução das desigualdades regionais e sociais. Por meio desse princípio poderão ocorrer a inclusão social e a melhoria na qualidade de vida.

\section{O Papel da Empresa no Desenvolvimento Sustentável}

De acordo com o relatório elaborado pela Comissão Mundial sobre Meio Ambiente e Desenvolvimento, intitulado "Nosso Futuro Comum" também conhecido como o Relatório de Brundtland, em 1987, ficou estabelecido que o atendimento das necessidades humanas ${ }^{21}$ é uma das concepções para a busca do desenvolvimento sustentável.

Segundo o referido relatório, o desenvolvimento sustentável é aquele que atende às necessidades das gerações presentes sem comprometer a possibilidade das futuras de atender também às suas, ressaltando a importância de atender às necessidades básicas de todos os indivíduos e proporcionar as oportunidades de realizar suas aspirações de uma vida melhor.

O processo relacionado ao desenvolvimento sustentável deverá adotar transformações na sociedade e na economia. Por meio do crescimento econômico e do consumo consciente a sociedade poderá ser transformada e ter as necessidades básicas, de alimentação, roupas, habitação, emprego e melhor qualidade de vida, atendidas.

Neste sentido, José Eli da Veiga (2006, p. 23) relaciona o crescimento econômico e o desenvolvimento humano, que deverão ocorrer, para que seja alcançado então o desenvolvimento, através da ampliação das capacidades humanas, que seria, o conjunto das coisas que as pessoas podem ser, ou fazer, na vida. "E são quatro as mais elementares: ter uma vida longa e saudável, ser instruído, ter acesso aos recursos necessários para um nível de vida digno e ser capaz de participar da vida da comunidade".

Partindo do conceito de desenvolvimento sustentável reporta-se ao papel que as empresas possuem neste processo. Analisando as lições de Barbieri e Cajazeiras, ${ }^{22}$ pode-se visualizar que o desenvolvimento sustentável não é apenas crescimento econômico, dentro do aspecto quantitativo de aumento de rendas, é também uma mudança de conceitos, é um

21 “O desenvolvimento sustentável é aquele que atende às necessidades do presente sem comprometer a possibilidade de as gerações futuras atenderem às suas próprias necessidades. Ele contém dois conceitos-chave: o conceito de "necessidades", sobretudo as necessidades dos pobres do mundo que devem receber a máxima prioridade; e a noção das limitações que o estágio da tecnologia e da organização social impõe ao meio ambiente, impedindo-o de atender às necessidades presentes e futuras." (NOSSO FUTURO COMUM, 1991, p. 46, grifo nosso)

${ }^{22}$ Abordando dimensões que compõe a sustentabilidade Barbieri e Cajazeiras (2012, p. 65-66) elencam a seguinte visão: “A sustentabilidade social trata da consolidação de processos que promovem a equidade na distribuição dos bens e da renda para melhorar substancialmente os direitos e as condições de amplas massas da população e reduzir as distâncias entre os padrões de vida das pessoas; A sustentabilidade econômica possibilita a alocação e a gestão eficiente dos recursos produtivos, bem como um fluxo regular de investimentos públicos e privados." 
desenvolvimento social e ambiental. ${ }^{23}$

Para relacionar o papel que a empresa desempenha no desenvolvimento sustentável, não pode ser deixada da fora a visão econômica, que reflete fatores relacionados à esfera do consumo, da diminuição da pobreza, do uso dos recursos naturais por aqueles que não possuem uma renda mínima adequada para suprir suas necessidades. Esta concepção está relacionada à busca, da melhor forma, de se reduzir as disparidades dos padrões de vida. ${ }^{24}$

Dentro do cenário da busca por um desenvolvimento sustentável, o crescimento econômico deverá ocorrer de forma estruturada. Devem ser estabelecidos padrões de consumo e produção ${ }^{25}$ sustentáveis, a serem observados pelas empresas, cabendo ao Estado fomentar políticas com este objetivo. As empresas devem promover não apenas a expansão de mercados e o acúmulo de riquezas, mas sim, a sua distribuição entre os entes que compõem a sociedade. ${ }^{26}$

A partir das ações que devem ser implementadas para que ocorra o desenvolvimento sustentável ${ }^{27}$, tanto no âmbito social, econômico como no ambiental, visualiza-se que as empresas possuem um papel fundamental para esta conquista. É por meio delas que a sociedade recebe as transformações que irão promover a inclusão social, por meio do trabalho, a satisfação das necessidades humanas básicas, a distribuição de rendas e a preservação dos recursos.

É notória a existência de problemas sociais e econômicos, que prejudicam a ocorrência do desenvolvimento sustentável. José Eli da Veiga (2010, p. 33-34) lembra em sua lição, que novos problemas convivem com outros antigos e que podem ser encontradas tanto em países

\footnotetext{
${ }^{23}$ Neste sentindo José Eli da Veiga (2006, p. 25) ressalta essa questão do uso dos recursos, ou seja, de como deverão ser utilizados de forma consciente para promover o desenvolvimento; "o desenvolvimento depende da maneira como os recursos gerado pelo crescimento econômico são utilizados - se para fabricar armas, ou para produzir alimentos; se para construir palácios, ou para fornecer água potável."

${ }^{24}$ Como pode ser observado no Princípio 5: Para todos os Estados e todos os indivíduos, como requisito indispensável para o desenvolvimento sustentável, irão cooperar na tarefa essencial de erradicar a pobreza, a fim de reduzir as disparidades de padrões de vida e melhor atender às necessidades da maioria da população do mundo. (DECLARAÇÃO DO RIO SOBRE MEIO AMBIENTE E DESENVOLVIMENTO, 1992 - grifo nosso) ${ }^{25}$ Como pode ser observado no Princípio 8: Para alcançar o desenvolvimento sustentável e uma qualidade de vida mais elevada para todos, os Estados devem reduzir e eliminar os padrões insustentáveis de produção e consumo, e promover políticas demográficas adequadas. . (DECLARAÇÃO DO RIO SOBRE MEIO AMBIENTE E DESENVOLVIMENTO, 1992 - grifo nosso)

26 “A satisfação das necessidades essenciais depende em parte de que se consiga o crescimento potencial pleno, e o desenvolvimento sustentável exige claramente que haja crescimento econômico em regiões onde tais necessidades não estão sendo atendidas. Onde já são atendidas, ele é compatível com o crescimento econômico, desde que esse crescimento reflita os princípios amplos da sustentabilidade e da não exploração dos outros. Mas o simples crescimento não basta. Uma grande atividade produtiva pode coexistir com a pobreza disseminada, e isto constitui um risco para o meio ambiente. Por isso o desenvolvimento sustentável exige que as sociedades atendam às necessidades humanas, tanto aumentando o potencial de produção quanto assegurando a todos as mesmas oportunidades." (NOSSO FUTURO COMUM, 1991, p. 47, grifo nosso)

${ }^{27}$ Em essência, o desenvolvimento sustentável é um processo de transformação no qual a exploração dos recursos, a direção dos investimentos, a orientação do desenvolvimento tecnológico e a mudança institucional se harmonizam e reforçam o potencial presente e futuro, a fim de atender às necessidades e aspirações humanas. (NOSSO FUTURO COMUM, 1991, p. 49)
} 
pobres como ricos. São eles: "a persistência da pobreza e de necessidades essenciais não satisfeitas; a ampla disseminação de fomes coletivas e crônicas; a violação de liberdades políticas elementares e de liberdades formais básicas, sem falar da ampla negligência diante da condição de agente das mulheres”. A partir desde cenário social, visualiza-se a responsabilidade das empresas por planejar e adotar condutas voltadas para o desenvolvimento.

De acordo com Amrtya Sen, que adota a visão da liberdade ${ }^{28}$ como elemento principal para efetivação do desenvolvimento, ao ferir a liberdade de algum indivíduo, o desenvolvimento sustentável não será alcançado. Por isso, faz-se necessária a efetiva implantação de um processo de desenvolvimento, que assegure a todos a sua liberdade ${ }^{29}$.

Ao relacionar o desenvolvimento sustentável com o alcance das liberdades individuais, observa-se a dignidade humana e o atendimento das suas necessidades, por meio do trabalho e do crescimento econômico. O papel desempenhado pelas empresas no desenvolvimento sustentável relaciona-se com a satisfação das necessidades básicas da atual sociedade, sem que isso possa comprometer as gerações futuras.

Ao buscar o desenvolvimento social, econômico e ambiental, verifica-se que as empresas estão diretamente ligadas ao cumprimento de sua função social, e mais: que suas atividades podem estabelecer para as comunidades onde se encontra inserida, a adoção de uma postura que respeita a existência digna ao mesmo tempo que promove o desenvolvimento econômico.

Através da empresa a sociedade experimenta as oportunidades de atender às suas necessidades básicas e à possibilidade de uma melhor condição de vida. Ao cumprir sua função social e adotar ações de responsabilidade social, as empresas desenvolvem o mercado, e promovem a inclusão social por meio do trabalho digno, da distribuição das riquezas acumuladas, e do aperfeiçoamento tecnológico para a utilização dos recursos ambientais.

\footnotetext{
${ }^{28}$ Nas palavras de Amartya Sen (2010, p. 29) "O desenvolvimento tem de estar relacionado sobretudo com a melhora da vida que levamos e das liberdades que desfrutamos."

${ }^{29}$ As liberdades que Amartya Sen aponta como promovidas pelo desenvolvimento, referem-se a liberdades individuais que devem ser consideradas como compromisso social. Segundo Sen (2010, p.48-49) "A liberdade individual é essencialmente um produto social, e existe uma relação de mão dupla entre (1) as disposições sociais que visam expandir as liberdades individuais e (2) o uso de liberdades individuais não só para melhorar a vida de cada um, mas também para tornar as disposições sociais mais apropriadas e eficazes."
} 


\section{Considerações finais}

A Constituição Federal de 1988 elenca princípios norteadores da Ordem Econômica Nacional. Princípios estes que têm como objetivo regular a economia e promover o desenvolvimento do País. Nesse sentido, todos os preceitos constitucionais que compõem a ordem econômica possuem um caráter social, para que o País consiga atingir o seu desenvolvimento nas duas esferas conjuntamente.

A ordem econômica passou a ser regida por princípios com conteúdo voltado para a proteção e o desenvolvimento da sociedade. Estes estipulam que o desenvolvimento econômico de nosso País deverá ser pautado na valorização do trabalho humano e na livre iniciativa com o objetivo de assegurar a todos a existência digna, conforme os ditames da justiça social. Para que isso ocorra, o Estado, as empresas e a sociedade devem observar os princípios da soberania nacional, propriedade privada, função social da propriedade, livre concorrência, defesa do consumidor, defesa do meio ambiente, redução das desigualdades regionais e sociais, busca do pleno emprego e o tratamento favorecido para as empresas de pequeno porte brasileiras.

Dentre os princípios da ordem econômica podemos destacar alguns que possuem um alto conteúdo social, tais como: função social da propriedade, defesa do meio ambiente, entre outros. O conteúdo social presente, nestes princípios, é o de proteger, beneficiar e resguardar os direitos da sociedade, para que o País possa se desenvolver economicamente sem que a sua sociedade sofra prejuízos e consequências graves relacionados ao desenvolvimento.

A função social das empresas ocorre quando as mesmas agem na prática das boas condutas. A empresa como a responsável por produzir e fazer circular bens e serviços para a nossa sociedade deve estar comprometida com as necessidades da coletividade. Quando uma empresa exerce suas atividades de acordo com os princípios da ordem econômica, passa a cumprir sua função social, pois atinge os objetivos esperados para o desenvolvimento econômico e social.

As atividades desempenhadas pelas empresas são bastante salutares para o crescimento e desenvolvimento econômico da nação. Os valores sociais que ela representa, a geração de empregos e renda são as principais contribuições que elevam o papel da empresa ao patamar de cumprimento da função social e do alcance do desenvolvimento sustentável.

Sem a pretensão de esgotar os questionamentos e as relações existentes entre os conceitos estudados, mas apenas despertar nos leitores uma visão mais consciente para os elementos que podem levar ao desenvolvimento sustentável, através do papel que a empresa desempenha, evidencia-se esta como um elemento de grande valia na busca pelo 
desenvolvimento sustentável.

\section{Referências bibliográficas}

ABNT - Associação Brasileira de Normas Técnicas, NBR ISO 26000/2010. Disponível em: $<$ http://www.pessoacomdeficiencia.gov.br/app/sites/default/files/arquivos/[field_generico_ima gens-filefield-description]_65.pdf > Acesso em: 25 nov. 2015.

AMARAL, Luiz Fernando de Camargo Prudente do. A função social da empresa: no direito constitucional econômico brasileiro. São Paulo: SRS Editora, 2008.

BARACHO, Hertha Urquiza. e JATOBÁ, Augusto César Maurício. Função Social e Responsabilidade Social à luz da Constituição Federal de 1988. Revista do Direito da UNISC, Santa Cruz do Sul. V. 1, n. 45, p. 46-60, jan.- abril. 2015.

BRASIL. Constituição da Republica Federativa do Brasil. Disponível em: < http://www.planalto.gov.br/ccivil_03/Constituicao/Constituicao.htm > Acesso em: 25 nov. 2015. . Lei $n^{\circ} 6.404$ de 1976. Publicada em 15 de dezembro de 1976. Disponível em: http://www.planalto.gov.br/ccivil/LEIS/L6404consol.htm Acesso em: 25 nov. 2015. BARBIERI, Jose Carlos; CAJAZEIRAS, Jorge Emanuel. Responsabilidade Social empresarial e empresa sustentável da teoria a pratica. São Paulo: Editora Saraiva, 2012.

COMPARATO, Fabio Konder. Direito Empresarial: estudos e pareceres. $1^{\text {o }}$ edição - São Paulo: Saraiva, 1995.

DECLARAÇÃO DO RIO SOBRE O MEIO AMBIENTE E DESENVOLVIMENTO. Rio de Janeiro, 1992. Disponível em: < http://www.onu.org.br/rio20/img/2012/01/rio92.pdf > Acesso em: 16 Jan. 2016.

LOPES, Alex Luís Luengo. A empresa privada à luz da Ordem Econômica Constitucional Brasileira de 1988: papel, função e responsabilidade social. Marília, 2006. Disponível em: 
<http://www.unimar.br/pos/trabalhos/arquivos/448b42b04424d7c1355117d37c7cfdfc.pdf> Acesso em: 25 Jan. 2016.

MAMEDE, Gladston. Direito empresarial brasileiro: empresa e atuação empresarial. $2^{\circ}$ edição - São Paulo: Atlas, 2007.

\section{NOSSO FUTURO COMUM. Comissão Mundial sobre Meio Ambiente e}

Desenvolvimento. $2^{\text {a }}$ Ed. Rio de Janeiro. Editora: Fundação Getulio Vargas. 1991. Disponível em: $<$ https://pt.scribd.com/doc/12906958/Relatorio-Brundtland-Nosso-Futuro-Comum-EmPortugues > Acesso em: 16 Jan. 2016.

NUSDEO, Fábio. Curso de Economia: Introdução ao Direito Econômico. $9^{a}$ edição. São Paulo: Editora Revista dos Tribunais, 2015.

REQUIÃO, Rubens. Curso de direito comercial. 26º edição - São Paulo: Saraiva, 2009.

SACHS, Ignacy. Caminhos para o desenvolvimento sustentável. Rio de janeiro: Garamond, 2002.

. Desenvolvimento includente, sustentável, sustentado. Rio de Janeiro: Garamond, 2008

SEN, Amartya. Desenvolvimento como Liberdade. Tradução Laura Texeira Motta: revisão técnica Ricardo Doninelli Mendes. São Paulo: Companhia das Letras, 2010

TELES, Giovanna Filomena Silveira. A função social da empresa. Disponível em: $<$ http://direito.newtonpaiva.br/revistadireito/docs/convidados/13_convidado_giovanna.pdf $>$ Acesso em: 16 Jan. 2016

TEIXEIRA, Luciana da Silva. Responsabilidade social empresarial. Disponível em: $<$ http://apache.camara.gov.br/portal/arquivos/Camara/internet/publicacoes/estnottec/pdf/2004 _6884.pdf> Acesso em: 25 Jan. 2016. 
TOMASEVICIUS FILHO, Eduardo. A Função Social da Empresa. Revista dos Tribunais. Ano 92, volume 810, abril de 2003, p. 33-50.

VEIGA, José Eli da. Desenvolvimento Sustentável: o desafio do século XXI. Rio de Janeiro: Garamond, 2010.

. Meio Ambiente e Desenvolvimento. São Paulo: Editora Senac São Paulo, 2006. 


\title{
O PAPEL REGULATÓRIO DA TRIBUTAÇÃO EXTRAFISCAL AMBIENTAL E SEU IMPACTO PARA A FUNÇÃO SOCIAL DA EMPRESA
}

\author{
Regina Célia de Carvalho Martins \\ Unimar - Universidade de Marília \\ Maria de Fátima Ribeiro \\ Unimar - Universidade de Marília
}

Resumo: A Constituição Federal estabeleceu no artigo 170 determinantes norteadoras do desenvolvimento econômico e neste contexto a empresa deve atender a diversos critérios. Entre eles, a livre iniciativa, respeitando a soberania nacional e promovendo a redução de desigualdades sociais, aos ditamos das relações de consumo e a necessidade de preservar o meio ambiente. Para tanto, as regulações estatais através de normas tributárias extrafiscais podem ser utilizadas como instrumentos estimuladores do desenvolvimento sustentável e também como agentes desestimuladores de condutas degradantes ambientais. Tais normas propiciam que a empresa cumpra sua função social, embasada nas premissas da sustentabilidade ambiental que ela deve respeitar.

Palavras-chave: Desenvolvimento econômico sustentável, função social da empresa, extrafiscalidade, regulação, condutas estimuladoras e desestimuladoras.

\section{Abstract/Resumen/Résumé}

The Federal Constitution established in article 170 determinants guiding economic development and in this context the company must meet several criteria. Among them, free enterprise, respecting national sovereignty and promoting the reduction of social inequalities, we say of the relations of consumption and the need to preserve the environment. To this end, state regulations through extra-fiscal tax rules can be used as instruments that stimulate sustainable development and also as agents that discourage environmental degrading behavior. These standards allow the company to fulfill its social function, based on the premises of environmental sustainability that it must respect. 
Keywords/Palabras-claves/Mots-clés: Sustainable economic development, Social function of the company, Extrafiscalidade. Regulation. Stimulating and discouraging behaviors.

\section{Introdução}

Como vencer o desafio de incentivar o desenvolvimento econômico de uma maneira sustentável - este o grande e talvez o maior dilema para as sociedades contemporâneas.

Sempre a Humanidade interagiu o meio ambiente, extraindo da natureza os recursos que julga necessários para atender suas necessidades e prazeres, impulsionando progresso e desenvolvimento.

Historicamente se partia da premissa que desenvolvimento era uma necessidade humana em reduzir desigualdades e promover a justiça distributiva, melhorando as condições sociais dos indivíduos, mas nesta visão limitada de "desenvolvimento" por longo tempo se deixou de considerar as variáveis ambientais das atividades humanidade, sendo necessário se reavaliar as definições de desenvolvimento na atualidade.

Bens ambientais transacionados sempre o foram em total negligência quanto a sua escassez; atualmente essa finitude dos bens ambientais resulta em aumento de seus preços, impulsionando a criação de novas tecnologias com o fito de poupar esses recursos que se escasseiam.

Percebe-se que o decurso do tempo, o crescimento econômico e a escassez dos bens ambientais orientaram uma reação social, já que que é a sociedade que acaba sofrendo com a poluição desordenada causada pela degradação ambiental

Neste cenário mudanças pontuais e eficientes devem se implantar para conter a degradação ambiental; assim é possível se perceber que com o desenvolvimento econômico, tecnológico e cultural, desponta também uma mudança de paradigmas em relação ao meio ambiente e sua preservação.

A observação dos fatos históricos nos mostra que a intervenção humana no meio ambiente, trazendo externalidades negativas, data do surgimento da espécie humana no planeta; entretanto a preocupação com a preservação ambiental é recente e no Brasil somente ganham maior intensidade após década de 1960, com uma fase de intenso movimento migratório das lides do campo para as áreas urbanas.

No final dos anos sessenta e início da década de setenta, a crise do petróleo exigiu uma reflexão mais efetiva sobre o futuro da humanidade no aspecto de sua relação com o meio ambiente. 
Neste cenário surge o conceito de "desenvolvimento sustentável" como um termo que expressa os anseios coletivos de continuar em sua jornada de desenvolvimento, mas atendendo a preservação ambiental.

Paralelamente, tentando se traçar as diretrizes necessárias para o preconizado desenvolvimento sustentável se aprofundam os estudos sobre as externalidades negativas da ação humana sobre o meio ambiente, bem como dos meios de reduzi-las.

A empresa se consubstancia em um dos atores principais deste cenário, já que ela objetiva lucro e crescimento, mas deve equalizar suas finalidades, equilibrando-as: se por um lado ela deve proporcionar desenvolvimento econômico, por outro deve fazê-lo de modo eficiente e sustentável, preocupando-se de forma integrativa com as externalidade ambientais que ocasiona, notadamente as negativas, que quais devem ser consideradas e internalizadas em seus custos operacionais.

Neste arcabouço, a interferência do Estado, através do processo regulatório é fundamental, discutindo-se neste artigo a importância do Direito Tributário como uma ferramenta eficiente a ser utilizada neste processo, para desestimular condutas degradantes ao meio ambiente.

Os tributos podem atuar como premissas estruturais neste processo social, notadamente os que são criados com funções extrafiscais, sendo este o enfoque direcionado neste artigo, demonstrar como a função extrafiscal do tributo pode contribuir para a redução da degradação ambiental, como mecanismo regulatório da conduta empresarial e humana, alcançando assim os fins sociais e ambientais em relação ao desenvolvimento empresarial/econômico buscado pela empresa.

\section{Regulação ambiental - função extrafiscal do tributo e proteção ambiental}

O Brasil participou da Conferência de Estocolmo em 1972, mas o fez uma atitude cética, como ainda era comum à "cultura ambiental” vigente. Mesmo assim, como resultado de sua participação criou a Secretaria Especial do Meio ambiente - SEMA (OLIVEIRA, 2008, p. 49). Timidamente se iniciava a investida governamental para a proteção ambiental.

A partir de então, diversas outras medidas forma tomadas; os Estados começara a criar seus órgãos ambientais, surgiu a Lei Federal da Política Nacional do Meio Ambiente - Lei 6.838/91, entre outros, até que a Constituição Federal de 1988 atribuiu status constitucional à proteção ambiental. 
$\mathrm{O}$ artigo 225 da Constituição consagra o meio ambiente como direito fundamental, essencial para a qualidade de vida saudável do ser humano. Impõe o citado artigo ao Poder Público e à coletividade o dever de preservar esse direito para presentes e futuras gerações.

Este direito fundamental se completa com outros, entre eles o direito à vida e dignidade humana previstos no artigo art. $1^{\circ}$, III da Carta Constitucional, uma vez que se reconhece que o meio ambiente é imprescindível para a preservação da vida humana.

A doutrina ambiental clássica corrobora com esta visão ao reconhecer que o direito à vida, com saúde e qualidade como um princípio fundamental exige para se concretizar um meio ambiente equilibrado. É o que se observa das lições de Sirvinskas, sobre o tema: "O que é meio ambiente ecologicamente equilibrado de uso comum do povo, mas essencial à vida humana? É aquele assegurado pelo respeito à dignidade humana. Esse princípio está arrolado expressamente no art. $1^{\circ}$, III, da CF." (SIRVINSKAS, 2003, p. 31)

Se por um lado, as normas constitucionais erigem o meio ambiente a um direito fundamental, por outro, é cediço que nem sempre existe por parte dos empreendedores, uma preocupação em explorar de forma responsável os recursos naturais, sendo comum a exploração predatória dos mesmos.

O Estado, responsável por assegurar os direitos fundamentais, é responsável por instituir instrumentos de proteção dos bens ambientais e pode ele encontrar na tributação, um aliado na defesa do meio ambiente, através da extrafiscalidade tributária.

Primordialmente a fixação de tributos tem por escopo a arrecadação de fundos para fazer frente às despesas públicas estatais, sendo esta sua função fiscal; contudo, é possível que o Estado atue de forma extrafiscal, ou seja, é possível que além do efeito fiscal que é inerente aos tributos, que alguns deles alcem efeitos outros denominados de extrafiscais, que visam produzir resultados específicos que não seja a simples arrecadação.

Nesse sentido, como bem pontua Paulo Carvalho de Barros, ao destacar que há tributos que se prestam, admiravelmente, para a introdução de expedientes extrafiscais. Outros, no entanto, inclinam-se mais ao setor da fiscalidade. Não existe, porém, entidade tributária que possa se dizer pura, no sentido de realizar tão-só a fiscalidade, ou, unicamente, a extrafiscalidade. (CARVALHO, 2000. P. 230)

A tributação fiscal ambiental se enquadra nestas características e pode servir como premissas e reforço positivo à pratica de atividades ambientalmente corretas; explica-se, não é interessante a imposição somente de penalização por condutas danosas ao meio ambiente, mas também a criação de mecanismos extrafiscais de incentivos à empresa que desenvolve atividades no cenário econômico nacional. 
$\mathrm{Na}$ Constituição Federal, não há menção expressa à extrafiscalidade. Da disciplina de alguns dispositivos, entretanto, infere-se implicitamente a sua presença, mediante a ampliação da função arrecadatória do tributo com objetivos extrafiscais, sobretudo no regramento de isenções, imunidades entre outros. Portanto, a extrafiscalidade encontra o seu fundamento de validade no texto constitucional, inclusive, como afirma Gouvêa, "já foi reconhecida como princípio, seja de maneira expressa, com a afirmação de sua existência, ou de maneira implícita, quando é contraposta aos princípios tradicionais do Direito Tributário" (GOUVÊA, 2006, p. 48).

As implicações ambientais contidas no artigo 225 da Constituição Federal sobre a proteção ambiental e seus desdobramentos, devem ser efetivadas pelo legislador infraconstitucional e cumpridas pelas empresas.

\section{1 - Os tributos ambientais - sanção penal e premial}

A crescente devastação dos ecossistemas do planeta, observada de modo avassalador nas últimas décadas, fez com que os Estados passassem a inserir nas pautas políticas de planejamentos, as repercussões ambientais que as decisões sobre política econômica, energética, agrícola, industrial, comercial e tributária necessitam possuir.

Surge assim o sistema de tributos onde o Estado, através de atuação extrafiscal, cria mecanismos de desestímulo de condutas poluidoras (sanção penal) e estímulo de condutas não poluidoras (sanção premial), entendendo que o meio ambiente equilibrado é direito de todos e dever do poder público.

Maria de Fátima Ribeiro ressalta essa possibilidade de atuação da política extrafiscal do Estado: "Por meio da política extrafiscal, o legislador poderá estimular ou desestimular comportamentos, de acordo com os interesses da sociedade, instituindo uma tributação regressiva ou progressiva, ou quanto à concessão de incentivos fiscais" (RIBEIRO, 2012. p. 224)

Segundo José Marcos Domingues Oliveira, é o princípio do poluidor pagador que sustenta a intervenção tributária do Estado para a proteção ambiental. O princípio do poluidor pagador é um dos responsáveis pela internalização de custos sociais da produção industrial. Através dele, os agentes econômicos que praticam atividades de impactação ambiental são compelidos a internalizar em seus custos de produção as externalidades ambientais negativas. (OLIVEIRA, 1999. p. 20) 
Assim destaca o autor em referência que os tributos ambientais têm dois sentidos:

(...)um sentido estrito e um sentido amplo. Em sentido estrito, tributo ambiental significa um tributo novo cobrado em razão do uso do Meio Ambiente pelos agentes econômicos. Já em sentido amplo, tributo ambiental é um tributo tradicional ou ordinário adaptado de molde a servir aos esforços de proteção ambiental. (OLIVEIRA, 2007, p. 63-64)

Nessa ordem de ideias, o princípio do poluidor-pagador como um princípio orientador das políticas públicas em matéria ambiental, pode ser projetado sobre o sistema tributário, não exigindo a criação de tributos ambientais. Nesse sentido, o princípio do poluidor pagador é uma condição de legitimidade do tributo ambiental (MATEO, 1991. P. 240).

O princípio do poluidor pagador tem natureza retributiva, determinando que o agente que polui seja compelido a "pagar" pelo dano, destacando-se que ele possui duas vertentes: uma de natureza impositiva, que significa o dever do Estado em cobrar daquele que polui um ressarcimento capaz de custear os serviços públicos destinados à preservação e recuperação ambientais ou às atividades de fiscalização ambiental, desenvolvidas pelo Poder Público; outra tem natureza seletiva permitindo ao Poder Público que majore a tributação com fito a privilegiar atividades de produção ou de consumo considerados como "ecologicamente corretos" e ao mesmo tempo desestimular a utilização de tecnologias defasadas, que levam a produção e consumo de bens que não são considerados ecologicamente corretos.

Tal princípio, que originalmente foi adotado pela OCDE através da Recomendação C(72), 128, de 26 de maio de 1972, complementada pela Recomendação C(74223), de 14 de novembro de 1974, parte da premissa de que o custo das medidas de proteção ambiental deve ser arcado por aqueles agentes econômicos que, de uma maneira ou outra, se beneficiam economicamente do meio ambiente, de forma tal que as externalidades ambientais negativas sejam internalizadas nos processos produtivos. Essas deseconomias externas não se veem refletidas nos preços do mercado e acabam representando custos socioambientais para a sociedade. (MONTERO, p. 341)

Comungando deste pensamento Edis Milaré entende que o princípio do poluidor pagador possui vocação redistributiva na medida em que faz com que o poluidor arque com os custos desta poluição, internalizando os custos ambientais de sua atividade; assim, se degrada o meio ambiente é responsável pela reparação do dano ou pela manutenção da qualidade ambiental. (MILARE, 1998 p. 84)

Os princípios em direito ambiental são fartos e nesse mesma seara, mas agora d modo premial, pode-se mencionar o Princípio do Protetor Recebedor, que prevê benefícios para o 
contribuinte que desenvolver suas atividades em respeito ao meio ambiente. Implementa o ideal do benefício oferecido pelo Estado ao empreendedor, inclusive por meio de políticas fiscais premiais por atividades que beneficiem o meio ambiente.

São de José Marcos Domingues Oliveira diz as palavras no sentido de que aplicam "sólidos fundamentos da doutrina kelseniana da sanção premial ou recompensatóra, por sua vez estribada no princípio retributivo (Vergeltung): assim, o Estado reconhece o esforço do cidadão em cumprir a lei, e não apenas castiga o recalcitrante; tributa-se menos - a título de prêmio quem não polui ou polui relativamente menos." (OLIVEIRA, 1999. p.42)

Neste panorama se percebe que, tanto a aplicação do princípio do poluidor pagador ou do protetor recebedor, o que exsurge é a função extrafiscal destes em matéria tributária, posto que utilizados para atingir a função social de proteção do meio ambiente.

Instituir tributos para a tutela de um bem ambiental específico e também a utilizar de tributos já existentes, quer seja de forma repressiva ou premial (isenções e benefícios), pode e deve ser utilizado pelo Estado tendo por premissa a tutela ambiental que se busca atingir.

Neste momento se pode perceber que um tributo voltado para o meio ambiente deve exercer duas finalidades; a primeira delas compor o custo sócio-ambiental da atividade da empresa, tornando esta responsável pelas externalidades ambientais negativas geradas pela atividade que deve suprir eventual degradação perpetrada em detrimento do meio ambiente $e a$ segunda se destina à função extrafiscal do tributo como fundamento da tributação ambiental.

Clara, portanto, tributação extrafiscal ambiental é um importante instrumento que se faz necessário para atingir o bem-estar coletivo, com vistas ao alcance do desenvolvimento sustentável, sem, entretanto, inviabilizar o crescimento econômico.

A extrafiscalidade presente na tributação, objetiva incentivar a prática de atividades econômicas que respeitem o direito coletivo ao meio ambiente saudável.

Por isso, transfere para o empreendedor, a responsabilidade pelas externalidades ambientais negativas por ele criadas, as quais, cumpridas adequadamente permitem à empresa cumprir seu papel social, tema dos tópicos seguintes.

\section{Responsabilidade social da empresa por externalidades negativas}

Definir função social da empresa engloba a premissa da certeza que a empresa não pode objetivar somente o lucro, mas também preocupar-se com os reflexos que suas decisões têm perante a sociedade, seja de forma geral, incorporando ao bem privado uma utilização voltada para a coletividade; ou de forma específica, trazendo realização social ao empresário e 
para todos aqueles que colaboraram para alcançar tal fim.

Destarte, a noção de responsabilidade social da empresa está diretamente ligada ao conceito de função social da propriedade e da livre iniciativa. Assim, o empresário pode fazer uso de todos os meios possíveis para alcançar a finalidade de sua atividade, desde que observe os ditames legais, incluindo-se os ambientais.

Ocorre muita confusão com relação ao tema e não são raros os casos em que se confunde a responsabilidade social com "ação social". Estes termos, no entanto, são distintos e a ação social está relacionada a projetos sociais ou ações sociais, como doações que a empresa, assim como o indivíduo, podem fazer, em benefício de algum projeto social ou grupo de pessoas necessitadas.

Filantropia empresarial tem como agente impulsionador a voluntariedade, movida por algum objetivo específico, como por exemplo, o religioso ou até com o objetivo de servir por propaganda empresarial. Trata-se de auxílio é eventual, descompromissado, não existe obrigação da empresa de acompanhar o desenvolvimento do projeto apoiado, a resolução do conflito discutido.

Outrossim a responsabilidade social da empresa é abrangente e está diretamente relacionada a ações efetivas da empresa com um grupo maior de pessoas e bens, que engloba consumidores, fornecedores, empregados e meio ambiente. permite o desenvolvimento econômico empresarial, o crescimento da empresa, incluindo neste cenário a responsabilidade pelo meio ambiente e por redução de desigualdades sociais.

São de José António Puppin de Oliveira as explanações sobre a definição de modelo de empresa socialmente responsável estabelecido por Davis e Blomstron:

Por exemplo, um dos modelos mais simples é o proposto por Davis e Blomstrom. Nele, as responsabilidades se expandem desde um círculo interior que trata de aspectos técnicos e econômicos, para englobar as responsabilidades trabalhistas e ambientais ligadas diretamente às atividades da empresa, até finalmente buscar o engajamento com aspectos fora das atividades da empresa, como pobreza e desigualdades sociais. A empresa e os gestores, à medida que buscam maior responsabilidade socioambiental, teriam, então, de arcar com uma gama crescente de preocupações além daquelas técnico-econômicas. (OLIVEIRA, 2008. p. 71)

Observa-se do explanado até o momento e das lições trazidas à colação a imprecisão que paira sobre o tema "responsabilidade social da empresa".

Ao que se nos parece, a somatória de todos os elementos indicados é o que define o comportamento de responsabilidade social desejável por parte de uma empresa no atual cenário político e econômico. 
O meio ambiente e sua preservação devem ser, dentro de todo este contexto, uma grande preocupação a se analisar, isto porque diretamente é afetado prelas atividades tecnológicas e industriais do ser humano e nem sempre ocorre uma análise econômica dos custos que esta intervenção gera, com isso surgem as externalidades negativas.

A humanidade sempre degradou o meio ambiente como mecanismo de produção extrativa para atender suas necessidades e interesses, sem inserir nos custos operacionais a exploração de recursos naturais, até porque, inicialmente cria que tais recursos seriam infinita e automaticamente repostos, o que não mais se sustenta.

Se nos primórdios da humanidade o meio ambiente servia para manutenção da vida humana, hoje é cediço e incontroverso que a preservação do meio ambiente é ponto fundamental a evitar que ocorra a extinção da vida na Terra.

Exige-se assim, que os meios de produção debrucem sua atenção para o desenvolvimento sustentável e a empresa tem importante função para a garantir o direito à vida com dignidade, cumprindo assim, o preceito do princípio da dignidade da pessoa humana estabelecido na Carta Constitucional, em seu artigo $1^{\circ}$, III. (GODOY, 2017, p. 27-28)

Impossível que a empresa atue sem observar os preceitos constitucionais que lhe são impostos pela nova ordem econômica, insertos no artigo 170 da Constituição.

Por certo exerce função social a empresa que dispõe dos recursos naturais de forma adequada e reduz ao mínimo o impacto de suas atividades no meio ambiente; para isso ela deve estar atenta às externalidades que ocasiona e quando estas forem negativas, deve atuar para reparar os danos e recuperar o meio ambiente.

A tributação extrafiscal é um importante fator à favor do Estado para regular esse comportamento empresarial. A gestão das empresas atualmente não pode mais ocorrer, sem levar em consideração o cumprimento da responsabilidade sócio-ambiental que ela possui frente ao desafio de se preservar o meio ambiente para as futuras gerações, o que passa necessariamente pelo controle das externalidades negativas de forma eficiente, fiscalizada por uma política pública eficiente.

A gestão responsável de uma empresa, do ponto de vista ambiental se define pela relação ética e transparente que ela mantém com todos os públicos com os quais se relaciona e pelo estabelecimento de metas empresariais compatíveis com o desenvolvimento sustentável da sociedade, preservando recursos ambientais, recuperando os lesados e investindo em tecnologias para reduzir impactos a bens ambientais.

Exemplos negativos de atividades empresarias, proveniente de corporações que estão instaladas mundialmente, afetam o meio ambiente, atuando como um retrocesso empresarial e 
um desrespeito ambiental, Entre eles, na obra de Steve Tombs y David Whyte alguns são citados e classificadas como criminosas e fraudulentas, entre eles:

\begin{abstract}
Volkswagen había instalado un software que permitía manipular los datos de emisiones de sus coches. El software detectaba cuándo se encontraba el automóvil en un banco de pruebas y cambiaba de posición para reducir al mínimo las emisiones de óxido de nitrógeno (NOx). Fuera del banco de pruebas, el coche volvía a la posición «normal» de mayor eficiencia para multiplicar hasta 40 veces el límite legal de emisiones. El 4 de noviembre, VW admitió que los dispositivos manipulados también fueron instalados en los motores de gasolina y enmascararon sus emisiones de $\mathrm{CO} 2$. La empresa también admitió haber instalado ese software en una lista de marcas propiedad de VW mucho mayor que la admitida previamente, incluidas Porsche, Audi, SEAT y Skoda. El número de vehículos afectados aumentaba cada día, entre ellos 700.000 coches en España (McHugh, 2015). Los delitos de Volkswagen - y claramente eran delitos - incluían el fraude organizado para asegurar la dispersión incontrolada del que puede ser nuestro mayor asesino contaminante, el NOx, responsable de la mitad de las muertes relacionadas con la contaminación en el mundo desarrollado, así como del principal causante del cambio climático: el $\mathrm{CO} 2$. Pese a esas devastadoras revelaciones, VW siguió vendiendo coches con sus emisiones medidas por dispositivos manipulados incluso después del «escándalo» conocido en septiembre de 2015, mientras negaba todo conocimiento de la dirección sobre el fraude perpetrado ( WHYTE, TOMBS, P. 15/16)UI
\end{abstract}

Comportamentos desta natureza são refutados em todos os sistemas jurídicos do mundo, não se podendo admitir que empresas somente façam uso do "discursos" politicamente correto em matéria ambiental as que efetivamente não internalizem esse comportamento sócio ambiental da empresa.

Exemplos como este servem para demonstrar que, lamentavelmente, não é somente o Brasil que necessita de políticas ambientais públicas eficazes; ao redor do mundo, repetem-se comportamentos reiterados em desrespeito ao meio ambiente e parece longe a data em que o discurso ambiental restará ultrapassado.

Retornando ao cenário nacional, não se pode deixar de observar a nossa realidade social e a necessidade de se atingir o desenvolvimento sustentável no Brasil, inclusive reduzindo desigualdades sociais.

Este é um processo de aprendizagem social de longo prazo, deve ser orientado e direcionado por políticas públicas eficientes que tenham por escopo um plano de desenvolvimento nacional.

Pelo exposto se observa que não é possível se exigir somente das empresas que desempenhem sozinha este papel; ele demanda uma pluralidade de atores sociais e ainda é necessário se considerar que interesses outros, presentes na sociedade, se colocam como um entrave em matéria de políticas públicas para o desenvolvimento sustentável (BEZERRA e BURSZTYN, 2000, p. 45). 
Em todo este complexo contexto, o lucro é e continuará sendo um dos pilares de sustentação para as empresa se mantenha no mercado, mas ao se observar o indicadores de uma boa gestão empresarial contábil, o que se pode perceber é que as empresas que adotaram a cultura da ecoeficiência demonstram a perfeita compatibilidade entre lucratividade e sustentabilidade e manejam de forma responsável suas externalidades.

A criação de mecanismos para reaproveitamento de matérias-primas, a promoção do reuso da água e racionalização da energia, reduzem o impacto do processo produtivo no meio ambiente e aumentam a competitividade do produto no mercado, tanto do ponto de vista tangível como do intangível, haja vista estar se surgindo um novo agente neste processo: o consumidor consciente quanto a dar preferência a produtos ecologicamente responsáveis.

Por final não esqueçamos o Estado com mecanismos de controle tributário criados para participar desta engrenagem coletiva em preservação ambiental.

Nas lições de Modesto Carvalhosa, proferidas no ano de 1976 ao comentar a Lei das Sociedades Anônimas, ou seja, 12 anos antes do advento da Constituição Federal de 1988, ele vislumbrava a necessidade da empresa manter como um de seus objetivos, a exploração econômica em conjunto à preservação ambiental. (CARVALHOSA, 1997, p. 238)

Com este pensamento ele inclui como uma das funções sociais da empresa o dever de preservar o meio ambiente, tudo isto bem antes do surgimento oficial do conceito de desenvolvimento sustentável ou da nova ordem constitucional que recepcionou o meio ambiente como um direito indissociável ao ser humano:

E ainda mais atual é a preocupação com os interesses de preservação ecológica, urbana e ambiental da comunidade em que a empresa atua. O compromisso com a preservação da natureza transcende, outrossim, os aspectos meramente comunitários, para se colocar num plano universal. A produção de elementos nocivos não só ao homem, como também à fauna e a flora, constitui dano de igual importância. (CARVALHOSA, 1997, p. 238)

Mais de 20 anos se passaram deste precioso conceito e ainda hoje a empresa ainda está aprendendo a se enquadrar no conceito de desenvolvimento sustentável, que vem acontecendo lentamente, como uma revolução silenciosa.

É necessário a ruptura de ações e de conceitos, como ocorre em qualquer processo revolucionário; o lucro, sob a ótica da sustentabilidade, deve ser objetivado de uma maneira mais ampla e a longo prazo. Já não se justifica mais a obtenção de lucro a qualquer preço.

Empresas que mantiverem a administração fundada somente no lucro e competitividade, ignorando as externalidades ambientais, acabarão por não se sustentar no mercado e virão a falir por teimar em não reconhecer que a mantença dos negócios exige o 
respeito ao meio ambiente e seus recursos.

Neste momento importante apresentar o conceito descrito por Sachs (1993) no que se refere a meio ambiente e sustentabilidade como:

\begin{abstract}
Sustentabilidade ecológica - refere-se à base física do processo de crescimento e tem como objetivo a manutenção de estoques dos recursos naturais, incorporados as atividades produtivas. Sustentabilidade ambiental - refere-se à manutenção da capacidade de sustentação dos ecossistemas, o que implica a capacidade de absorção e recomposição dos ecossistemas em face das agressões antrópicas. Sustentabilidade social - refere-se ao desenvolvimento e tem por objetivo a melhoria da qualidade de vida da população. Para o caso de países com problemas de desigualdade e de inclusão social, implica a adoção de políticas distributivas e a universalização de atendimento a questões como saúde, educação, habitação e seguridade social. Sustentabilidade política - refere-se ao processo de construção da cidadania para garantir a incorporação plena dos indivíduos ao processo de desenvolvimento. Sustentabilidade econômica - refere-se a uma gestão eficiente dos recursos em geral e caracteriza-se pela regularidade de fluxos do investimento público e privado. Implica a avaliação da eficiência por processos macro sociais. (SACHS, 1993, p. 27)
\end{abstract}

Em verdade, a doutrina reconhece e o exemplo negativo da Volkswagen apresentado, são suficientes e demonstrar que ainda estamos diante de um grande desafio quando se fala em desenvolvimento sustentável e que ele é um norte para o século XXI, diante da era da globalização, que não pode ser esquecida neste processo.

Corroborando com esta assertiva temos as palavras de José Eli da Veiga, quando afirma: "Desenvolvimento Sustentável: o desafio para o século XXI" ele afirma que o conceito de desenvolvimento sustentável é uma utopia para o século XXI, apesar de defender a necessidade de se buscar um novo paradigma científico capaz de substituir os paradigmas do "globalismo". (VEIGA, 2005, p. 20)

Nomes conceituados vem se debruçando há mais de uma década para denifir o desenvolvimento sustentável, a exemplo de Satterthwaite que o define como sendo uma resposta efetiva às necessidades humanas nas cidades com um mínimo ou preferencialmente nenhuma transferência dos custos da produção, consumo ou resíduos para outras pessoas ou ecossistemas, o que se busca hoje e para o futuro (SATTERTHWAITE, apud MENEGAT, 2004).

Portanto, reconhece Satterthwaite que e desenvolvimento sustentável deve ser uma resultado da equação de desenvolvimento social, econômico e da preservação ambiental, conjuntamente, o que demonstra que a empresa, neste contexto não pode mais ser observada pelo interesse econômico de seu sócios no lucro, mas ela dever observar as externalidades ambientais negativas eu ocasiona e equilibrar este processo, internalizando e equilibrando essa equação com o lucro pretendido. 
Lamentavelmente e apesar do conceito de Satterhwaite já datar de mais de 14 anos, ainda hoje se verificam lamentáveis exemplos como o da Volkswagen, ocorrido entre os anos de 2014 e 2016, em uma atitude totalmente contrária a que se espera das empresas atualmente.

Percebe-se, por via de consectários, que ainda não ultrapassamos sequer a fase de educação ambiental no Brasil e, quiçá em várias outras partes do mundos; portanto, no Brasil, a regulação das externalidades, tema do próximo tópico, é agente fundamental a fomentar a obtenção dos resultados pretendidos de desenvolvimento sustentável.

\section{Tributação extrafiscal - regulação de externalidades negativas ambientais}

A externalidade negativa ambiental implica maior poluição devido à subestimação de custos em poluir o ambiente e por consequência, viabiliza a permanência no setor econômico de agentes de produção "inviáveis" e que não demonstram preocupação com a responsabilidade ambiental, situação que permite ao agente poluir inadvertidamente, transferindo para o meio ambiente e a sociedade, o custo ambiental de sua produção.

As externalidades negativas, em casos semelhantes são supedâneo para o interesse do Estado intervir, criando mecanismos de correção das mesmas, defendendo, assim, o bem estar social; geralmente o Estado atua por meio da regulação, sendo comum a criação de instrumentos como a incidência de imposto ou mesmo a fixação de limites polutivos, para tentar conter este processo danoso.

A implementação de políticas públicas por intermédio do tributo, principalmente em face da sua finalidade extrafiscal, tem a propriedade de corrigir externalidades, positivas e negativas. Nesse sentido, a tributação, como mecanismo de implementação de políticas públicas, pode ter como propósito, incentivar a geração de empregos ou ser utilizada como instrumento para viabilizar o ingresso de estudantes carentes ao ensino superior.

A regulação deve ser um instrumento eficiente a permitir que se mantenha a livre concorrência de produtos e serviços, focando um conjunto de análises que tenham por objetivo evitar as falhas de mercado e atender o interesse público.

No mesmo sentido as palavras de Vicente Bagnoli (2008) sobre a regulação:

As acepções do termo regulação referem-se às normas de organização da atividade econômica pelo Estado, tanto pela concessão de serviços públicos quanto pelo poder de polícia. Especificamente no campo econômico, diz respeito à redução da intervenção direta do Estado e à concentração econômica (BAGNOLI, 2008. p. 83). 
Regular externalidades tem como objetivo internalizar e reduzir o impacto não precificado, isto porque a premissa de que o preço do produto não reflete seu verdadeiro custo para a sociedade, ultrapassa questões monetárias e atinge o meio ambiente e bem estar social, demonstrando a necessidade da regulação.

A regulação pode tanto se destinar as externalidades positivas, gerando incentivos ao empreendedor, como pode se destinar a regular as externalidades negativas, visando eliminar danos sociais e ambientais, evitando que empresas se beneficiem e tenhas lucros indevidos, por trabalharam irregularmente, sem respeito ambiental.

Krugman e Wells observam os mecanismos de governança que devem observar a regulação das externalidades

(i) ao analisar os efeitos colaterais - as externalidades causadas aos terceiros -o governo pode impor um controle direto levando o mercado rumo à quantidade correta de efeitos colaterais de maneira direta;

(ii) ao analisar a atividade original, e não seus efeitos, o governo pode aplicar políticas que afetam a atividade original, alcançando indiretamente a quantidade correta de efeitos colaterais (KRUGMAN; WELLS, 2007, p. 430).

O caminho para se atingir o que se denomina por ótimo social, onde há externalidades é fazer com que as empresas foquem no custo marginal social e não no custo marginal privado somente. Por isso, as políticas públicas devem levar as empresas a focar sua produção tendo em vista o interesse social e não apensa o interesse dos sócios ou acionistas (COOTER, 2010).

No Brasil, o estabelecimento do Estado neoliberal e do processo de globalização, motivou as privatizações e concessões de serviços públicos, durante a década de 90 , gerando diminuição da atuação estatal e fortalecimento da iniciativa privada.

Esse cenário permeou um intenso processo de transformação no modelo de administração pública e surgiram as denominadas agências reguladoras. São elas órgãos administrativos, que se incumbem de regular setores de mercado para assegurar direitos e o próprio funcionamento do mercado, atuando também na regulação ambiental.

A regulamentação das atividades empresariais por parte do Estado, através da criação de tributos extrafiscais, vem se mostrando a melhor forma para minimizar custos ambientais, porque ela contém uma série de regramentos jurídicos provenientes que interferem no modo de produção e, portanto, na ecoeficiência das empresas, afetando o mercado; ou seja, mudando paradigmas operacionais.

Quando se trata de regulação, Salomão Filho alerta para a necessidade se se reconhecer que convivem aspectos econômico e sociais, sendo também importante se perceber que, por 
vezes, um prepondera sobre o outro, dependendo da natureza do setor regulado. (SALOMÃO FILHO, 2001. p. 21)

Inegável que a tributação com viés ecológico possui caráter regulatório e neste sentido nos ensina Ferraz (2001) apud (SOUZA 2009, p.136-137): “os tributos ecologicamente orientados, são aqueles que influenciam na decisão econômica de modo a tornar mais interessante a opção ecologicamente mais adequada".

A tributação ambiental, como já dito alhures, pode ser concebida como sendo o emprego de instrumentos tributários que propiciem a geração dos recursos necessários à prestação de serviços públicos de natureza ambiental, com viés fiscal ou arrecadatório, mas também para direcionar o comportamento do contribuinte para a proteção do meio ambiente, sendo este o aspecto extrafiscal e regulatório Costa, 2005 apud (SOUZA, 2009, p.136)

Desta forma e tomando-se por base a Constituição Federal, dela extraímos a possibilidade de se considerar diversos tributos existentes sobre os auspícios de caráter preservacionista, tudo isso embasado nos artigos 225 e 170, inciso VI da Carta Magna, havendo, portanto, não vedação constitucional para esse fim. (SOUZA, 2009, p. 137).

Assim, e no que tange a atividades econômicas que tenham ingerência sobre o meio ambiente, forçoso se concluir que a regulamentação deve servir de defesa do ecossistema e aqui prepondera, sem sombra de dúvidas, o interesse social, que é assegurado pela carta constitucional.

A sociedade brasileira vem gradativamente evoluindo de uma visão da degradação ambiental como um mal necessário, para com o reconhecimento da finitude de recursos naturais, percebendo que o uso inadequado do meio ambiente é sempre prejudicial a manutenção da vida humana.

Por tal razão, forçoso se reconhecer que na regulação deste setor prepondera o interesse social; a sociedade, neste processo, atua como importante vetor a ser considerado paralelamente aos interesses das empresas, na pressão política sobre as instituições legisladoras para que regulem o mercado e contenham externalidades negativas sobre o meio ambiente.

Por derradeiro, no que concerne à regulação é fundamental se evitar a ocorrência do colapso regulatório, que ocorre quando a regulamentação proposta se mostra ineficiente para resolver os problemas para a qual se destina, ou também em casos em que acaba por gerar problemas não intencionais na eficiência dos agentes.

Evitar ocorrência do colapso regulatório exige que o agente regulador tenha independência, recursos materiais para atuar e indispensável qualificação técnica. 
Assim, nos países menos desenvolvidos, como é o caso do Brasil, uma regulamentação contrária aos interesses de grupos políticos importantes, sempre tem grande chance de incorrer no colapso regulatório, colocando em dúvidas a garantia ao direito e efetividade do procedimento, situação esta que deve se tentar evitar a todo custo, já que deve sempre preponderar o interesse social na preservação do meio ambiente.

\section{Conclusão}

No Brasil a proteção ambiental foi erigida a direito fundamental pela Constituição Federal, a qual reconhece o meio ambiente equilibrado como direito fundamental de todos e dever do Estado (art. 225), intimamente ligado ao direito à vida (art. $5^{\circ}$, caput).

Como consectário, a proteção do meio ambiente é atualmente princípio da ordem econômica do Brasil, exigindo políticas econômicas e produtivas do país que possibilitem ao Estado brasileiro atuar no sentindo de tratar de forma diferente os processos e as atividades produtivas conforme o impacto ambiental que elas possam gerar (art. 170, VI, CFRB/88).

Busca-se desta forma, uma nova roupagem para o desenvolvimento econômico alicerçada em preceitos ecológicos. Atingir este objetivo demanda a evolução da consciência ambiental e o Estado, enquanto administrador e garantidor de direitos, desempenha papel fundamental para garantir a preservação ambiental.

O Sistema Tributário Nacional, como parte da ordem econômica do Estado passa a inserir a tutela do meio ambiente na criação, incidência e cobrança de tributos, fazendo surgir os tributos ambientais, criados com fim específico de custeio de serviços destinados à proteção ambiental.

Surgem também aqueles que, por sua forma de incidência, criando isenções e benefícios, exercem função extrafiscal de proteção dos bens ambientais, tendo sido estes últimos o foco deste trabalho, tendo-se em vista, inclusive, a função social da empresa neste contexto, posto que ela é a mola de engrenagem propulsora da economia e uso dos bens ambientais, portanto, destinatária da norma.

Assim e porque a degradação ambiental está diretamente vinculada aos modelos de produção industrial e consumo vigente no país, a extrafiscalidade ambiental surge como alternativa efetiva para a "criação" de uma consciência ecológica na sociedade, isto porque incidirá não somente naqueles que cometem crimes ambientais, mas também em toda a cadeia produtiva e de consumo onde será inserido o tributo, ampliando-se, pois, o leque de pessoas envolvidas na solução da problemática da tutela ambiental. 
Paralelamente, a extrafiscalidade ambiental também pode ser utilizada de forma benéfica, como sansão premial, gerando isenções e benefícios fiscais em favor dos contribuintes que, no desenvolver de suas atividades, poluam menos ou não poluam, incentivando, sobremaneira, o desenvolvimento da ideia de proteção ambiental.

Do exposto se pode perceber que o conceito clássico de empresa e sua visão limitada ao lucro do empreendedor, mudaram com o tempo e as necessidades sociais, apesar de algumas empresais ainda insistirem em ignorar os reclamos ambientais, conforme exemplos citados.

É possível se concluir que a empresa não pode mais ser analisada somente pelo viés econômico. O lucro, objetivo que impulsiona a economia é o motivo fundamental que leva à criação de empresas, mas deve ser analisado atualmente com as devidas reservas que todo o contexto sócio-político-ambiental exige.

Visão egocentrista da empresa praticada por longo tempo, atualmente não satisfaz as necessidades sociais. Obter lucros sem a devida preocupação com o efetivo desenvolvimento social é fórmula que não se adequa à realidade atual.

A Constituição Federal atualmente apresenta este viés de desenvolvimento econômico, onde alinha vários objetivos, respeitando a livre iniciativa, mas determinando que a empresa deve cumprir também uma função social, aliando o desenvolvimento econômico ao social, reduzindo desigualdades e preservando o meio ambiente para as atuais e futuras gerações.

O desafio de criar uma nova ordem econômica baseada na livre iniciativa, mas com um Estado Mínimo, é árdua tarefa a se concretizar e à empresa neste contexto, cabe o papel de adequar seus interesses de obtenção de lucro às necessidades de preservação e recuperação ambiental, ou seja, a empresa deve ser responsável pelas externalidades ambientais negativas que ocasiona.

Com o presente artigo, se buscou discorrer sobre a importância desta mudança de paradigmas axiológicos empresariais, para que seja possível efetivar-se, na prática, o legislador constitucional estabeleceu como um Estado que promova a efetiva Justiça Social e preserve o meio ambiente.

Demonstrou-se que a tributação exerce um papel de destaque neste contexto, por tratar-se de instrumento regulatório das atividades empresariais a exigir o novo comportamento da empresário no século 21.

Assim, fundada em normas constitucionais e num grande arcabouço de regras infraconstitucionais, sabe-se que no Brasil, ainda estamos diante de uma longa jornada para conscientização da necessidade de defesa ambiental e mudanças de paradigmas empresariais, desafio que está apenas começando. 


\section{Referências bibliográficas}

BAGNOLI, Vicenti. Direito Econômico.3 ed. Editora Atlas S. A, 2008

BEZERRA, M. C. L.; BURSZTYN, M. (cood.). Ciência e Tecnologia para o desenvolvimento sustentável. Brasília: Ministério do Meio Ambiente e dos Recursos.

CARVALHO, Paulo de Barros. Curso de direito tributário, 13a ed. São Paulo: Saraiva, 2000 .

CARVALHOSA, Modesto. LATORRACA, Nilton. Comentários à lei das sociedades anônimas. São Paulo. Saraiva, 1997, v. 3

COOTER, Robert; ULEN Thomas. Direito e economia. 5 ed. Porto Alegre: Bookman Companhia Editora, 2010

GODOY, Sandro Marcos. O meio ambiente e a função socioambiental da empresa $-1^{\mathrm{a}}$ ed. Birigui/SP: Editora Boreal, 2017

GOUVÊA, Marcus de Freitas. A extrafiscalidade no direito tributário. Belo Horizonte: Del Rey, 2006.

KRUGMAN, Paul, WELLS, Robin. Introdução à economia. Rio de Janeiro. Elsevier Editora Ltda., 2007.

MATEO, Ramón Martín. Tratado de derecho ambiental. v. I. Madri: Trivium, 1991.

MILARÉ, Édis. Princípios fundamentais do direito do ambiente. Revista Justitia. vols. 181/184. jan./dez 1998.

MONTERO, Carlos E. Peralta. O Fundamento e a Finalidade Extrafiscal dos Tributos Ambientais, in Revista de Direito da Cidade vol. 05, $\mathrm{n}^{\circ}$ 02, p.316-364. 
MOREIRA, Rafael Soares. Tributação Extrafiscal e Meio Ambiente: rumo a concepção de tributo ambiental. Disponível em:< http://www3.pucrs.br/pucrs/files/uni/ poa/direito/graduacao/tcc/tcc2/trabalhos2011_2/rafael_moreira.pdf > Acesso em : 26 de dez de 2017.

NUNES, Cleucio Santos, Direito tributário e meio ambiente - São Paulo: Dialética, 2005.

OLIVEIRA, José Antônio Puppim de. Empresas na sociedade: sustentabilidade e responsabilidade social. Rio de Janeiro: Elsevier, 2008.

OLIVEIRA, José Marcos Domingues. Direito Tributário e Meio Ambiente: proporcionalidade, tipicidade aberta, afetação da receita. Rio de Janeiro: Renovar, 1999 e 2007.

OLIVEIRA, José Marcos Domingues. Direito Tributário e Meio Ambiente: Rio de Janeiro, Forense, 2007.

RIBEIRO, Maria de Fátima; GRUPENMACHER, Betina Treiger; CAVALCANTE, Denise Lucena Cavalcante; QUEIROZ, Mary Elbe Queiroz: Novos horizontes da tributação: um diálogo luso-brasileiro. EDIÇÕES ALMEDINA S.A. Coimbra. 2012

SACHS, Ignacy. Estratégias de Transição para do século XXI - Desenvolvimento e Meio Ambiente. São Paulo: Studio Nobel - Fundação para o desenvolvimento administrativo, 1993.

SALOMÃO FILHO, Calixto. Regulação da Atividade Econômica: Princípios e Fundamentos Jurídicos. 1, São Paulo. Malheiros, 2001

SATTERTHWAITE, David. Como as cidades podem contribuir para o Desenvolvimento Sustentável., apud MENEGAT, Rualdo e ALMEIDA, Gerson (org.). Desenvolvimento Sustentável e Gestão Ambiental nas Cidades, Estratégias a partir de Porto Alegre. Porto Alegre: UFRGS Editora, 2004

SIRVINSKAS. Luís Paulo. Manual de Direito Ambiental. 2. ed. Saraiva, 2003. 
SOUZA, Jorge Henrique de Oliveira. Tributação e meio ambiente - Belo Horizonte: Del Rey, 2009.

TOMBS, Steve y WHYTE, David. La Empresa Criminal. Por qué las corporaciones deben ser abolidas. Traducción de: JIMÉNES, Daniel, BERNAT, Ignasi y FORERO, Alejandro. Barcelona. Icaria Editoral, 2016

VEIGA, José Eli da. Cidades Imaginárias - O Brasil é menos urbano do que se calcula. Campinas: Editora da Unicamp, 2005. 


\title{
TRIBUTAÇÃO E DESIGUALDADES REGIONAIS: NECESSIDADE DE INTERLOCUÇÃO ENTRE ECONOMIA E DIREITO PARA A CONCRETIZAÇÃO DO DESENVOLVIMENTO SUSTENTÁVEL
}

\author{
Maria Marconiete Fernandes Pereira \\ Centro Universitário de João Pessoa (UNIPÊ). Controladoria Geral do Estado da Paraíba. \\ Flávia de Paiva Medeiros de Oliveira \\ Centro Universitário de João Pessoa (UNIPÊ). Universidade Estadual da Paraíba (UEPB)
}

\begin{abstract}
Resumo
O legislador constituinte abraçou a ideia de desenvolvimento a partir de uma perspectiva econômica e social, o que se expressa desde o preâmbulo do texto constitucional quando o elenca como uma das finalidades do Estado Democrático, ao lado do exercício dos direitos individuais e sociais. Nessa perspectiva, faz-se mister analisar as normas tributárias indutoras como instrumentos hábeis a fomentar a redução das desigualdades regionais e, por conseguinte, concretizar o princípio do desenvolvimento sustentável, a partir de um diálogo entre economia e direito, o que, à guisa de conclusão, viabiliza a sustentabilidade pelo prisma social.
\end{abstract}

Palavras-chaves: Tributação; normas tributárias indutoras; desigualdades regionais; desenvolvimento sustentável. Sustentabilidade social.

\section{Abstract/Resumen/Résumé}

The constituent legislator embraced the idea of development from an economic and social perspective, which is expressed from the preamble of the constitutional text when the elenco as one of the aims of the Democratic State, along with the exercise of individual and social rights. From this perspective, it is necessary to analyze the tax rules as inductive instruments as instruments to promote the reduction of regional inequalities and, therefore, to implement the principle of sustainable development, based on a dialogue between economy and law, which, in the conclusion, makes sustainability via social prism.

Keywords/Palabras-claves/Mots-clés: Taxation; Regulatory tax rules; regional inequalities; sustainable development; social sustainability; 


\section{Introdução}

A redução das desigualdades regionais e sociais figura no texto constitucional como um dos objetivos da República Federativa do Brasil (art. $3^{\circ}$, inciso III). Ao lado desse objetivo, o legislador constituinte abraçou a ideia de desenvolvimento como sinônimo de crescimento econômico, social e político. Nessa perspectiva, a Carta Magna preceitua, no art. 170, caput, que a ordem econômica tem por finalidade assegurar a todos existência digna, partindo de ditames de justiça e tendo como um de seus princípios a redução das desigualdades regionais e sociais.

Essa concepção constitucional ampla sobre a ordem econômica se coaduna com o princípio do desenvolvimento sustentável, cuja importância se acentuou na década de 1970, com a Conferência de Estocolmo, tendo encontrado assento nos textos das cartas constitucionais promulgadas posteriormente. No entanto, o desenvolvimento sustentável não pode ficar restrito a uma dimensão meramente ecológica. Ao contrário, esse princípio se concretiza na prática cotidiana do ser humano, na medida em que se estimulam comportamentos economicamente viáveis, ambientalmente corretos e socialmente justos. Infere-se, portanto, que a sustentabilidade assume uma conotação econômica, ambiental e social.

Nessa perspectiva, o problema deste artigo consiste em: o diálogo entre economia e direito favorece a concretização do princípio do desenvolvimento sustentável e subsidia a utilização de normas tributárias indutoras como mecanismo de redução das desigualdades regionais? A hipótese da qual se parte é a de que ordem econômica normatizada na Constituição Federal de 1988 tem como um de seus princípios a redução das desigualdades regionais, o que autoriza a intervenção do Estado no mercado com vistas a minimizar tais desigualdades.

O objetivo geral do presente trabalho é analisar as normas de tributação indutoras como hábeis a promover a redução das desigualdades regionais. Para alcançar esse objetivo, pretende-se analisar a natureza jurídica do princípio do desenvolvimento sustentável, em que se reconhece a necessidade de redução das desigualdades regionais e sociais no marco do ordenamento jurídico pátrio. Como também, demonstrar a necessidade de diálogo entre economia e direito, como um instrumento capaz de viabilizar o desenvolvimento nacional igualitário, para fins de concretização da vontade do legislador constituinte.

Somente quando se observa que o princípio do desenvolvimento sustentável assume um caráter pluridimensional, é possível perceber a intrínseca relação existente com a redução das desigualdades regionais, na perspectiva da justiça social. Para que se possam alcançar os 
objetivos propostos neste estudo, utilizar-se-á a pesquisa bibliográfica, com base na leitura formativa, adotando-se os métodos dedutivo e qualitativo.

À guisa de conclusão, observa-se que a aplicação de normas de tributação indutoras se coaduna com o princípio do desenvolvimento sustentável. Tais normas têm o potencial de concretizar a perspectiva social da sustentabilidade, viabilizando, dessa forma, a redução das desigualdades regionais.

\section{Natureza jurídica do princípio constitucional de redução das desigualdades sociais e regionais}

A fórmula política adotada pelo legislador constituinte, já esboçada no preâmbulo da Carta Constitucional vigente, considera o desenvolvimento como uma das finalidades a serem alcançadas pelo Estado brasileiro, caracterizado como democrática de direito. A avaliação isolada desse desiderato, no contexto preambular, não permite inferir, com clareza, qual o seu alcance. Todavia, quando avaliado à luz de outros princípios insculpidos na Carta Magna, dessume-se qual a real intenção do legislador constituinte. Ao fazer menção ao desenvolvimento como uma das finalidades a ser perseguida pelo Estado brasileiro, considerou tal princípio não apenas como sinônimo de crescimento econômico, mas também como vetor de promoção social e política.

Nesse sentido, o citado preâmbulo da Constituição Federal de 1988 considera que o exercício dos direitos sociais constitui um pressuposto indispensável à concretização do desenvolvimento. A análise da fórmula política consagrada no texto constitucional e dos valores que a concretizam permite dessumir que o ordenamento constitucional abraçou a noção de desenvolvimento defendida por Bercovici (2005, p. 53), ao afirmar: “[O] crescimento sem desenvolvimento, como já foi dito, é aquele que ocorre com a modernização, sem qualquer transformação nas estruturas econômicas e sociais. Assim, o conceito de desenvolvimento compreende a ideia de crescimento, superando-a".

Essa perspectiva do desenvolvimento como crescimento econômico, social e político se coaduna com os objetivos fundamentais da República Federativa do Brasil, insculpidos no art. $3^{\circ}$, da Constituição Federal de 1988, entre os quais se destaca o já referido inciso III. Esse dispositivo constitucional enuncia o princípio da igualdade material (real ou substancial). Porém, deverá ser entendido em sintonia com o princípio da igualdade formal, que possui três dimensões. 
A primeira é a dimensão envolvendo a segurança jurídica, ou seja, a igualdade jurídica, que exige a superação dos privilégios outorgados a um grupo determinado de pessoas. A segunda é de natureza processual, que supõe a existência de um mesmo procedimento legal para todos os cidadãos. A terceira diz respeito à igualdade formal, que entende a igualdade como equiparação e como diferenciação. Essa última dimensão se expressa no princípio da não discriminação. Parte do pressuposto de que as condições pessoais não devem ser levadas em conta para se estabelecer tratamento diferenciado, salvo quando considerado sob o prisma valorativo (MARTÍNEZ, 1999, p. 283-284).

A igualdade formal está prevista no art. $5^{\circ}$, caput, da Carta Magna, ao dispor que “todos são iguais perante a lei”. Esse princípio consagra a regra geral que proíbe a adoção de diferenças injustificadas entre os indivíduos. Exige, portanto, a aplicação do direito subjetivo de igualdade de tratamento em igualdade de condições. O citado dispositivo deve ser interpretado em harmonia com o art. $3^{\circ}$, III, ao estabelecer que um dos objetivos fundamentais da República Federativa do Brasil é a redução das desigualdades sociais e regionais. Interpretando-se os dois dispositivos em conjunto, abre-se a possibilidade de se aplicar um tratamento diferenciado. Exige-se, no entanto, que existisse condições desigualadoras capazes de justificar a diferenciação, sem que tal medida se caracterize como um tratamento discriminatório.

Como se observa, o princípio constitucional da igualdade material (real ou substancial) consiste na possibilidade de se poder tratar desigualmente os desiguais, sempre que isso seja necessário para alcançar um maior índice de igualdade real entre os indivíduos. Nesse sentido, Martínez (1999, p. 289) anota " [L] igualdad material supondría el criterio adecuado para que todos pudiesen llegar en igualdad de condiciones a ese ejercicio de la libertad protectora y de la libertad de participación, y sería el criterio material para realizar la libertad promocional".

$\mathrm{O}$ fato de o princípio da igualdade material anteceder, constitucionalmente, o princípio da igualdade formal tem uma importante consequência prática. É que o poder público deverá, sempre, buscar alcançar a igualdade real entre os indivíduos. Nesse contexto, a redução das desigualdades sociais e regionais assume o contorno de norma constitucional de caráter impositivo e de cunho econômico. É reconhecida também com essa natureza pelo texto constitucional como um princípio da ordem econômica (art. 170, VII). Depreende-se, então, que tais princípios podem ser considerados como valores fundamentais pretendidos pelo Estado brasileiro, no cenário da ordem jurídica esboçada constitucionalmente. Sobre a temática, enfatiza Bercovici (2005, p. 105): 
Os princípios constitucionais fundamentais, como os do artigo $3^{\circ}$, possuem caráter obrigatório, com vinculação imperativa para todos os poderes públicos, ou seja, conformam a legislação, a prática judicial e a atuação dos órgãos estatais, que devem agir no sentido de concretizá-los. São marcos do desenvolvimento do ordenamento, funcionando como parâmetro essencial para a interpretação e concretização da constituição.

De acordo com o texto constitucional, a redução das desigualdades sociais e regionais figura como um dos principais vetores da ordem econômica. Para a consecução desse objetivo, a Carta Magna confere ao Estado o dever de incentivar, planejar e fiscalizar as atividades que lhe são afetas. O art. 174 da Constituição Federal deixa claro que o Estado, como agente normativo e regulador da atividade econômica, tem como uma de suas atribuições a incumbência de incentivar e planejar a atividade econômica. Nesse aspecto, deve atuar, de forma determinante, no âmbito do setor público e, como órgão indicativo, no campo do setor privado. Um dos propósitos dessa intervenção é reduzir as desigualdades existentes entre as regiões do país.

Desse normativo constitucional resulta que não remanesce para o Estado, nem para os seus agentes políticos, qualquer margem para agir fora desses parâmetros e regramentos. Significa que, nos limites de suas competências normativas e reguladoras, os órgãos estatais não podem editar normas que fujam aos pressupostos estabelecidos constitucionalmente (SENA SEGUNDO, 2007, p. 378).

Têm, portanto, o Estado e seus agentes respaldo constitucional para, por meio de normas tributárias indutoras, estimular comportamentos diferenciados, capazes de fomentar o desenvolvimento de regiões brasileiras menos favorecidas do ponto de vista econômico. Isso porque o comando das normas constitucionais contidas no art. $3^{\circ}$, incisos II e III, justifica a diferenciação, que pode ser adotada por normas indutoras, visando ao desenvolvimento nacional igualitário.

É evidente o espírito do legislador constituinte, ao enxergar a necessidade de reduzir as desigualdades sociais e regionais, considerando esse princípio como norteador do sistema constitucional brasileiro. E o fez com a finalidade amenizar as consequências históricas da economia brasileira que se pautou em ciclos econômicos. Esse modelo se centrava em processos exploratórios em uma região específica do país, relegando-se as demais à sua própria sorte, enquanto durasse o tempo de vida útil daquela espécie de exploração.

Embora seja considerado um ideal e não uma norma imperativa, o preâmbulo da Constituição Federal preconiza que o Estado brasileiro deve assegurar o "exercício dos direitos sociais e individuais". Fica claro que esse ideal não se coaduna com o modelo clássico de 
centralização do crescimento econômico e social, em uma área isolada do território brasileiro. Ao contrário, deve haver um esforço do Estado para que o desenvolvimento alcance todas as regiões do país, de forma igualitária.

Para tanto, deverá, obrigatoriamente, promover a integração nacional e a concretização de todos os princípios previstos na ordem constitucional brasileira. Conforme determina o art. $174, \S 1^{\circ}$, “a lei estabelecerá as diretrizes e bases do planejamento do desenvolvimento nacional equilibrado, o qual incorporará e compatibilizará os planos nacionais e regionais de desenvolvimento". Cabe a essa lei regulamentadora criar estratégias para concretizar o objetivo previsto no art. $3^{\circ}$, III, da Carta Magna.

Resta, assim, demonstrado que a redução das desigualdades sociais e regionais funciona como um instrumento por meio do qual se estimula o desenvolvimento integral do país, sob a perspectiva de crescimento econômico, social e político. O inciso II do art. $3^{\circ}$ reconhece da Constituição Federal de 1988, reconhece a necessidade de se garantir o desenvolvimento nacional para, logo após, no inciso III, estabelecer, como um dos objetivos da República, a redução das desigualdades sociais e regionais.

Esse objetivo pressupõe a racionalização dos valores econômicos e sociais que resultam do processo de desenvolvimento de todas as regiões que integram o território brasileiro. Como se sabe, historicamente, as populações que vivem em regiões menos favorecidas economicamente não têm acesso aos benefícios do desenvolvimento, na sua acepção ampla.

Essa repartição igualitária resultante do processo de desenvolvimento integrado está em sintonia com o princípio do desenvolvimento sustentável, como se verá adiante. É justamente a consecução desse objetivo que demonstra a necessidade de criação e aplicação de normas tributárias indutoras, como forma de amenizar as desigualdades regionais e sociais.

\section{O poder de tributar como instrumento de concretização do desenvolvimento sustentável}

A conscientização sobre a defesa do meio ambiente começou a ser despertada a partir da Conferência de Estocolmo, realizada em 1972, que demonstrou a necessidade de cooperação internacional para a defesa e proteção desse bem jurídico. A partir daquele evento, deu-se visibilidade internacional a um problema que atingia, em maior ou menor escala, todos os países. Foram vistas com preocupação as consequências geradas por esse grave problema, cujas proporções não podiam ser avaliadas individualmente por cada membro da comunidade 
internacional, passando a ser visto sob uma perspectiva global. Segundo Le Prestre (2000), a Conferência de Estocolmo motivou o surgimento de questionamentos acerca do futuro do planeta e de que forma a degradação ambiental afetaria as gerações vindouras.

A Organização das Nações Unidas (ONU) se posicionou formalmente sobre o princípio do desenvolvimento sustentável. Em 1987, aprovou o relatório intitulado "Nosso futuro comum", assegurando que o desenvolvimento sustentável só seria obtido a partir de um processo de mudança. Para isso, a exploração dos recursos, o direcionamento dos investimentos e o desenvolvimento tecnológico deveriam se harmonizar com as aspirações das necessidades humanas das presentes e das futuras gerações (ONU, 1991, p. 49). Essa concepção de desenvolvimento sustentável ganhou eco no final do século XX, revelando a falência do modelo de crescimento econômico adotado até então. Mostrou-se que tal modelo não era capaz de garantir o desenvolvimento qualitativo do ser humano (COELHO; ARAÚJO, s/d).

Nessa conjuntura, toma-se como ponto de partida o pressuposto de que o desenvolvimento sustentável é um modelo que reconhece a necessidade de aliar crescimento econômico e preservação dos recursos ambientais. Em razão desse corolário, torna-se imperioso considerar que a sustentabilidade aparece como um instrumento de concretização do princípio constitucional em comento na vida diária do ser humano. Somente por meio de ações desenvolvimentistas sustentáveis, podem-se adotar estratégias economicamente viáveis, ambientalmente corretas e socialmente justas para a construção de uma sociedade que busca concretizar os ideais de igualdade e solidariedade. Com efeito, sustentabilidade aparece como o meio pelo qual se põe em prática o modelo de desenvolvimento sustentável, cuja implementação deve ser feita de forma holística, sob a perspectiva social, econômica e ambiental.

Na perspectiva econômica, a sustentabilidade pretende estabelecer o equilíbrio entre a utilização de recursos naturais e a produção de riquezas. No aspecto social, busca criar um modo de convívio social no qual a liberdade, a segurança, o bem-estar, o desenvolvimento, a igualdade e a justiça constituam instrumentos capazes de fomentar a criação de uma sociedade solidária e participativa, preocupada com o bem-estar, tanto das presentes quanto das futuras gerações.

Ao se defender esse modelo de sustentabilidade, busca-se garantir que o desenvolvimento ocorra de forma equilibrada. O objetivo, portanto, é promover não apenas a preservação dos recursos naturais como também a inclusão social, com a participação democrática dos sujeitos envolvidos nos processos decisórios. Quando se fala em dimensão, o objetivo do desenvolvimento sustentável é garantir a preservação dos recursos naturais para as 
presentes e as futuras gerações. Esse modelo desenvolvimentista deve-se manter equilibrado ao longo do tempo, sob uma perspectiva dinâmica, pluridimensional e coletiva (COELHO; ARAUJO, s/d). Essa concepção pluridimensional tem como ponto de partida a superação do paradigma que considera o ser humano como senhor e proprietário exclusivo dos recursos ambientais. Quando se analisa a sustentabilidade sob o viés holístico, o ser humano passa à condição apenas de gestor dos recursos que integram o conjunto dos bens naturais, ficando responsável pela administração de tais recursos, cuidando para não esgotá-los.

No caput do art. 225 da Constituição Federal de 1988, o legislador constituinte destacou a responsabilidade coletiva pela a concretização da sustentabilidade, sob a perspectiva sistêmica. Nesse sentido, prescreveu que é dever de toda a coletividade defender e preservar o meio ambiente para as presentes e as futuras gerações. Dessa forma, cabe ao poder público, em sua prerrogativa de instituir tributos, agir em consonância com os ditames constitucionais. Nessa perspectiva, deve aplicar o sistema tributário não apenas como instrumento de arrecadação, mas também com a finalidade de induzir a prática de comportamentos capazes de concretizar a sustentabilidade. Na discussão da temática objeto do presente artigo, convém enfatizar que a redução das desigualdades sociais e regionais deve ser concebida como um dos objetivos fundamentais da República Federativa do Brasil. Dessa forma, adota-se a concepção da sustentabilidade social acima delineada, na medida em que se busca concretizar o desenvolvimento nacional igualitário e gerador de inclusão social.

A concepção sistêmica de sustentabilidade defende a ideia de uma tributação sustentável, entendida como aquela que recai sobre atividades econômicas lícitas, geradoras de tributos capazes de dar suporte à administração pública. Visa a alcançar um equilíbrio dinâmico entre as dimensões sociais, econômicas e ambientais do desenvolvimento sustentável. Uma política fiscal sustentável não deverá ter como único parâmetro a arrecadação. Ao contrário, deverá buscar inibir práticas lesivas, bem como estimular comportamentos capazes de fomentar a concretização do caráter pluridimensional da sustentabilidade. Ao expressar esse entendimento, Freitas (2016, p. 829), anota:

Logo, o modelo proposto de tributação sustentável justifica-se para arrecadar. Mas não só. Tem de servir, sem sobrecarga funcional, para inibir práticas lesivas à saúde pública, subsídios insensatos e renúncias insanas. Ao mesmo tempo, a eleição dos tributos haverá de ser calibrada e justificada para estimular a contínua inserção dos hábitos de produção, consumo e pós-consumo, apropriados ao desenvolvimento imantado pela sustentabilidade multidimensional. 
Para o citado autor, Freitas (2016, p. 831), um modelo sustentável de tributação permite fazer-se uma avaliação anterior e posterior dos benefícios líquidos das políticas públicas. Essa avaliação é feita a partir da verificação dos impactos observados mediante uma análise prospectiva entre os resultados líquidos esperados do tributo e os custos de compliance, nas esferas sociais, ambientais e econômicas. Tal análise permite verificar se houve uma harmonização entre os benefícios que se pretende alcançar com a instituição do tributo e as prioridades constitucionais, gerando uma melhoria continuada nas condições globais do ambiente e da sociedade.

Esse novo modelo de tributação é denominado pelo mencionado autor de sustentável, em contraposição ao modelo tradicional chamado de cinza, que busca, exclusivamente, a arrecadação de receitas. O modelo sustentável é plenamente compatível com a instituição de uma política tributária que, para além da preservação do meio ambiente, almeje também a redução das desigualdades regionais. Esse sistema repercute na prática de inclusão social, mormente, quando se analisa a promoção do desenvolvimento como um dos objetivos da República Federativa do Brasil, ao lado da redução das desigualdades regionais.

Assim, o Estado deve buscar a redução das desigualdades sociais e regionais por meio da instituição de um modelo sustentável de tributação. Para tanto, é necessário criar e aplicar normas tributárias capazes de induzir comportamentos hábeis a gerar o desenvolvimento econômico, social e ambiental igualitário entre as regiões que integram o território brasileiro.

A política de tributação brasileira fundamenta-se em um objeto definido, conforme estabelece o direito positivo. Leva também em consideração a doutrina gerada a partir desse sistema cujas bases linguísticas originam-se de um contexto teórico sobre normas jurídicas. Além disso, ao se estabelecer o objeto da ciência, há que se incorporar a dimensão da função da linguagem, para que se possa, dentro do próprio sistema, encontrar adequados entendimentos textuais (WARAT, 1995).

Nesse sentido, cabe ao intérprete singularizar os fatos linguísticos, de modo a chegar à cerne do objeto da ciência, cabendo à linguagem permitir a interação dos conhecimentos (TOMÉ, 2011; WARAT, 1995). Não se pode, nesse modelo, aplicar a sugestão de Ross ( 1971, p. 28), que "consiste na apresentação de termos ou enunciados com o único objetivo de fazer crer em determinadas situações inexistentes. Mais do que uma falsidade, deve-se falar agora de uma ficção". A esse respeito, acrescenta Warat (1995, p. 68-69): “com a condição fabuladora de sentido, pretende-se fazer acreditar que há uma proteção em abstrato, esquecendo-se suas condições reais de existência. Estamos, desta maneira, diante da lei como garantia formal, o que, por sua vez, não deixa de ser uma engenhosa fórmula de fabulação". 
É preciso esclarecer que a linguagem prescritiva do direito positivo induz a comportamentos humanos de manifestações intersubjetivas capazes de alterá-las. Sob essa ótica, Tomé (2011, p. 194) enfatiza as perspectivas funcionais do direito. Por seu turno, Carvalho (2013, p. 230) ressalta que o direito positivo está sujeito à formalização da lógica como parte da linguagem prescritiva, com uma proposição significativa em relação à norma jurídica. Significa que função e estrutura normativas estão conectadas no ordenamento jurídico. As proposições conduzem a um entendimento de que função e estrutura não são excludentes.

A norma jurídica apresenta uma lógica específica da qual deve ser abstraída a intenção de seus elementos para a construção normativa de valores e objetivos. Com essa visão, assinala Carvalho (2013, p. 119): “[O] estruturalismo é, em essência, uma teoria da norma jurídica. O funcionalismo, por seu turno, é uma teoria que visa a descobrir como o direito pode alcançar suas finalidades". É preciso reconhecer a importância estruturalista do direito na análise funcionalista, notadamente do direito tributário, na perspectiva de uma visão positivista para a ciência jurídica brasileira.

A teoria jurídica está permeada de valores portadores das metas pretendidas e de possibilidades a serem alcançadas. Nesse aspecto, pergunta-se: caracterizado como linguagem posta pela normatividade da tributação, por meio das normas tributárias indutoras, será que o direito permite uma investigação extraída da dogmática jurídica, na busca de assegurar-se a função social, de maneira interdisciplinar? O direito, como metalinguagem, não pode limitarse a uma forma de representação dos fenômenos jurídicos, uma vez que a realidade normatizada não pode ser alterada de forma instantânea.

Considera-se, especialmente, a aplicação das normas tributárias indutoras como instrumentos capazes de reduzir as desigualdades regionais. Nesse caso, é importante estabelecer a interdisciplinaridade da análise econômica do direito (law and economics), para a concretização da função normativa. A esse respeito, esclarece Canado (2011, p. 816):

\footnotetext{
A plena consciência da específica forma de existência das normas jurídicas (hipotético-condicional) permite ao jurista investigar, sob o ponto de vista econômico, as normas enquanto fatos resultantes de produções legislativas e, inovadoramente, retornar ao modo específico de ser do direito para torná-lo mais adequado à realidade.
}

As normas tributárias indutoras têm justamente o propósito de induzir ou influenciar comportamentos dos agentes econômicos, por meio de diretrizes adequadas. A tributação é um instrumento que deve ser utilizado para a indução dos comportamentos dos agentes econômicos. Segundo ELALI (2007), não tem necessariamente caráter arrecadatório, aplicando-se, de modo 
geral, para influenciar determinados segmentos que precisam ser estimulados, no sentido de adotarem condutas positivas e eficazes.

Como fundamento de aplicação, as normas tributárias devem conter a dimensão indutora, exercida através da extrafiscalidade. Em primeiro lugar, essa medida é tomada por meio de uma por intervenção indireta, a partir da regulação econômica, sob a perspectiva de falhas de mercado (externalidades negativas) e assimetrias, para fins de estimular os contribuintes. Em seguida, a extrafiscalidade deve impulsionar a atividade de fomento, delimitada pela relação jurídico-tributária, para fins de considerar a possibilidade de redução de desigualdades (TOMKOWSKI, 2015).

A intervenção do Estado na economia se configura como uma escolha política, consubstanciada em instrumentos constitucionais, os quais devem ser hermeneuticamente conjugados para sua efetivação. A interpretação teleológica da intervenção, que se pode depreender da ordem econômica adotada pela Constituição Federal de 1988, faz-se melhor compreensível pela aplicação metodológica da análise econômica do direito. Consolida-se com a aplicação de instrumentos de incentivos e a previsão de custos de transação, entre outros meios que se fizerem necessários. No texto constitucional, destaca-se o papel destinado ao Estado, como agente normativo e regulador da atividade econômica. Porém, deve ter presença reduzida no mercado, de modo a poder abrir mais espaço às atividades privadas. Desse processo emerge a necessidade de regulação, por parte do Estado, de setores anteriormente ocupados por entidades públicas, para fins de preservar os objetivos previstos no texto constitucional.

Ao fazer a intervenção em atividades econômicas, o Estado atua de forma peculiar no tempo e no espaço, levando em consideração o contexto de transformações estruturais. Moreira Neto (2005, p.102) analisa as espécies de intervenção do Estado, destacando as seguintes: a) intervenção regulatória, que ocorre quando o Estado impõe prescrições legais sobre o desempenho de atividades econômicas ou sociais privadas; b) intervenção concorrencial, que acontece quando o Estado exerce atividades de natureza privada, em regime de concorrência; c) intervenção monopolista, que se verifica quando o Estado exerce atividades de natureza privada, sem concorrência; d) intervenção sancionatória, que se efetiva quando o Estado impõe sanções punitivas.

Já de acordo com a classificação adotada por Grau (2008, p.147), a intervenção do Estado no mercado pode ocorrer por direção ou por indução. A primeira efetiva-se através de normas imperativas direcionadas aos agentes econômicos, enquanto a intervenção por indução é exercida através de normas dispositivas. Nesse caso, o Estado desenvolve mecanismos de participação como agente econômico, aplicando normas de comportamento ou então 
executando a regulação, por meio de leis que regem os mercados.

A adoção de incentivos para aquecer o mercado tem como pressuposto uma decisão política. Tal medida é consubstanciada numa relação estabelecida entre Estado e mercado, em que há interferência do governo nas atividades de mercado. A atuação governamental inspirada na teoria econômica neoclássica é admissível como resposta às falhas de mercado, principalmente na área de serviços públicos (MEIRELLES, 2010). No âmbito tributário, as falhas do mercado necessitam de correção por meio de incentivos fiscais. Nesse caso, aplicamse as normas tributárias indutoras, uma vez que o Estado detém a capacidade de recolher esse atributo com base em normas jurídicas (ELALI, 2007). Por sua vez, Carvalho (2005, p.260) defende a intervenção do Estado no fenômeno econômico, sob a seguinte justificativa:

\begin{abstract}
A interferência do Estado na economia dá-se através da regulamentação dos atos econômicos. Isso significa que o Estado, seja manifestado pelo Legislativo, Executivo ou Judiciário, emite mensagens prescritivas visando a regular condutas nessa ou naquela direção. Como o Estado age através do direito, i.é, através de critérios ditados pelo sistema jurídico, em última análise, é o direito que interfere nos demais subsistemas, dentre eles o econômico.
\end{abstract}

\title{
4. Análise econômica do direito: a tributação como meio de combate à desigualdade regional
}

Segundo Mackaay; Rousseau (2015, p. 5), “entender o direito implica entender o movimento próprio das peças que é programado para o reger”. Dessa forma, para que se possa compreender o poder de tributar e os efeitos esperados, no âmbito da temática em análise, é preciso indagar a respeito do papel das instituições diante desse panorama. Na concepção de North (1990, 3), as instituições devem ser entendidas como sendo capazes de estabelecer as regras do jogo em uma sociedade. Já segundo Salama (2017, p. 15), elas devem aprovar e aplicar tanto as regras formais quanto as regras informais que pautam a atuação dos diversos agentes e entes sociais. Entre outros aspectos, a análise econômica do direito resgata a percepção do real conceito de instituições jurídicas, com base em uma racionalidade subjacente. Essa análise apresenta ferramentas conceituais para atualizar as instituições, uma vez que não há uma limitação envolvendo a questão econômica.

O núcleo inicial utilizado para difundir as proposições econômicas no direito veio com o artigo The problem of social cost, publicado por Ronald Coase no Journal of Law and Economics, em 1960. Em seu texto, o autor propõe a adoção do método dos custos de transação, como repercussão do pensamento defendido pela corrente conhecida como Nova Economia 
Institucional. Essa doutrina fundamenta-se nas vertentes teóricas de análise do desenvolvimento econômico e na teoria dos contratos. Na atualidade, a análise econômica se expandiu para abranger diversas áreas do direito, especialmente, do direito tributário. No entanto, não se confunde com o direito econômico. Este estuda a intervenção e a regulação do Estado nos mercados, enquanto a análise econômica se volta à regulação dos mercados pelo Estado, captando os incentivos do instituto jurídico (SALAMA, 2017, 17).

A análise econômica do direito deve ser vista como ferramenta instrumental de avaliação de incentivos postos no mercado, quando da atuação estatal. Para tanto, são feitas inserções de propostas de remodelações, no ordenamento jurídico, para buscar a efetividade principiológica da ordem econômica, em consonância com os objetivos fundamentais da República brasileira. Há, portanto, necessidade de adequação entre desenvolvimento socioeconômico e redução das desigualdades. Caso não se vislumbre a materialização desse comando constitucional, poderá ocorrer desperdício de recursos públicos ou sua inadequada alocação, com consequente ineficácia.

O diálogo entre economia e direito se faz imprescindível, para que se possa chegar a uma teoria social, a partir da investigação econômica que se revele mais compatível com os anseios da sociedade, com instrumentos jurídicos exequíveis. Nessa perspectiva, a interação entre os objetivos fundamentais da República Federativa do Brasil, juntamente com a ordem econômica, e a tributação indutora resultam em uma unidade sistêmica do ordenamento jurídico. A esse respeito, assinala Schoueri (2005, p. 8): “Direito é, por excelência, um conjunto de regras sistematizadas que se harmonizam, visando regular as relações de interação na sociedade, com a perspectiva de comandos lógicos que corporificam o chamado sistema jurídico de um determinado Estado".

Nessa concepção, o direito passa a ser visto como mediador de adoção de regras e solucionadas de problemas na unidade jurídica, de forma a viabilizar a harmonização das normas constitucionais, viabilizando também a unidade da Constituição. Analisando a temática, anota Muller (1999, p.72): “O intérprete deve procurar ajustar eventuais contradições que apareçam como resultados parciais no processo da concretização de modo a harmonizá-las umas com as outras no resultado". Adotando-se uma interpretação funcionalista, o direito pode alcançar suas finalidades, a partir dos meios adotados e dos fins perseguidos, possibilitando verificar os efeitos na ordem social. Nesse contexto, pensar em tributação e desigualdades permite enxergar a teoria jurídica como estando permeada de valores. Busca-se, com isso, fazer com que as normas constitucionais sejam cumpridas, de modo a que possam alcançar as pretendidas metas (CARVALHO, 2013, p. 119-122). 
A Carta Constitucional de 1988 corrobora esse pensamento, quando dispõe, no art. 146-A: "Lei complementar poderá estabelecer critérios especiais de tributação, com o objetivo de prevenir desequilíbrios da concorrência, sem prejuízo da competência de a União, por lei, estabelecer normas de igual objetivo". Assim, é preciso compreender que a ordem jurídica possibilita a somatização de efeitos sociais gerados pelas normas. A aplicação de normas tributárias indutoras, como estímulo de produção de incentivos, cumpre objetivos que extrapolam os aspectos econômicos. É que a relação custo-benefício deve resultar em compensações sociais, uma vez que a atividade estatal também possui o papel de fomentar a redução das desigualdades.

O sistema de tributação pode desempenhar uma função de natureza extrafiscal, na medida em que o tributo pode ser utilizado como mecanismo de regulação das atividades desenvolvidas pela iniciativa privada. Sob essa ótica, assume funções com o objetivo de induzir comportamentos não somente econômicos como também sociais (ELALI, 13). No centro dessa sistemática, permeada de valores constitucionais, a sustentabilidade abre o caminho para o desenvolvimento, a partir do entendimento de uma linguagem de política fiscal convergente. No campo da extrafiscalidade, a tributação pode desempenhar a função instrumental de redistribuição de renda. Consequentemente, contribuirá para promover a redução das desigualdades. No entanto, alguns analistas, embora admitam que a intervenção do Estado seja importante, reconhecem a ineficiência estatal para chegar a essa igualdade material.

\section{Considerações finais}

$\mathrm{Na}$ atualidade o sistema tributário passa a considerar a sustentabilidade pela via das normas tributárias indutoras. Busca-se, dessa forma, promover o desenvolvimento, que possa contribuir para a redução das desigualdades regionais. A aplicação das normas tributárias indutoras nas atividades econômicas tem por objetivo dar suporte aos setores econômicos, de forma a possibilitar o equilíbrio sustentável, de acordo com os fundamentos constitucionais.

As diretrizes adotadas para reduzir as desigualdades sociais e regionais devem estar em sintonia com a ordem econômica e o poder de tributar. Nessa conjuntura, a iniciativa privada precisa ser convocada a fazer parte desse projeto de desenvolvimento sustentável. Observe-se, por fim, que a intervenção do Estado no mercado deverá estar sempre vinculada aos princípios vetores constitucionais da igualdade e da sustentabilidade, cujo objetivo maior é a redução das desigualdades regionais e sociais. 


\section{Referências bibliográficas}

BERCOVICI, Gilberto. Constituição econômica e desenvolvimento: uma leitura a partir da Constituição de 1988. São Paulo: Malheiros, 2005.

CANADO, Vanessa Rahal. Desenvolvimento, direito, economia, fiscalidade e extrafiscalidade: análise da natureza dos incentivos e benefícios fiscais sob uma perspectiva interdisciplinar. In SANTI, Eurico Marcos Diniz (coord). Tributação e desenvolvimento: homenagem ao professor Aires Barreto. São Paulo: Quartier, 2011.

CARVALHO, Cristiano. Teoria da decisão tributária. São Paulo: Saraiva, 2013.

CARVALHO, Cristiano. Teoria do sistema jurídico. São Paulo: Quartier, 2005.

COELHO, Saulo de Oliveira Pito; ARAÚJO, André Fabiano Guimarães de. A sustentabilidade como princípio constitucional sistêmico e sua relevância na efetivação interdisciplinar da ordem constitucional econômica e social: para além do ambientalismo e do desenvolvimentismo. Disponível em $<$ https://mestrado.direito.ufg.br/up/14/o/artigo_prof_saulo.pdf >. Acesso em 03 mar.2016.

COMPAGNONI, Rudimar Luis. Empregos verdes como mecanismo de redução de impactos ambientais. Disponível em $<\mathrm{http}$ ://www.ambito-juridico.

com.br/site/index.php/?n_link=revista_artigos_leitura\&artigo_id=12423\&revista_caderno $>$. Acesso em 08 ago. 2016.

ELALI, André. Incentivos fiscais, neutralidade tributária e desenvolvimento econômico: a questão da redução das desigualdades regionais e sociais. In MARTINS, Ives Gandra da Silva; ELALI, André; PEIXOTO, Marcelo Magalhães (coords.). Incentivos fiscais: questões pontuais nas esferas federal, estadual e municipal. São Paulo: MP, 2007.

GRAU, Eros Roberto. A ordem econômica na Constituição de 1988. 13.ed. São Paulo: Malheiros, 2008.

FREITAS, Juarez. O tributo e o desenvolvimento sustentável. In Revista Novos Estudos 
Jurídicos. vol. 21, n. 3, set./dez. 2016. Disponível em https://siaiap32.univali.br/seer/ index.php/nej/article/view/9682. Acesso em 24 abr. 2018.

LE PRESTRE, Philipe. Ecopolítica internacional. São Paulo: Senac, 2000.

MACKAAY, Ejam; ROUSSEAU, Stéphane. Análise econômica do direito. Tradução de Rachel Sztajn. 2.ed. São Paulo: Atlas, 2015.

MARTINEZ, Gregório Peces-Barba. Curso de derechos fundamentales: teoria general. Madrid: Universidad Carlos III, 1999.

MEIRELLES, Dimária Silva e. Teorias de mercado e regulação: por que os mercados e o governo falham? Cad. EBAPE.BR, Rio de Janeiro, v. 8, n. 4. Dec. 2010 . Available from $<$ http://www.scielo.br/scielo.php?script=sci_arttext\&pid=S167939512010000400006\&lng=en \&nrm=iso $>$. Acesso em 28 jul. 2017.

MOREIRA NETO, D. de F. O novo papel do estado na economia. Revista de Direito Público da Economia - RDPE, n. 11, p. 99-120, 2005

MULLER, Friedrich. Métodos de trabalho do direito constitucional. Tradução por Peter Naumann. Porto Alegre: Síntese, 1999.

NORTH, Douglass C. Institutions, institutional change and economic performance. Cambridge University Press, 1990.

ONU. Nosso futuro comum. 2 ed. Rio de Janeiro: Fundação Getúlio Vargas, 1991.

ROSS, Alf. Lógica de las normas, Madrid: Tecnos, 1971.

SALAMA, Bruno Meyerhof. Estudos em direito \& economia [livro eletrônico]: micro, macro e desenvolvimento. Curitiba: Editora Virtual Gratuita - EVG, 2017. 
SENA SEGUNDO, Oswalter de Andrade. O princípio constitucional da redução das desigualdades regionais e sociais e sua efetivação jurídico-política na ordem econômica. In Revista Direito e Liberdade, vol. 7, n. 3, jul./dez. 2007.

TOMÉ, Fabiana Del Padre. A extrafiscalidade tributária como instrumento para concretizar políticas públicas. In SANTI, Eurico Marcos Diniz (coord). Tributação e desenvolvimento: homenagem ao professor Aires Barreto. São Paulo: Quartier, 2011.

TOMKOWSKI, Fábio. Análise comportamental do direito e economia: sistema tributário e sustentabilidade. In Revista Direito à Sustentabilidade, v.1, n.2, 2015. Disponível em http://e-revista.unioeste.br/index.php/direitoasustentabilidade/article/view/12423. Acesso em 29 jul 2017.

WARAT, Luis Alberto. O direito e sua linguagem. 2. ed. Porto Alegre: Fabris, 1995. 
E

Este livro reúne artigos científicos apresentados e debatidos nos Grupos de Trabalho: "DIREITO, GOVERNANÇA, NOVAS TECNOLOGIAS" e "DESENVOLVIMENTO ECONÔMICO SUSTENTÁVEL, GLOBALIZAÇÃO E TRANSFORMAÇÕES NA ORDEM SOCIAL E ECONÔMICA" no decorrer do VIII Encontro Internacional do CONPEDI (Conselho Nacional de Pesquisa e Pós-Graduação em Direito - Brasil), realizado entre os dias 06 e 08 de setembro de 2018 na cidade de Zaragoza - Espanha. 